Supporting Information for:

\title{
Ligand-Based Phase Control in Porous Zirconium Coordination Cages
}

Aeri J. Gosselin, ${ }^{\dagger} \ddagger$ Gerald E. Decker, ${ }^{\dagger \ddagger}$ Brett W. McNichols, $§$ James E. Baumann, $§$ Glenn P. A. Yap, ${ }^{\dagger}$ Alan Sellinger ${ }^{\S}$ Eric D. Bloch ${ }^{*} \dagger$

${ }^{\dagger}$ Department of Chemistry and Biochemistry, University of Delaware, Newark, DE 19716, United States $\S$ Department of Chemistry, Colorado School of Mines, Golden, Colorado 80401, United States

†These authors contributed equally. 


\section{List of Contents}

Ligand Abbreviations and Compound Names

Detailed Ligand Experimental Procedures and ${ }^{1} \mathrm{H}$ NMR

Chart S1 - Ligands and their respective abbreviations.

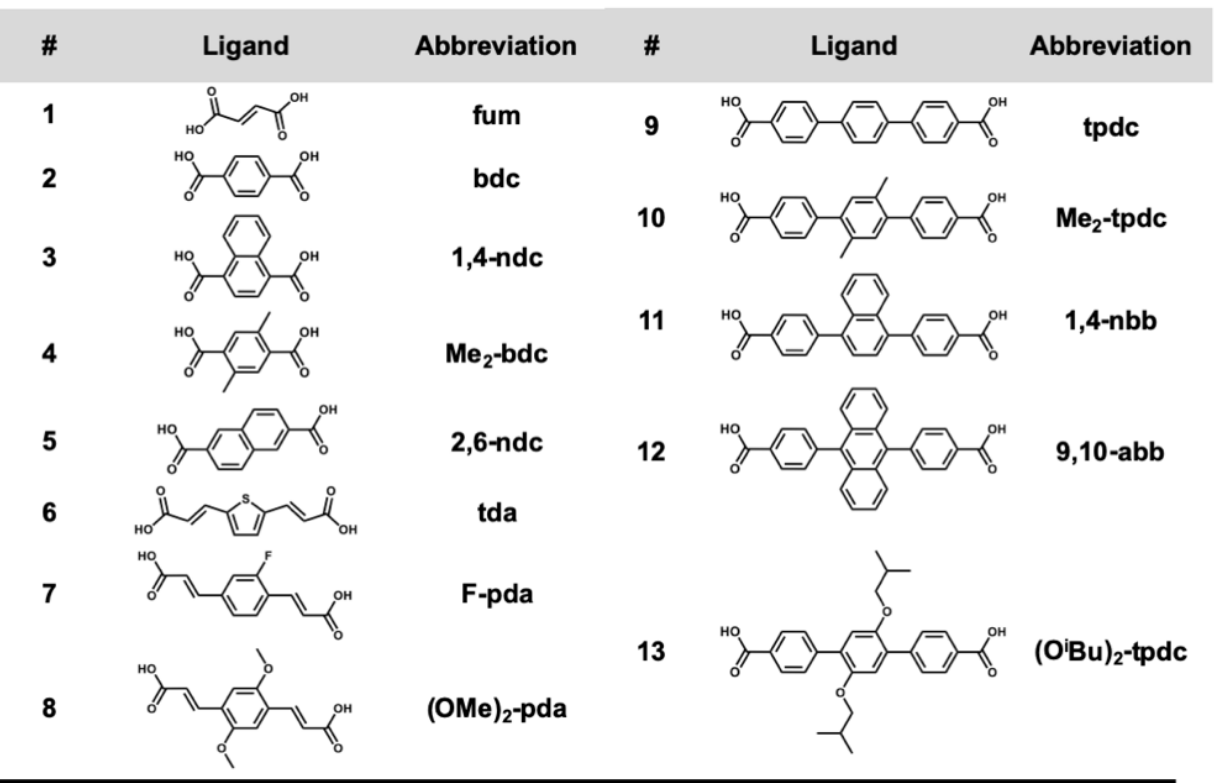

List of compound names:

1C: $\quad\left[\mathrm{Zr}_{6}\left(\mu_{3}-\mathrm{O}\right)_{2}\left(\mu_{2}-\mathrm{OH}\right)_{6}(\mathrm{Cp})_{6}(\mathrm{fum})_{3}\right]^{2+}$

2T: $\quad\left[\mathrm{Zr}_{12}\left(\mu_{3}-\mathrm{O}\right)_{4}\left(\mu_{2}-\mathrm{OH}\right)_{12}(\mathrm{Cp})_{12}(\mathrm{bdc})_{6}\right]^{4+}$

2C: $\quad\left[\mathrm{Zr}_{6}\left(\mu_{3}-\mathrm{O}\right)_{2}\left(\mu_{2}-\mathrm{OH}\right)_{6}(\mathrm{Cp})_{6}(\mathrm{bdc})_{3}\right]^{2+}$

3T: $\quad\left[\mathrm{Zr}_{12}\left(\mu_{3}-\mathrm{O}\right)_{4}\left(\mu_{2}-\mathrm{OH}\right)_{12}(\mathrm{Cp})_{12}(1,4-\mathrm{ndc})_{6}\right]^{4+}$

3C: $\quad\left[\mathrm{Zr}_{6}\left(\mu_{3}-\mathrm{O}\right)_{2}\left(\mu_{2}-\mathrm{OH}\right)_{6}(\mathrm{Cp})_{6}(1,4-\mathrm{ndc})_{3}\right]^{2+}$

4T: $\quad\left[\mathrm{Zr}_{12}\left(\mu_{3}-\mathrm{O}\right)_{4}\left(\mu_{2}-\mathrm{OH}\right)_{12}(\mathrm{Cp})_{12}\left(\mathrm{Me}_{2}-\mathrm{bdc}\right)_{6}\right]^{4+}$

5T: $\quad\left[\mathrm{Zr}_{12}\left(\mu_{3}-\mathrm{O}\right)_{4}\left(\mu_{2}-\mathrm{OH}\right)_{12}(\mathrm{Cp})_{12}(2,6-\mathrm{ndc})_{6}\right]^{4+}$

5C: $\quad\left[\mathrm{Zr}_{6}\left(\mu_{3}-\mathrm{O}\right)_{2}\left(\mu_{2}-\mathrm{OH}\right)_{6}(\mathrm{Cp})_{6}(2,6-\mathrm{ndc})_{3}\right]^{2+}$

6C: $\quad\left[\mathrm{Zr}_{6}\left(\mu_{3}-\mathrm{O}\right)_{2}\left(\mu_{2}-\mathrm{OH}\right)_{6}(\mathrm{Cp})_{6}(\mathrm{tda})_{3}\right]^{2+}$

7T: $\quad\left[\mathrm{Zr}_{12}\left(\mu_{3}-\mathrm{O}\right)_{4}\left(\mu_{2}-\mathrm{OH}\right)_{12}(\mathrm{Cp})_{12}(\mathrm{~F}-\mathrm{pda})_{6}\right]^{4+}$

7C: $\quad\left[\mathrm{Zr}_{6}\left(\mu_{3}-\mathrm{O}\right)_{2}\left(\mu_{2}-\mathrm{OH}\right)_{6}(\mathrm{Cp})_{6}(\mathrm{~F}-\mathrm{pda})_{3}\right]^{2+}$

8T: $\quad\left[\mathrm{Zr}_{12}\left(\mu_{3}-\mathrm{O}\right)_{4}\left(\mu_{2}-\mathrm{OH}\right)_{12}(\mathrm{Cp})_{12}\left((\mathrm{OMe})_{2}-\mathrm{pda}\right)_{6}\right]^{4+}$

9C: $\quad\left[\mathrm{Zr}_{6}\left(\mu_{3}-\mathrm{O}\right)_{2}\left(\mu_{2}-\mathrm{OH}\right)_{6}(\mathrm{Cp})_{6}(\mathrm{tpdc})_{3}\right]^{2+}$

10T: $\quad\left[\mathrm{Zr}_{12}\left(\mu_{3}-\mathrm{O}\right)_{4}\left(\mu_{2}-\mathrm{OH}\right)_{12}(\mathrm{Cp})_{12}\left(\mathrm{Me}_{2} \text {-tpdc }\right)_{6}\right]^{4+}$

10C: $\quad\left[\mathrm{Zr}_{6}\left(\mu_{3}-\mathrm{O}\right)_{2}\left(\mu_{2}-\mathrm{OH}\right)_{6}(\mathrm{Cp})_{6}\left(\mathrm{Me}_{2} \text {-tpdc }\right)_{3}\right]^{2+}$

11T: $\quad\left[\mathrm{Zr}_{12}\left(\mu_{3}-\mathrm{O}\right)_{4}\left(\mu_{2}-\mathrm{OH}\right)_{12}(\mathrm{Cp})_{12}(1,4-\mathrm{nbb})_{6}\right]^{4+}$

11C: $\quad\left[\mathrm{Zr}_{6}\left(\mu_{3}-\mathrm{O}\right)_{2}\left(\mu_{2}-\mathrm{OH}\right)_{6}(\mathrm{Cp})_{6}(1,4-\mathrm{nbb})_{3}\right]^{2+}$

12T: $\quad\left[\mathrm{Zr}_{12}\left(\mu_{3}-\mathrm{O}\right)_{4}\left(\mu_{2}-\mathrm{OH}\right)_{12}(\mathrm{Cp})_{12}(9,10-\mathrm{abb})_{6}\right]^{4+}$

13T: $\quad\left[\mathrm{Zr}_{12}\left(\mu_{3}-\mathrm{O}\right)_{4}\left(\mu_{2}-\mathrm{OH}\right)_{12}(\mathrm{Cp})_{12}\left(\left(\mathrm{O}^{\mathrm{i} B u}\right)_{2} \text {-tpdc }\right)_{6}\right]^{4+}$ 


\section{Detailed Ligand Experimental Procedures and ${ }^{1} \mathrm{H}$ NMR}

General Considerations. All reagents were obtained from commercial vendors and used without purification, excluding solvents. Dichloromethane (DCM, ACS reagent grade), anhydrous tetrahydrofuran (THF, $\geq 99.9 \%$ ), methyl acrylate (>99\%), N,N-dicyclohexylmethylamine ( $\mathrm{NCy}_{2} \mathrm{Me}$, $97 \%)$ and anhydrous magnesium sulfate $\left(\mathrm{MgSO}_{4}\right)$, were obtained from Sigma-Aldrich. Sodium hydroxide ( $\mathrm{NaOH}$, Pearl 97\%) was obtained from Fisher Scientific. Bis(tri-tert-butylphosphine) palladium $\left(\mathrm{Pd}\left[\mathrm{P}\left({ }^{\mathrm{t}} \mathrm{Bu}\right)_{3}\right]_{2}, 98 \%\right)$ was obtained from Strem Chemicals. Hydrochloric acid $(\mathrm{HCl}, \mathrm{ACS})$ was obtained from Macron Fine Chemicals. N,N-Dimethylformamide (DMF) was obtained from a solvent purification system (SPS) and stored in a brown amber bottle on 4 A sieves.

\section{Thermal Stability TGA}

At least $10 \mathrm{mg}$ of zirconium cage was loaded onto an aluminum pan. Samples were heated up to $600{ }^{\circ} \mathrm{C}$ at a rate of $2{ }^{\circ} \mathrm{C}$ per minute while exposed to a continuous flow of $\mathrm{N}_{2}$.

\section{Mass Spectrometry}

Generally, $\sim 3 \mathrm{mg}$ of zirconium cage was massed into a $4 \mathrm{~mL}$ vial, then $4 \mathrm{~mL}$ of the respective solvent was added to the vial. Simulated mass spectroscopy data was collected from enviPAT web 2.4 , envipat.eawag.ch. ${ }^{1}$

\section{${ }^{1} \mathrm{H}$ NMR measurements}

Generally, $\sim 10 \mathrm{mg}$ of cage was dissolved in $750 \mu \mathrm{L}$ of the respective deuterated solvent. The solution was then filtered before analysis.

\section{Gas Adsorption measurements}

Low-pressure adsorption measurements were obtained on a Micromeritics Tristar II PLUS at 77 $\mathrm{K}$ and $195 \mathrm{~K}$ for $\mathrm{N}_{2}$ and $\mathrm{CO}_{2}$, respectively. Generally, chloroform washed material ( 100 mg) was dried under dynamic vacuum at room temperature until a free-flowing powder was obtained. The dried powder was then transferred into glass gas adsorption tubes and dried on a Micromeritics 3-Flex degas station at room temperature. Samples were finally activated while heating under dynamic vacuum for 18 hours. 


\section{Synthesis of $\mathrm{Me}_{2}-\mathrm{H}_{2}$ bdc}

The following synthesis has been modified from a previously published paper. ${ }^{2}$ In an $\mathrm{N}_{2}$ glovebox, magnesium metal $(0.9 \mathrm{~g}, 37 \mathrm{mmol})$ and anhydrous THF $(50 \mathrm{~mL})$ were measured into a $500 \mathrm{~mL}$ Schlenk flask. The Schlenk flask was removed from the box and put under flowing $\mathrm{N}_{2}$. 1,4Dibromo-2,5-dimethylbenzene $(2 \mathrm{~g}, 7.6 \mathrm{mmol})$ was added to the Schlenk flask. The mixture was heated to $60{ }^{\circ} \mathrm{C}$ while stirring. Once at temperature, iodine $(0.045 \mathrm{~g}, 0.18 \mathrm{mmol})$ was added to the reaction. The reaction mixture was then allowed to stir at $60^{\circ} \mathrm{C}$ overnight. The reaction was then cooled to room temperature before being placed into a reagent alcohol/dry ice bath. The reaction was allowed to cool for 15 minutes before adding excess dry ice into the Schlenk flask. The reaction was then left overnight to slowly warm to room temp. Once warm, $\sim 2 \mathrm{M} \mathrm{HCl}$ solution $(60 \mathrm{~mL})$ was added slowly into the Schlenk flask whereupon the reaction bubbled violently. Once the reaction stopped bubbling, $\mathrm{DI} \mathrm{H}_{2} \mathrm{O}(150 \mathrm{~mL})$ was added into the Schlenk flask to precipitate desired product. Solid was then collected via vacuum filtration. ${ }^{1} \mathrm{H}$ NMR $\left(400 \mathrm{MHz}, \mathrm{DMSO}-d_{6}\right) \delta$ $7.69(\mathrm{~s}, 2 \mathrm{H}), 2.45(\mathrm{~s}, 6 \mathrm{H})$.
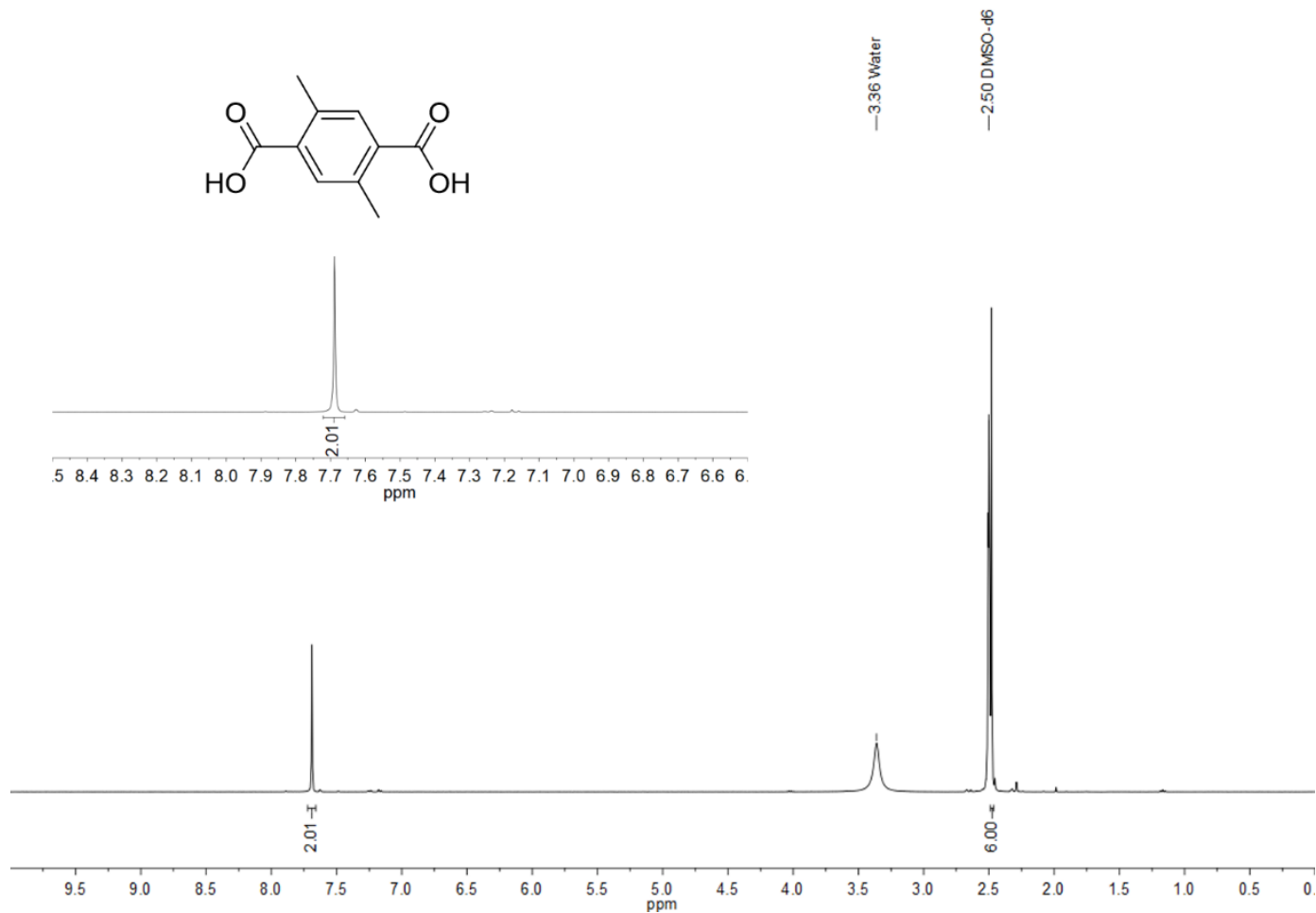

Figure S1. ${ }^{1} \mathrm{H}$ NMR analysis of $\mathrm{Me}_{2}-\mathrm{H}_{2}$ bdc. 


\section{Synthesis of $\mathrm{H}_{2}$ tpdc}

The following synthesis has been modified from a previously published paper. ${ }^{3} \mathrm{In}$ a $100 \mathrm{~mL}$ round bottom flask para-terphenyl $(1.50 \mathrm{~g}, 6.51 \mathrm{mmol})$ and oxalyl chloride $(3.35 \mathrm{~mL}, 39.00 \mathrm{mmol})$ was dissolved in carbon disulfide $(30 \mathrm{~mL})$. The round bottom was then placed in an ice bath followed by the addition of aluminum chloride $(1.475 \mathrm{~g}, 11.06 \mathrm{mmol})$. The solution was stirred for an hour before adding more aluminum chloride $(0.870 \mathrm{~g}, 6.51 \mathrm{mmol})$ before stirring at room temperature for 24 hours. The mixture was then poured into crushed ice until the mixture turned yellow. The carbon disulfide in the solution was removed by reduced pressure before filtering the aqueous suspension. The mixture was then washed with dilute hydrochloric acid and diethyl ether before drying overnight in an oil bath at $50{ }^{\circ} \mathrm{C}$. A pale yellow solid was obtained. ${ }^{1} \mathrm{H}$ NMR $(400 \mathrm{MHz}$, $\left.\mathrm{CDCl}_{3}\right) \delta 8.24(\mathrm{~d}, J=8.4 \mathrm{~Hz}, 4 \mathrm{H}), 7.80(\mathrm{~d}, J=9.0 \mathrm{~Hz}, 8 \mathrm{H})$.
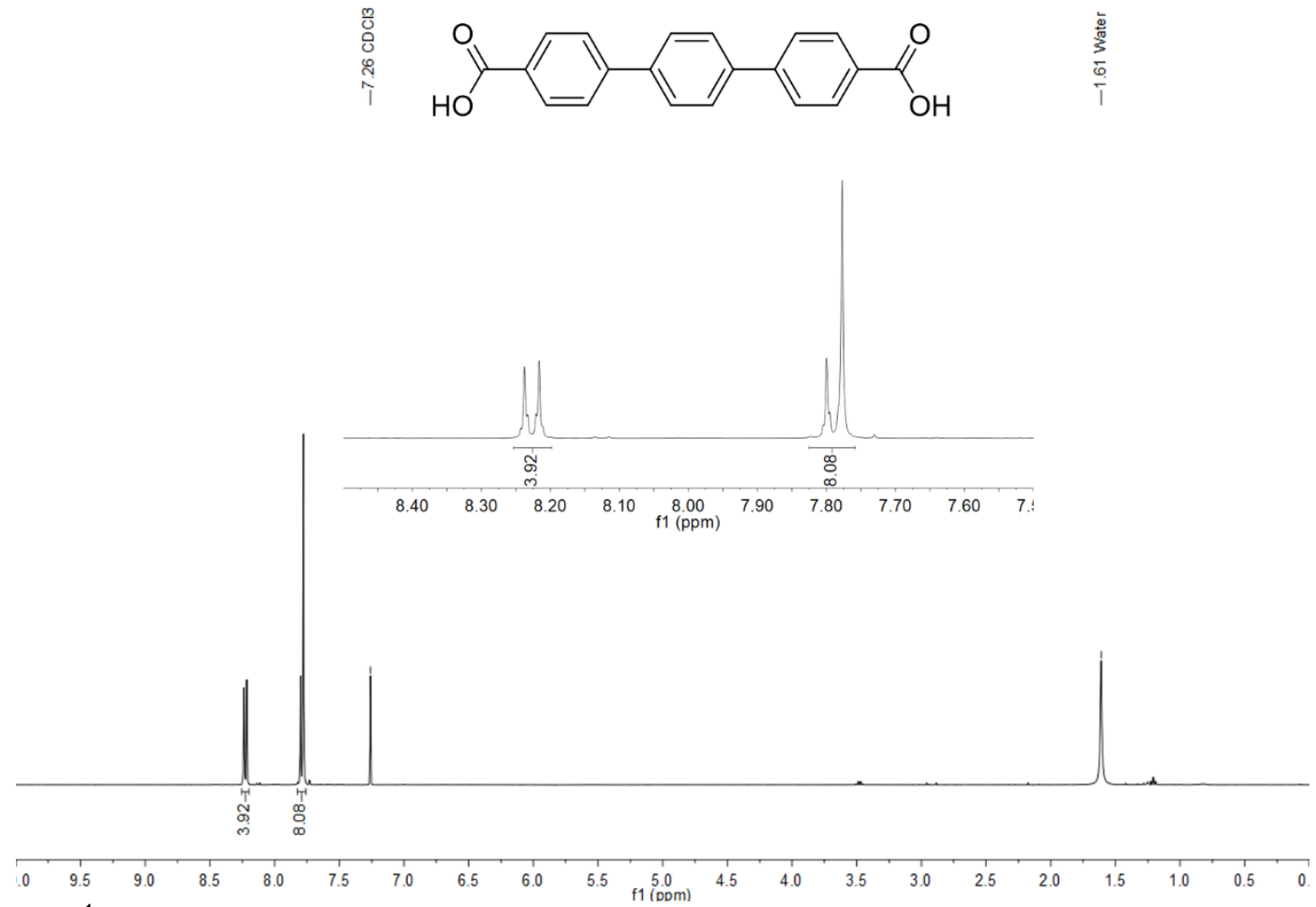

Figure S2. ${ }^{1} \mathrm{H}$ NMR analysis of $\mathrm{H}_{2}$ tpdc. 


\section{Synthesis of $\mathrm{Me}_{2}-\mathrm{H}_{2} \mathrm{tpdc}$}

The following synthesis has been modified from a previously published paper. ${ }^{4}$ In a $100 \mathrm{~mL}$ RBF 1,4-dioxane $(42 \mathrm{~mL})$ and $\mathrm{DI} \mathrm{H}_{2} \mathrm{O}(21 \mathrm{~mL})$ were combined and sparged with $\mathrm{N}_{2}$ for one hour. In a 3-neck, $500 \mathrm{~mL}$ RBF 1,4-dibromo-2,5-dimethyl benzene (2 g, $7.6 \mathrm{mmol})$, 4methoxycarbonylphenylboronic acid $(2.861 \mathrm{~g}, 15.9 \mathrm{mmol})$, cesium fluoride $(6.95 \mathrm{~g}, 45 \mathrm{mmol})$ and [1,1'-bis(diphenylphosphino)ferrocene]dichloropalladium(II) $(0.29 \mathrm{~g}, 0.4 \mathrm{mmol})$ were combined under flowing $\mathrm{N}_{2}$. The 1,4-dioxane/water mixture was then cannula transferred into the 3-neck RBF. The reaction mixture was then refluxed at $100{ }^{\circ} \mathrm{C}$ for four days. The reaction was then cooled to room temperature and the solid in the RBF was collected via vacuum filtration. The solid was washed with fresh $\mathrm{DI} \mathrm{H}_{2} \mathrm{O}$ and used without further purification. The crude product was transferred into a $250 \mathrm{~mL}$ RBF and was combined with THF $(30 \mathrm{~mL})$, ethanol $(30 \mathrm{~mL}), \mathrm{DI} \mathrm{H} \mathrm{H}_{2} \mathrm{O}(30$ $\mathrm{mL}$ ) and sodium hydroxide $(1.92 \mathrm{~g}, 48 \mathrm{mmol})$. The reaction mixture was refluxed at $66{ }^{\circ} \mathrm{C}$ for 24 hours. Upon cooling to room temperature, the volatile solvents were removed under reduced pressure. Concentrated $\mathrm{HCl}$ was then added until the $\mathrm{pH}$ of the slurry reached approximately 1. The solid was then collected via vacuum filtration, washed with fresh $\mathrm{DI}_{2} \mathrm{O}$ and dried overnight. ${ }^{1} \mathrm{H}$ NMR $\left(400 \mathrm{MHz}\right.$, DMSO- $\left.d_{6}\right) \delta 8.03(\mathrm{~d}, J=8.3 \mathrm{~Hz}, 4 \mathrm{H}), 7.53(\mathrm{~d}, J=8.3 \mathrm{~Hz}, 4 \mathrm{H}), 7.20(\mathrm{~s}, 2 \mathrm{H})$, $2.24(\mathrm{~s}, 6 \mathrm{H})$.
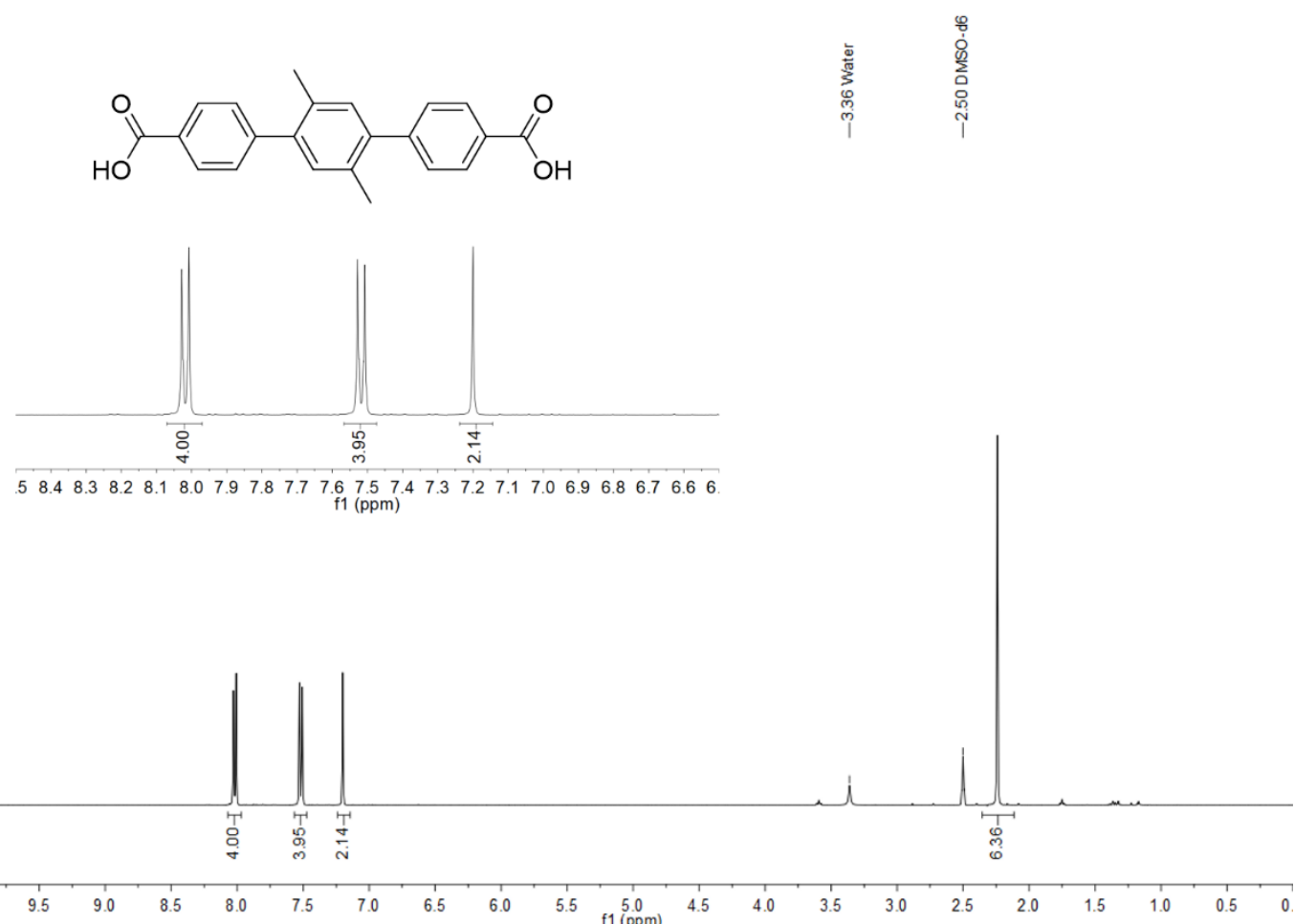

Figure S3. ${ }^{1} \mathrm{H}$ NMR analysis of $\mathrm{Me}_{2}-\mathrm{H}_{2} \mathrm{tpdc}$. 


\section{Synthesis of $1,4-\mathrm{H}_{2} \mathrm{nbb}$}

The following synthesis has been modified from a previously published paper. ${ }^{4} \mathrm{In}$ a $100 \mathrm{~mL}$ RBF 1,4-dioxane $(42 \mathrm{~mL})$ and $\mathrm{DI} \mathrm{H}_{2} \mathrm{O}(21 \mathrm{~mL})$ were combined and sparged with $\mathrm{N}_{2}$ for one hour. In a 3-neck, $500 \mathrm{~mL}$ RBF 1,4-dibromonaphthalene (2 g, $7 \mathrm{mmol}$ ), 4-methoxycarbonylphenylboronic acid $(2.77 \mathrm{~g}, 15.4 \mathrm{mmol})$, cesium fluoride $(6.4 \mathrm{~g}, 42 \mathrm{mmol})$ and [1,1'bis(diphenylphosphino)ferrocene]dichloropalladium(II) $(0.285 \mathrm{~g}, 0.35 \mathrm{mmol})$ were combined under flowing $\mathrm{N}_{2}$. The 1,4-dioxane/water mixture was then cannula transferred into the 3-neck RBF. The reaction mixture was then refluxed at $100{ }^{\circ} \mathrm{C}$ for four days. The reaction was then cooled to room temperature and the solid in the RBF was collected via vacuum filtration. The solid was washed with fresh $\mathrm{DI} \mathrm{H}_{2} \mathrm{O}$ and used without further purification. The crude product was transferred into a $250 \mathrm{~mL} \mathrm{RBF}$ and was combined with THF $(30 \mathrm{~mL})$, ethanol $(30 \mathrm{~mL}), \mathrm{DI} \mathrm{H} 2 \mathrm{O}(30$ $\mathrm{mL}$ ) and sodium hydroxide $(1.67 \mathrm{~g}, 42 \mathrm{mmol})$. The reaction mixture was refluxed at $66{ }^{\circ} \mathrm{C}$ for 24 hours. Upon cooling to room temperature, the volatile solvents were removed under reduced pressure. Concentrated $\mathrm{HCl}$ was then added until the $\mathrm{pH}$ of the slurry reached approximately 1 . The solid was then collected via vacuum filtration, washed with fresh $\mathrm{DI}_{2} \mathrm{O}$ and dried overnight. ${ }^{1} \mathrm{H}$ NMR $\left(400 \mathrm{MHz}\right.$, DMSO-d $\left.\mathrm{d}_{6}\right) \delta 8.12(\mathrm{~d}, J=8.1 \mathrm{~Hz}, 4 \mathrm{H}), 7.87-7.84(\mathrm{~m}, 2 \mathrm{H}), 7.76(\mathrm{~d}, J=8.3 \mathrm{~Hz}$, $4 \mathrm{H}), 7.55(\mathrm{t}, J=9.9 \mathrm{~Hz}, 4 \mathrm{H})$.

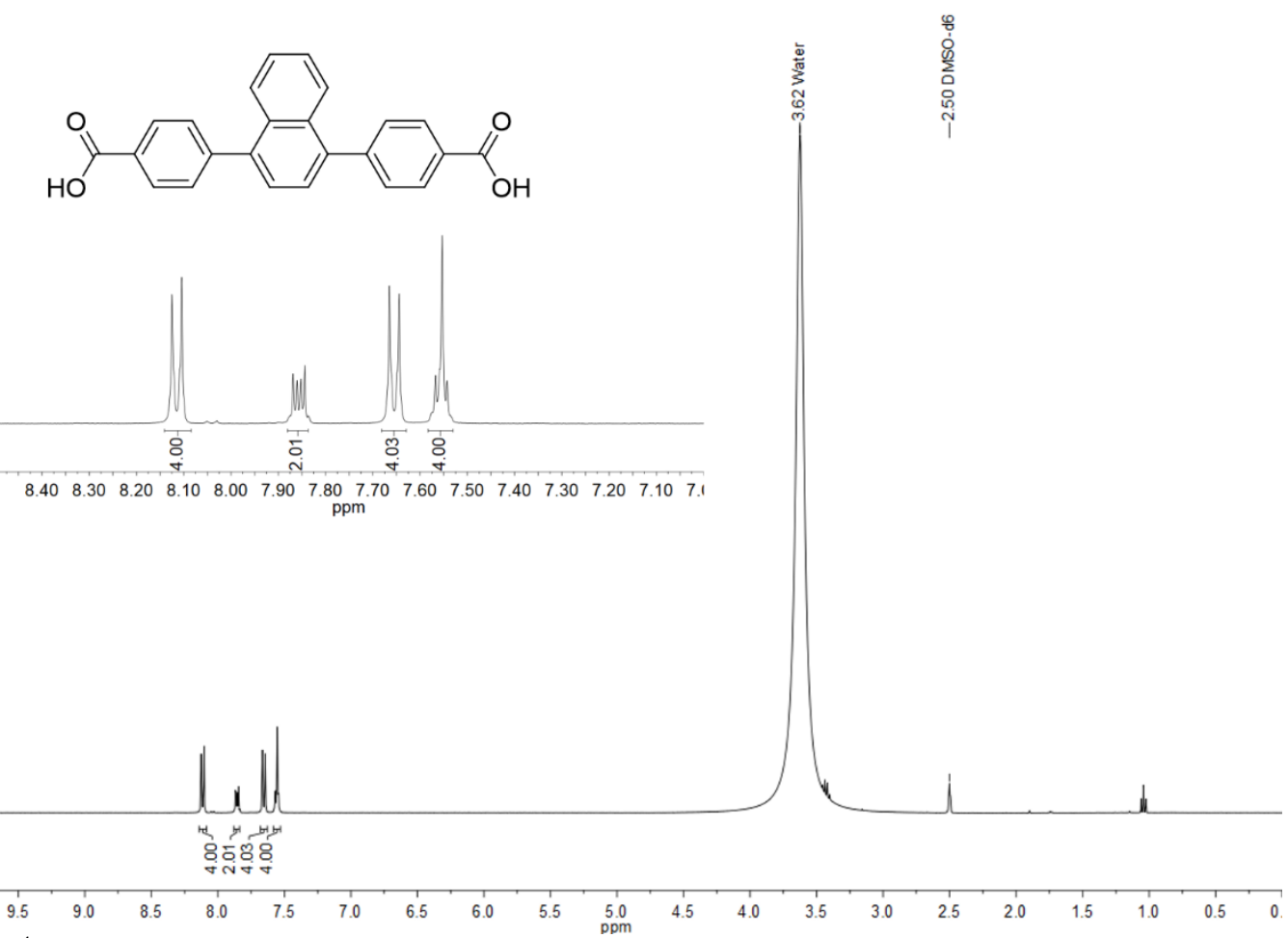

Figure S4. ${ }^{1} \mathrm{H}$ NMR analysis of $1,4-\mathrm{H}_{2} \mathrm{nbb}$. 


\section{Synthesis of $9,10-\mathrm{H}_{2} \mathrm{abb}$}

The following synthesis has been modified from a previously published paper. ${ }^{4}$ In a $100 \mathrm{~mL}$ RBF 1,4-dioxane $(42 \mathrm{~mL})$ and $\mathrm{DI} \mathrm{H}_{2} \mathrm{O}(21 \mathrm{~mL})$ were combined and sparged with $\mathrm{N}_{2}$ for one hour. In a 3-neck, $500 \mathrm{~mL}$ RBF 9,10-dibromoanthracene (2 g, $5.9 \mathrm{mmol})$ ), 4-methoxycarbonylphenylboronic acid $(2.36 \mathrm{~g}, 13.1 \mathrm{mmol})$, cesium fluoride $(5.4 \mathrm{~g}, 35.7 \mathrm{mmol})$ and [1,1'bis(diphenylphosphino)ferrocene]dichloropalladium(II) $(0.243 \mathrm{~g}, 0.3 \mathrm{mmol})$ were combined under flowing $\mathrm{N}_{2}$. The 1,4-dioxane/water mixture was then cannula transferred into the 3-neck RBF. The reaction mixture was then refluxed at $100^{\circ} \mathrm{C}$ for four days. The reaction was then cooled to room temperature and the solid in the RBF was collected via vacuum filtration. The solid was washed with fresh $\mathrm{DI} \mathrm{H}_{2} \mathrm{O}$ and used without further purification. The crude product was transferred into a $250 \mathrm{~mL} \mathrm{RBF}$ and was combined with THF $(30 \mathrm{~mL})$, ethanol $(30 \mathrm{~mL}), \mathrm{DI} \mathrm{H}_{2} \mathrm{O}(30 \mathrm{~mL})$ and sodium hydroxide $(1.43 \mathrm{~g}, 35.7 \mathrm{mmol})$. The reaction mixture was refluxed at $66^{\circ} \mathrm{C}$ for 24 hours. Upon cooling to room temperature, the volatile solvents were removed under reduced pressure. Concentrated $\mathrm{HCl}$ was then added until the $\mathrm{pH}$ of the slurry reached approximately 1 . The solid was then collected via vacuum filtration, washed with fresh $\mathrm{DI} \mathrm{H}_{2} \mathrm{O}$ and dried overnight. ${ }^{1} \mathrm{H}$ NMR $\left(400 \mathrm{MHz}, \mathrm{DMSO}-\mathrm{d}_{6}\right) \delta 8.23(\mathrm{~d}, J=8.2 \mathrm{~Hz}, 4 \mathrm{H}), 7.62(\mathrm{~d}, J=8.3 \mathrm{~Hz}, 4 \mathrm{H}), 7.56-7.54(\mathrm{~m}, 4 \mathrm{H})$, $7.47-7.44(\mathrm{~m}, 4 \mathrm{H})$.
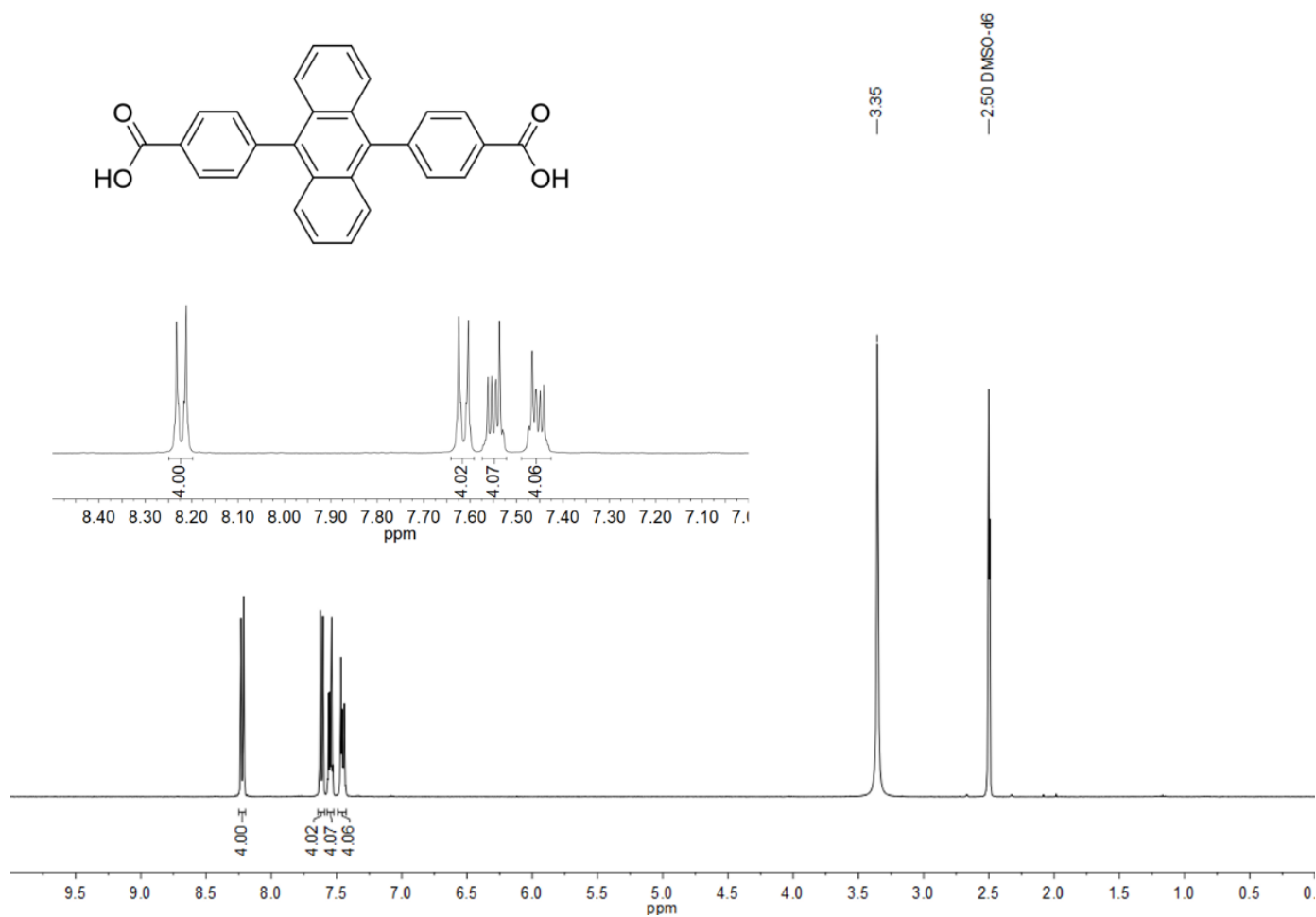

Figure S5. ${ }^{1} \mathrm{H}$ NMR analysis of $9,10-\mathrm{H}_{2}$ abb. 
Synthesis of 2,5-dibromobenzene-1,4-diol

2,5-dibromobenzene-1,5-diol was prepared according to literature methods. ${ }^{5}{ }^{1} \mathrm{H} \mathrm{NMR}(400 \mathrm{MHz}$, DMSO-d $\left.d_{6}\right) \delta 7.33(\mathrm{~s}, 2 \mathrm{H})$.

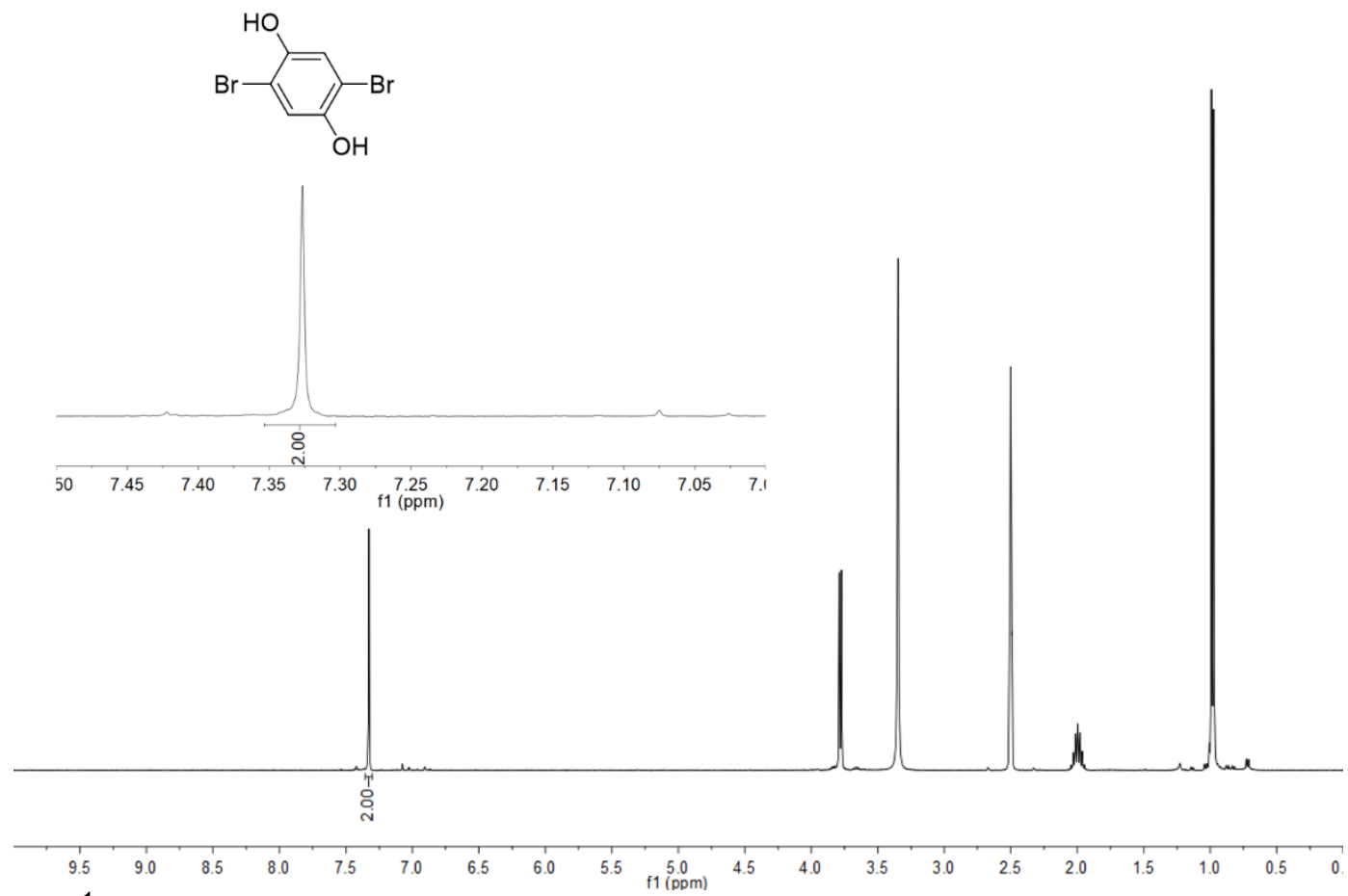

Figure S6. ${ }^{1} \mathrm{H}$ NMR analysis of 2,5-dibromobenzne-1,4-diol. 


\section{Synthesis of $\left(\mathrm{O}^{\mathrm{i}} \mathrm{Bu}\right)_{2}-\mathrm{H}_{2}$ tpdc}

The following synthesis has been modified from a previously published paper. ${ }^{4}$ In a 3-neck, 250 $\mathrm{mL}$ RBF 2,5-dibromobenzene-1,5-diol $(2.68 \mathrm{~g}, 10 \mathrm{mmol})$ and potassium carbonate $(3.5 \mathrm{~g}, 25$ $\mathrm{mmol}$ ) were combined and left under a flowing nitrogen atmosphere for one hour. Anhydrous DMF $(30 \mathrm{~mL})$ was added to the RBF. 1-lodo-2-methylpropane $(3.45 \mathrm{~mL}, 30 \mathrm{mmol})$ was pippeted into the reaction mixture. The reaction was then heated at $65^{\circ} \mathrm{C}$ for four days. The reaction was then

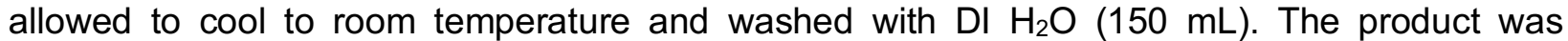
extracted using chloroform $(100 \mathrm{~mL})$ and isolated under reduced pressure. The resulting red product, potassium carbonate $(3.5 \mathrm{~g}, 25 \mathrm{mmol})$ and dry DMF $(20 \mathrm{~mL})$ were combined in a $250 \mathrm{~mL}$ RBF. 1-lodo-2-methylpropane ( $3.45 \mathrm{~mL}, 30 \mathrm{mmol}$ ) was added to the $250 \mathrm{~mL}$ RBF. The resulting reaction mixture was heated at $65^{\circ} \mathrm{C}$ for an additional two days. The reaction was cooled to room temperature and then $\mathrm{DI} \mathrm{H}_{2} \mathrm{O}(200 \mathrm{~mL})$ was added to the RBF. Red solid precipitated out of solution and was collected via vacuum filtration. The crude red product was used without further purification. 1,4-Dioxane $(42 \mathrm{~mL})$ and $\mathrm{DI} \mathrm{H}_{2} \mathrm{O}(21 \mathrm{~mL})$ were combined in a $100 \mathrm{~mL} R B F$ and sparged with $\mathrm{N}_{2}$ for one hour. In a 3-neck, $500 \mathrm{~mL} \mathrm{RBF}$, the resulting product from above $(\sim 1 \mathrm{~g}$, $2.9 \mathrm{mmol}), 4$-methoxycarbonylphenylboronic acid $(1.14 \mathrm{~g}, 6 \mathrm{mmol})$, cesium fluoride $(2.6 \mathrm{~g}, 17.3$ $\mathrm{mmol}$ ), and [1,1'-bis(diphenylphosphino)ferrocene]dichloropalladium(II) $(0.118 \mathrm{~g}, 0.14 \mathrm{mmol})$ were combined under flowing $\mathrm{N}_{2}$. The 1,4-dioxane/ $\mathrm{H}_{2} \mathrm{O}$ mixture was then cannula transferred into the $500 \mathrm{~mL}$ RBF. The resulting reaction mixture was then refluxed at $100^{\circ} \mathrm{C}$ for four days. The reaction was then cooled to room temperature. The reaction mixture was transferred into a 600 $\mathrm{mL}$ beaker and the reaction vessel rinsed with $\mathrm{DI} \mathrm{H}_{2} \mathrm{O}(150 \mathrm{~mL})$ which was then added to the beaker. The product was then extracted with ethyl acetate $(100 \mathrm{~mL})$. Resulting insoluble grey solid was then removed via vacuum filtration and the filtrate was transferred into a $1 \mathrm{~L}$ separatory funnel. The ethyl acetate layer was washed with brine $(3 \times 30 \mathrm{~mL})$, transferred into a $250 \mathrm{~mL}$ RBF and then removed under reduced pressure. The resulting solid was used without further purification and combined with THF $(30 \mathrm{~mL})$, ethanol $(30 \mathrm{~mL}), \mathrm{DI} \mathrm{H}_{2} \mathrm{O}(30 \mathrm{~mL})$ and sodium hydroxide $(0.7 \mathrm{~g}, 17.3 \mathrm{mmol})$. The resulting reaction mixture was refluxed at $66^{\circ} \mathrm{C}$ for 24 hours. The reaction was then cooled to room temperature and the volatile solvents were removed under reduced pressure. Concentrated $\mathrm{HCl}$ was added via pipet until the $\mathrm{pH}$ of the solution was approximately 1 . The resulting solid was collected via vacuum filtration and washed with $\mathrm{DI}_{2} \mathrm{O}$. $\left(400 \mathrm{MHz}, \mathrm{DMSO}-\mathrm{d}_{6}\right) \delta 8.00(\mathrm{~d}, J=8.4 \mathrm{~Hz}, 4 \mathrm{H}), 7.73(\mathrm{~d}, J=8.5 \mathrm{~Hz}, 4 \mathrm{H}), 7.1(\mathrm{~s}, 2 \mathrm{H}), 3.79(\mathrm{~d}, J=$ $6.4 \mathrm{~Hz}, 4 \mathrm{H}), 1.91$ (septet, $J=8.3 \mathrm{~Hz}, 2 \mathrm{H}), 0.89(\mathrm{~d}, J=6.7 \mathrm{~Hz}, 12 \mathrm{H})$. 


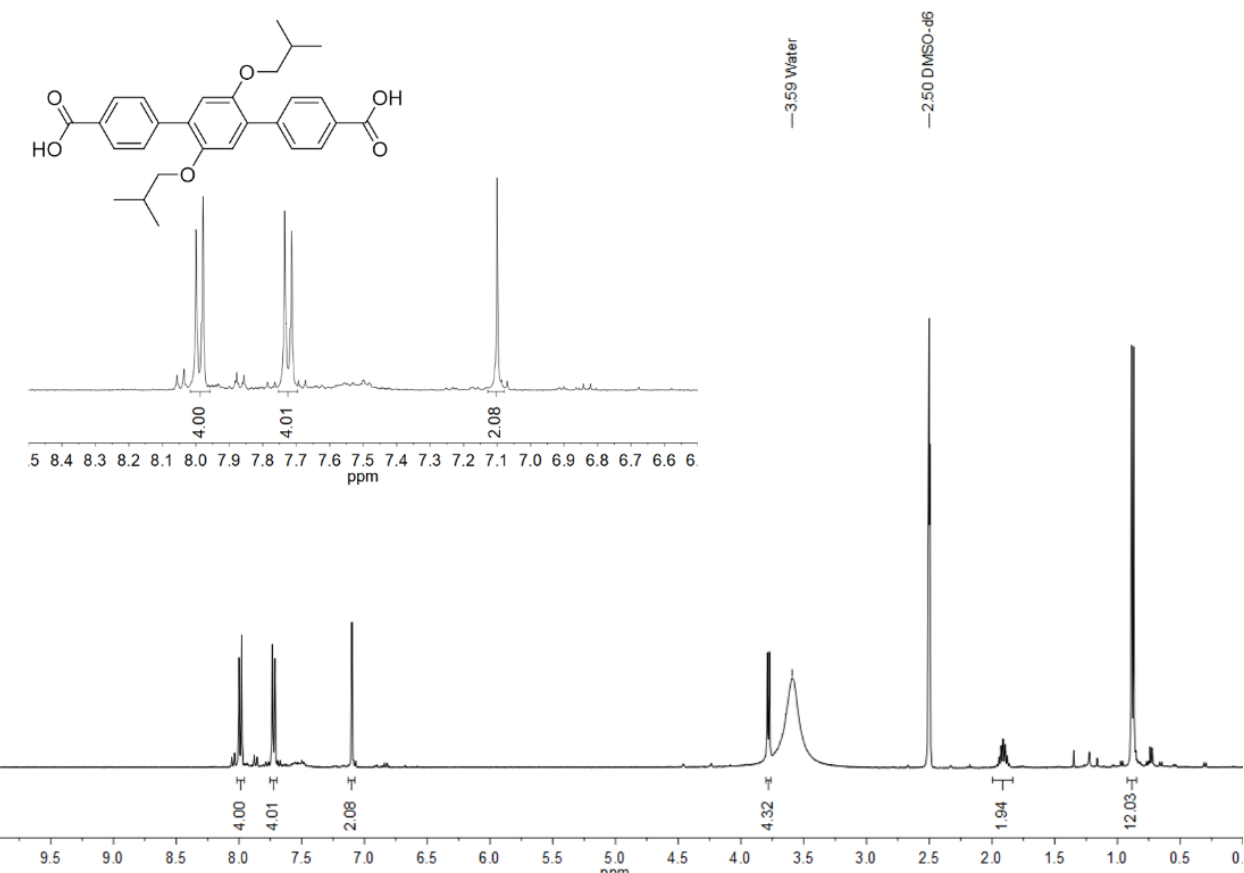

Figure S7. ${ }^{1} \mathrm{H}$ NMR analysis of $\left(\mathrm{O}^{\mathrm{i}} \mathrm{Bu}\right)_{2}-\mathrm{H}_{2} \mathrm{tpdc}$. 


\section{Synthesis of precursor to $\mathrm{H}_{2} \mathrm{tda}$}

Dimethyl 3,3'-(thiophene-2,5-diyl) (2E,2'E)-diacrylate followed the general synthesis above with the only change being that a manual column was performed with $10 \%$ ethyl acetate, $5 \%$ DCM and $85 \%$ hexanes. Resulting in a matte yellow powder. The following NMR spectra are located in Figure S8-S9.

${ }^{1} \mathrm{H}$ NMR $\left(500 \mathrm{MHz}, \mathrm{DMSO}-d_{6}\right) \delta 7.75$ (d, J = $\left.16.0 \mathrm{~Hz}, 2 \mathrm{H}\right), 7.53(\mathrm{~s}, 2 \mathrm{H}), 6.30$ (d, J = $\left.15.4 \mathrm{~Hz}, 2 \mathrm{H}\right)$, $3.68(\mathrm{~s}, 6 \mathrm{H})$.

${ }^{13} \mathrm{C}$ NMR $(126 \mathrm{MHz}$, DMSO-D $)$ ס 166.66, 141.89, 137.16, 118.34, 52.17.
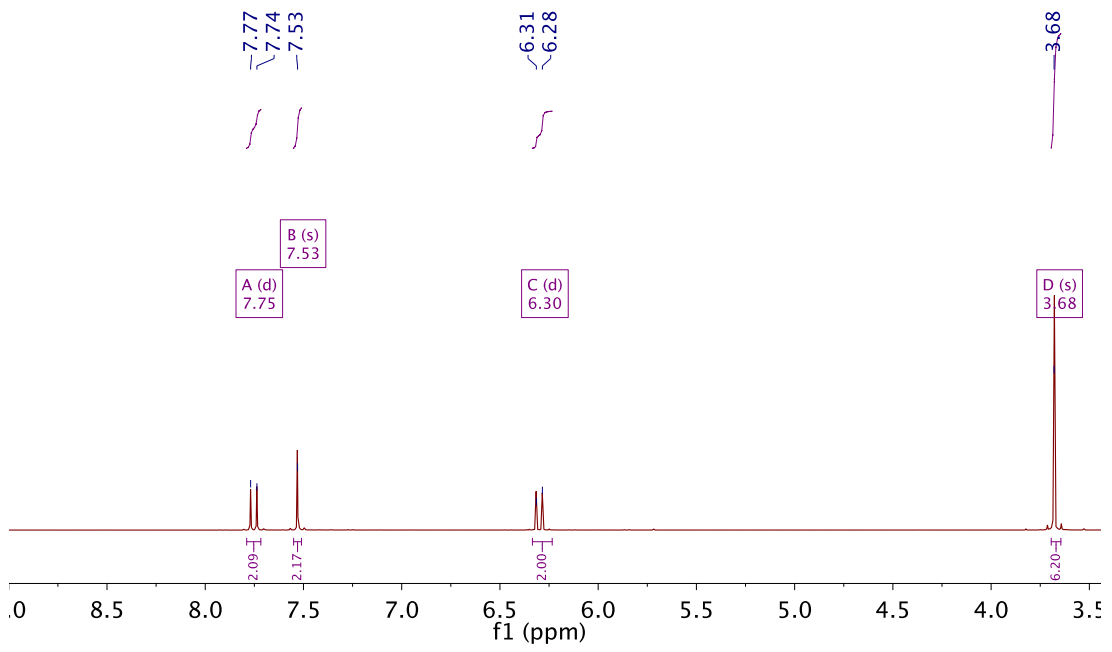

'H NMR (500 MHz, DMSO- $\left.d_{6}\right) 87.75$ (d, $\left.J=16.0 \mathrm{~Hz}, 2 \mathrm{H}\right), 7.53(\mathrm{~s}, 2 \mathrm{H}), 6.30(\mathrm{~d}, J=15.4 \mathrm{~Hz}$ $2 \mathrm{H}), 3.68(\mathrm{~s}, 6 \mathrm{H})$.

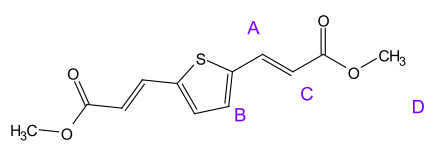

Figure S8. ${ }^{1} \mathrm{H}$ NMR of precursor to $\mathrm{H}_{2} \mathrm{tda}$.
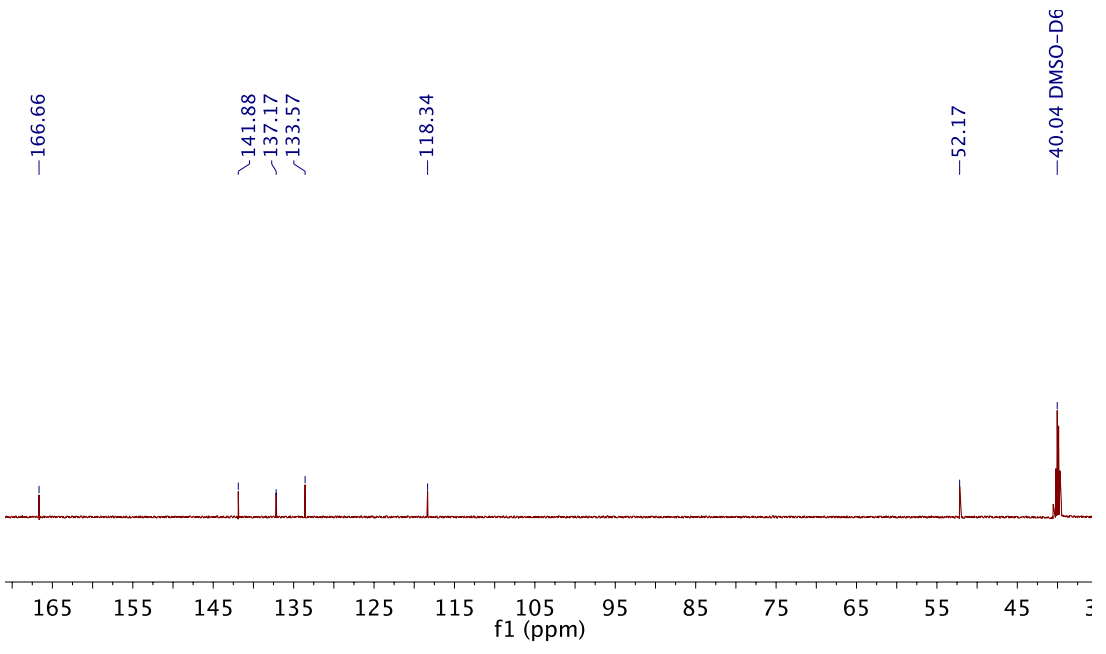

NMR (126 MHz, DMSO-D $\left.D_{6}\right) \delta 166.66,141.88,137.17,133.57,118.34,52.17,40.04$.

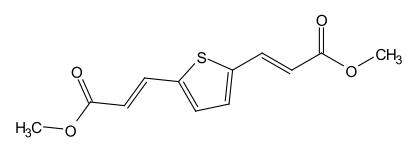

Figure S9. ${ }^{13} \mathrm{C}$ NMR of precursor to $\mathrm{H}_{2}$ tda. 


\section{Synthesis of $\mathrm{H}_{2}$ tda}

(2E,2'E)-3,3'-(thiophene-2,5-diyl) diacrylic acid followed the general synthesis above resulting in a matte yellow powder. The following NMR spectra are located in Figure S10-S11.

${ }^{1} \mathrm{H}$ NMR $\left(500 \mathrm{MHz}, \mathrm{DMSO}-d_{6}\right) \delta 7.75(\mathrm{~d}, J=16.0 \mathrm{~Hz}, 2 \mathrm{H}), 7.53(\mathrm{~s}, 2 \mathrm{H}), 6.30(\mathrm{~d}, J=15.4 \mathrm{~Hz}, 2 \mathrm{H})$, $3.68(\mathrm{~s}, 6 \mathrm{H})$.

${ }^{13} \mathrm{C}$ NMR $(126 \mathrm{MHz}$, DMSO-D 6 ) $\delta$ 167.52, 141.80, 136.65, 133.15, 119.78.
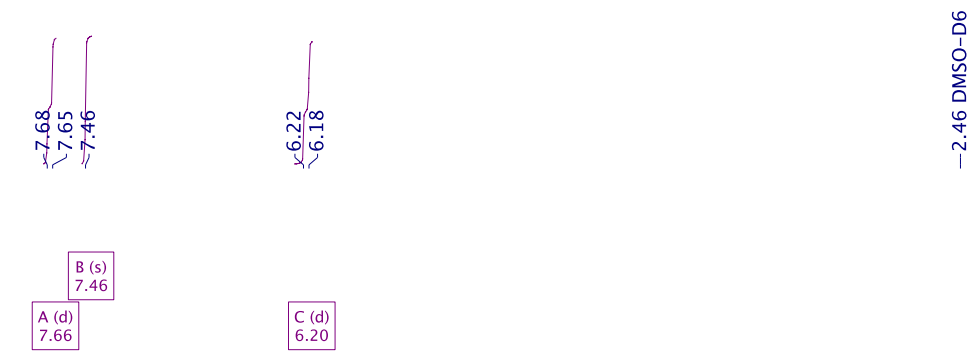

\begin{tabular}{l}
$C(d)$ \\
6.20 \\
\hline
\end{tabular}
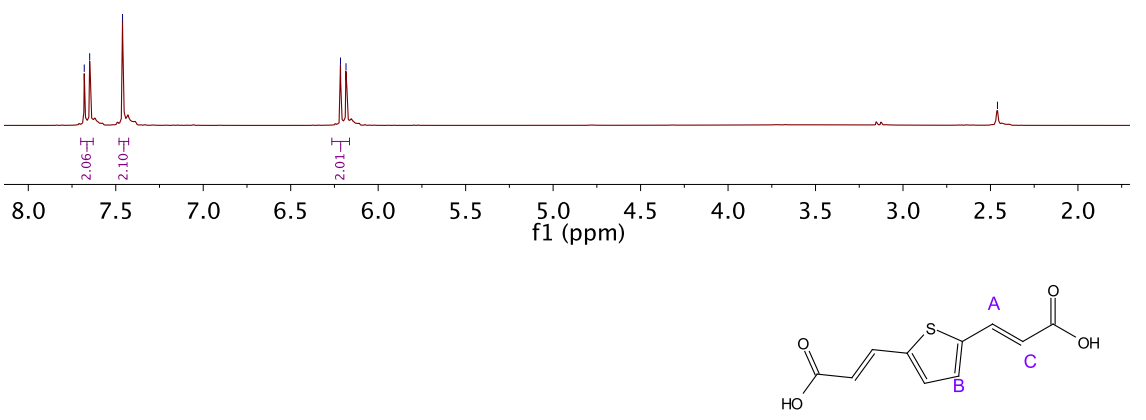

Figure S10. ${ }^{1} \mathrm{H}$ NMR of $\mathrm{H}_{2}$ tda.

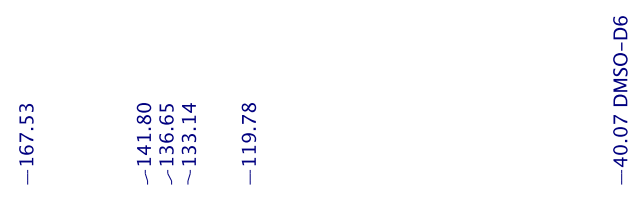

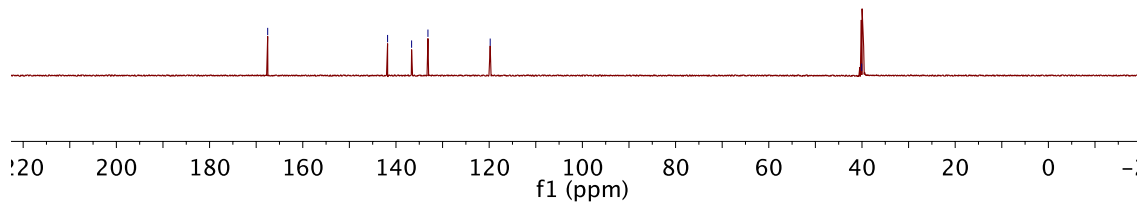

${ }^{13} \mathrm{C} \mathrm{NMR}(126 \mathrm{MHz}$, DMSO-D $)$ ) $167.53,141.80,136.65,133.14,119.78,40.07$.

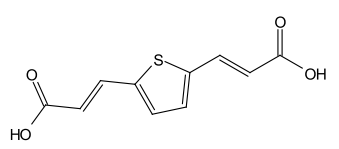

Figure S11. ${ }^{13} \mathrm{C}$ NMR of $\mathrm{H}_{2}$ tda. 


\section{Synthesis of precursor to $(\mathrm{OMe})_{2}-\mathrm{H}_{2} \mathrm{pda}$}

Dimethyl 3,3'-(2,5-dimethoxy-1,4-phenylene) (2E,2'E)-diacrylate followed the general synthesis above, but instead of an extraction with DCM and acidic water the crude was stirred in acid water overnight and then filtered through a silica plug. In addition, trimethylamine was used instead of the N,N-dicyclohexylmethylamine. Resulting in a yellow powder. The following NMR spectrum is located in Figure S12.

${ }^{1} \mathrm{H}$ NMR $\left(500 \mathrm{MHz}, \mathrm{DMSO}-d_{6}\right) \delta 7.83(\mathrm{~d}, J=15.6 \mathrm{~Hz}, 1 \mathrm{H}), 7.39(\mathrm{~s}, 1 \mathrm{H}), 6.77(\mathrm{~d}, J=15.9 \mathrm{~Hz}, 1 \mathrm{H})$, $3.84(\mathrm{~s}, 3 \mathrm{H}), 3.69(\mathrm{~s}, 3 \mathrm{H})$.

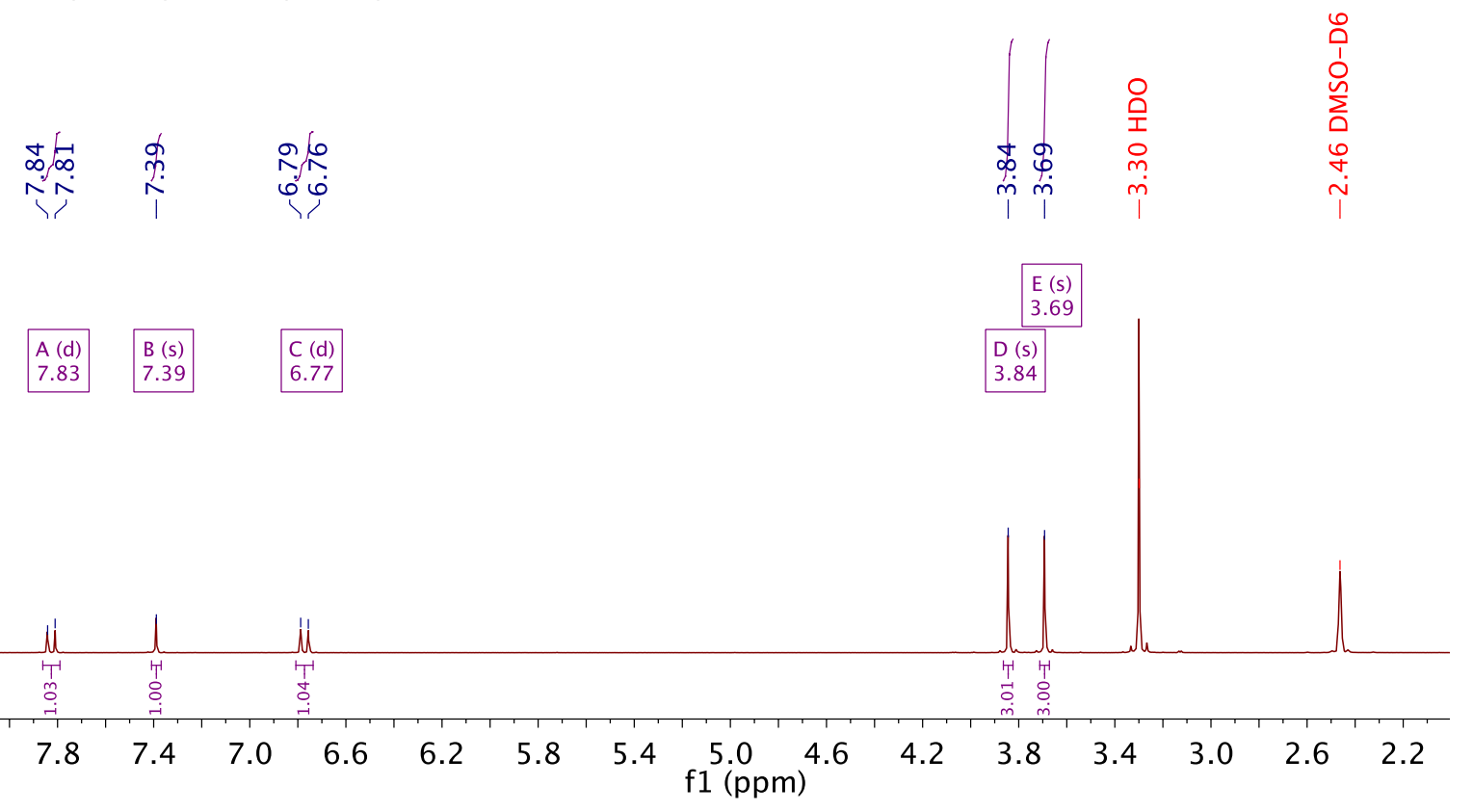

${ }^{1} \mathrm{H}$ NMR $\left(500 \mathrm{MHz}\right.$, DMSO- $\left.d_{6}\right) \delta 7.83(\mathrm{~d}, J=15.6 \mathrm{~Hz}, 1 \mathrm{H}), 7.39(\mathrm{~s}, 1 \mathrm{H}), 6.77(\mathrm{~d}, J=15.9 \mathrm{~Hz}$, $1 \mathrm{H}), 3.84(\mathrm{~s}, 3 \mathrm{H}), 3.69(\mathrm{~s}, 3 \mathrm{H})$.

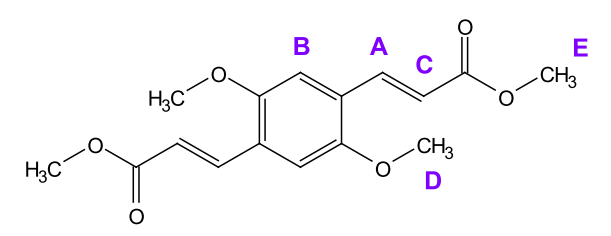

Figure S12. ${ }^{1} \mathrm{H}$ NMR of precursor to $(\mathrm{OMe})_{2}-\mathrm{H}_{2} \mathrm{pda}$. 


\section{Synthesis of $(\mathrm{OMe})_{2}-\mathrm{H}_{2}$ pda}

$\left(2 E, 2^{\prime} E\right)-3,3$ '-(2,5-Dimethoxy-1,4-phenylene) diacrylic acid followed the general synthesis above. Resulting in a bright yellow powder. The following NMR spectra are located in Figure S13-S14.

${ }^{1} \mathrm{H}$ NMR $(500 \mathrm{MHz}$, DMSO-d $) \delta 12.38(\mathrm{~s}, 1 \mathrm{H}), 7.78(\mathrm{~d}, J=16.0 \mathrm{~Hz}, 1 \mathrm{H}), 7.34(\mathrm{~s}, 1 \mathrm{H}), 6.65(\mathrm{~d}, J$ $=16.1 \mathrm{~Hz}, 1 \mathrm{H}), 3.83(\mathrm{~s}, 3 \mathrm{H})$.

${ }^{13} \mathrm{C}$ NMR $\left(126 \mathrm{MHz}, \mathrm{DMSO}-\mathrm{D}_{6}\right) \delta$ 168.33, 152.40, 138.25, 125.73, 121.14, 111.61 56.80.
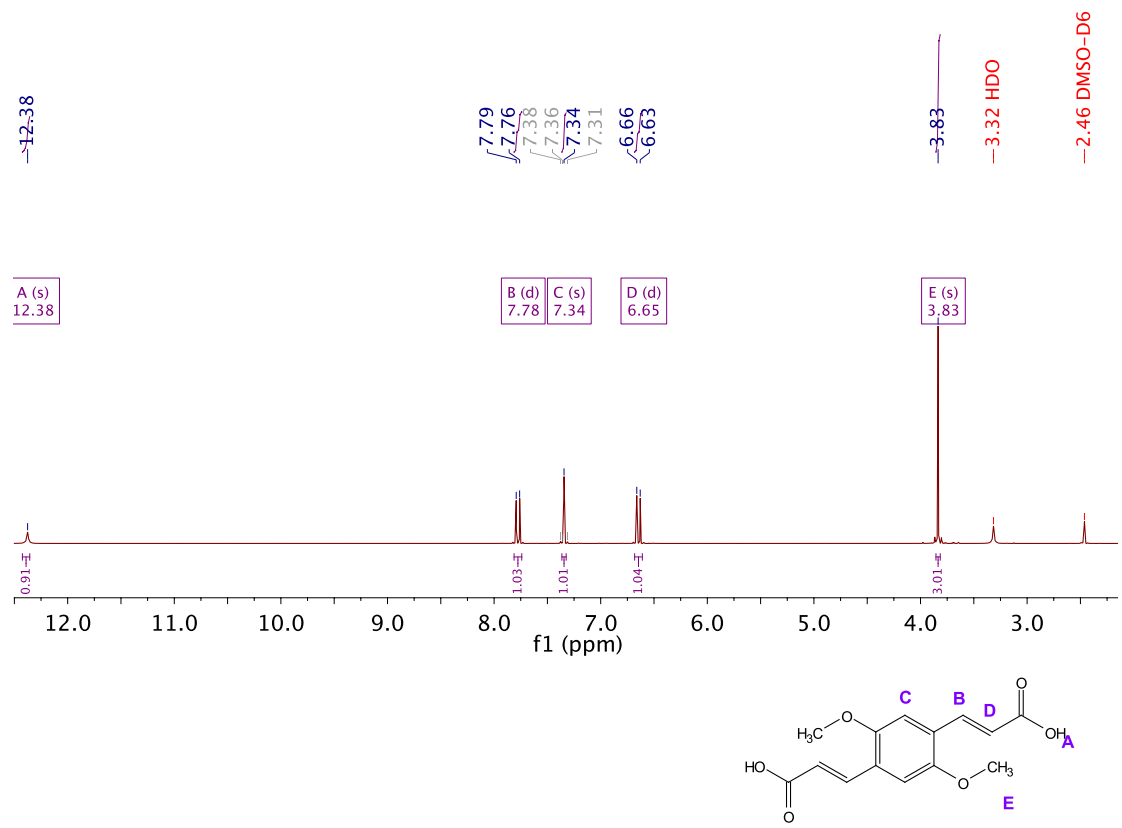

Figure S13. ${ }^{1} \mathrm{H}$ NMR of $(\mathrm{OMe})_{2}-\mathrm{H}_{2} \mathrm{pda}$.

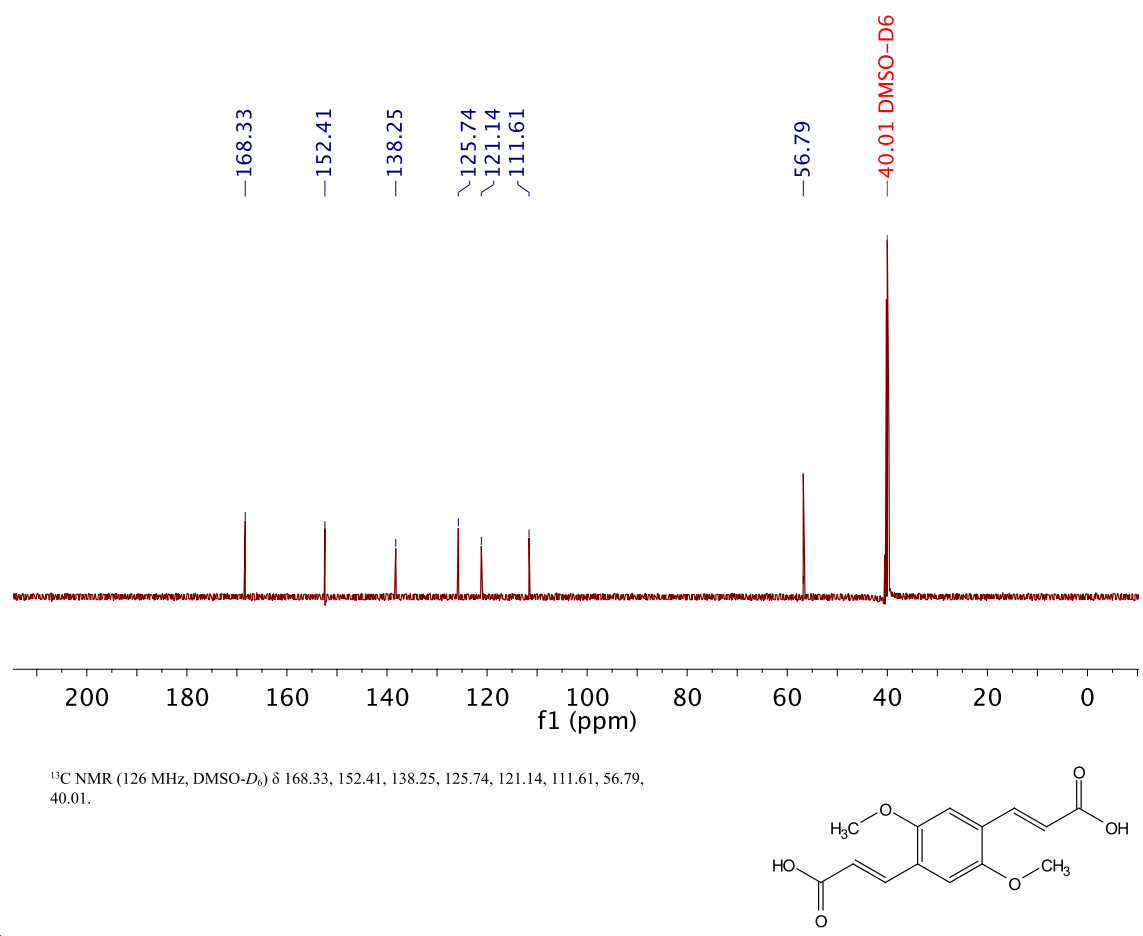

Figure S14. ${ }^{13} \mathrm{C}$ NMR of $(\mathrm{OMe})_{2}-\mathrm{H}_{2} \mathrm{pda}$. 


\section{Synthesis of precursor to $\mathrm{F}-\mathrm{H}_{2}$ pda}

Dimethyl 3,3'-(2-fluoro-1,4-phenylene) (2E,2'E)-diacrylate followed the general synthesis above, but instead of an extraction with DCM and acidic water the crude was stirred in acid water overnight and then filtered through a silica plug. Resulting in a shiny white powder. The following NMR spectra are located in Figure S15-S16.

${ }^{1} \mathrm{H}$ NMR $(500 \mathrm{MHz}$, DMSO-d $)$ $\delta 7.85(\mathrm{~s}, 1 \mathrm{H}), 7.72-7.53(\mathrm{~m}, 4 \mathrm{H}), 6.79-6.66(\mathrm{~m}, 2 \mathrm{H}), 3.70(\mathrm{~s}$, $6 \mathrm{H})$.

${ }^{13} \mathrm{C}$ NMR (126 MHz, DMSO- $\left.D_{6}\right) \delta 166.89,162.16,160.16,142.90,138.81,136.05,130.19$, $125.61,123.74,121.75,120.99,115.90,115.72,52.24,52.16,40.05$.

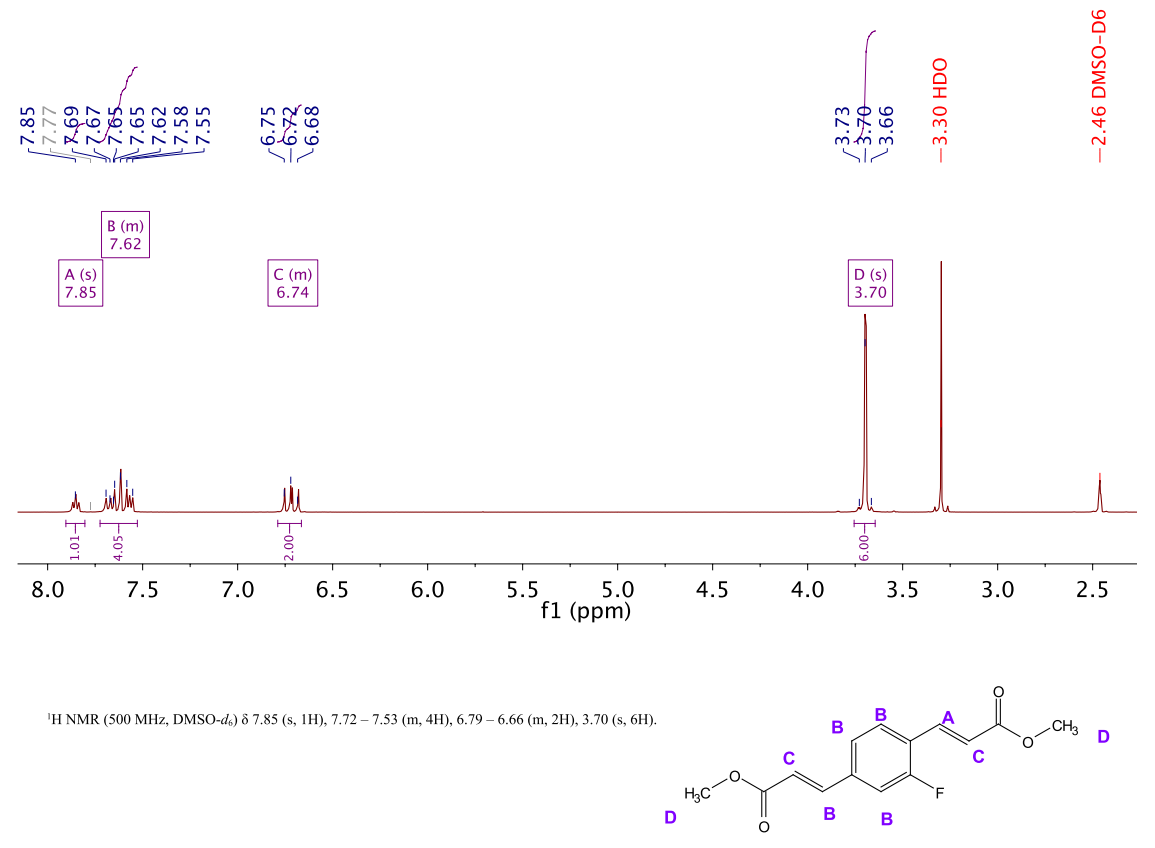

Figure S15. ${ }^{1} \mathrm{H}$ NMR of precursor to $\mathrm{F}-\mathrm{H}_{2}$ pda.

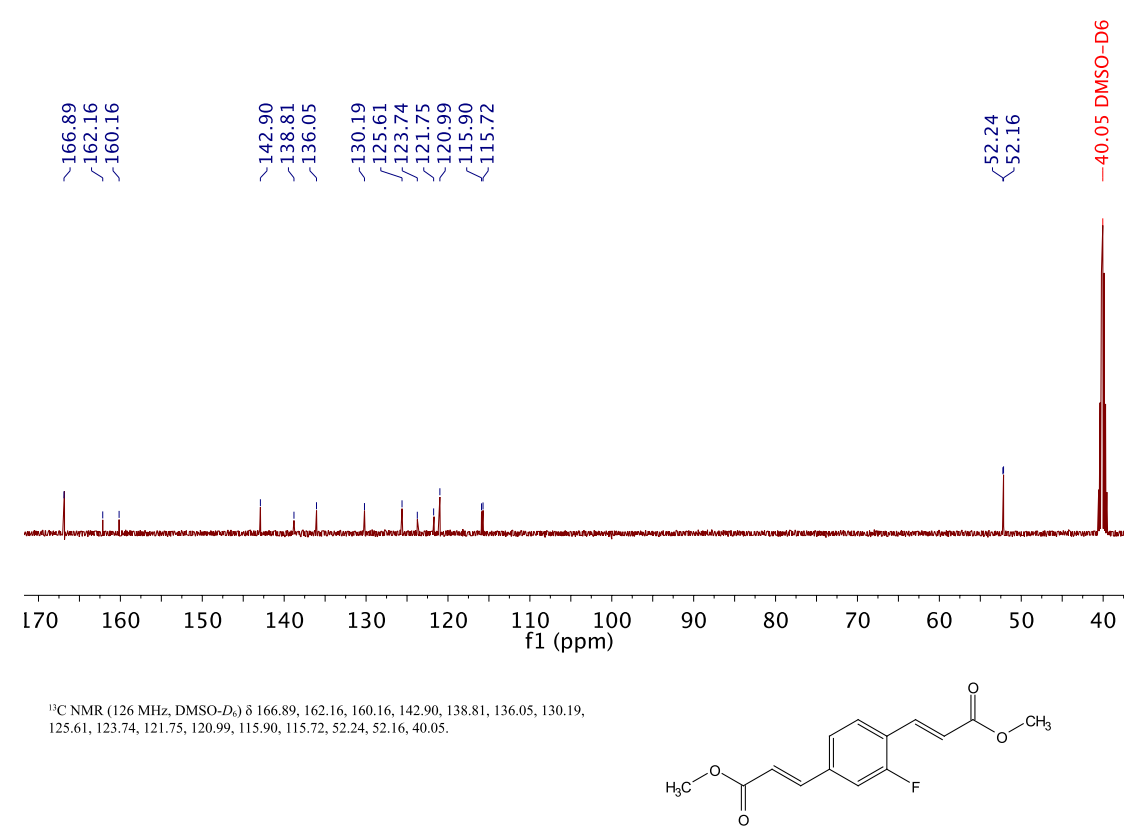

Figure S16. ${ }^{13} \mathrm{C}$ NMR of precursor - dimethyl 3,3'-(2-fluoro-1,4-phenylene)(2E,2'E)-diacrylate. 


\section{Synthesis of F-H $\mathrm{H}_{2}$ pda}

$\left(2 E, 2^{\prime} E\right)-3,3$ '-(2-Fluoro-1,4-phenylene) diacrylic acid followed the general synthesis above. Resulting in a white powder. The following NMR spectra are located in Figure S17-S18.

${ }^{1} \mathrm{H}$ NMR $\left(500 \mathrm{MHz}\right.$, DMSO- $\left.d_{6}\right) \delta 7.81(\mathrm{~s}, 1 \mathrm{H}), 7.69-7.46(\mathrm{~m}, 4 \mathrm{H}), 6.62(\mathrm{t}, J=13.9 \mathrm{~Hz}, 2 \mathrm{H})$.

${ }^{13} \mathrm{C}$ NMR (126 MHz, DMSO-D6) $\delta 167.80,167.73,162.09,160.10,142.32,138.80,138.73$, 135.51, 130.04, 125.39, 123.74, 123.64, 123.11, 123.07, 122.31, 115.74, 115.56, 40.27.
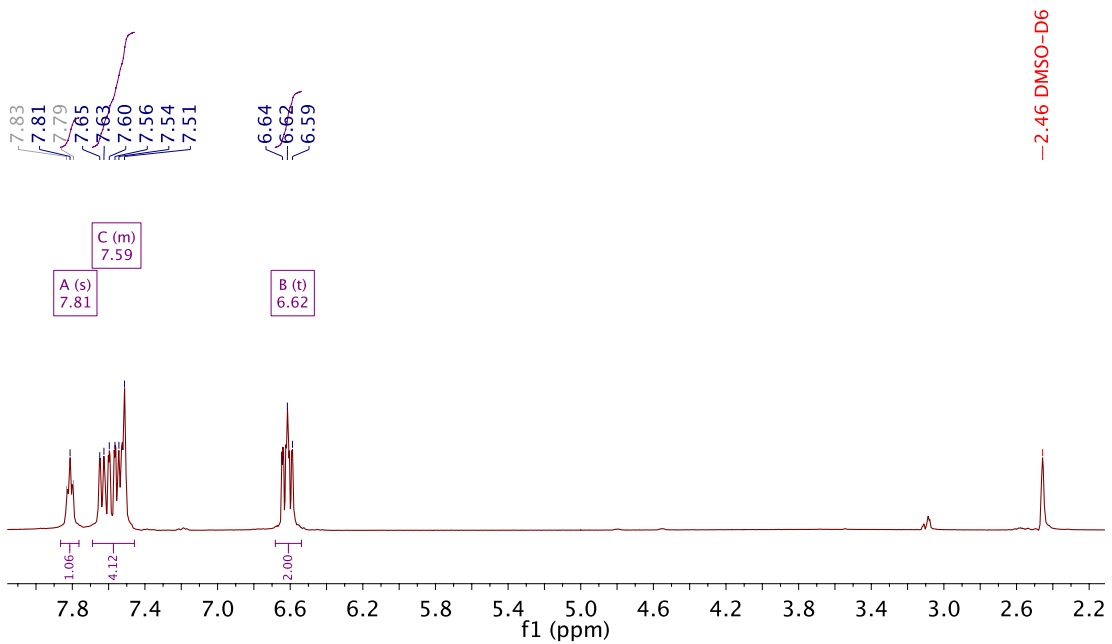

${ }^{\prime} \mathrm{H}$ NMR $\left(500 \mathrm{MHz}\right.$, DMSO- $\left.d_{6}\right) 87.81(\mathrm{~s}, 1 \mathrm{H}), 7.69-7.46(\mathrm{~m}, 4 \mathrm{H}), 6.62(\mathrm{t}, J=13.9 \mathrm{~Hz}, 2 \mathrm{H})$.

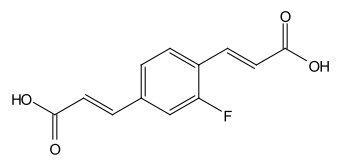

Figure S17. ${ }^{1} \mathrm{H}$ NMR of F-H $\mathrm{H}_{2}$ pda.

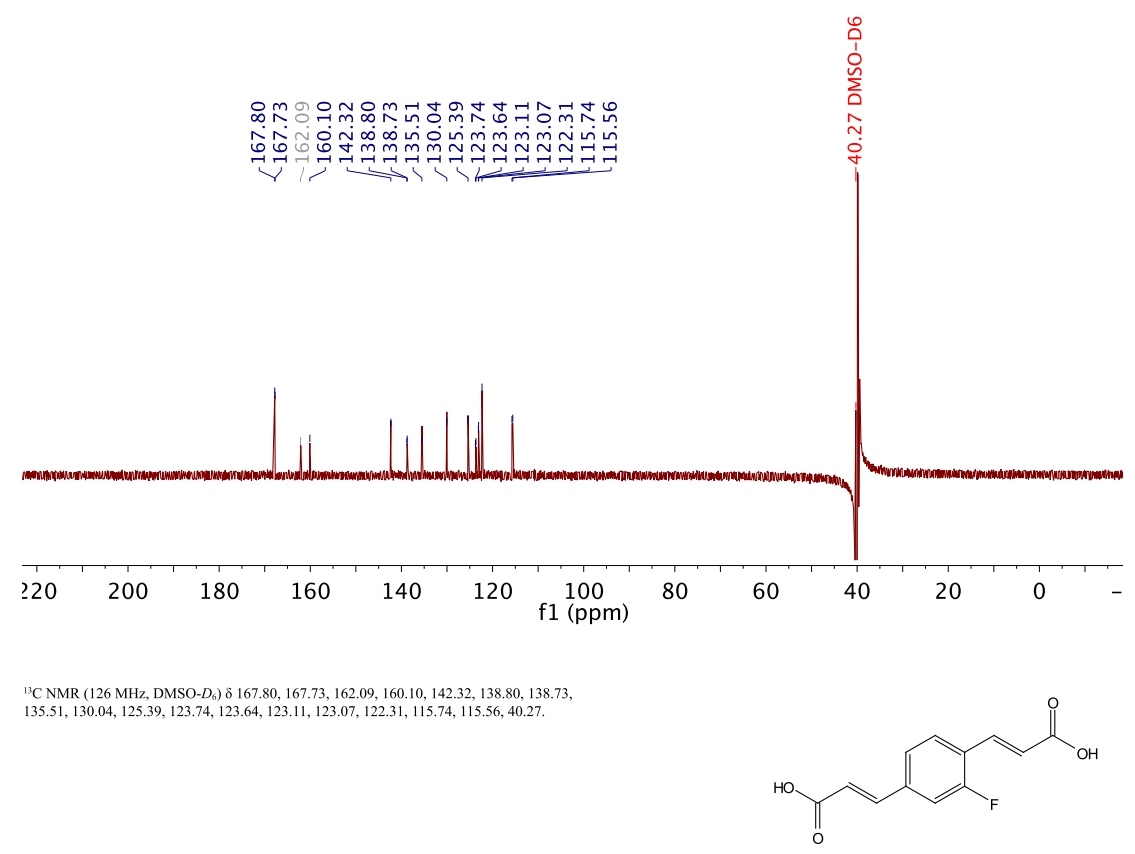

Figure S18. ${ }^{13} \mathrm{C}$ NMR of $\mathrm{F}-\mathrm{H}_{2}$ pda. 


\section{Detailed Cage Experimental Procedures}

Synthesis of $1 \mathrm{C}$ In a $20 \mathrm{~mL}$ vial zirconocene dichloride (350 mg, $1.2 \mathrm{mmol}$ ) and fumaric acid $\left(\mathrm{H}_{2} \mathrm{fum}\right)(69.6 \mathrm{mg}, 0.6 \mathrm{mmol})$ were dissolved in DMF $(20 \mathrm{~mL})$. The stock solution $(1 \mathrm{~mL})$ and $\mathrm{DI}$ water $(100 \mu \mathrm{L})$ were transferred to a $7 \mathrm{~mL}$ vial and heated at $65^{\circ} \mathrm{C}$ for 8 hours. White crystalline solid was collected via pipet and transferred into a $20 \mathrm{~mL}$ vial. Upon collection of all sample vials the slurry was centrifuged, and mother liquor decanted. Activated material was prepared by washing as synthesized cage in fresh DMF three times, with solvent replaced every 24 hours. The DMF solvated material was then exchanged three times with chloroform, with fresh solvent added every 24 hours. Chloroform solvated material was then activated under dynamic vacuum at room temperature.

Synthesis of 2T/C_CI In a $20 \mathrm{~mL}$ vial zirconocene dichloride $(672 \mathrm{mg}, 2.3 \mathrm{mmol})$ and terephthalic acid $\left(\mathrm{H}_{2} \mathrm{bdc}\right)(191.0 \mathrm{mg}, 1.15 \mathrm{mmol})$ were dissolved in DMF $(19 \mathrm{~mL})$. The stock solution $(2.375$ $\mathrm{mL}$ ) and DI water $(77 \mu \mathrm{L})$ were transferred to a $7 \mathrm{~mL}$ vial and heated at $65^{\circ} \mathrm{C}$ for 8 hours. White crystalline powder was collected via pipet and transferred into a $20 \mathrm{~mL}$ vial. Upon collection of all sample vials the slurry was centrifuged, and mother liquor decanted. Activated material for NMR and mass spectrometry was prepared by washing as synthesized cage in DMF three times, with solvent replaced every 24 hours. The DMF solvated material was then exchanged three times with chloroform, with fresh solvent added every 24 hours. Chloroform solvated material was then activated under dynamic vacuum at room temperature.

Synthesis of 2T/C_OTf 2T/C_Cl-15DMF (197 $\mathrm{mg}, 0.045 \mathrm{mmol})$ and silver trifluoromethanesulfonate $(47 \mathrm{mg}, 0.18 \mathrm{mmol})$ were combined in a tinfoil wrapped $20 \mathrm{~mL}$ scintillation vial. Methanol $(10 \mathrm{~mL})$ was added to the vial. The resulting mixture was stirred in darkness at room temperature for 3 days. The resulting slurry was then centrifuged, and the mother liquor removed via pipet. The methanol was then removed under reduced pressure resulting in off-white cage product. Single-crystal quality material was obtained by dissolving as synthesized material in methanol and recrystallizing via diffusion with diethyl ether. Material for NMR and mass spectrometry was obtained by collecting the non-cubic crystals/crystalline powder via pipet and then washing with diethyl ether, finally the material was dried under dynamic vacuum at room temperature.

Synthesis of 3 T/C In a $20 \mathrm{~mL}$ vial zirconocene dichloride (350 mg, $1.2 \mathrm{mmol}$ ) and 1,4naphthalene dicarboxylic acid $\left(1,4-\mathrm{H}_{2} \mathrm{ndc}\right)(0.130 \mathrm{~g}, 0.6 \mathrm{mmol})$ were dissolved in DMA $(20 \mathrm{~mL})$. The stock solution $(0.5 \mathrm{~mL})$ and DI water $(60 \mu \mathrm{L})$ were transferred to a $4 \mathrm{~mL}$ vial. The $4 \mathrm{~mL}$ vial was placed into a $20 \mathrm{~mL}$ vial containing ethyl acetate $(3 \mathrm{~mL})$ and left to diffuse for 48 hours. Cubic and non-cubic crystals were collected via pipet and transferred into a $20 \mathrm{~mL}$ vial. Upon collection of all sample vials, the mother liquor was removed via pipet. Activated material for NMR and mass spectrometry was obtained by washing as synthesized material in DMA. Solvent was exchanged with fresh DMA three times with solvent replaced every 24 hours. DMA solvated material was washed with chloroform three times with solvent replaced every 24 hours. Activated material was obtained by removing the chloroform under dynamic vacuum at room temperature.

Synthesis of 4T_Cl In a $20 \mathrm{~mL}$ vial zirconocene dichloride $(175 \mathrm{mg}, 0.6 \mathrm{mmol})$ and 2,5dimethylbenzene-1,4-dicarboxylic acid $\left(\mathrm{Me}_{2}-\mathrm{H}_{2} \mathrm{bdc}\right)(96.6 \mathrm{mg}, 0.5 \mathrm{mmol})$ was dissolved in DMF $(10 \mathrm{~mL})$. The stock solution was combined with DI water $(500 \mu \mathrm{L})$ and was heated at $65^{\circ} \mathrm{C}$ for 8 hours. Phase-pure cubic crystals/white crystalline solid was collected via scrapping the as synthesized material from the side of the vial. The slurry was then centrifuged, and the mother liquor decanted off. Activated material was prepared by washing as synthesized cage in fresh DMF three times, with solvent replaced every 24 hours. The DMF solvated material was then 
exchanged three times with chloroform, with fresh solvent added every 24 hours. Chloroform solvated material was then activated under dynamic vacuum at $85^{\circ} \mathrm{C}$.

Synthesis of 4T_OTf 4T_Cl-16DMF (200 mg, $0.0436 \mathrm{mmol})$ and silver trifluoromethanesulfonate (43.4 mg, $0.169 \mathrm{mmol}$ ) were combined in a tinfoil wrapped $20 \mathrm{~mL}$ scintillation vial. Methanol (10 $\mathrm{mL}$ ) was added to the vial. The resulting mixture was stirred in darkness at room temperature for 3 days. The resulting slurry was then centrifuged, and the mother liquor removed via pipet. The methanol was then removed under reduced pressure resulting in off-white cage product. Activated material was prepared by washing as synthesized cage in fresh DMF three times, with solvent replaced every 24 hours. The DMF solvated material was then exchanged three times with chloroform, with fresh solvent added every 24 hours. Chloroform solvated material was then activated under dynamic vacuum at $100{ }^{\circ} \mathrm{C}$. Single-crystal quality material was obtained by dissolving the white powder in methanol and recrystallizing via diffusion with Ethyl Acetate.

Synthesis of $5 \mathrm{~T} / \mathrm{C}$ In a $20 \mathrm{~mL}$ vial zirconocene dichloride $(350 \mathrm{mg}, 1.2 \mathrm{mmol}$ ) and 2,6napthalenedicarboxylic acid $\left(2,6-\mathrm{H}_{2} \mathrm{ndc}\right)(129.7 \mathrm{mg}, 0.6 \mathrm{mmol})$ were dissolved in DMF $(20 \mathrm{~mL})$. The stock solution $(1 \mathrm{~mL})$ and DI water $(150 \mu \mathrm{L})$ were transferred to a $7 \mathrm{~mL}$ vial and heated at 65 ${ }^{\circ} \mathrm{C}$ for 8 hours. Cubic and non-cubic crystals were collected via pipet and transferred into a $20 \mathrm{~mL}$ vial. Upon collection of all sample vials, the slurry was centrifuged, and mother liquor decanted off. Activated material was prepared by washing as synthesized cage in fresh DMF three times, with solvent replaced every 24 hours. The DMF solvated material was then exchanged three times with chloroform, with fresh solvent added every 24 hours. Chloroform solvated material was then activated under dynamic vacuum at room temperature.

Synthesis of $6 \mathrm{C}$ In a $20 \mathrm{~mL}$ vial zirconocene dichloride (350 mg, $1.2 \mathrm{mmol}$ ) and (2E,2'E)-3,3'(thiophene-2,5-diyl) diacrylic acid $\left(\mathrm{H}_{2} \mathrm{tda}\right)(134.4 \mathrm{mg}, 0.6 \mathrm{mmol})$ were dissolved in DMA (20 mL). The stock solution $(1.5 \mathrm{~mL})$ and DI water $(50 \mu \mathrm{L})$ were transferred into a $7 \mathrm{~mL}$ vial and heated at $65{ }^{\circ} \mathrm{C}$ for 8 hours. Non-cubic crystals/yellow crystalline solid was collected via pipet. Upon collection of all sample vials, the slurry was centrifuged, and mother liquor decanted off. Activated material was prepared by washing as synthesized cage in fresh DMA three times, with solvent replaced every 24 hours. The DMA solvated material was then exchanged three times with chloroform, with fresh solvent added every 24 hours. Chloroform solvated material was then activated under dynamic vacuum at room temperature.

Synthesis of 7T/C In a $20 \mathrm{~mL}$ vial zirconocene dichloride (350 mg, $1.2 \mathrm{mmol}$ ) and (2E,2'E)-3,3'(2-Fluoro-1,4-phenylene) diacrylic acid $\left(\mathrm{F}-\mathrm{H}_{2} \mathrm{pda}\right)(141.7 \mathrm{mg}, 0.6 \mathrm{mmol})$ were dissolved in DMA $(20 \mathrm{~mL})$. The stock solution $(1 \mathrm{~mL})$ and $\mathrm{DI}$ water $(60 \mu \mathrm{L})$ were transferred into a $4 \mathrm{~mL}$ vial. The 4 $\mathrm{mL}$ vial was placed into a $20 \mathrm{~mL}$ vial containing ethyl acetate $(3 \mathrm{~mL})$ and left to diffuse at room temperature for 48 hours. Cubic and non-cubic crystals were collected by scrapping off the crystals from the sides of the vial and transferring solid into a $20 \mathrm{~mL}$ vial. Activated material was prepared by washing as synthesized cage in fresh DMA three times, with solvent replaced every 24 hours. The DMA solvated material was then exchanged three times with chloroform, with fresh solvent added every 24 hours. Chloroform solvated material was then activated under dynamic vacuum at room temperature.

Synthesis of $8 \mathrm{~T}$ In a $20 \mathrm{~mL}$ vial zirconocene dichloride $(350 \mathrm{mg}, 1.2 \mathrm{mmol})$ and $\left(2 E, 2^{\prime} E\right)-3,3^{\prime}-$ (2,5-Dimethoxy-1,4-phenylene) diacrylic acid $\left((\mathrm{OMe})_{2}-\mathrm{H}_{2} \mathrm{pda}\right)(141.7 \mathrm{mg}, 0.6 \mathrm{mmol})$ were dissolved in DMA $(20 \mathrm{~mL})$. The stock solution $(5 \mathrm{~mL})$ and DI water $(300 \mu \mathrm{L})$ were transferred into a $20 \mathrm{~mL}$ vial. The $20 \mathrm{~mL}$ vial was placed into a $100 \mathrm{~mL}$ glass media jar containing acetone (15 $\mathrm{mL}$ ) and left to diffuse at room temperature for 48 hours. Yellow cubic crystals were collected by scrapping the material off the sides of the vial. Activated material for NMR and mass spectrometry 
was prepared by washing as synthesized cage in fresh acetone three times, with solvent replaced every 24 hours. Acetone solvated material was then activated under dynamic vacuum at room temperature.

Synthesis of $9 \mathrm{C}$ In a $20 \mathrm{~mL}$ vial zirconocene dichloride (350 mg, $1.2 \mathrm{mmol}$ ) and p-terphenyl-4,4"dicarboxylic acid $\left(\mathrm{H}_{2} \mathrm{tpdc}\right)(186.4 \mathrm{mg}, 0.6 \mathrm{mmol})$ were dissolved in dry DMF $(20 \mathrm{~mL})$. The stock solution $(3 \mathrm{~mL})$ and DI water $(450 \mu \mathrm{L})$ were transferred to a $7 \mathrm{~mL}$ vial and heated at $65{ }^{\circ} \mathrm{C}$ for 8 hours. White crystalline material was collected via pipet and transferred to a $20 \mathrm{~mL}$ vial. Upon collection of all sample vials the slurry was centrifuged, and the mother liquor decanted off. Activated material for NMR and mass spectrometry was prepared by washing as synthesized material with fresh DMF three times, with solvent replaced every 24 hours. DMF solvated material was exchanged with chloroform three times, with solvent replaced every 24 hours. Activated material was obtained by removing the chloroform under dynamic vacuum at room temperature.

Synthesis of 10T/C_CI In a $20 \mathrm{~mL}$ vial zirconocene dichloride (350 mg, $1.2 \mathrm{mmol}$ ) and 2',5'dimethyl-p-terphenyl-4,4"-dicarboxylic acid $\left(\mathrm{Me}_{2}-\mathrm{H}_{2} \mathrm{tpdc}(212.7 \mathrm{mg}, 0.6 \mathrm{mmol})\right.$ were dissolved in dry DMF $(20 \mathrm{~mL})$. The stock solution $(10 \mathrm{~mL})$ and DI water $(1 \mathrm{~mL})$ were transferred into a $20 \mathrm{~mL}$ vial and heated at $65^{\circ} \mathrm{C}$ for 8 hours. Cubic and non-cubic crystals were collected via scrapping as synthesized material off the sides of sample vial. The slurry was then centrifuged, and mother liquor decanted off. Activated material was prepared by washing as synthesized cage in fresh DMF three times, with solvent replaced every 24 hours. The DMF solvated material was then exchanged three times with chloroform, with fresh solvent added every 24 hours. Chloroform solvated material was then activated under dynamic vacuum at $65^{\circ} \mathrm{C}$.

Synthesis of 10T/C_OTf 10C_Cl-16DMF (316 $\mathrm{mg}, \quad 0.145 \mathrm{mmol})$ and silver trifluoromethanesulfonate $(74 \mathrm{mg}, 0.29 \mathrm{mmol})$ were combined in a tinfoil wrapped $20 \mathrm{~mL}$ scintillation vial. Methanol $(10 \mathrm{~mL})$ was added to the vial. The resulting mixture was stirred in darkness at room temperature for 3 days. The resulting slurry was then centrifuged, and the mother liquor removed via pipet. The methanol was then removed under reduced pressure resulting in off-white cage product. Single-crystal quality material was obtained by dissolving as synthesized material in methanol and recrystallizing via diffusion with Ethyl Acetate.

Synthesis of $11 \mathrm{~T} / \mathrm{C}$ In a $20 \mathrm{~mL}$ vial zirconocene dichloride (350 mg, $1.2 \mathrm{mmol}$ ) and 1,4naphthalene bisbenzoic acid $\left(1,4-\mathrm{H}_{2} \mathrm{nbb}\right)(221 \mathrm{mg}, 0.6 \mathrm{mmol})$ were dissolved in dry DMF $(20 \mathrm{~mL})$. The stock solution $(1 \mathrm{~mL})$ and DI water $(150 \mu \mathrm{L})$ were transferred into a $4 \mathrm{~mL}$ vial. The $4 \mathrm{~mL}$ vial was placed into a $20 \mathrm{~mL}$ vial containing ethyl acetate $(3 \mathrm{~mL})$ and left to diffuse at room temperature for 48 hours. Cubic crystals were washed with fresh ethyl acetate three times with solvent replaced every 24 hours. Activated material for NMR and mass spectrometry was obtained by drying ethyl acetate washed material under flowing nitrogen at room temperature.

Synthesis of $12 \mathrm{~T}$ In a $20 \mathrm{~mL}$ vial zirconocene dichloride (350 mg, $1.2 \mathrm{mmol}$ ) and 9,10-anthracene bisbenzoic acid $\left(9,10-\mathrm{H}_{2} \mathrm{abb}\right)(251 \mathrm{mg}, 0.6 \mathrm{mmol})$ were dissolved in DMA (20 mL). The stock solution was heated to $100^{\circ} \mathrm{C}$, the hot solution $(5 \mathrm{~mL})$ and DI water $(500 \mu \mathrm{L})$ were transferred into a $20 \mathrm{~mL}$ vial. The $20 \mathrm{~mL}$ vial was placed into a $100 \mathrm{~mL}$ glass media jar containing chloroform (15 $\mathrm{mL}$ ) and left to diffuse at room temperature for 48 hours. Large cubic crystals were collected via pipet. Activated material was prepared by washing as synthesized cage in fresh DMA three times, with solvent replaced every 24 hours. The DMA solvated material was then exchanged three times with chloroform, with fresh solvent added every 24 hours. Chloroform solvated material was then activated under dynamic vacuum at room temperature. 
Synthesis of $13 \mathrm{~T}$ In a $20 \mathrm{~mL}$ vial zirconocene dichloride (175 mg, $0.6 \mathrm{mmol})$ and 2',5'diisobutoxide- $p$-terphenyl-4,4"-dicarboxylic acid $\left(\left(\mathrm{O}^{\prime} \mathrm{Bu}\right)_{2}-\mathrm{H}_{2} \mathrm{tpdc}\right)(138 \mathrm{mg}, 0.3 \mathrm{mmol})$ were dissolved in dry DMF $(20 \mathrm{~mL})$. The stock solution $(0.5 \mathrm{~mL})$ and DI water $(100 \mu \mathrm{L})$ were transferred into a $4 \mathrm{~mL}$ vial. The $4 \mathrm{~mL}$ vial was placed into a $20 \mathrm{~mL}$ vial containing ethyl acetate $(3 \mathrm{~mL})$ and left to diffuse at room temperature for 72 hours. Cubic octahedral crystals were washed with fresh ethyl acetate three times with solvent replaced every 24 hours. Activated material for NMR and mass spectrometry was obtained by drying ethyl acetate washed material under flowing nitrogen at room temperature. 


\section{Zirconium Cage ${ }^{1} \mathrm{H}$ NMR}
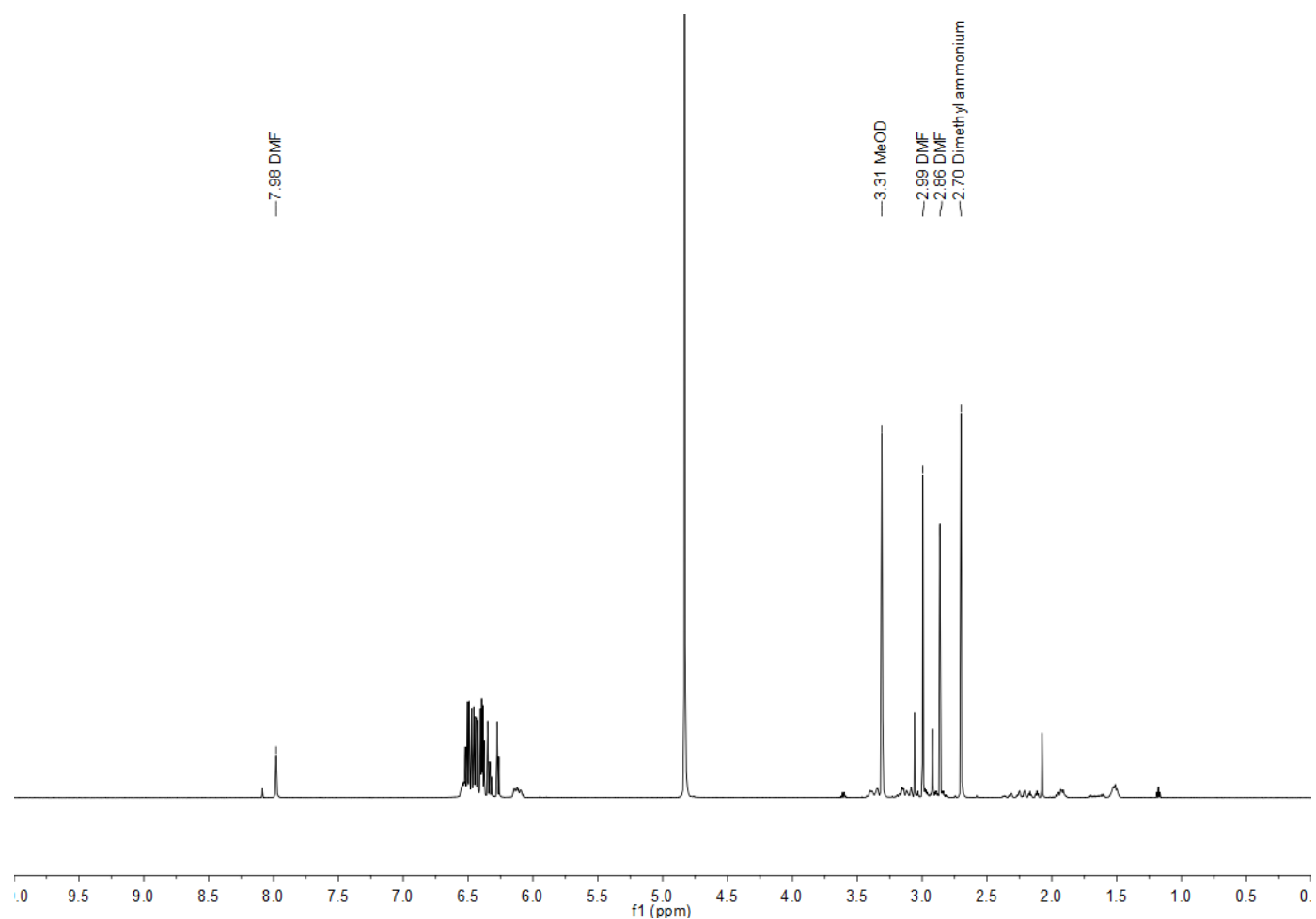

Figure S19. ${ }^{1} \mathrm{H}$ NMR analysis of $1 \mathrm{C}$ in Methanol- $d_{4}$.
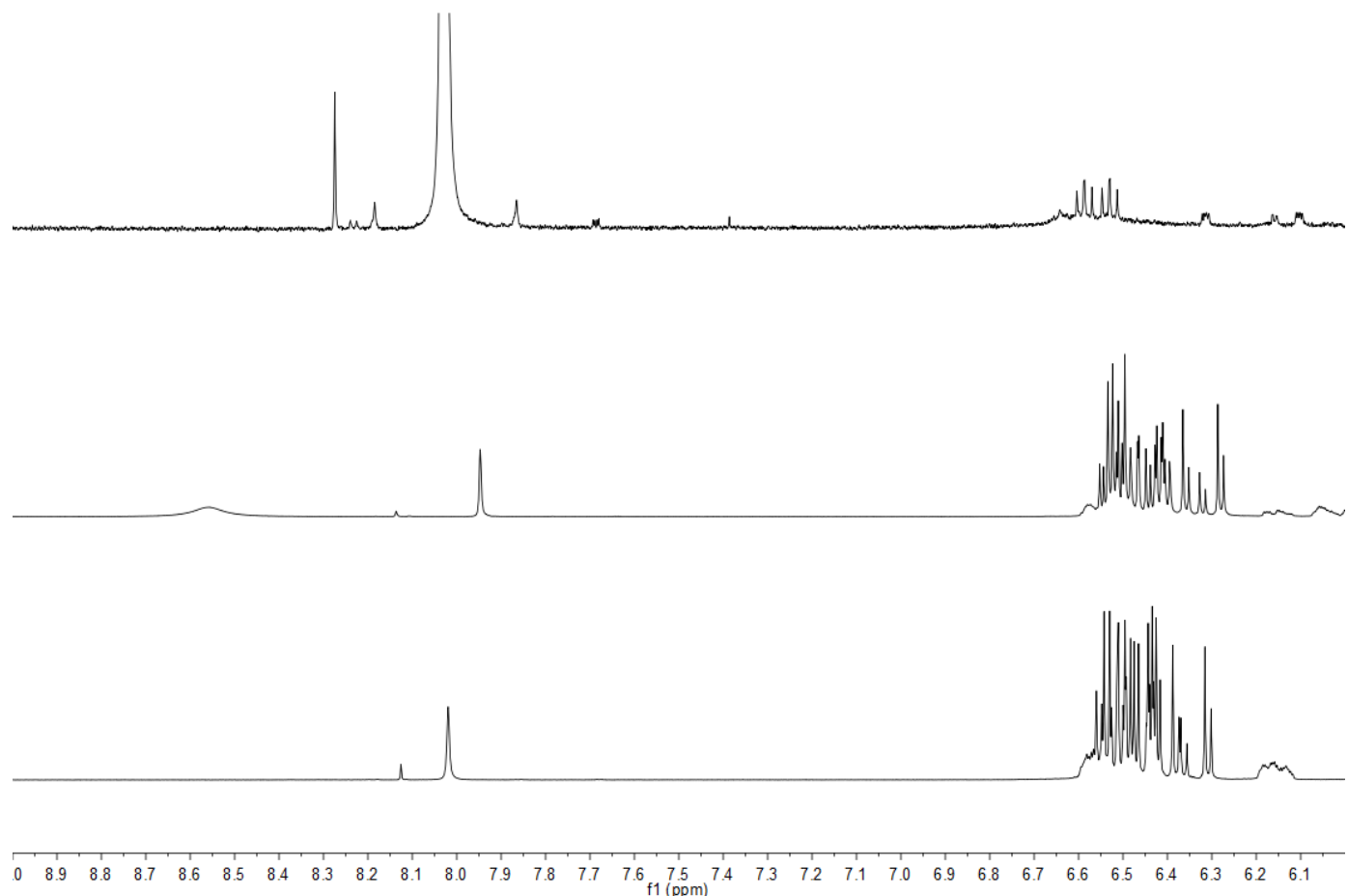

Figure S20. ${ }^{1} \mathrm{H}$ NMR analysis of $1 \mathrm{C}$ in Methanol- $d_{4}$ (bottom), DMSO- $d_{6}$ (middle), and DMF- $d_{7}$ (top). 


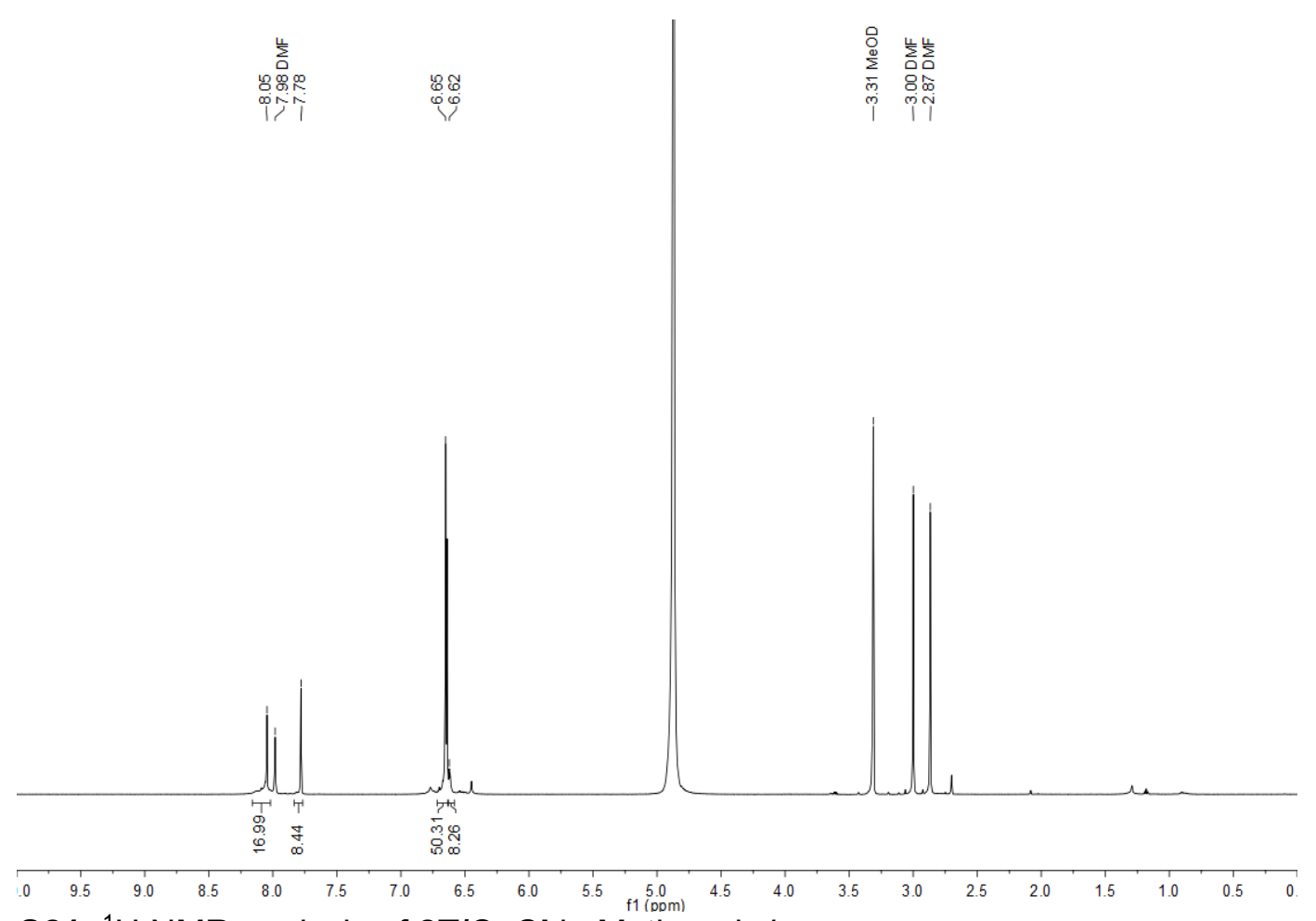

Figure S21. ${ }^{1} \mathrm{H}$ NMR analysis of 2T/C_Cl in Methanol- $d_{4}$.
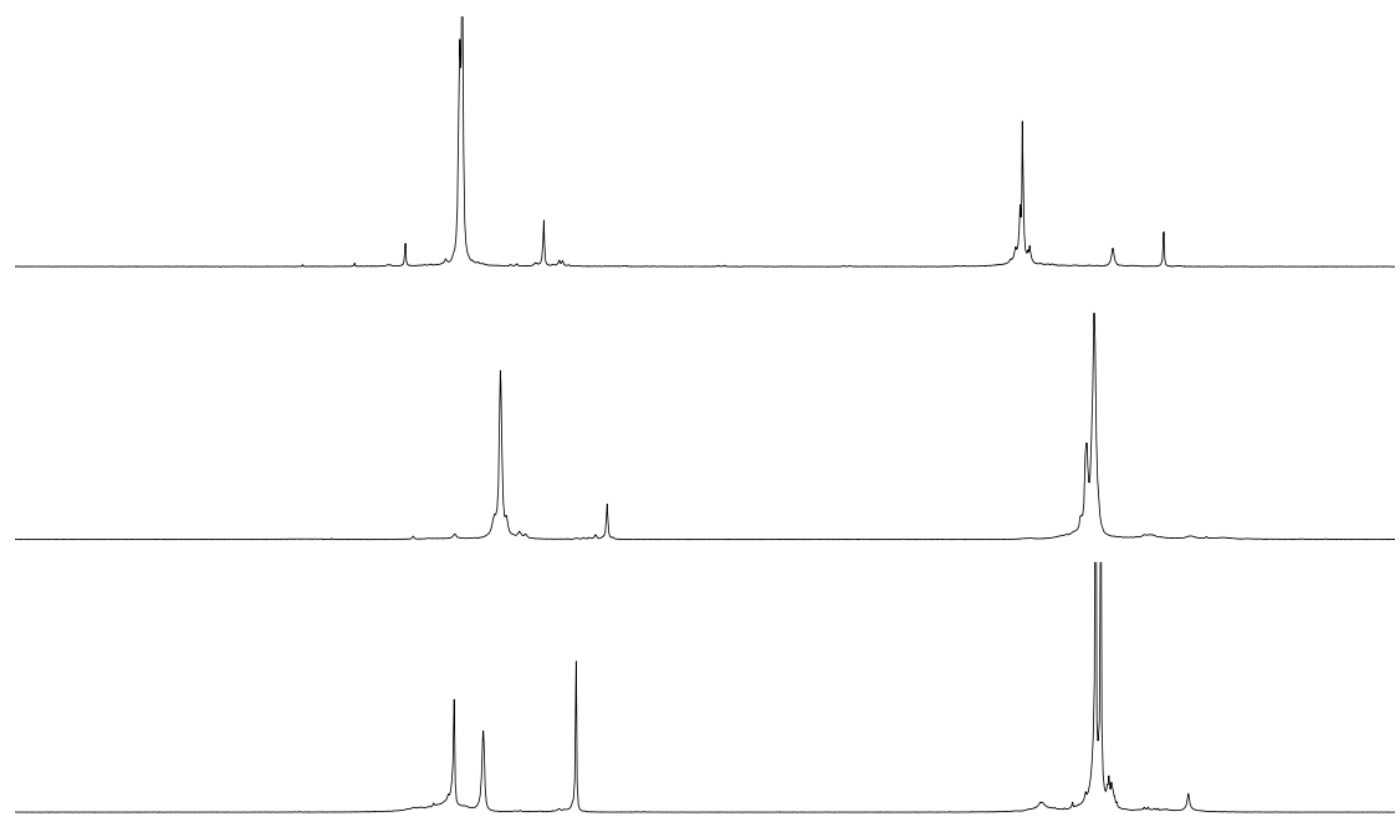

\begin{tabular}{lllllllllllllllllllllllllllllllllllllll}
\hline 0 & 8.9 & 8.8 & 8.7 & 8.6 & 8.5 & 8.4 & 8.3 & 8.2 & 8.1 & 8.0 & 7.9 & 7.8 & 7.7 & 7.6 & 7.5 & 7.4 & 7.3 & 7.2 & 7.1 & 7.0 & 6.9 & 6.8 & 6.7 & 6.6 & 6.5 & 6.4 & 6.3 & 6.2 & 6.1 & 6
\end{tabular}

Figure S22. ${ }^{1} \mathrm{H}$ NMR analysis of 2T/C_Cl in Methanol- $d_{4}$ (bottom), DMSO- $d_{6}$ (middle), and DMF$d_{7}$ (top). 


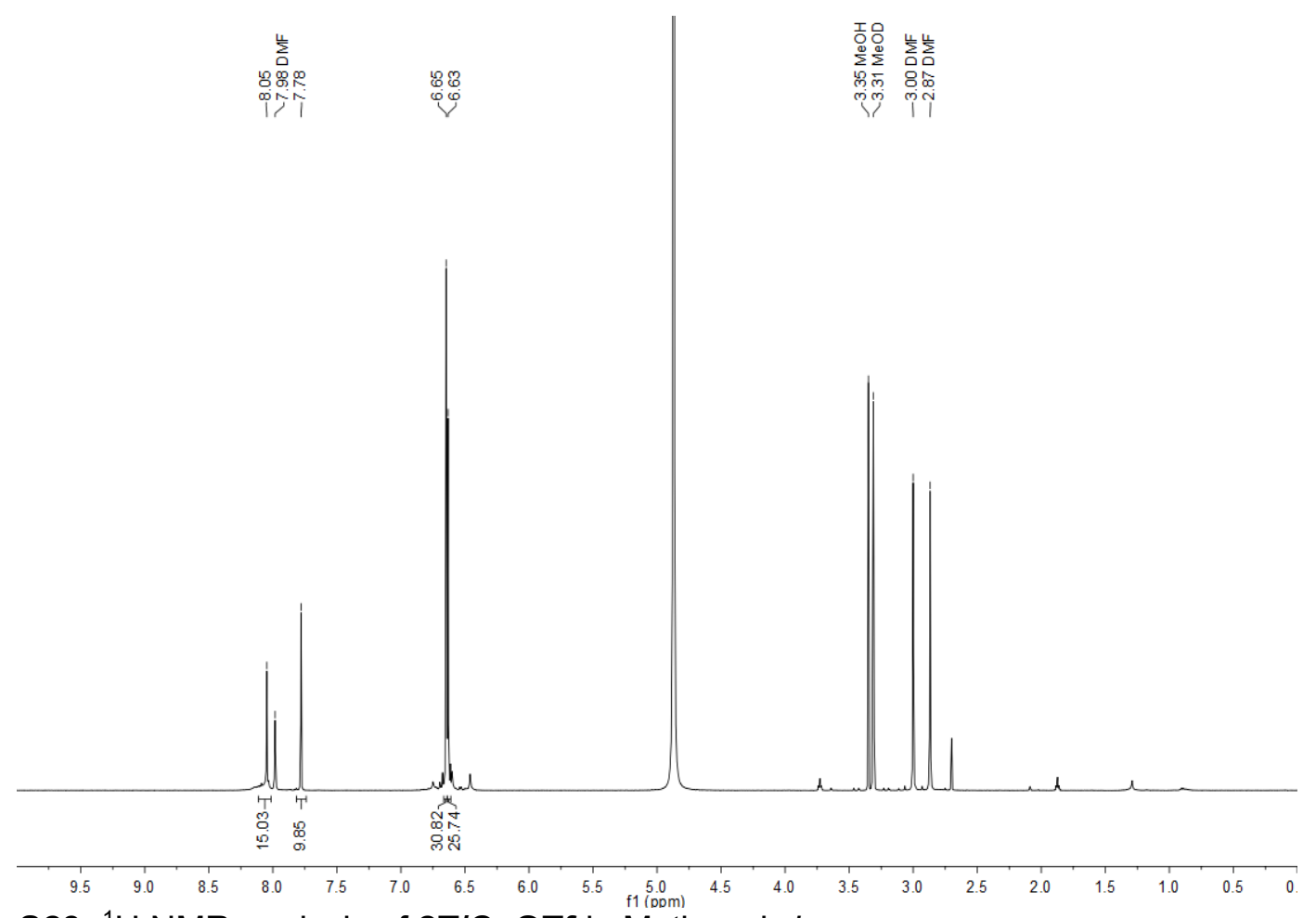

Figure S23. ${ }^{1} \mathrm{H}$ NMR analysis of 2T/C_OTf in Methanol- $d_{4}$.

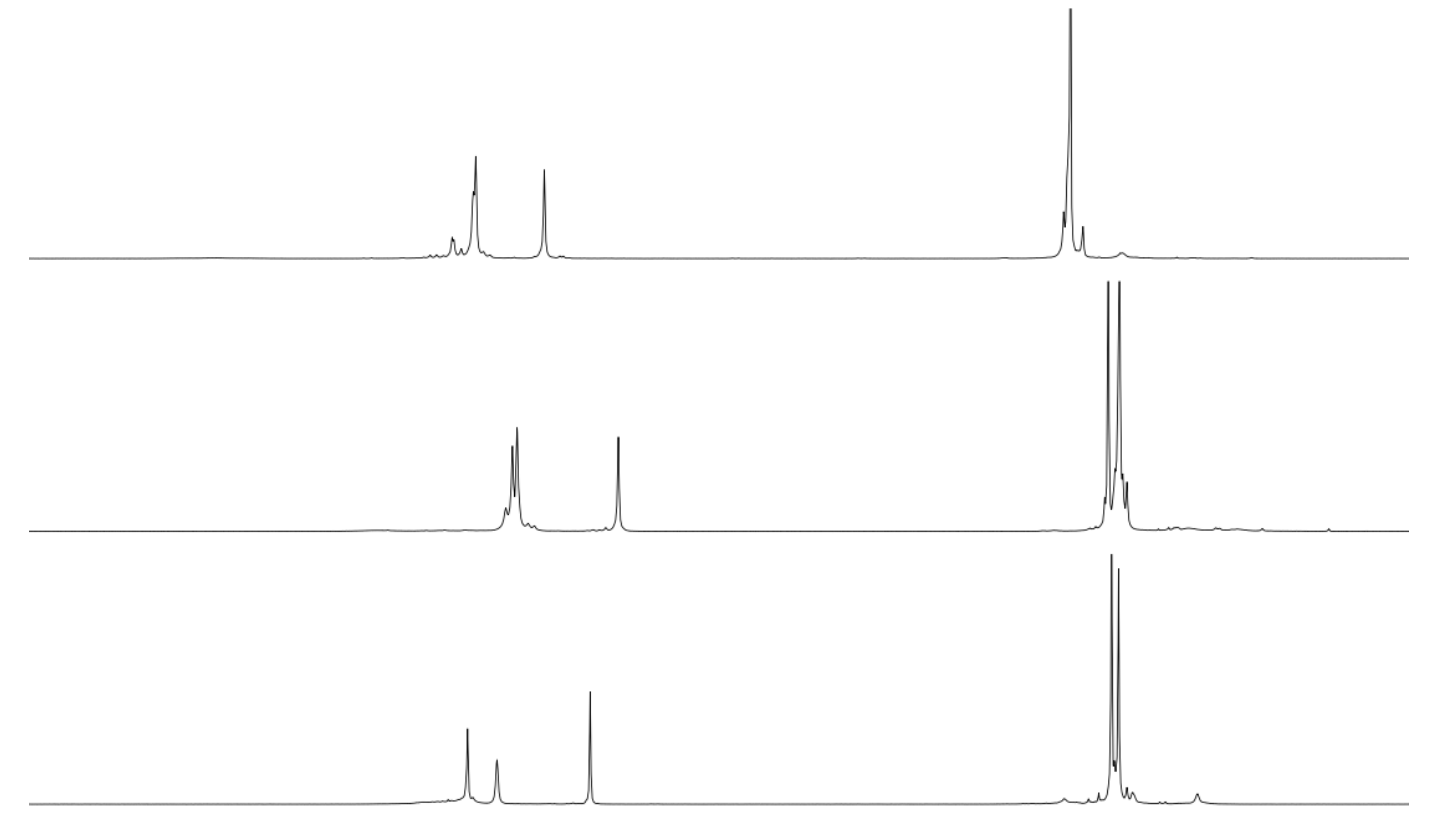

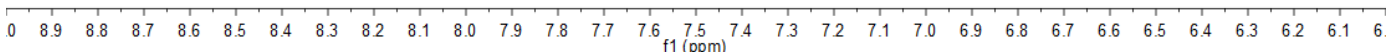

Figure S24. ${ }^{1} \mathrm{H}$ NMR analysis of 2T/C_OTf in Methanol- $d_{4}$ (bottom), DMSO- $d_{6}$ (middle), and DMF$d_{7}$ (top). 


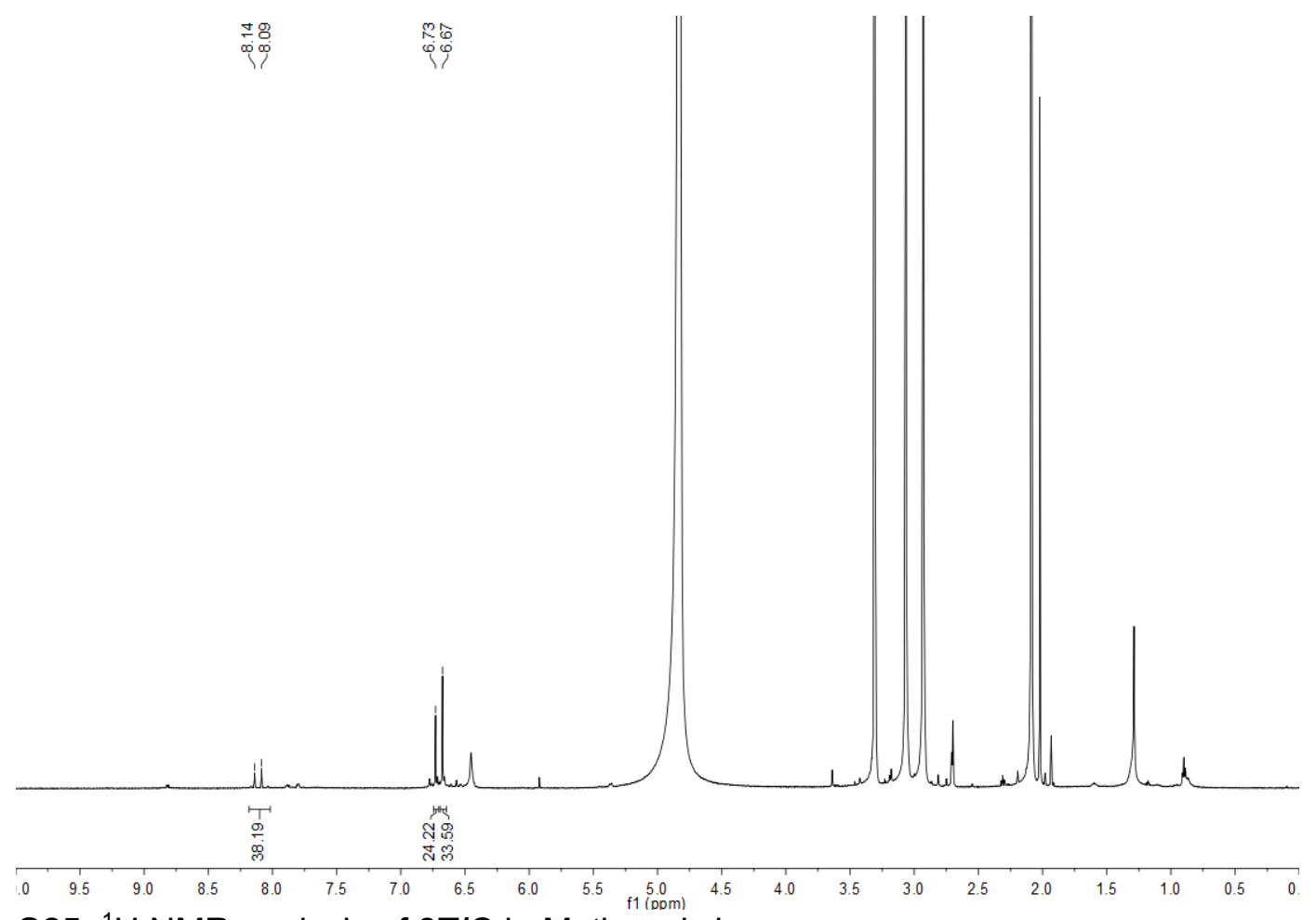

Figure S25. ${ }^{1} \mathrm{H}$ NMR analysis of 3T/C in Methanol- $d_{4}$.
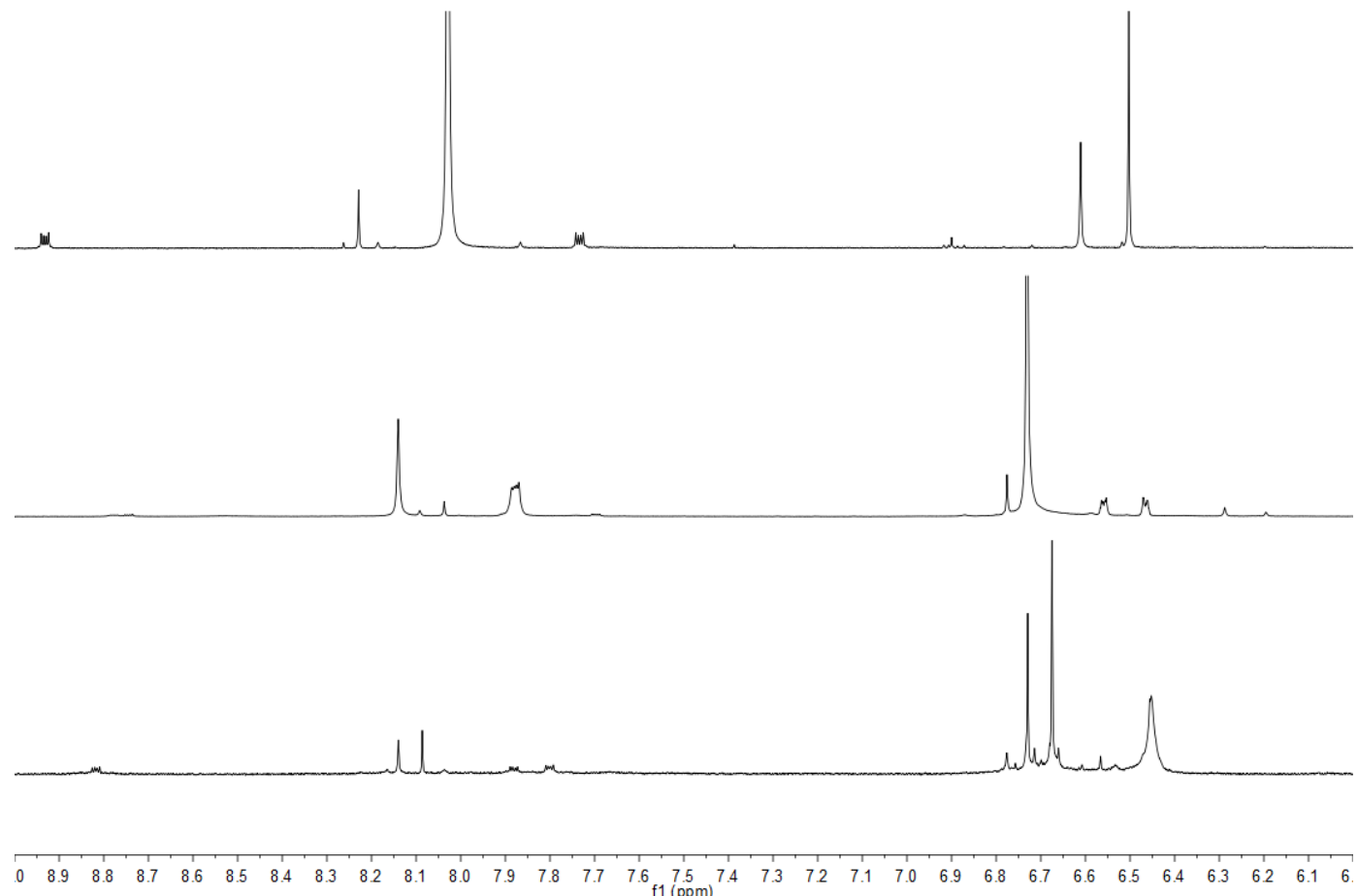

Figure S26. ${ }^{1} \mathrm{H}$ NMR analysis of $3 \mathrm{~T} / \mathrm{C}$ in Methanol- $d_{4}$ (bottom), DMSO- $d_{6}$ (middle), and DMF- $d_{7}$ (top). 


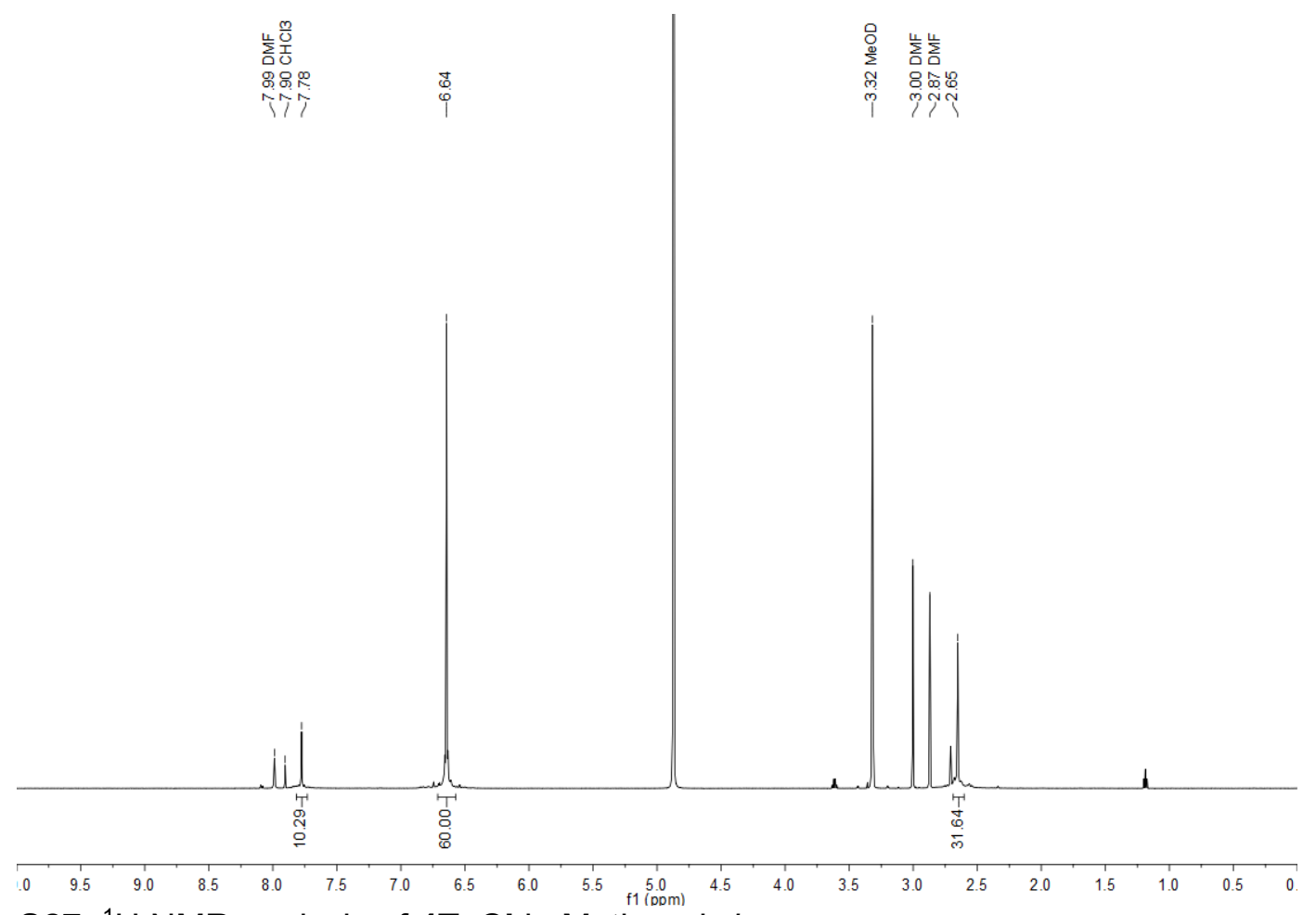

Figure S27. ${ }^{1} \mathrm{H}$ NMR analysis of 4T_CI in Methanol- $d_{4}$.
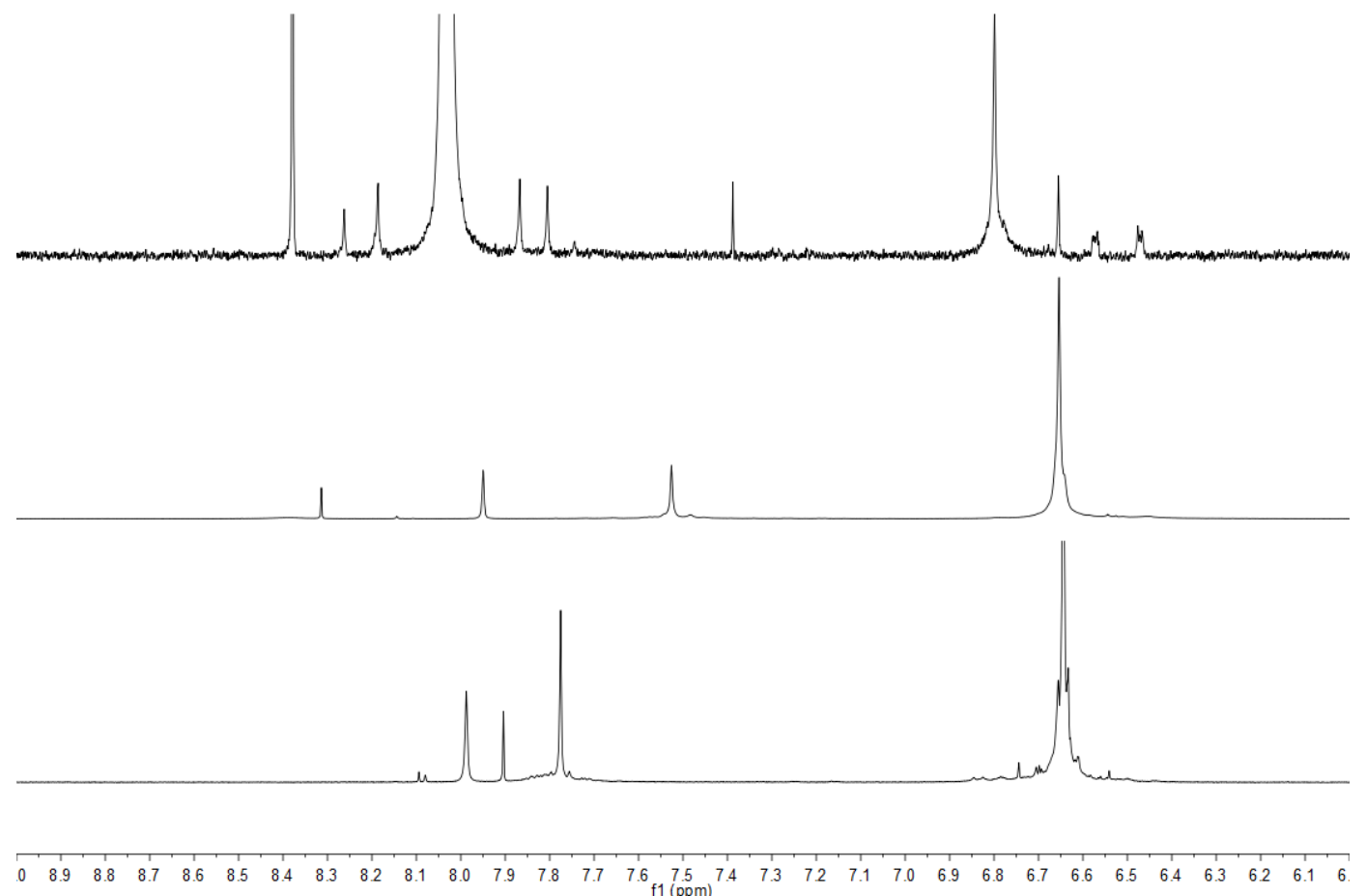

Figure S28. ${ }^{1} \mathrm{H}$ NMR analysis of $4 \mathrm{~T}_{-} \mathrm{Cl}$ in Methanol- $d_{4}$ (bottom), DMSO- $d_{6}$ (middle), and DMF- $d_{7}$ (top). 


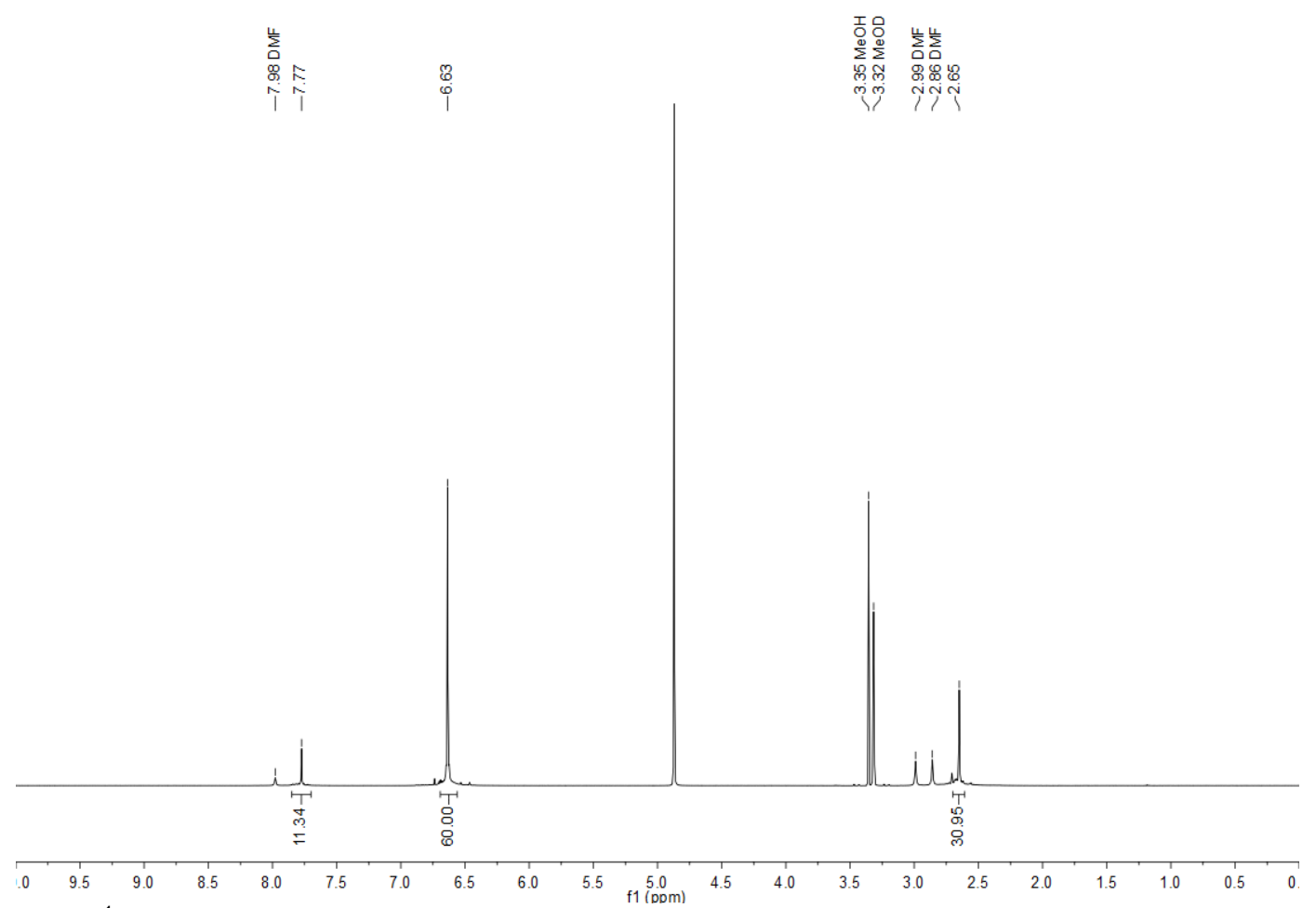

Figure S29. ${ }^{1} \mathrm{H}$ NMR analysis of 4T_OTf in Methanol- $d_{4}$.

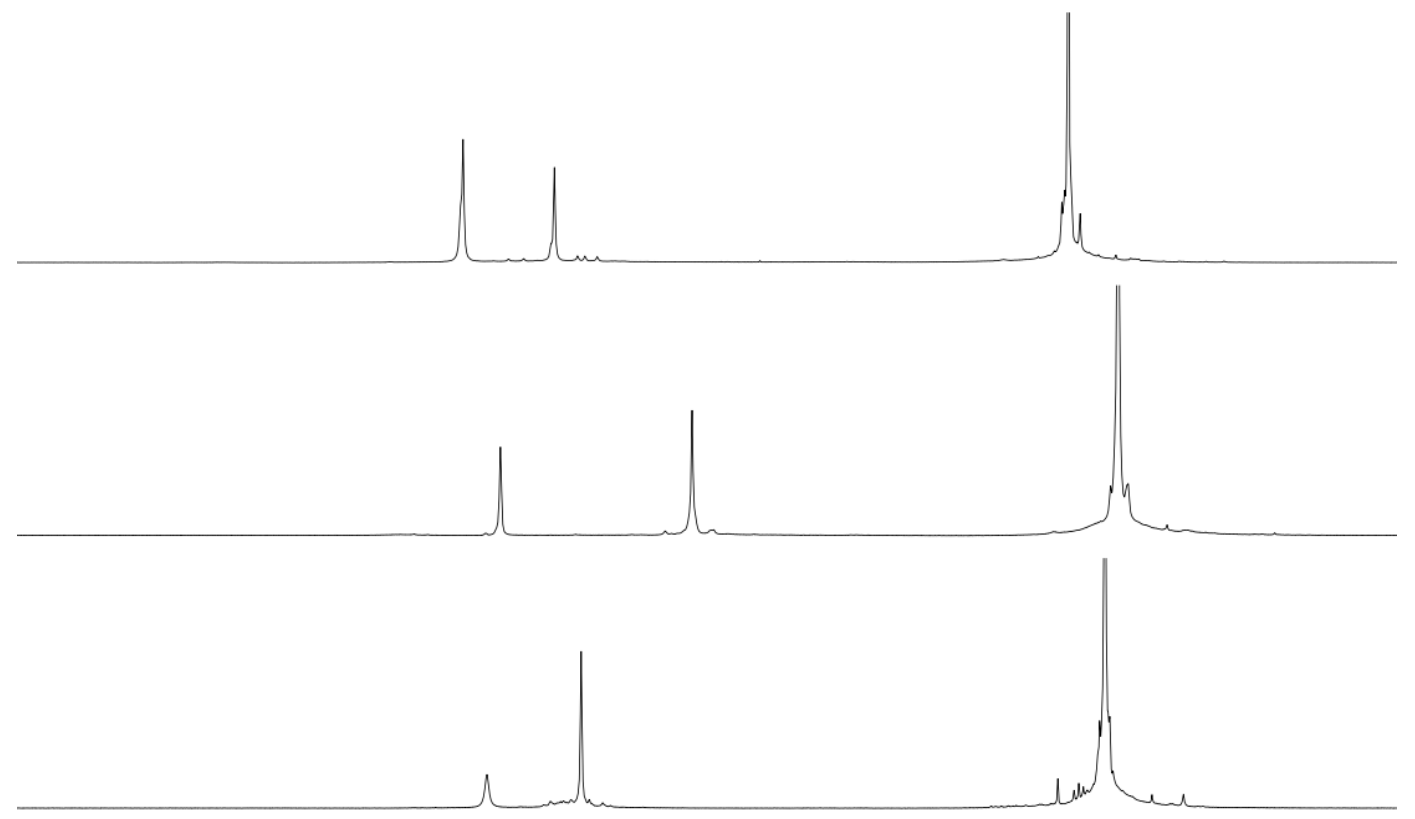

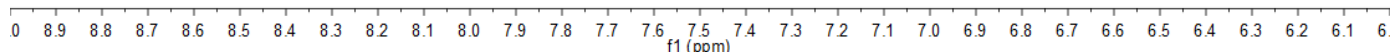

Figure S30. ${ }^{1} \mathrm{H}$ NMR analysis of 4 T_OTf in Methanol- $d_{4}$ (bottom), DMSO- $d_{6}$ (middle), and DMF$d_{7}$ (top). 


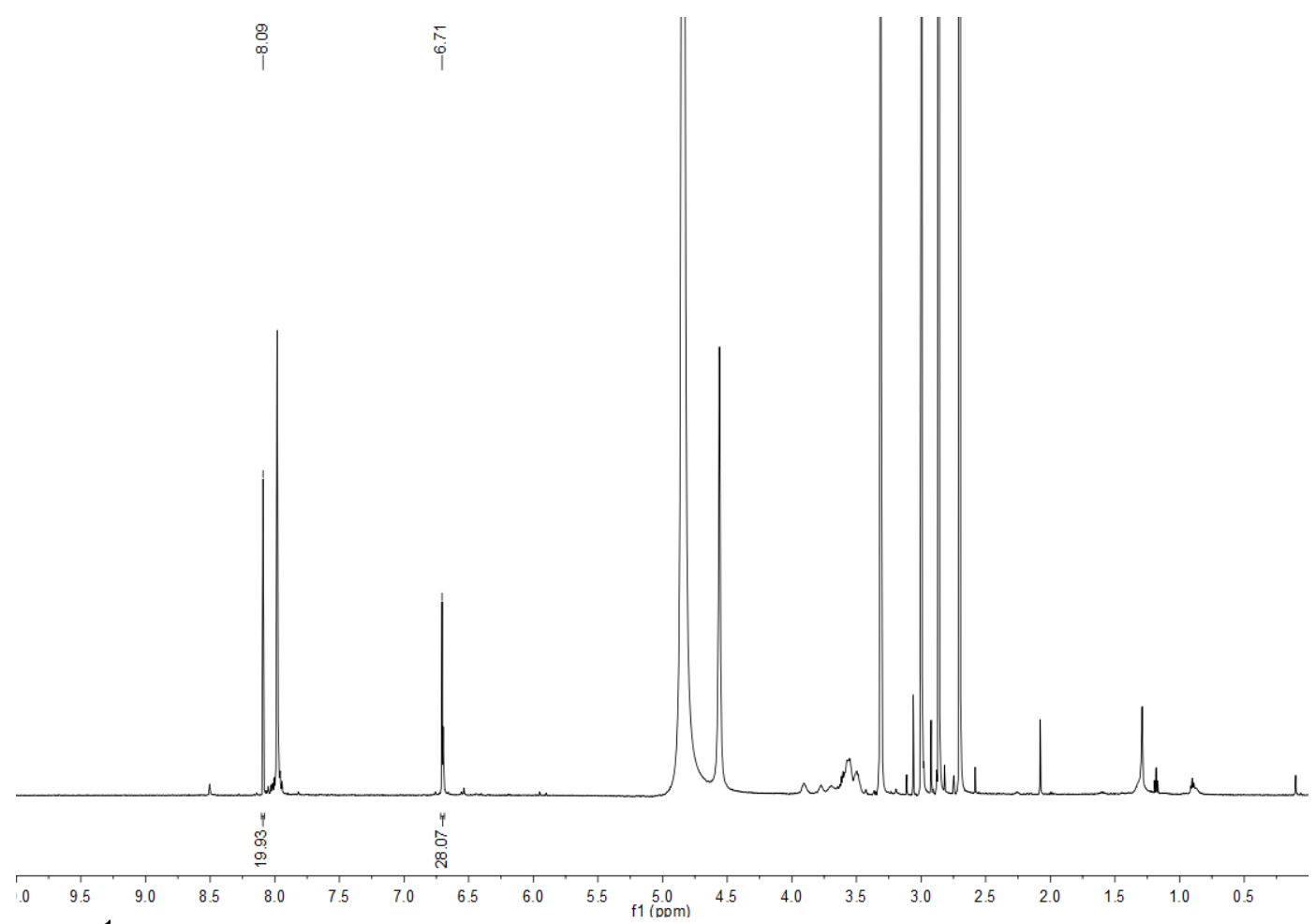

Figure S31. ${ }^{1} \mathrm{H}$ NMR analysis of $5 T / C$ in Methanol- $d_{4}$.
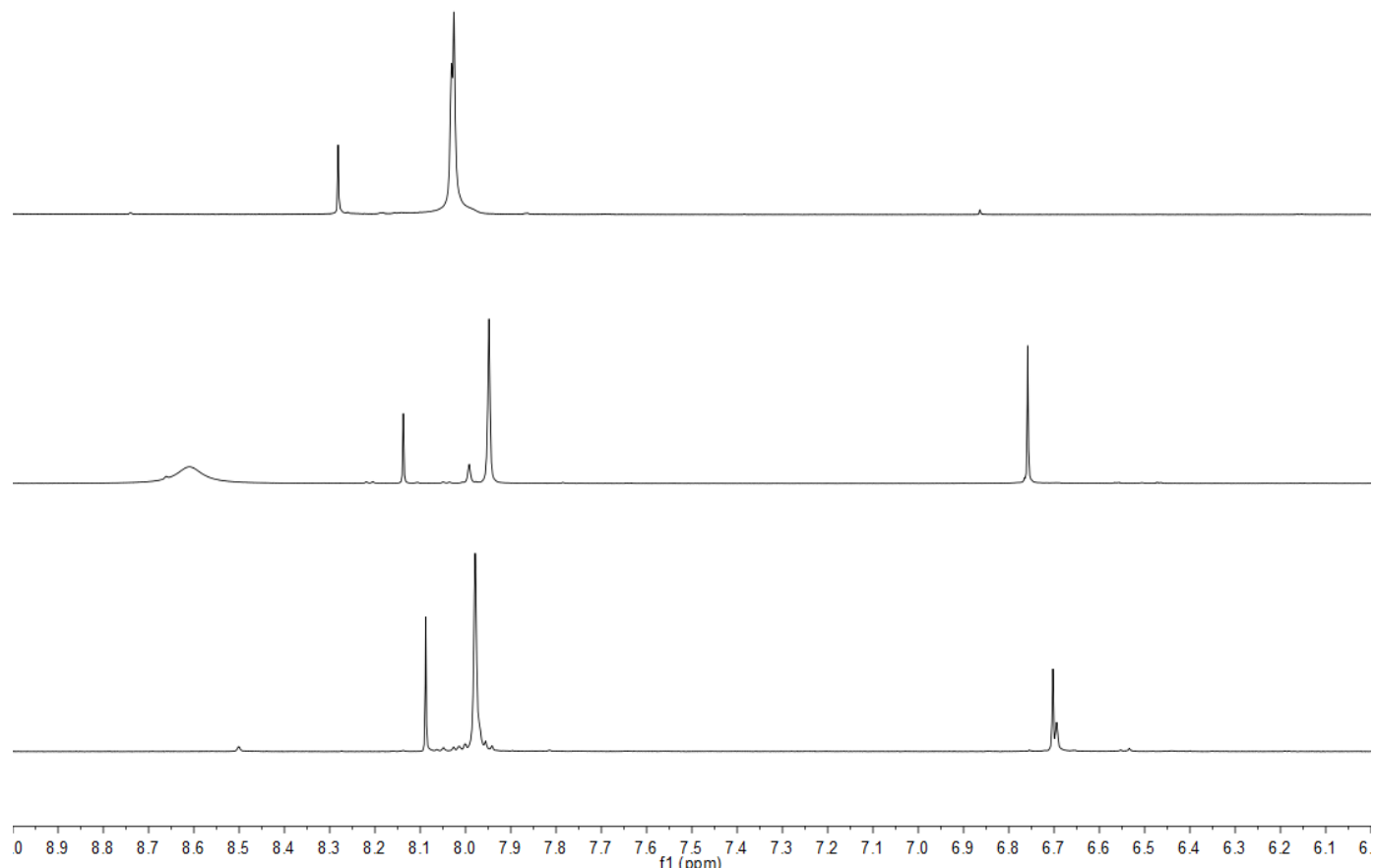

Figure S32. ${ }^{1} \mathrm{H}$ NMR analysis of $5 \mathrm{~T} / \mathrm{C}$ in Methanol- $d_{4}$ (bottom), DMSO- $d_{6}$ (middle), and DMF- $d_{7}$ (top). 


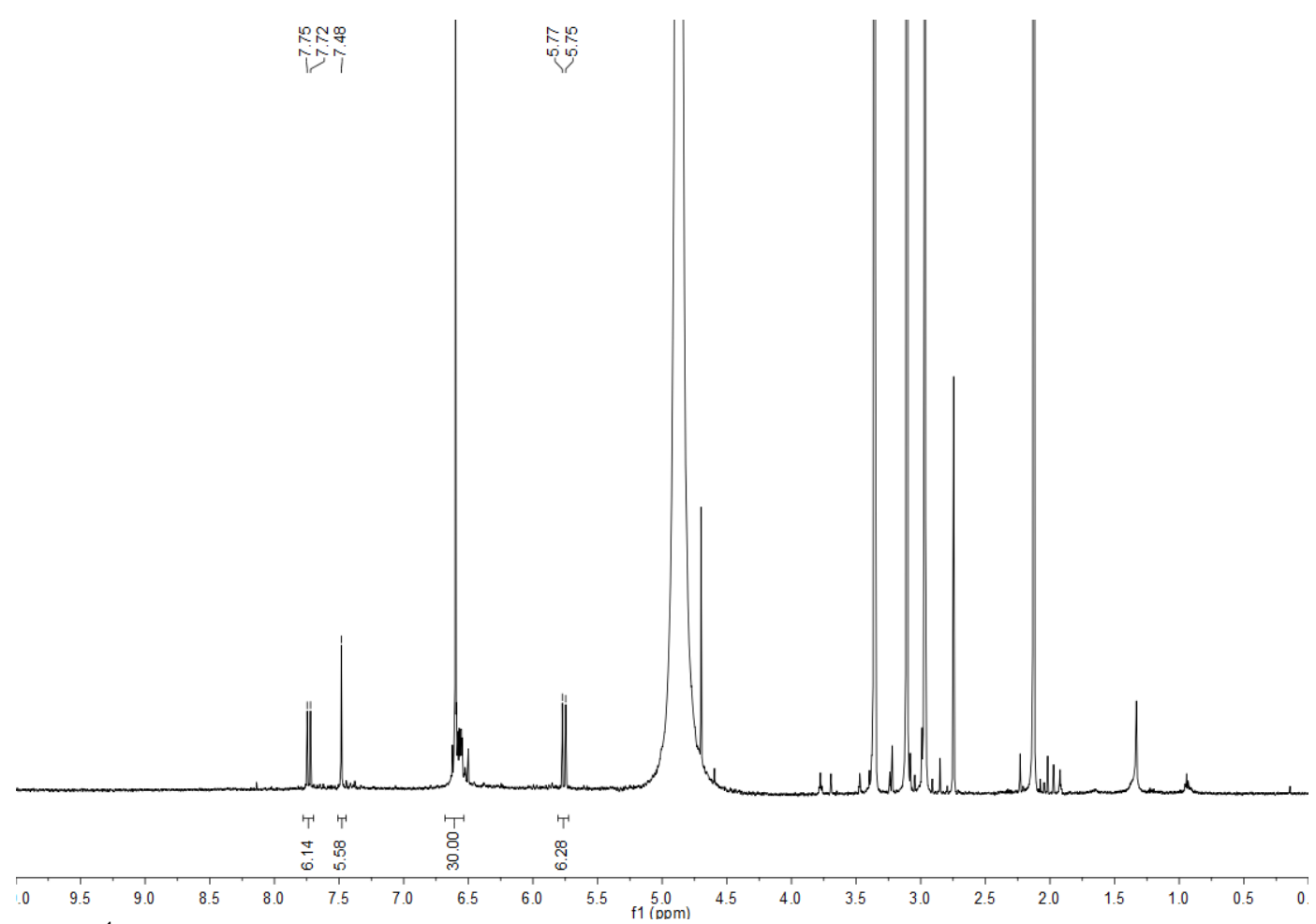

Figure S33. ${ }^{1} \mathrm{H}$ NMR analysis of $6 \mathrm{C}$ in Methanol- $d_{4}$.
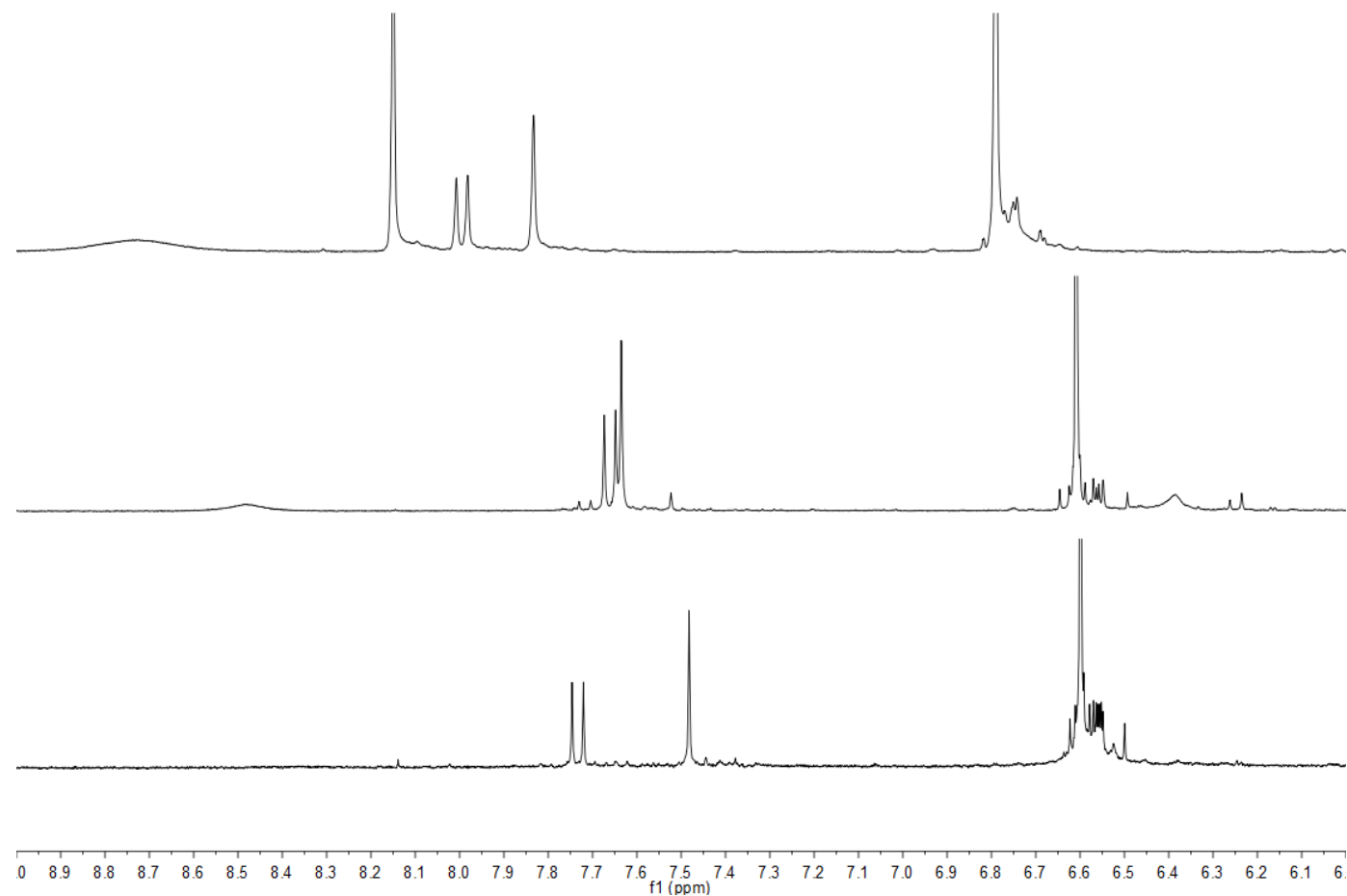

Figure S34. ${ }^{1} \mathrm{H}$ NMR analysis of $6 \mathrm{C}$ in Methanol- $d_{4}$ (bottom), DMSO- $d_{6}$ (middle), and DMF- $d_{7}$ (top). 


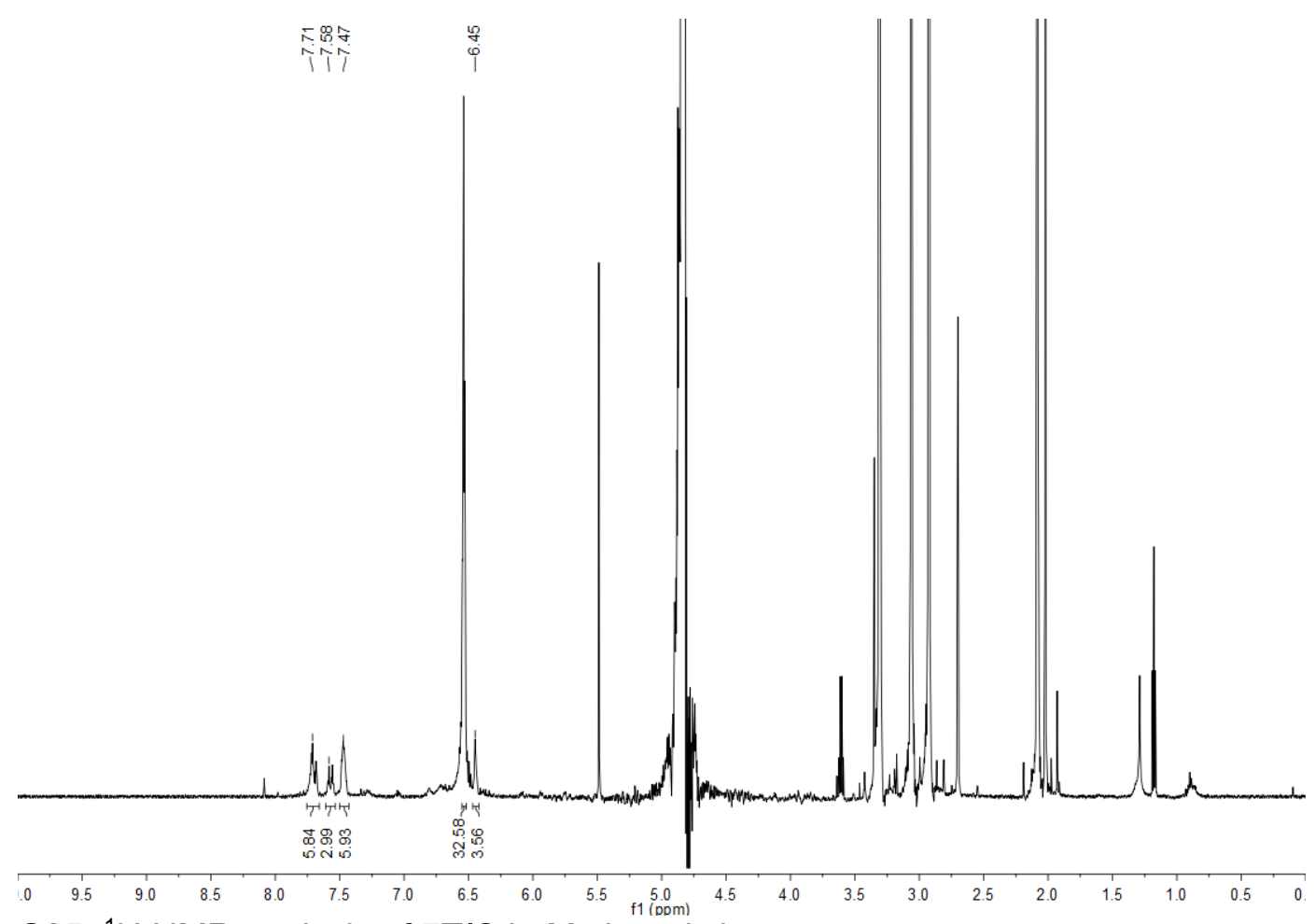

Figure S35. ${ }^{1} \mathrm{H}$ NMR analysis of $7 \mathrm{~T} / \mathrm{C}$ in Methanol- $d_{4}$.
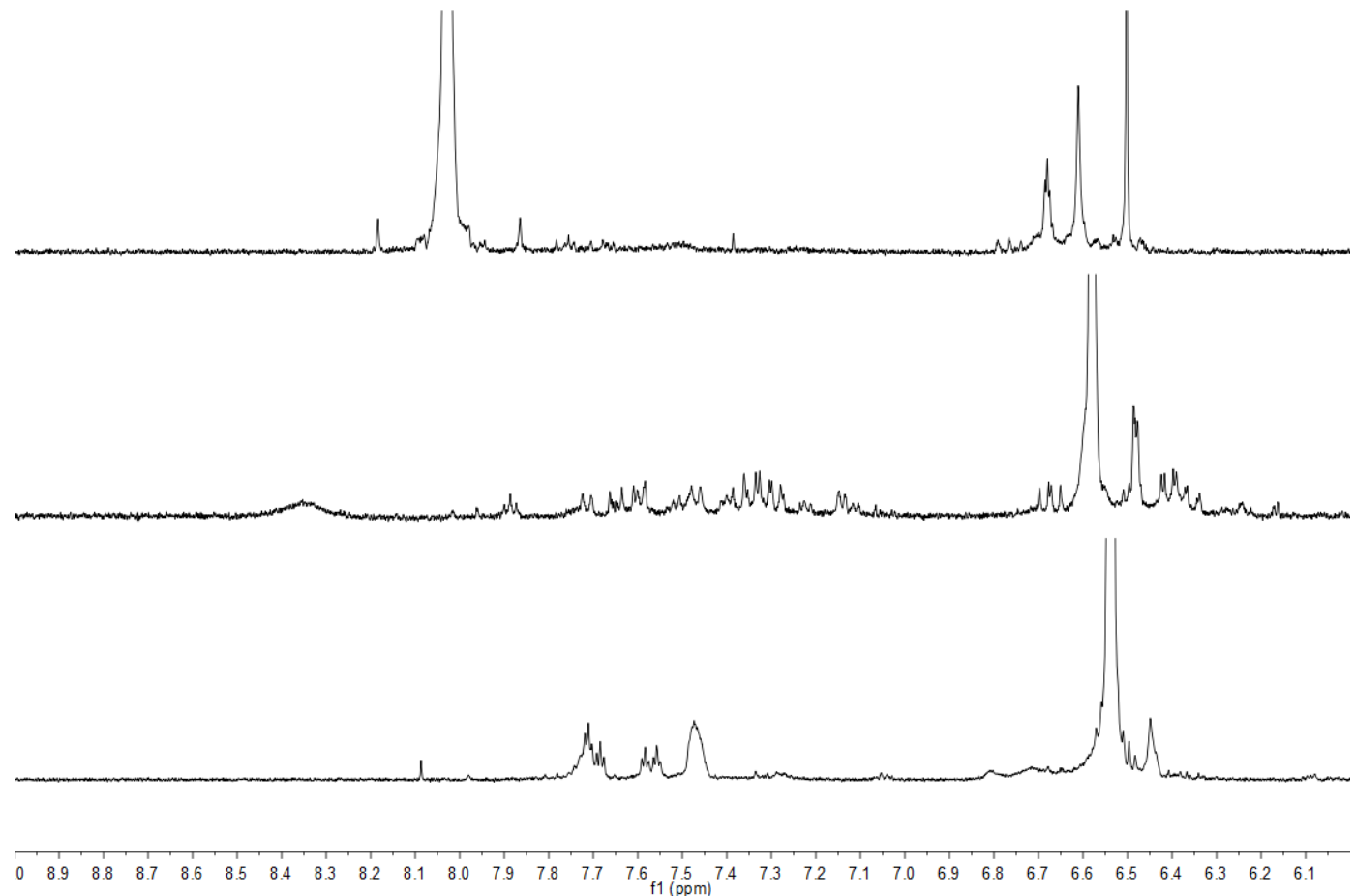

Figure S36. ${ }^{1} \mathrm{H}$ NMR analysis of 7T/C in Methanol- $d_{4}$ (bottom), DMSO- $d_{6}$ (middle), and DMF- $d_{7}$ (top). 


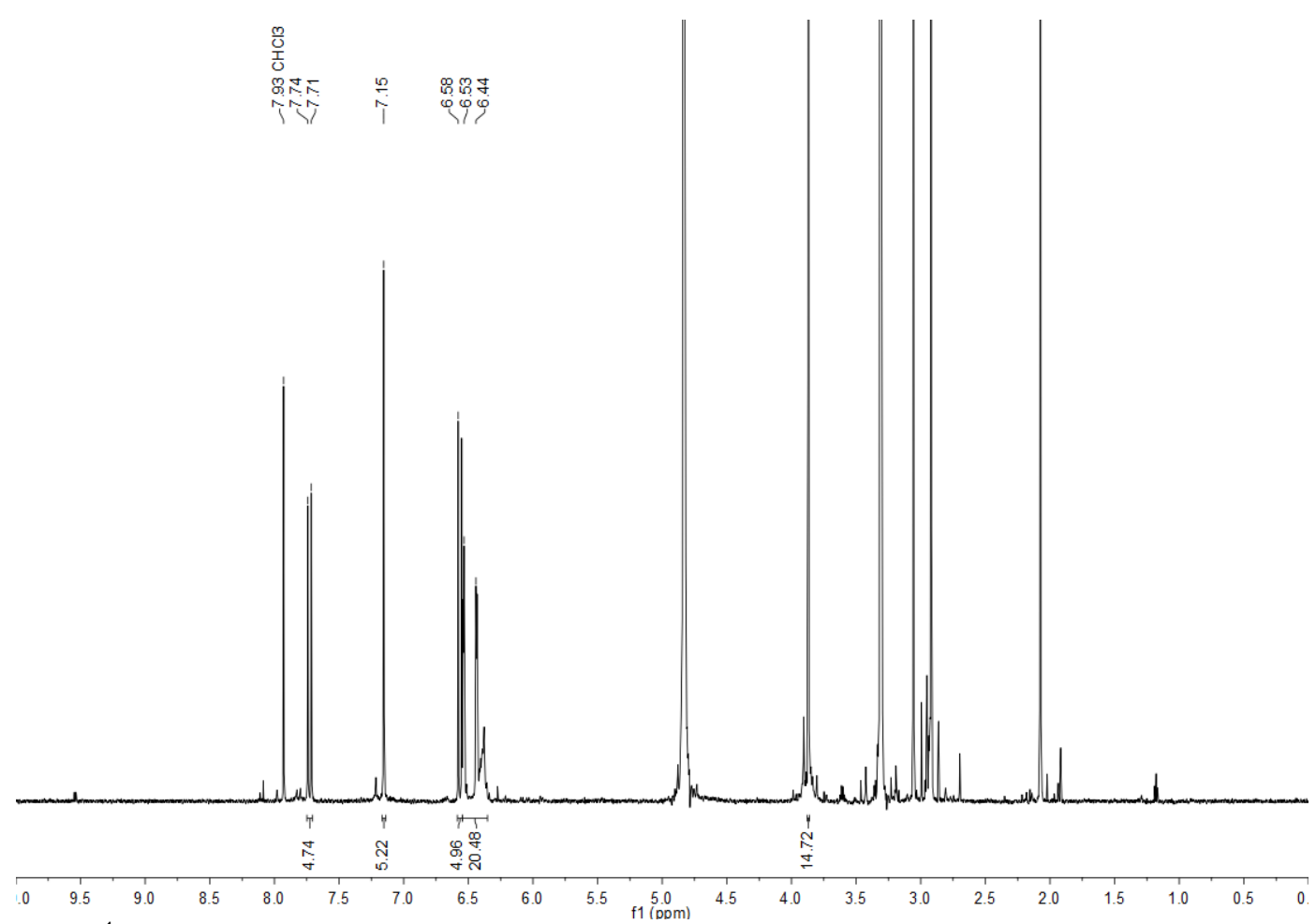

Figure S37. ${ }^{1} \mathrm{H}$ NMR analysis of $8 \mathrm{~T}$ in Methanol- $d_{4}$.
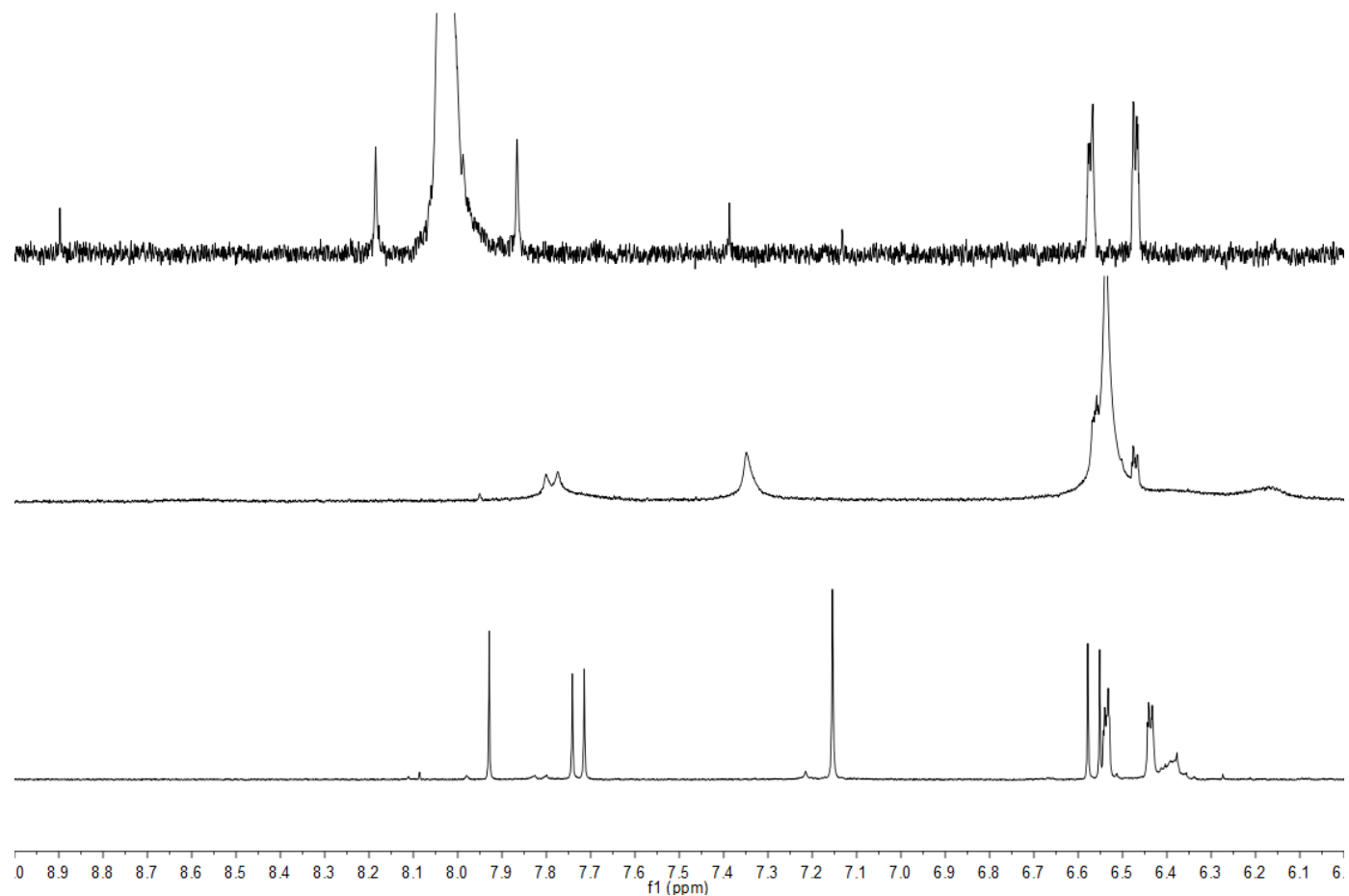

Figure S38. ${ }^{1} \mathrm{H}$ NMR analysis of $8 \mathrm{~T}$ in Methanol- $d_{4}$ (bottom), DMSO- $d_{6}$ (middle), and DMF- $d_{7}$ (top). 


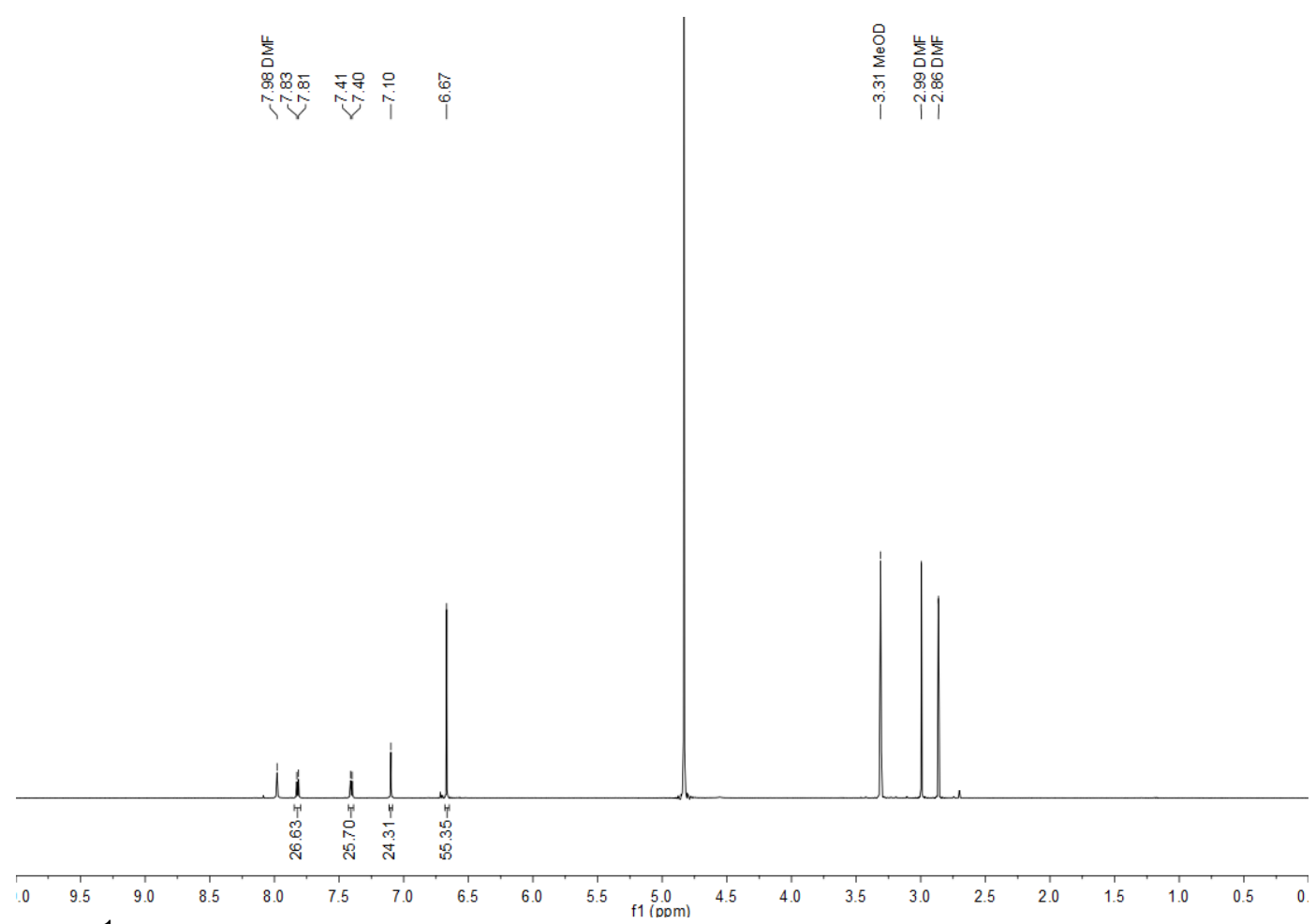

Figure S39. ${ }^{1} \mathrm{H}$ NMR analysis of $9 \mathrm{C}$ in Methanol- $d_{4}$.
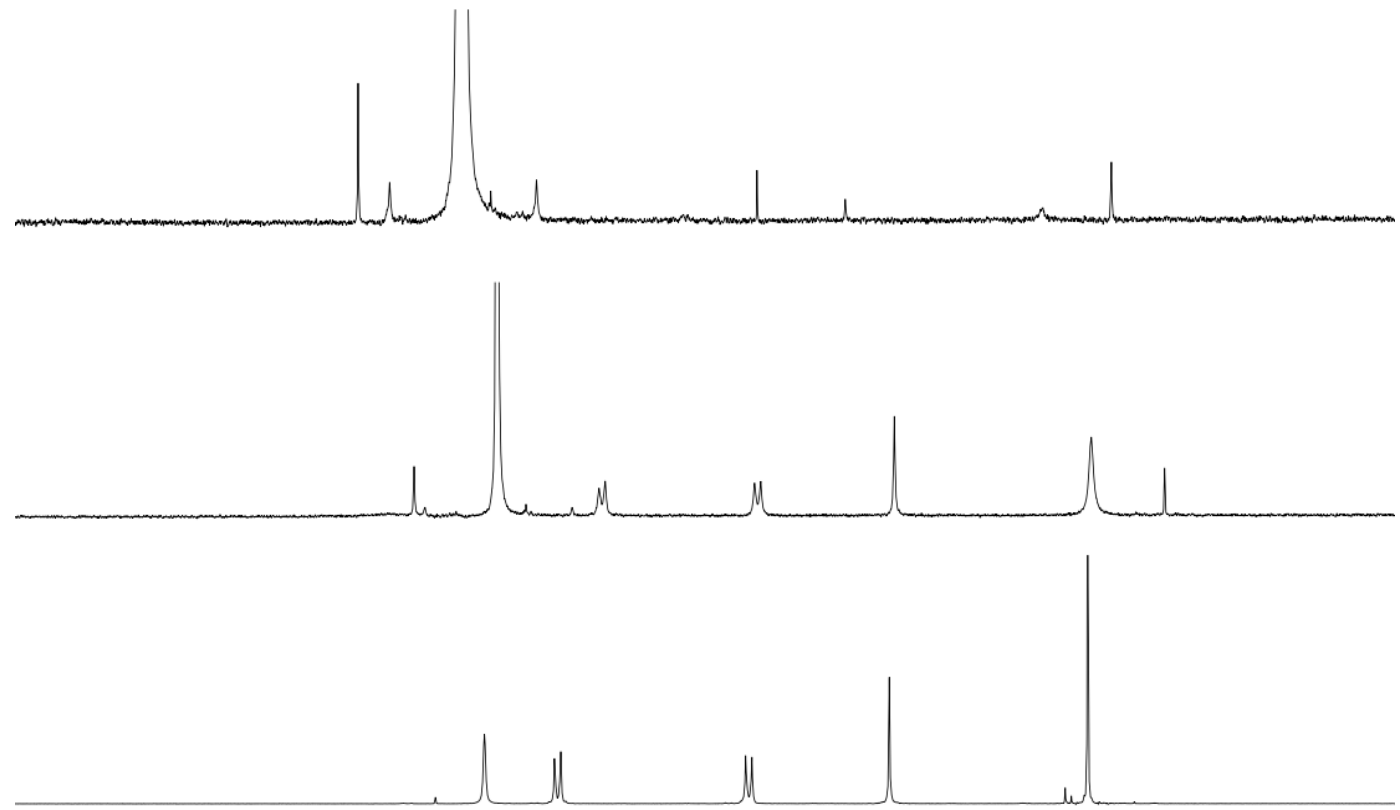

\begin{tabular}{lllllllllllllllllllllllllllllllllllllllll}
\hline 0 & 8.9 & 8.8 & 8.7 & 8.6 & 8.5 & 8.4 & 8.3 & 8.2 & 8.1 & 8.0 & 7.9 & 7.8 & 7.7 & 7.6 & 7.5 & 7.4 & 1 & 1 & 1 & 1 & 1 & 1 & 1 & 1 & 1 & 1 & 1 & 1 & 1 & 1 \\
\hline
\end{tabular}

Figure S40. ${ }^{1} \mathrm{H}$ NMR analysis of $9 \mathrm{C}$ in Methanol- $d_{4}$ (bottom), DMSO- $d_{6}$ (middle), and DMF- $d_{7}$ (top). 


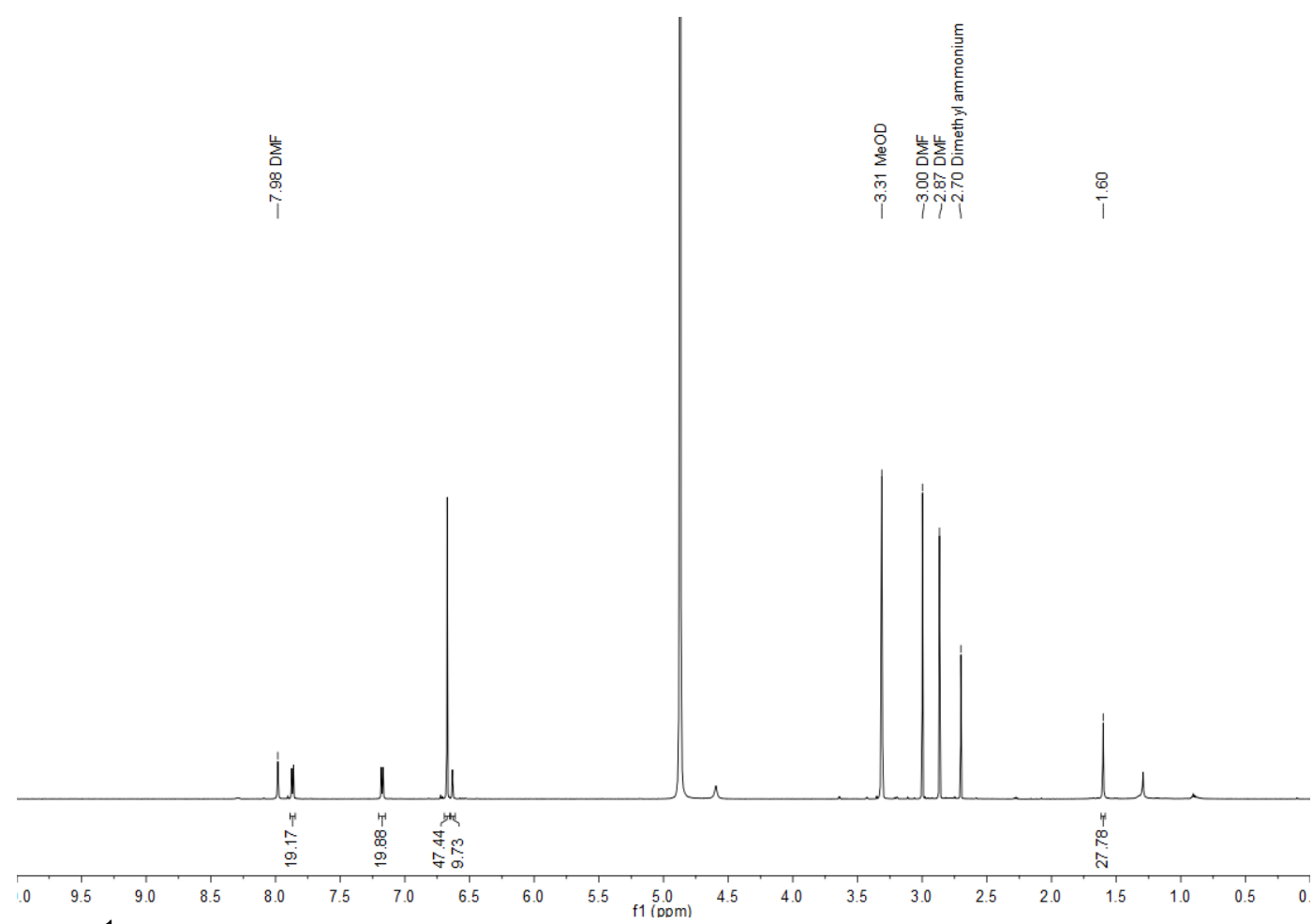

Figure S41. ${ }^{1} \mathrm{H}$ NMR analysis of $10 \mathrm{C} \_\mathrm{Cl}$ in Methanol- $d_{4}$.
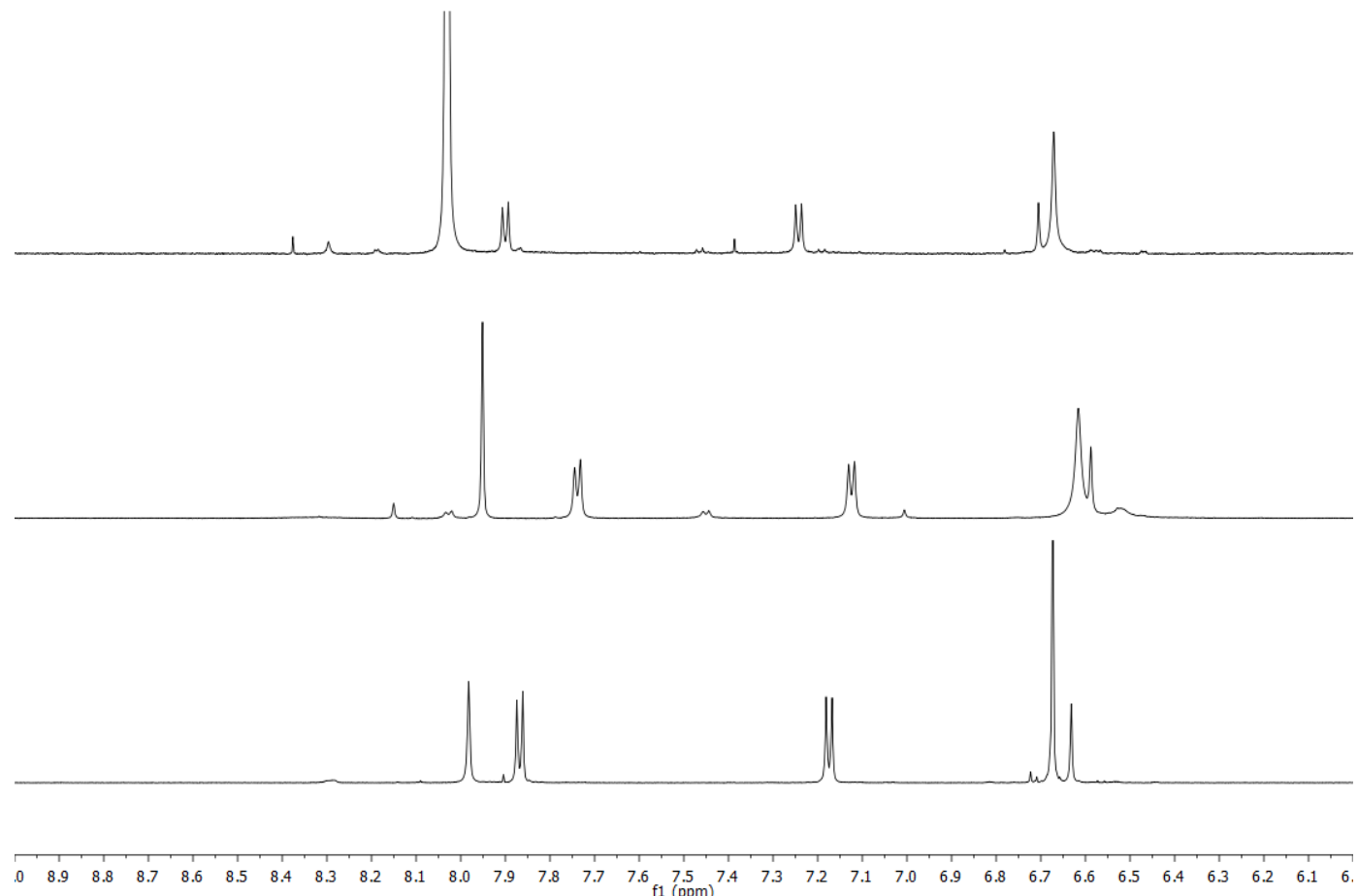

Figure S42. ${ }^{1} \mathrm{H}$ NMR analysis of $10 \mathrm{C} \_\mathrm{Cl}$ in Methanol- $d_{4}$ (bottom), DMSO- $d_{6}$ (middle), and DMF$d_{7}$ (top). 


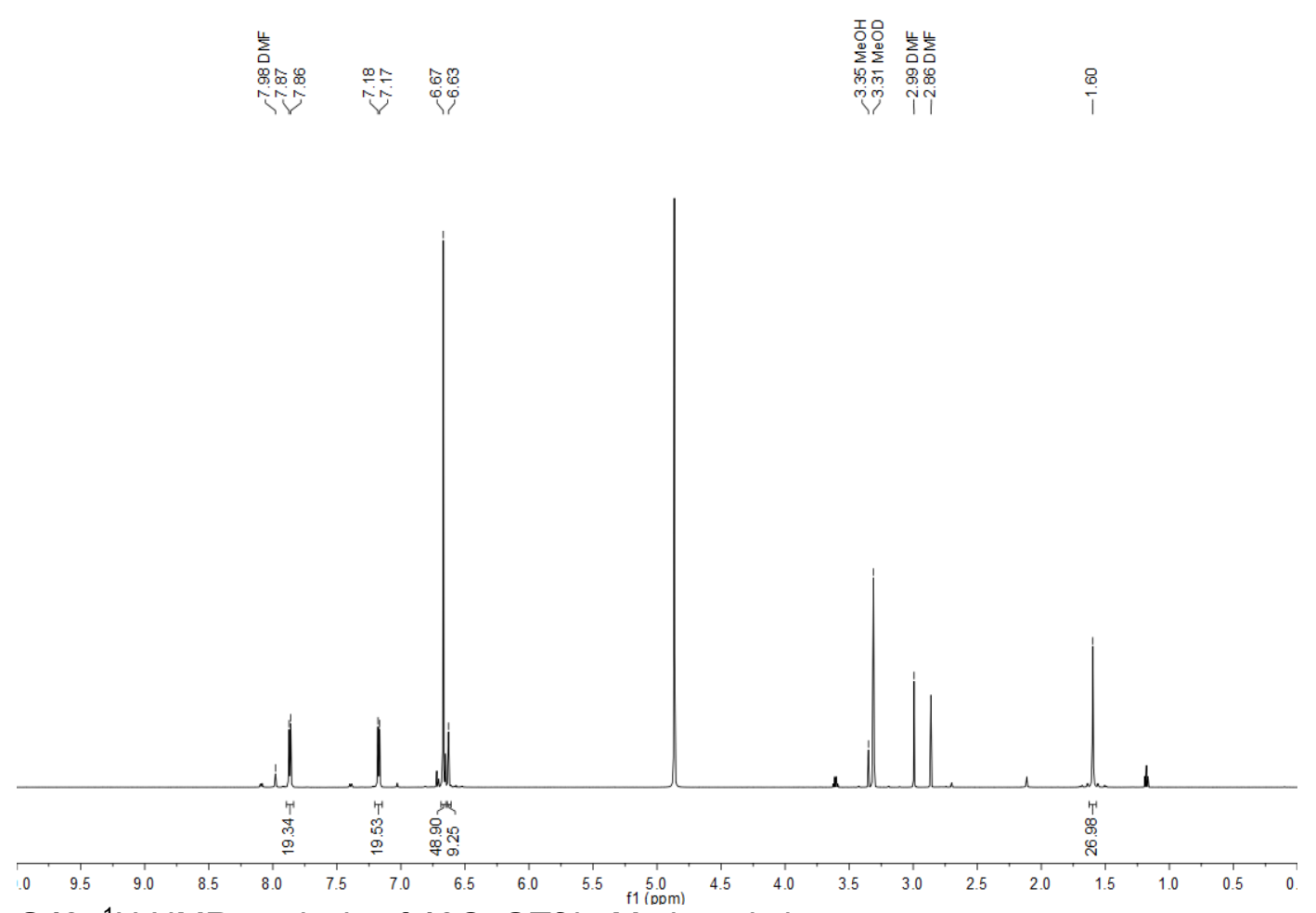

Figure S43. ${ }^{1} \mathrm{H}$ NMR analysis of 10C_OTf in Methanol- $d_{4}$.

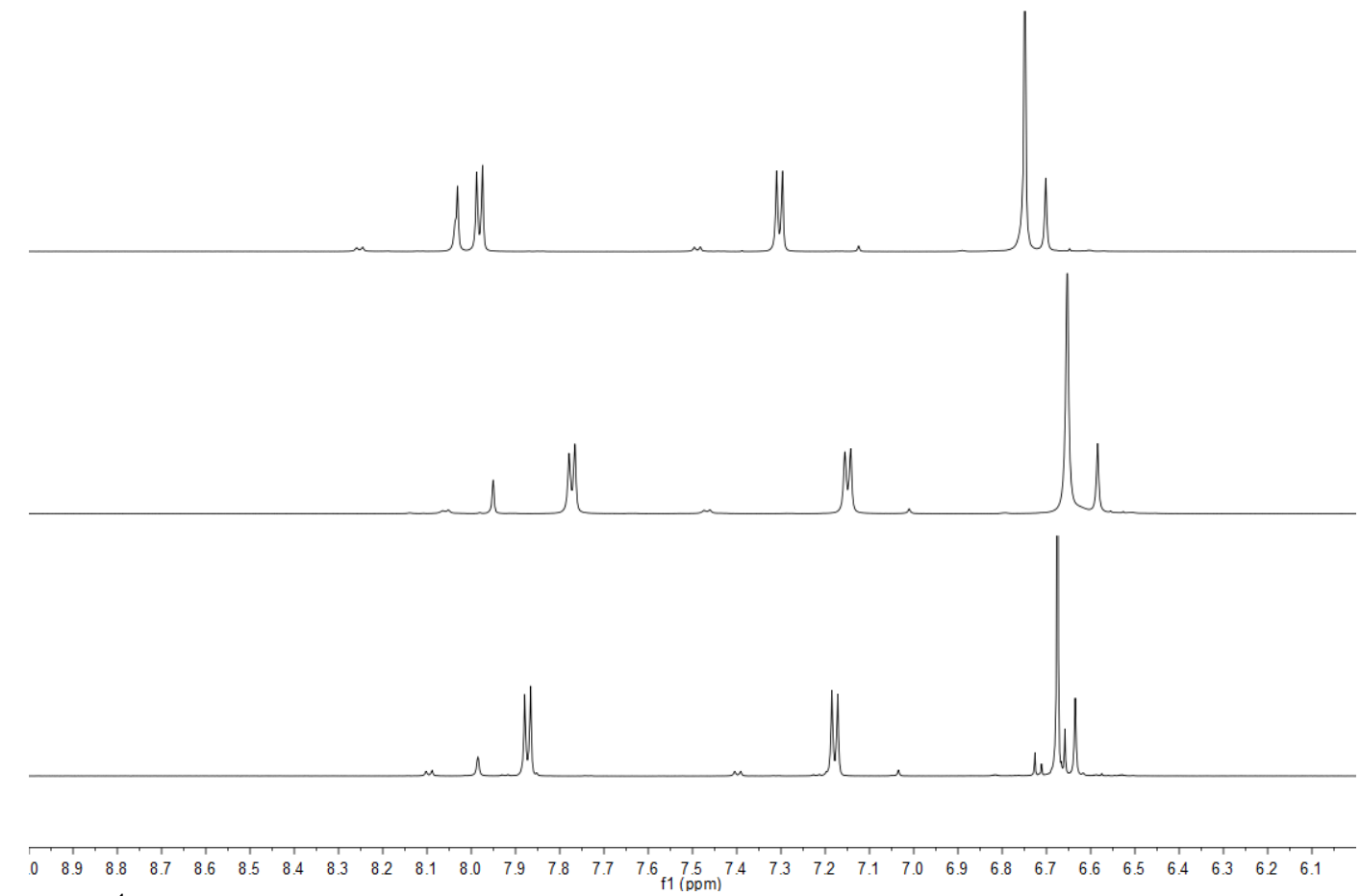

Figure S44. ${ }^{1} \mathrm{H}$ NMR analysis of 10C_OTf in Methanol- $d_{4}$ (bottom), DMSO- $d_{6}$ (middle), and DMF$d_{7}$ (top). 


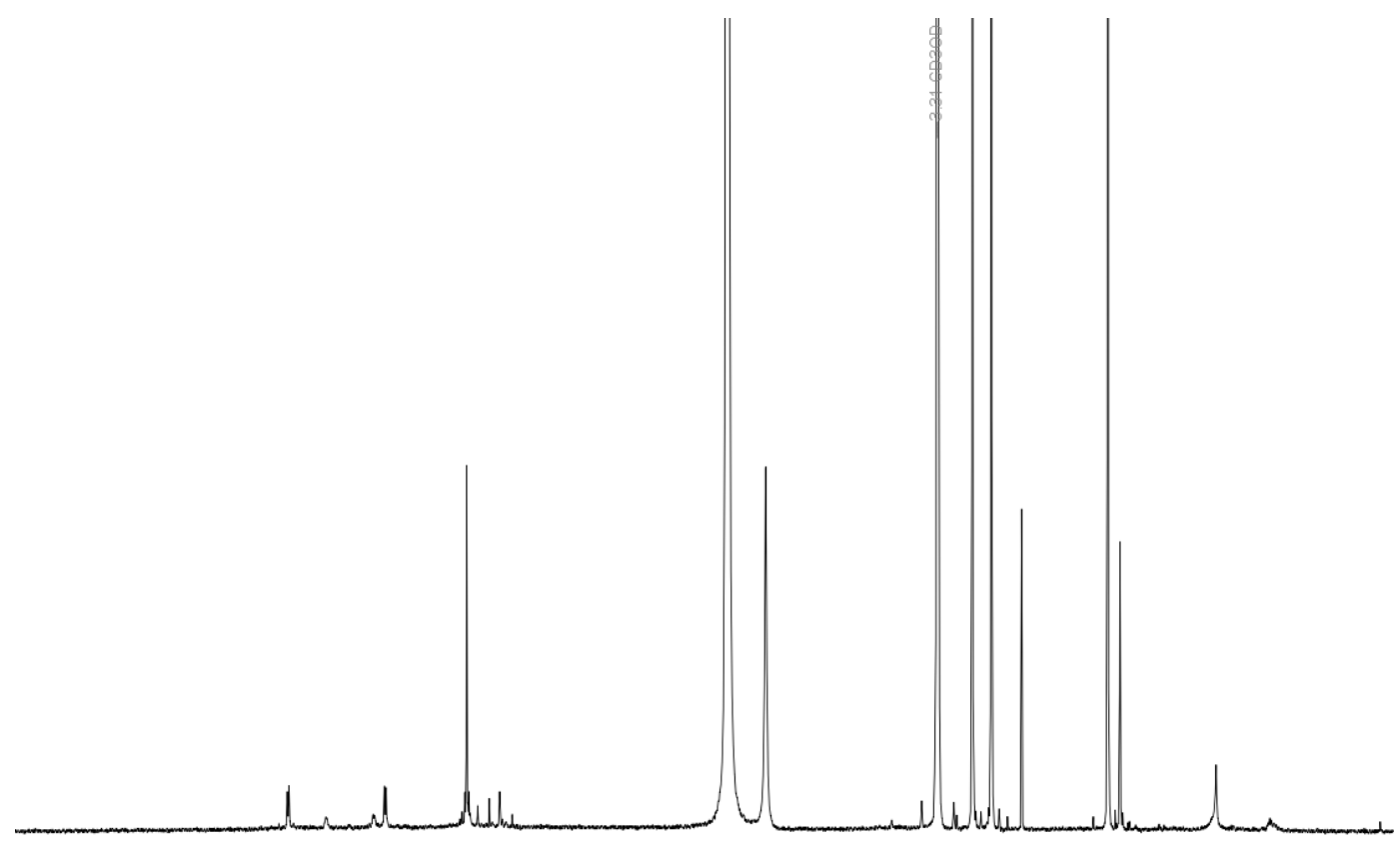

Figure S45. ${ }^{1} \mathrm{H}$ NMR analysis of $11 \mathrm{~T} / \mathrm{C}$ in Methanol- $d_{4}$.
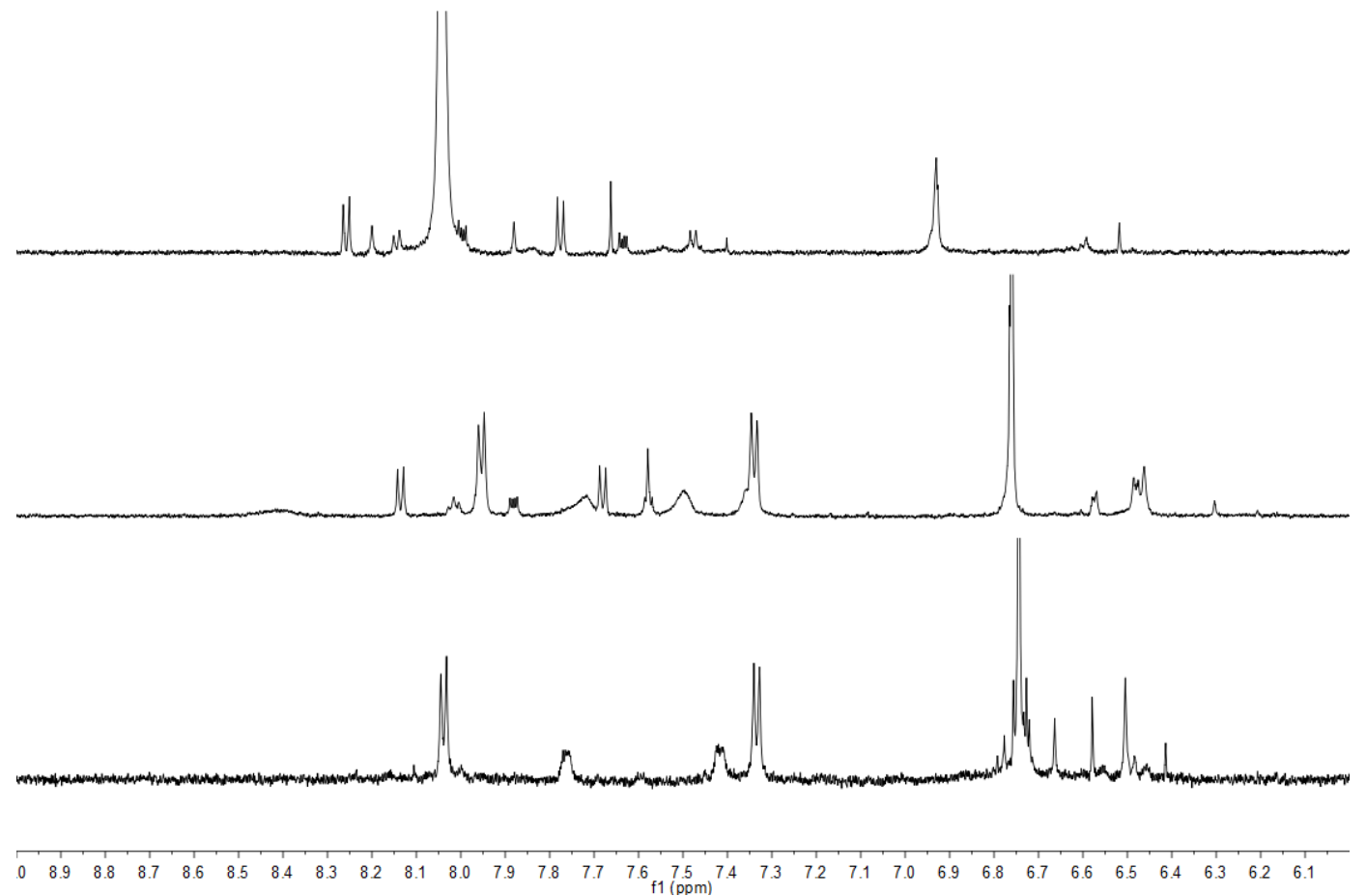

Figure S46. ${ }^{1} \mathrm{H}$ NMR analysis of $11 \mathrm{~T} / \mathrm{C}$ in Methanol- $d_{4}$ (bottom), DMSO- $d_{6}$ (middle), and DMF- $d_{7}$ (top). 


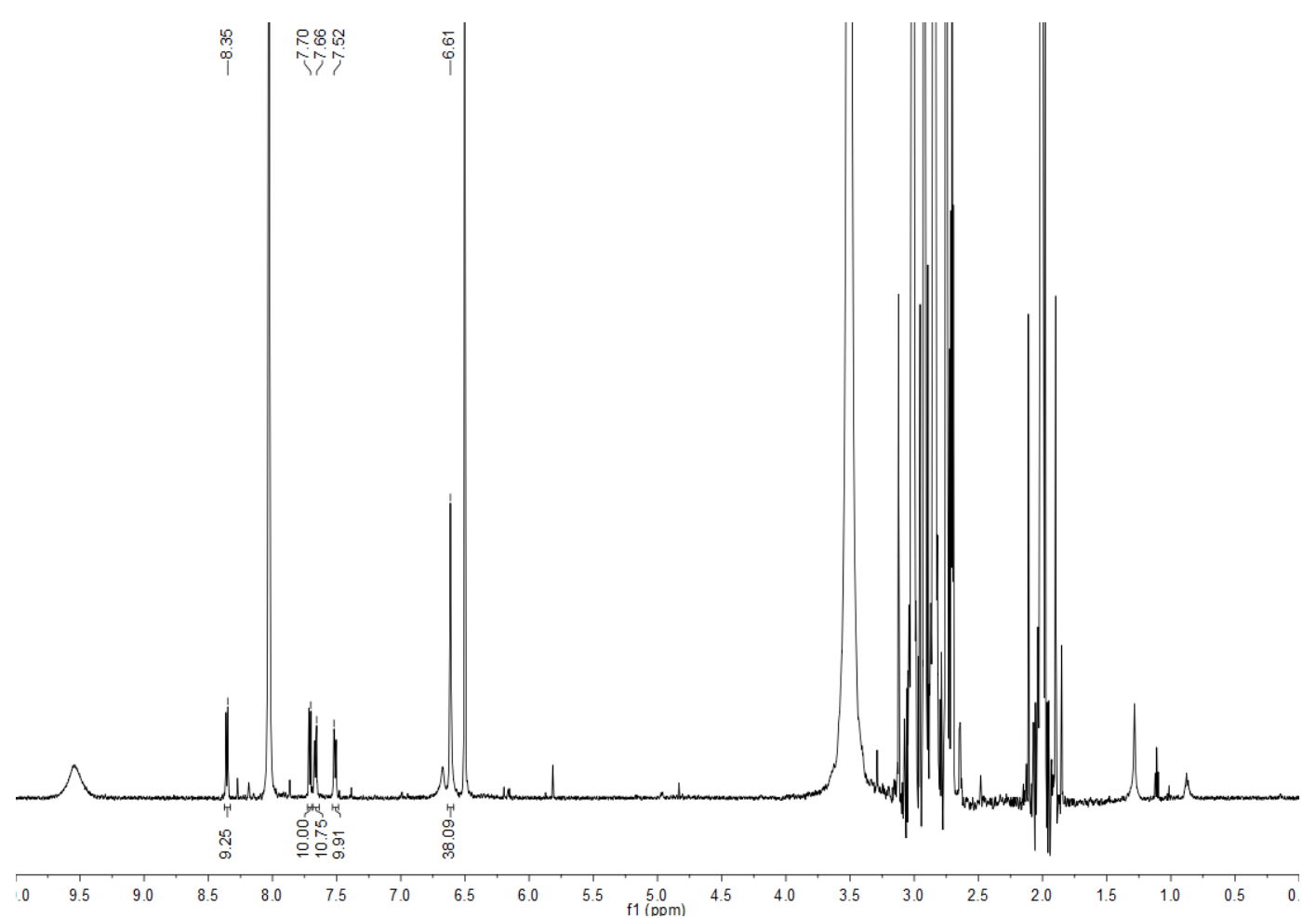

Figure S47. ${ }^{1} \mathrm{H}$ NMR analysis of $12 \mathrm{~T}$ in DMF- $d_{7}$.
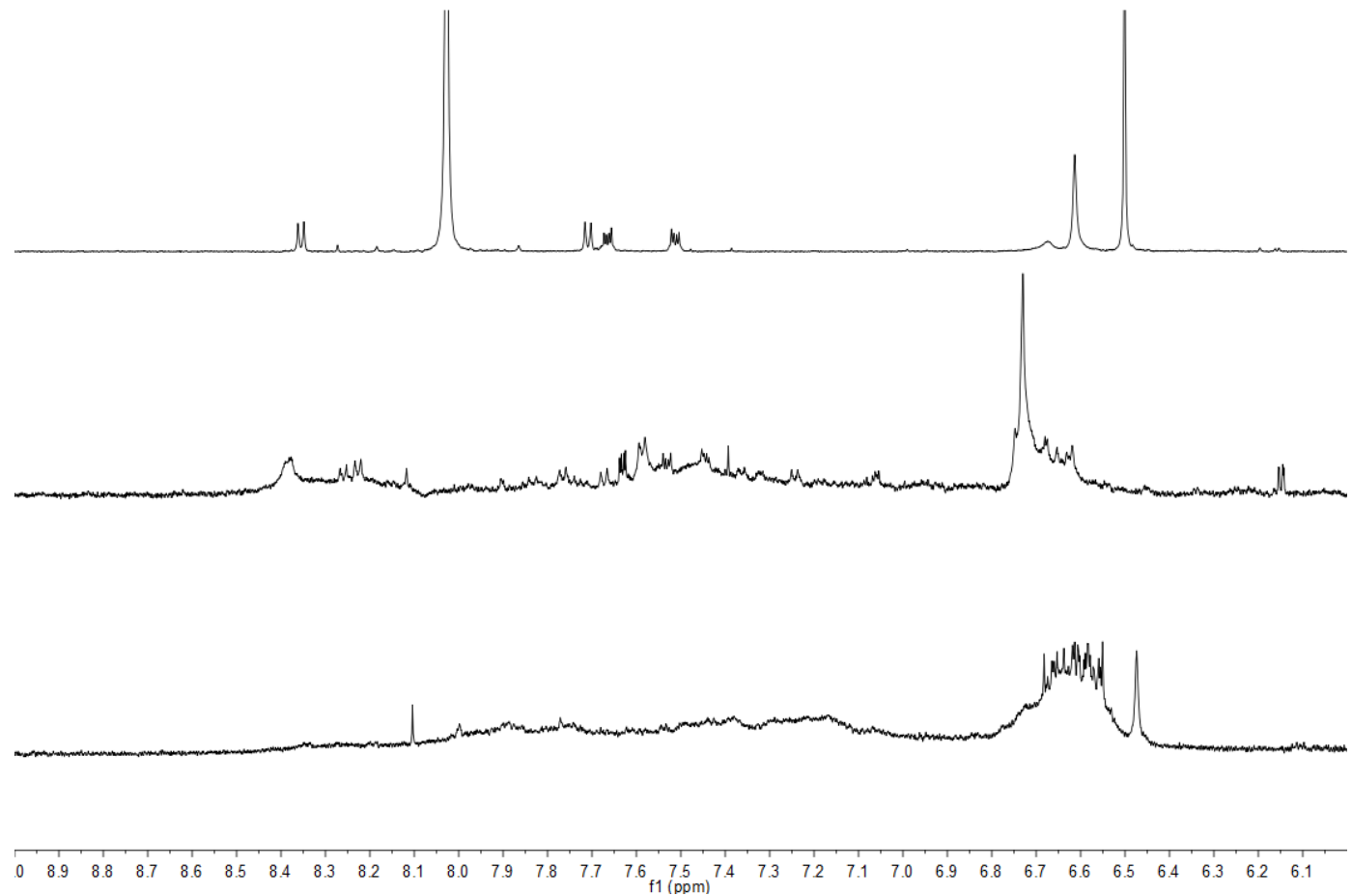

Figure S48. ${ }^{1} \mathrm{H}$ NMR analysis of $12 \mathrm{~T}$ in Methanol- $d_{4}$ (bottom), DMSO- $d_{6}$ (middle), and DMF- $d_{7}$ (top). 
Zirconium Cage Mass Spectrometry-For all samples, peaks below $0.5 \mathrm{~min}$ are background for low-resolution mass spec.
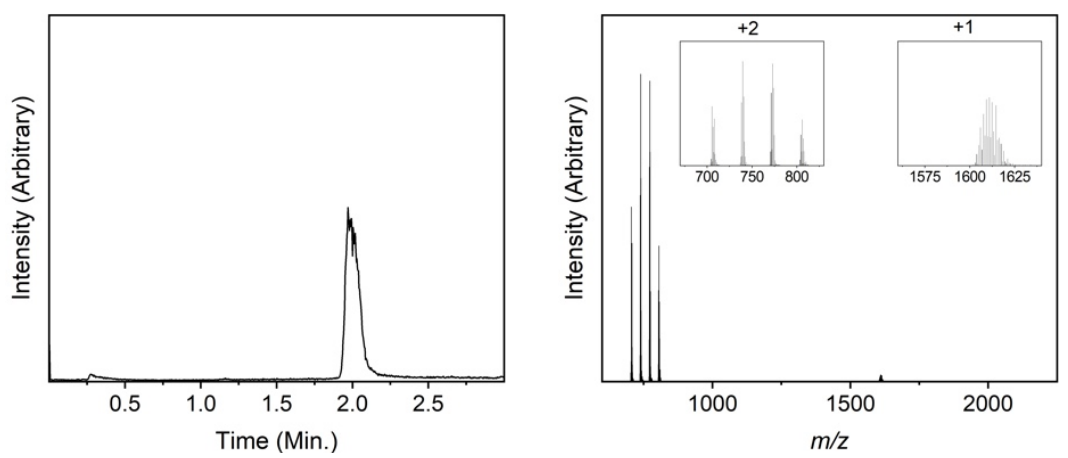

Figure S49. (Left) Low-resolution ESI-mass spectrometry data for $1 \mathrm{C}$ in $\mathrm{MeOH}$. The presence of one peak indicates a singular phase, in this case, a cigar. (Right) Low-resolution ESI-mass spectrum of $1 \mathrm{C}$ in $\mathrm{MeOH}$. The presence of only $2+$ and $1+$ peaks indicates the phase is a cigar. The four peaks present in the $2+$ region are a result of encapsulated cyclopentadiene.
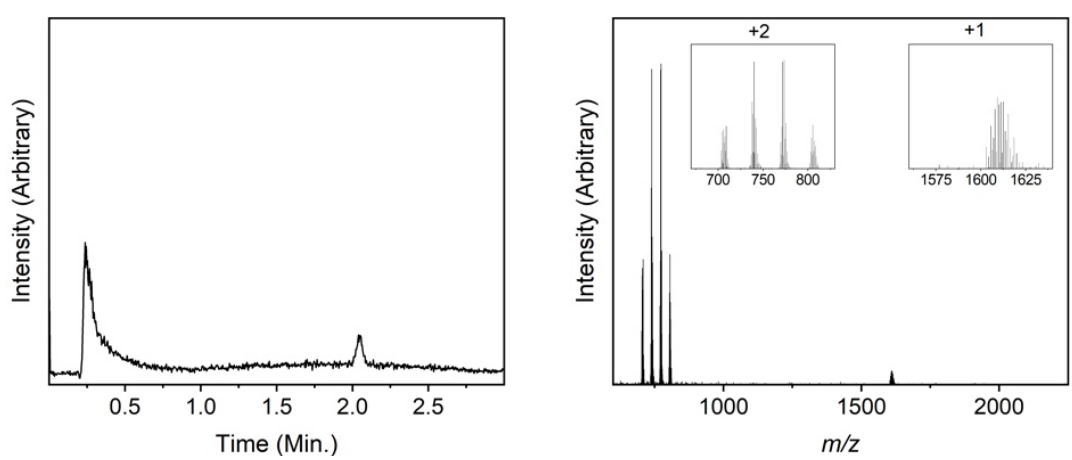

Figure S50. (Left) Low-resolution ESI-mass spectrometry data for 1C in DMF. The presence of one peak indicates a singular phase, in this case, a cigar. (Right) Low-resolution ESI-mass spectrum of $1 \mathrm{C}$ in $\mathrm{MeOH}$. The presence of only $2+$ and $1+$ peaks indicates the phase is a cigar. The four peaks present in the $2+$ region are a result of encapsulated cyclopentadiene.
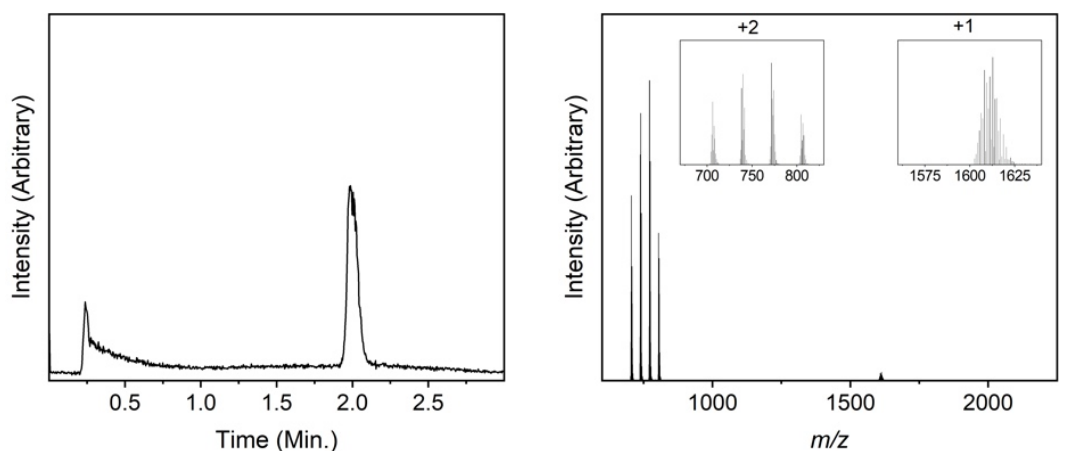

Figure S51. Low-resolution ESI-mass spectrometry data for 1C in DMSO. The presence of one peak indicates a singular phase, in this case, a cigar. (Right) Low-resolution ESI-mass spectrum of $1 \mathrm{C}$ in $\mathrm{MeOH}$. The presence of only $2+$ and a $1+$ peaks indicates the phase is a cigar. The four peaks present in the $2+$ region are a result of encapsulated cyclopentadiene. 


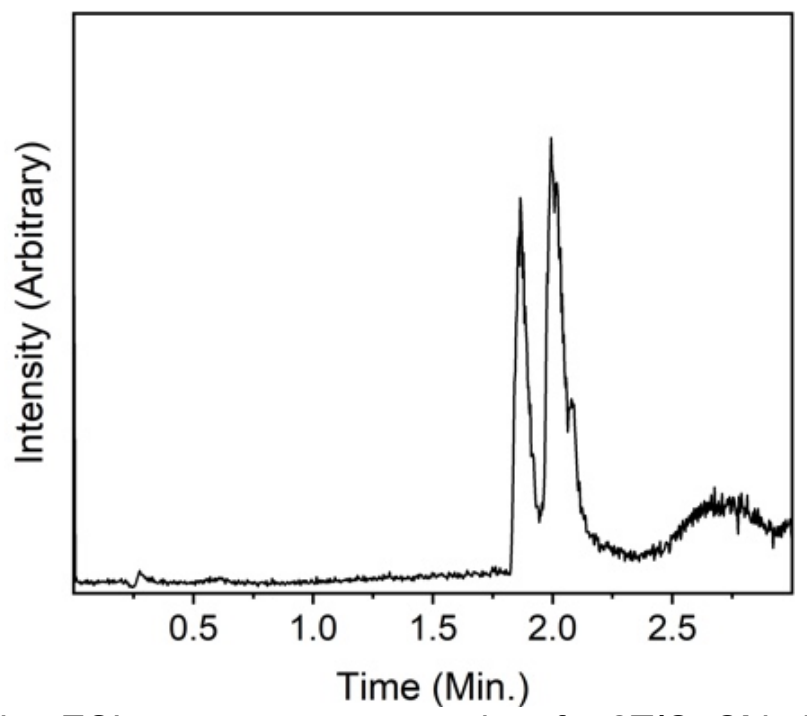

Figure S52. Low-resolution ESI-mass spectrometry data for $2 \mathrm{~T} / \mathrm{C} \_\mathrm{Cl}$ in $\mathrm{MeOH}$. The presence of two peaks indicates a mixture of the cigar and tetrahedron phases.
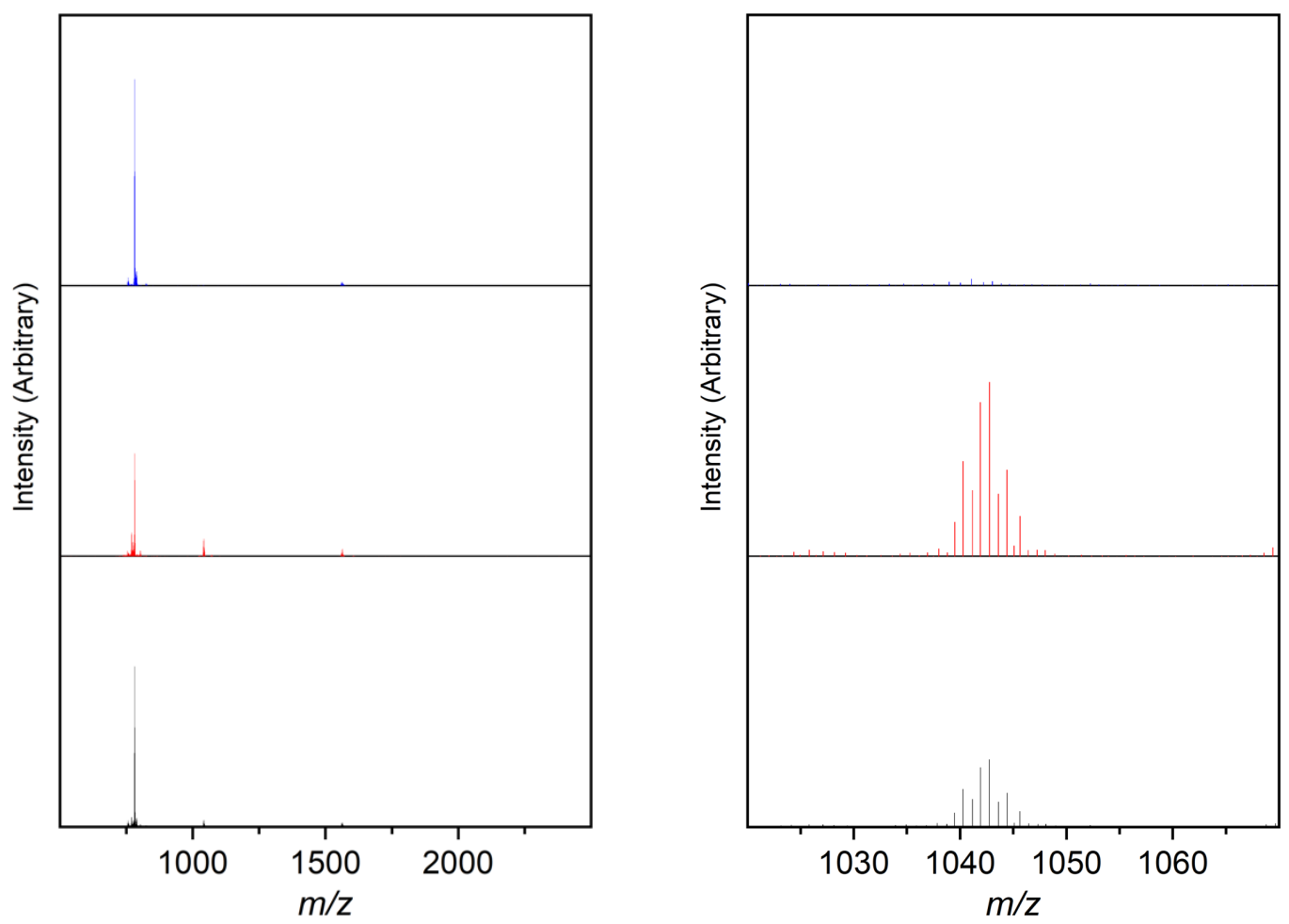

Figure S53. Low-resolution ESI-mass spectra of $2 \mathrm{~T} / \mathrm{C}$ _Cl in $\mathrm{MeOH}$ integrated over different time regions. Integration over the $1.96-2.2$ minutes (top left, blue) region in the raw data in figure S52 yields peaks at 782.1 and $1563.3 \mathrm{~m} / \mathrm{z}$. These peaks are consistent with the $2+$ and $1+\mathrm{m} / \mathrm{z}$ values for the cigar phase. Integration over the 1.8-1.96 minutes (middle, red) region in the raw data in figure S52 yields peaks at 782.1, 1042.5, $1563.3 \mathrm{~m} / \mathrm{z}$. These peaks are consistent with the 4+, $3+$, and $2+\mathrm{m} / \mathrm{z}$ values for the tetrahedron phase. Integration over the $1.8-2.2$ minutes (bottom, black) region in the raw data in figure S52 yields peaks at $782.1,1042.5,1563.3 \mathrm{~m} / \mathrm{z}$. These peaks are consistent with the $4+/ 2+, 3+$, and $2+/ 1+\mathrm{m} / \mathrm{z}$ values for a mixture of tetrahedron and cigar phases. The central portion of each spectra is zoomed in on the figure on the right. 


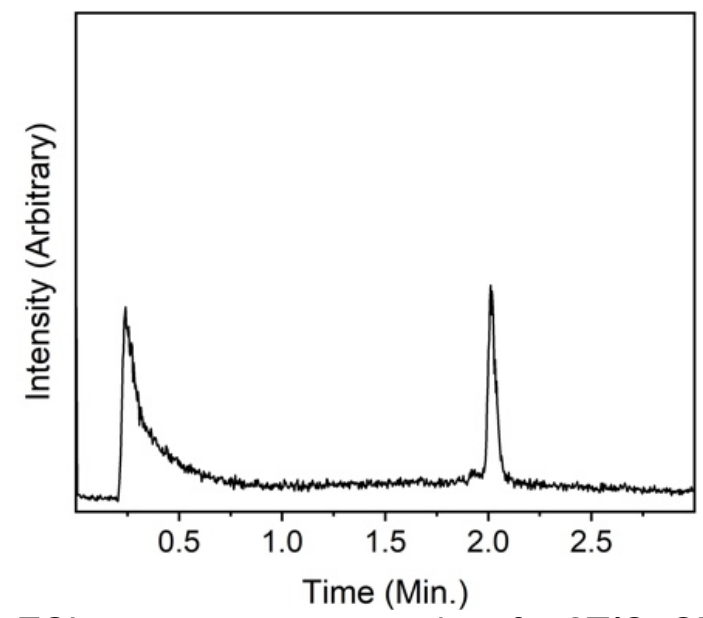

Figure S54. Low-resolution ESI-mass spectrometry data for 2T/C_CI in DMF. The presence of two peaks indicates a mixture of the cigar and tetrahedron phases.
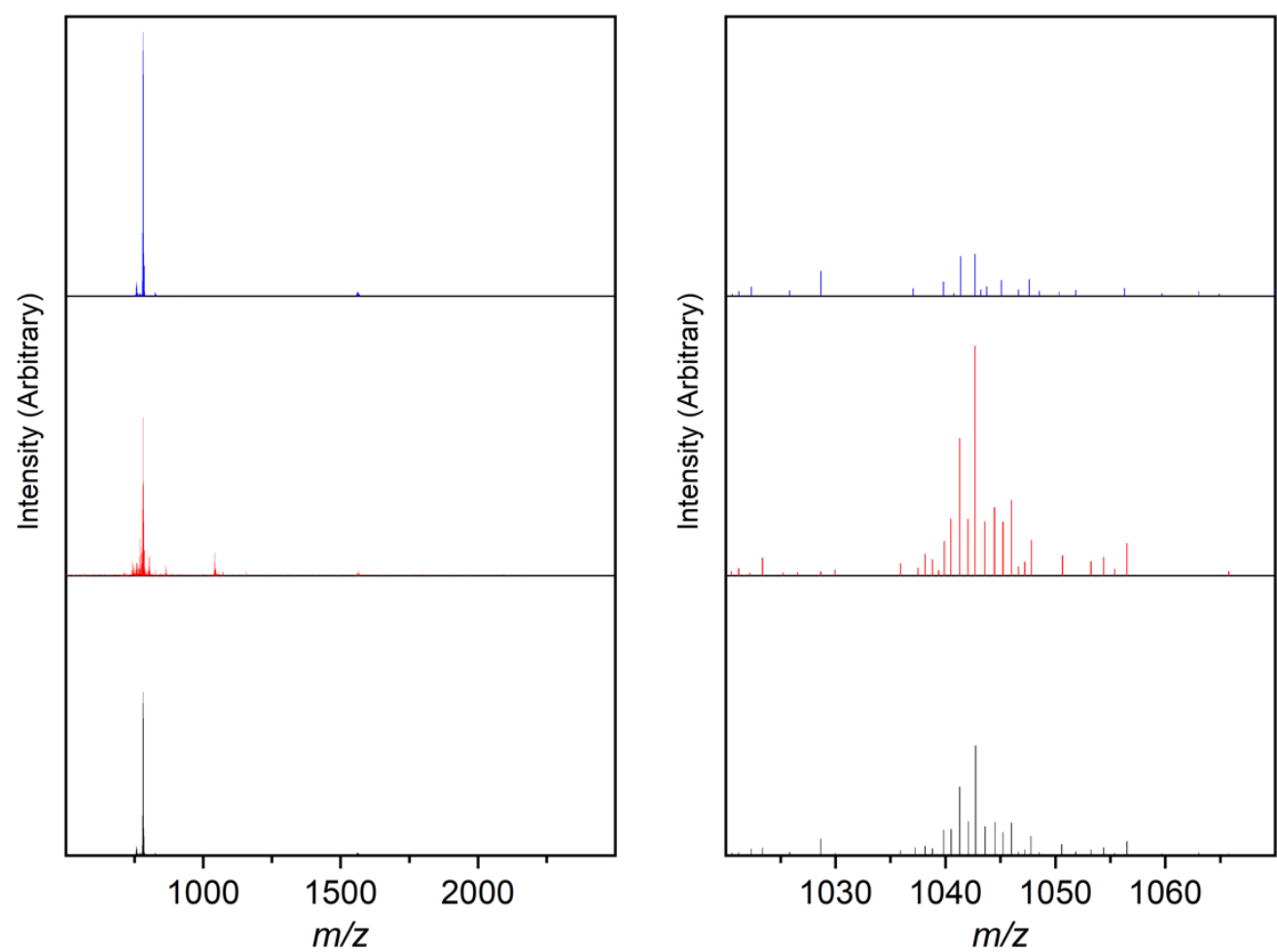

Figure S55. Low-resolution ESI-mass spectrum of 2T/C_Cl in DMF integrated over different time regions. Integration over the 1.96 - 2.2 minutes (top left, blue) region in the raw data in figure S54 yields peaks at 782.1 and $1563.3 \mathrm{~m} / \mathrm{z}$. These peaks are consistent with the $2+$ and $1+\mathrm{m} / \mathrm{z}$ values for the cigar phase. Integration over the $1.8-1.96$ minutes (middle, red) region in the raw data in figure S54 yields peaks at $781.5,1042.8,1562.7 \mathrm{~m} / \mathrm{z}$. These peaks are consistent with the 4+, $3+$, and $2+\mathrm{m} / \mathrm{z}$ values for the tetrahedron phase. Integration over the $1.8-2.2$ minutes (bottom, black) region in the raw data in figure S54 yields peaks at 781.8, 1042.8, $1562.7 \mathrm{~m} / \mathrm{z}$. These peaks are consistent with the $4+/ 2+, 3+$, and $2+/ 1+\mathrm{m} / \mathrm{z}$ values for a mixture of tetrahedron and cigar phases. The central portion of each spectra is zoomed in on the figure on the right. 


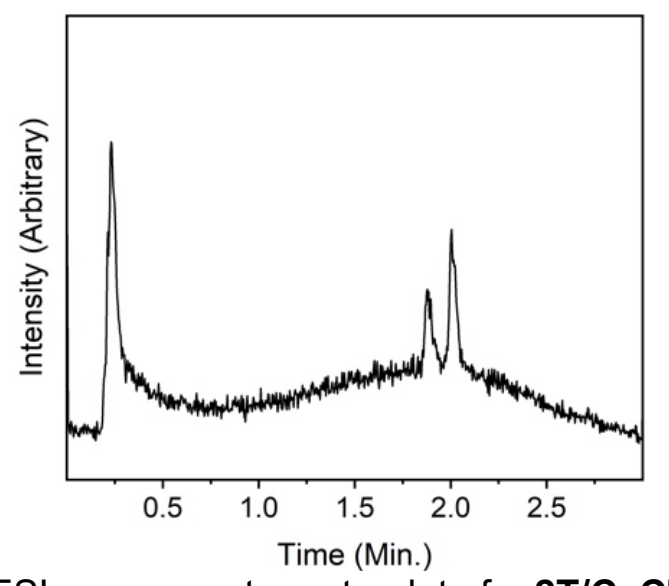

Figure S56. Low-resolution ESI-mass spectrometry data for 2T/C_CI in DMSO. The presence of two peaks indicates a mixture of the cigar and tetrahedron phases.
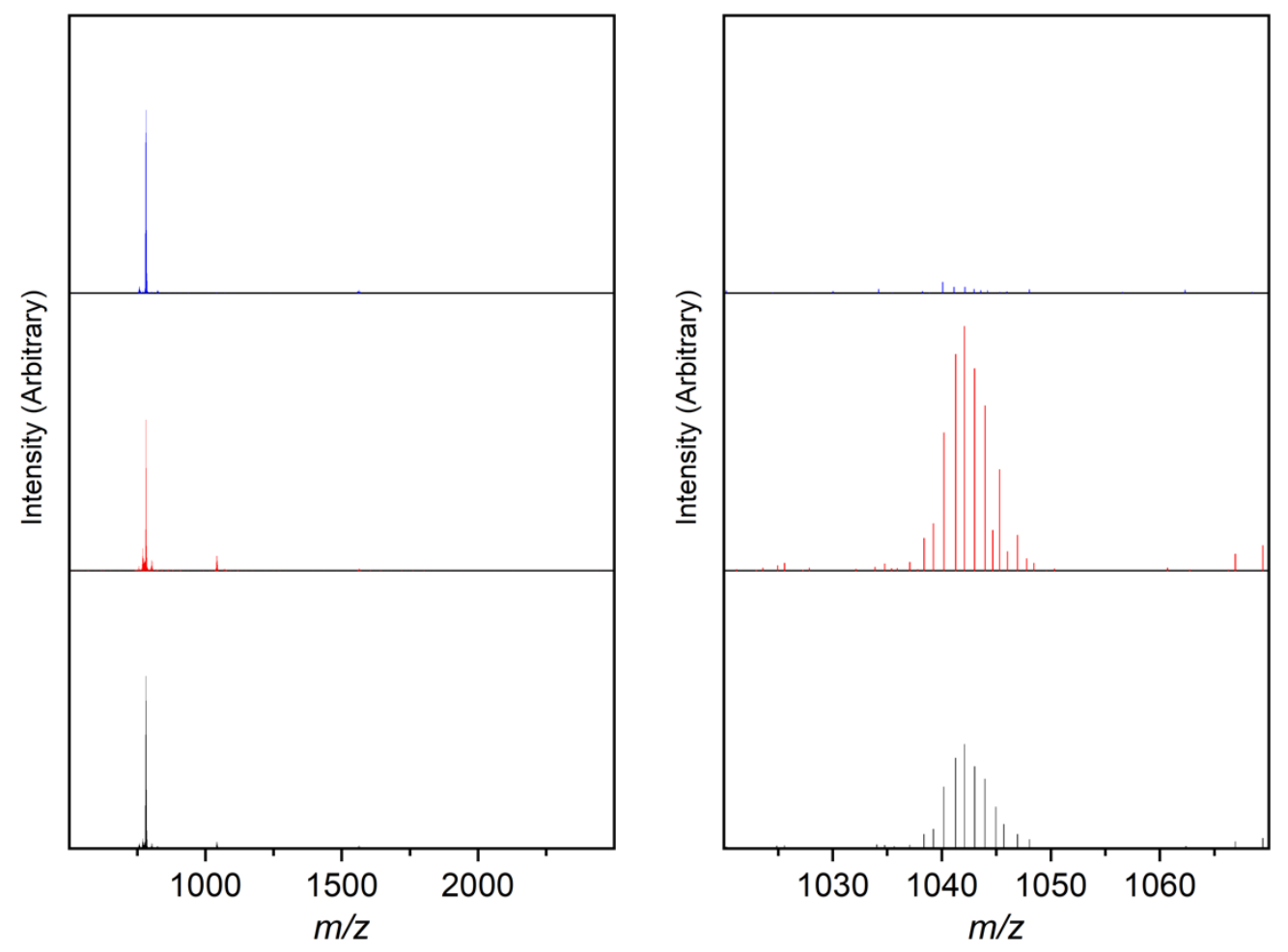

Figure S57. Low-resolution ESI-mass spectrum of 2T/C_CI in DMSO integrated over different time regions. Integration over the $1.96-2.2$ minutes (top left, blue) region in the raw data in figure $\mathrm{S} 56$ yields peaks at 782.1 and $1563.3 \mathrm{~m} / \mathrm{z}$. These peaks are consistent with the $2+$ and $1+\mathrm{m} / \mathrm{z}$ values for the cigar phase. Integration over the 1.8 - 1.96 minutes (middle, red) region in the raw data in figure S56 yields peaks at 782.1, 1042.5, $1563.3 \mathrm{~m} / \mathrm{z}$. These peaks are consistent with the $4+, 3+$, and $2+\mathrm{m} / \mathrm{z}$ values for the tetrahedron phase. Integration over the $1.8-2.2$ minutes (bottom, black) region in the raw data in figure $S 56$ yields peaks at $782.1,1042.5,1563.3 \mathrm{~m} / \mathrm{z}$. These peaks are consistent with the $4+/ 2+, 3+$, and $2+/ 1+\mathrm{m} / \mathrm{z}$ values for a mixture of tetrahedron and cigar phases. The central portion of each spectra is zoomed in on the figure on the right. 


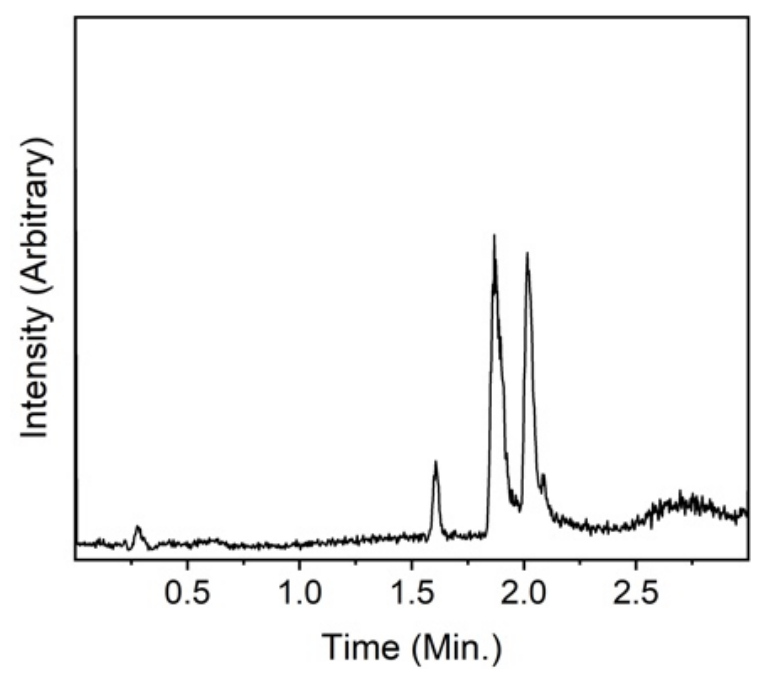

Figure S58. Low-resolution ESI-mass spectrometry data for 2T/C_OTf in $\mathrm{MeOH}$. The presence of two peaks indicates a mixture of the cigar and tetrahedron phases.
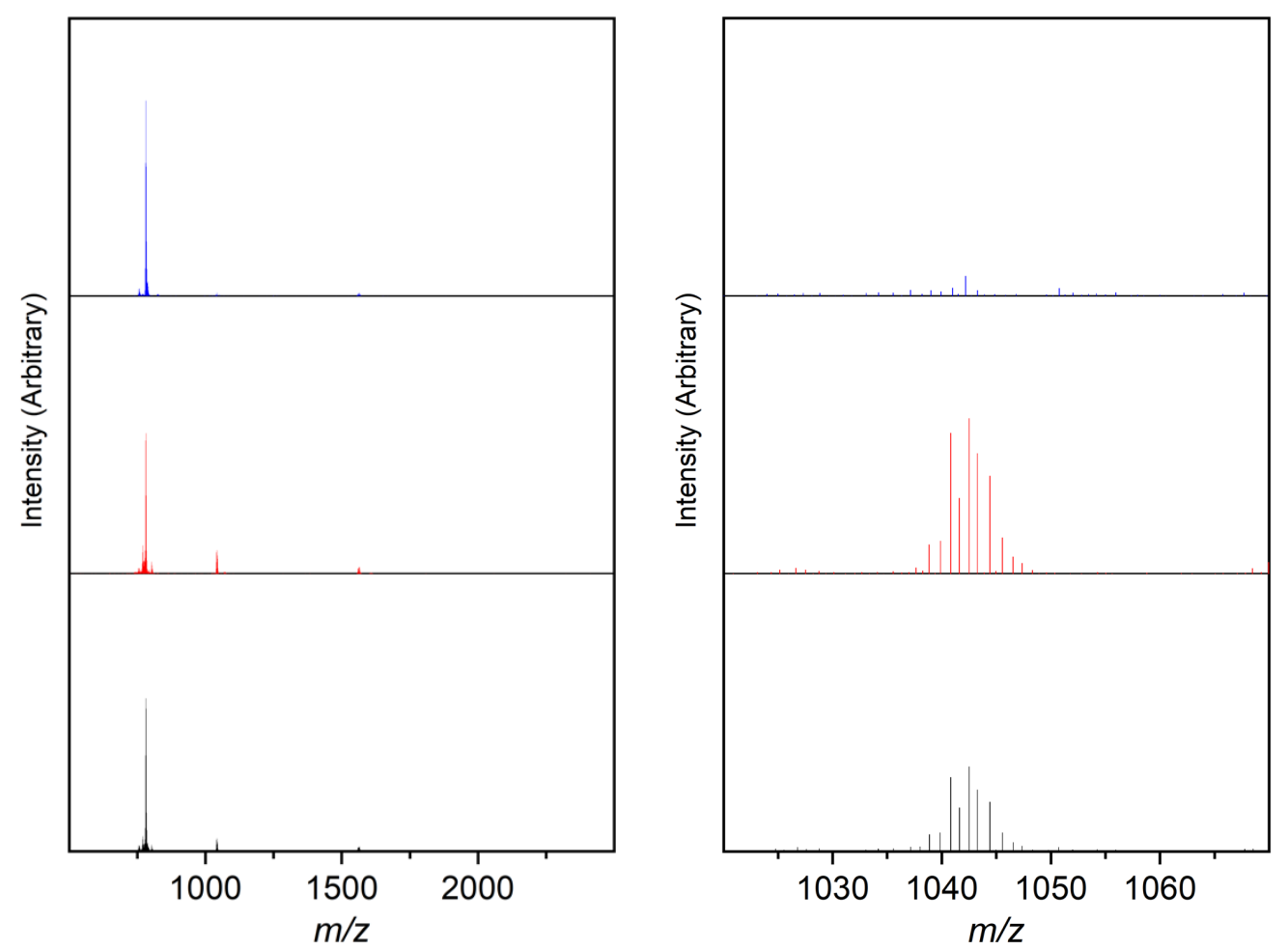

Figure S59. Low-resolution ESI-mass spectrum of 2T/C_OTf in MeOH integrated over different time regions. Integration over the 1.96-2.2 minutes (top left, blue) region in the raw data in figure S58 yields peaks at 782.1 and $1563.3 \mathrm{~m} / \mathrm{z}$. These peaks are consistent with the $2+$ and $1+\mathrm{m} / \mathrm{z}$ values for the cigar phase. Integration over the 1.8 - 1.96 minutes (middle, red) region in the raw data in figure S58 yields peaks at $782.1,1042.5,1563.3 \mathrm{~m} / \mathrm{z}$. These peaks are consistent with the $4+, 3+$, and $2+\mathrm{m} / \mathrm{z}$ values for the tetrahedron phase. Integration over the $1.8-2.2$ minutes (bottom, black) region in the raw data in figure $S 58$ yields peaks at $782.1,1042.5,1563.3 \mathrm{~m} / \mathrm{z}$. These peaks are consistent with the $4+/ 2+, 3+$, and $2+/ 1+\mathrm{m} / \mathrm{z}$ values for a mixture of tetrahedron and cigar phases. The central portion of each spectra is zoomed in on the figure on the right. 


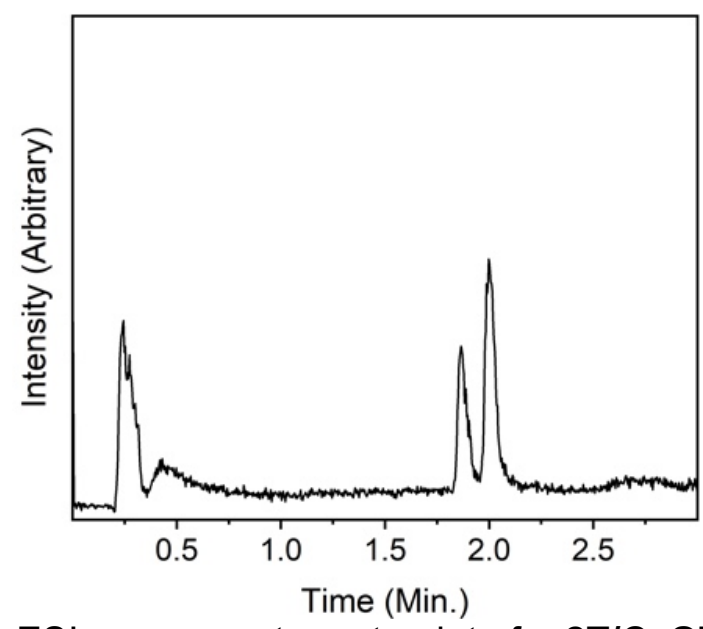

Figure S60. Low-resolution ESI-mass spectrometry data for 2T/C_OTf in DMF. The presence of two peaks indicates a mixture of the cigar and tetrahedron phases.
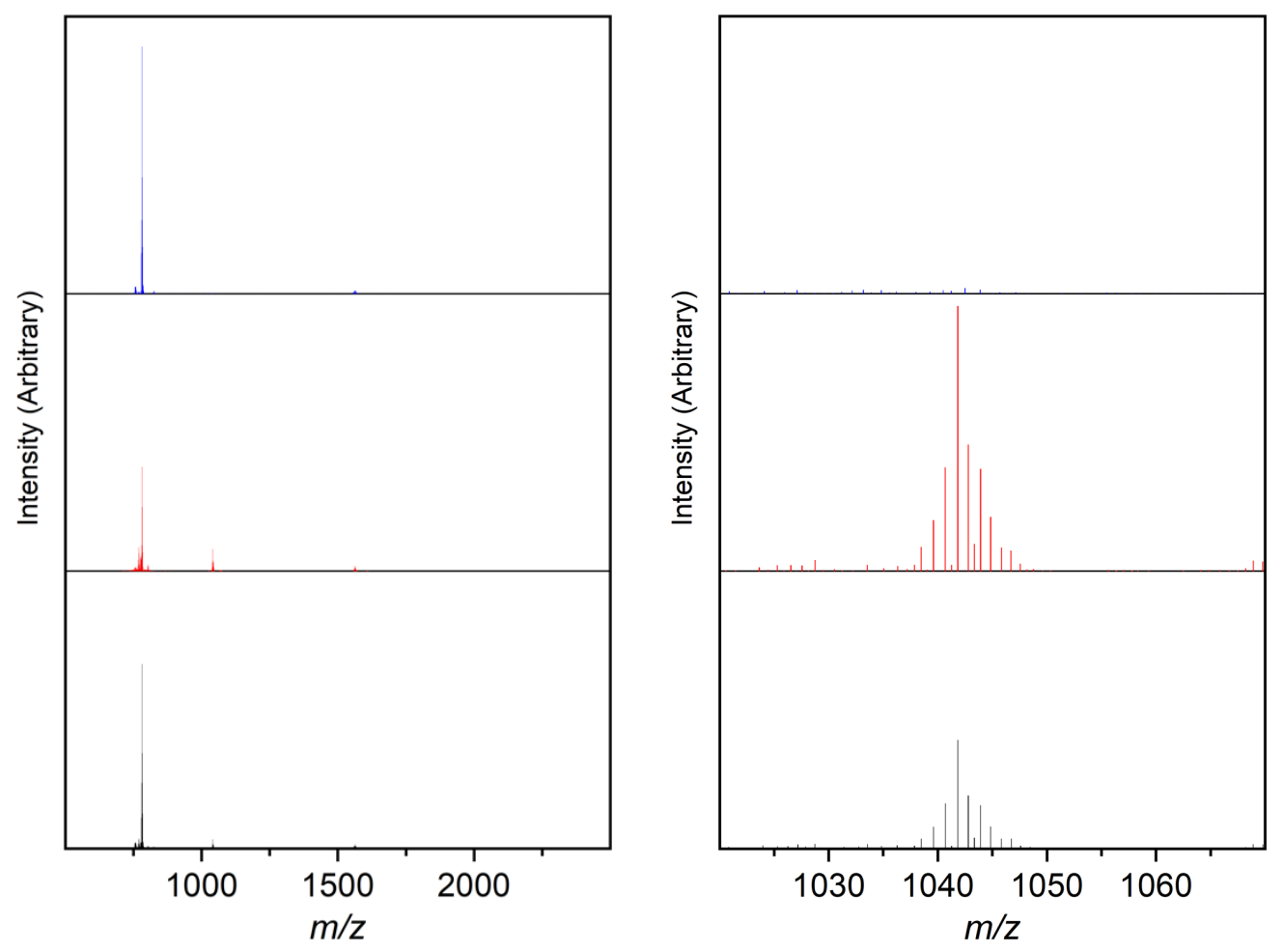

Figure S61. Low-resolution ESI-mass spectrum of 2T/C_OTf in DMF integrated over different time regions. Integration over the $1.96-2.2$ minutes (top left, blue) region in the raw data in figure S60 yields peaks at 782.1 and $1563.3 \mathrm{~m} / \mathrm{z}$. These peaks are consistent with the $2+$ and $1+\mathrm{m} / \mathrm{z}$ values for the cigar phase. Integration over the 1.8 - 1.96 minutes (middle, red) region in the raw data in figure S60 yields peaks at 782.1, 1042.5, $1563.3 \mathrm{~m} / \mathrm{z}$. These peaks are consistent with the $4+, 3+$, and $2+\mathrm{m} / \mathrm{z}$ values for the tetrahedron phase. Integration over the $1.8-2.2$ minutes (bottom, black) region in the raw data in figure $S 60$ yields peaks at $782.1,1042.5,1563.3 \mathrm{~m} / \mathrm{z}$. These peaks are consistent with the $4+/ 2+, 3+$, and $2+/ 1+\mathrm{m} / \mathrm{z}$ values for a mixture of tetrahedron and cigar phases. The central portion of each spectra is zoomed in on the figure on the right. 


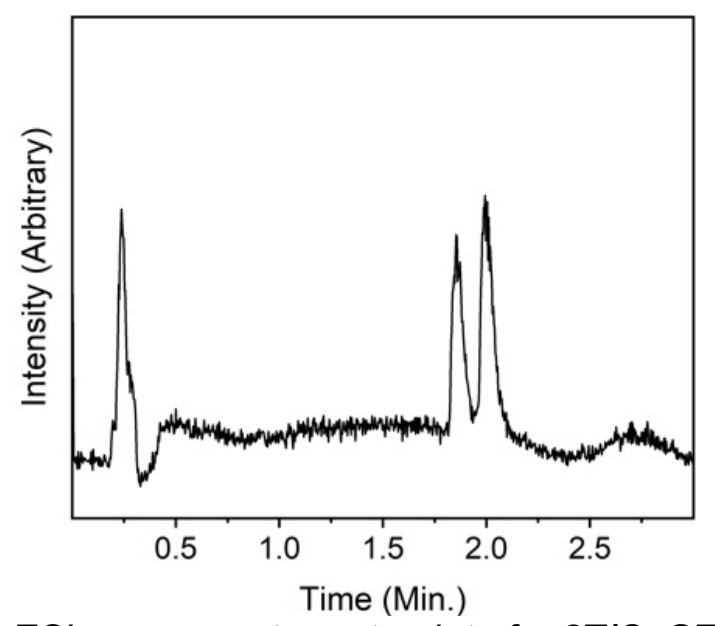

Figure S62. Low-resolution ESI-mass spectrometry data for 2T/C_OTf in DMSO. The presence of two peaks indicates a mixture of the cigar and tetrahedron phases.
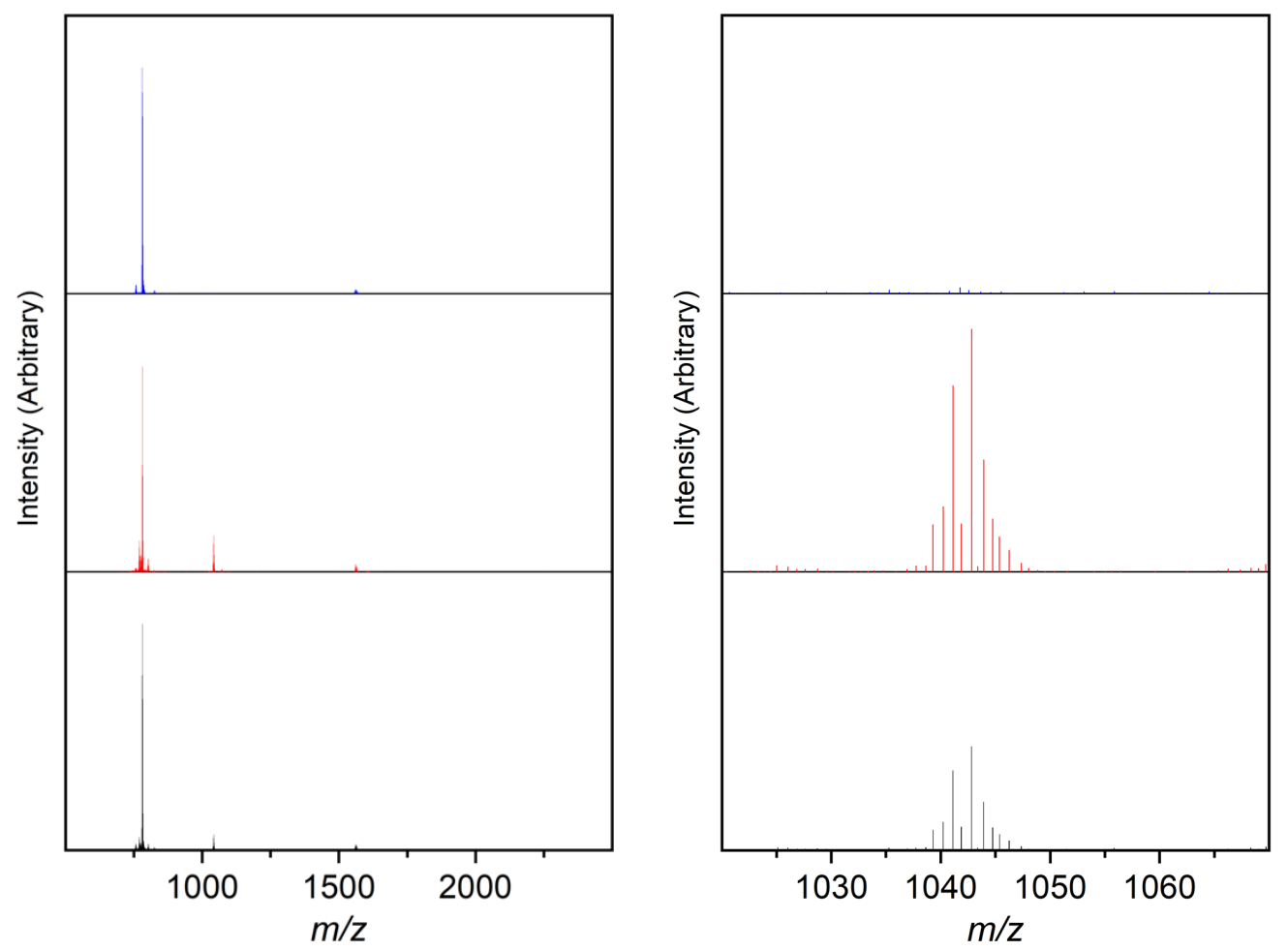

Figure S63. Low-resolution ESI-mass spectrum of 2T/C_OTf in DMSO integrated over different time regions. Integration over the $1.96-2.2$ minutes (top left, blue) region in the raw data in figure $\mathrm{S} 62$ yields peaks at 782.1 and $1563.3 \mathrm{~m} / \mathrm{z}$. These peaks are consistent with the $2+$ and $1+\mathrm{m} / \mathrm{z}$ values for the cigar phase. Integration over the 1.8 - 1.96 minutes (middle, red) region in the raw data in figure S62 yields peaks at 782.1, 1042.5, $1563.3 \mathrm{~m} / \mathrm{z}$. These peaks are consistent with the $4+, 3+$, and $2+\mathrm{m} / \mathrm{z}$ values for the tetrahedron phase. Integration over the $1.8-2.2$ minutes (bottom, black) region in the raw data in figure $S 62$ yields peaks at $782.1,1042.5,1563.3 \mathrm{~m} / \mathrm{z}$. These peaks are consistent with the $4+/ 2+, 3+$, and $2+/ 1+\mathrm{m} / \mathrm{z}$ values for a mixture of tetrahedron and cigar phases. The central portion of each spectra is zoomed in on the figure on the right. 

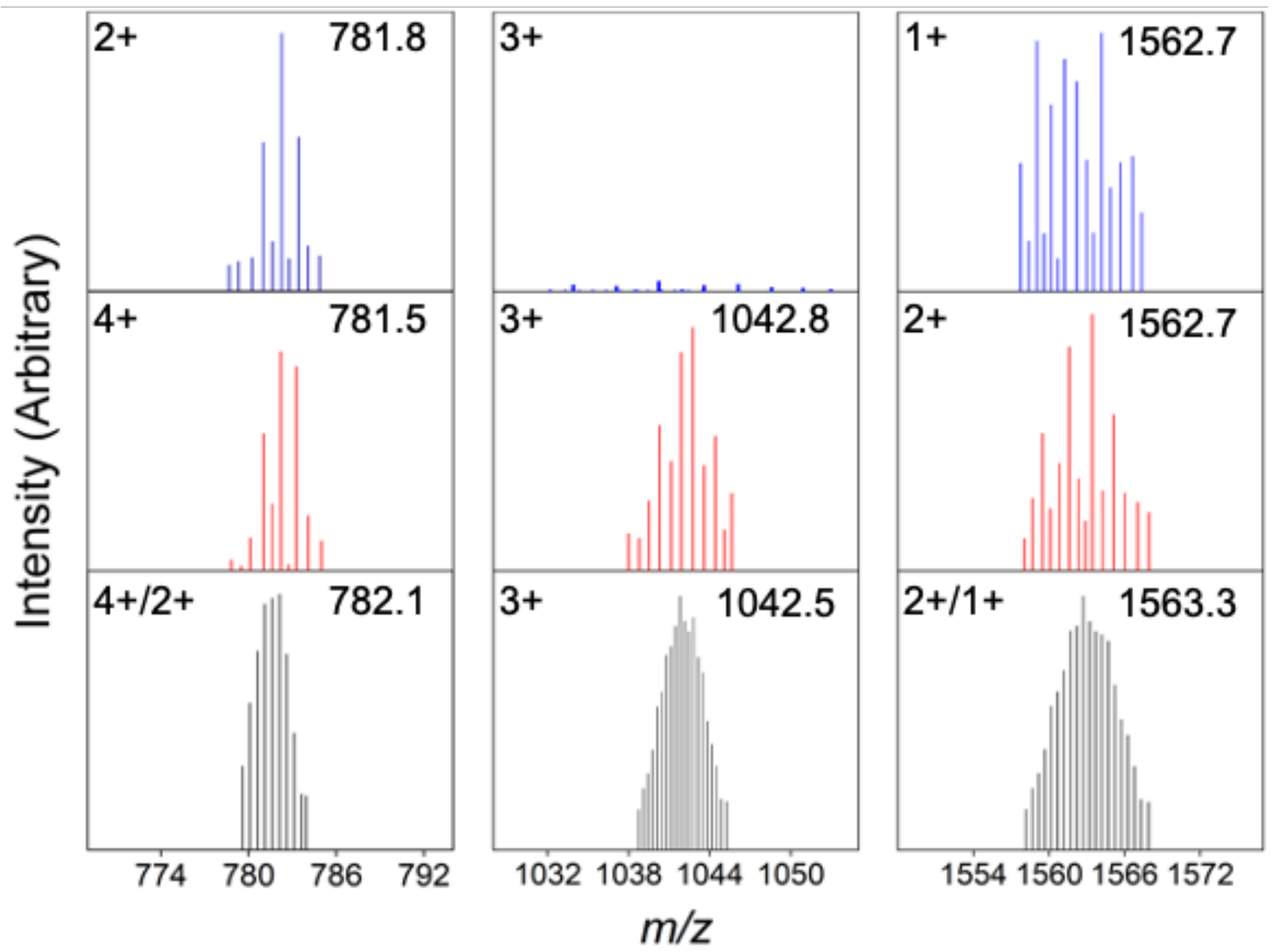

Figure S64 - Simulated (black) vs tetrahedron (red) and cigar (blue) mass spectrum of 2T/C in $\mathrm{MeOH}$.

Species of 2T/C present in the mass spectrometry experiments.

$$
\begin{gathered}
\text { 4+/2+: }\left[\mathrm{Zr}_{12}\left(\mu_{3}-\mathrm{O}\right)_{4}\left(\mu_{2}-\mathrm{OH}\right)_{12}(\mathrm{Cp})_{12}(\mathrm{bdc})_{6}\right]^{4+} /\left[\mathrm{Zr}_{6}\left(\mu_{3}-\mathrm{O}\right)_{2}\left(\mu_{2}-\mathrm{OH}\right)_{6}(\mathrm{Cp})_{6}(\mathrm{bdc})_{3}\right]^{2+} \\
3+:\left[\mathrm{Zr}_{12}\left(\mu_{3}-\mathrm{O}\right)_{4}\left(\mu_{2}-\mathrm{OH}\right)_{11}\left(\mu_{2}-\mathrm{O}\right)_{1}(\mathrm{Cp})_{12}(\mathrm{bdc})_{6}\right]^{3+}
\end{gathered}
$$$$
2+/ 1+:\left[\mathrm{Zr}_{12}\left(\mu_{3}-\mathrm{O}\right)_{4}\left(\mu_{2}-\mathrm{OH}\right)_{10}\left(\mu_{2}-\mathrm{O}\right)_{2}(\mathrm{Cp})_{12}(\mathrm{bdc})_{6}\right]^{2+} /\left[\mathrm{Zr}_{6}\left(\mu_{3}-\mathrm{O}\right)_{2}\left(\mu_{2}-\mathrm{OH}\right)_{5}\left(\mu_{2}-\mathrm{O}\right)_{1}(\mathrm{Cp})_{6}(\mathrm{bdc})_{3}\right]^{1+}
$$ 

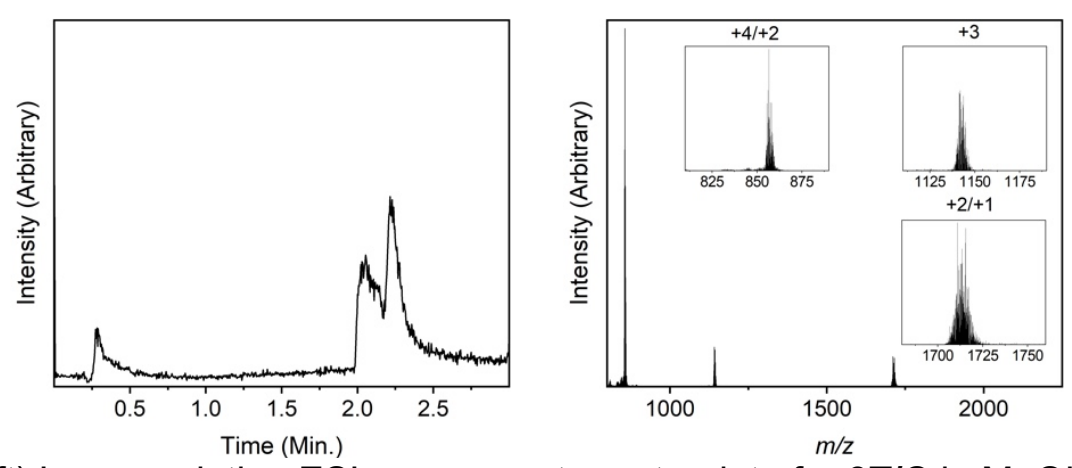

Figure S65. (Left) Low-resolution ESI-mass spectrometry data for 3T/C in $\mathrm{MeOH}$. The presence of two peaks indicates a mixture of the cigar and tetrahedron phases. (Right) Low-resolution ESImass spectrum of $\mathbf{3 T} / \mathbf{C}$ in $\mathrm{MeOH}$.
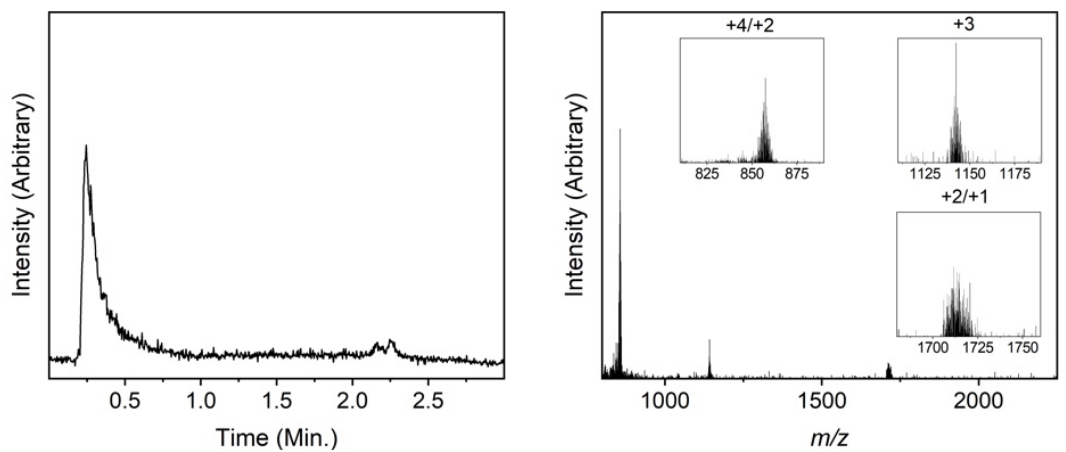

Figure S66. (Left) Low-resolution ESI-mass spectrometry data for 3T/C in DMA. (Right) Lowresolution ESI-mass spectrum of 3T/C in DMA.
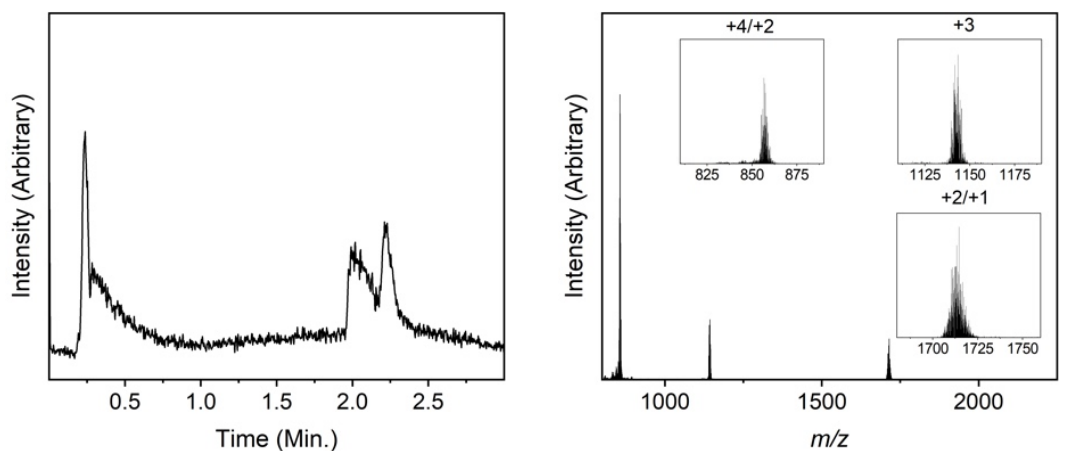

Figure S67. (Left) Low-resolution ESI-mass spectrometry data for 3T/C in DMSO. The presence of two peaks indicates a mixture of the cigar and tetrahedron phases. (Right) Low-resolution ESImass spectrum of 3 T/C in DMSO. 

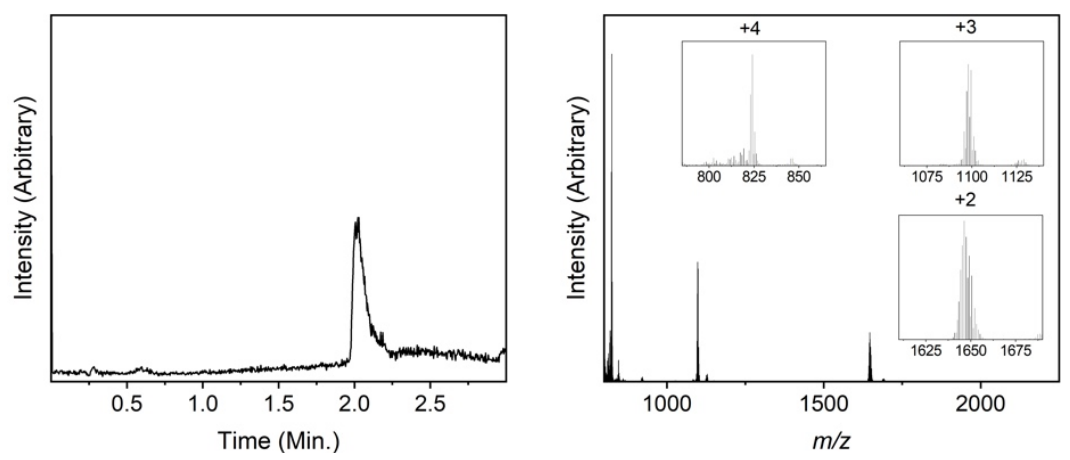

Figure S68. (Left) Low-resolution ESI-mass spectrometry data for 4T_CI in $\mathrm{MeOH}$. The presence of one peak indicates a singular phase, in this case, a tetrahedron. (Right) Low-resolution ESImass spectrum of 4T_Cl in $\mathrm{MeOH}$. The presence of $4+, 3+$, and $2+$ peaks indicates the phase is a tetrahedron.
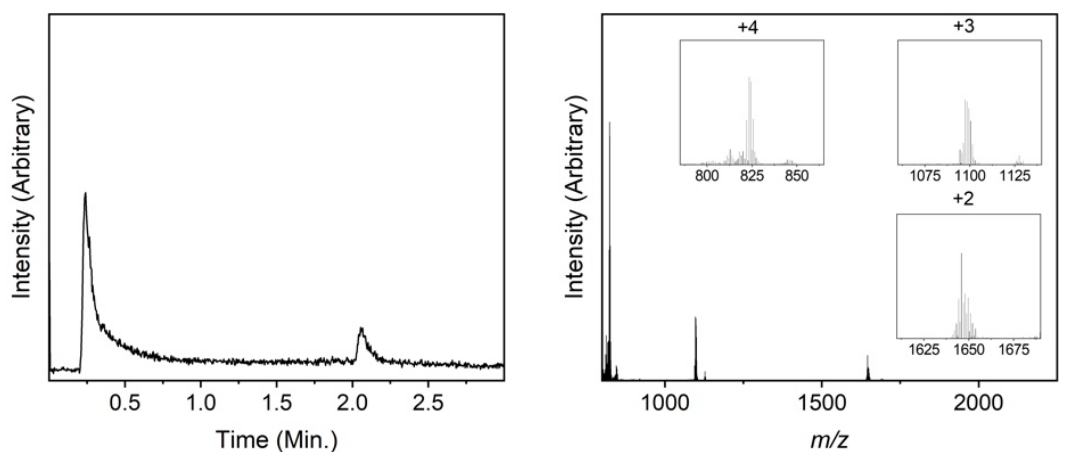

Figure S69. (Left) Low-resolution ESI-mass spectrometry data for 4T_Cl in DMF. The presence of one peak indicates a singular phase, in this case, a tetrahedron. (Right) Low-resolution ESImass spectrum of $4 \mathrm{~T} \_\mathbf{C l}$ in DMF. The presence of $4+, 3+$, and $2+$ peaks indicates the phase is a tetrahedron.
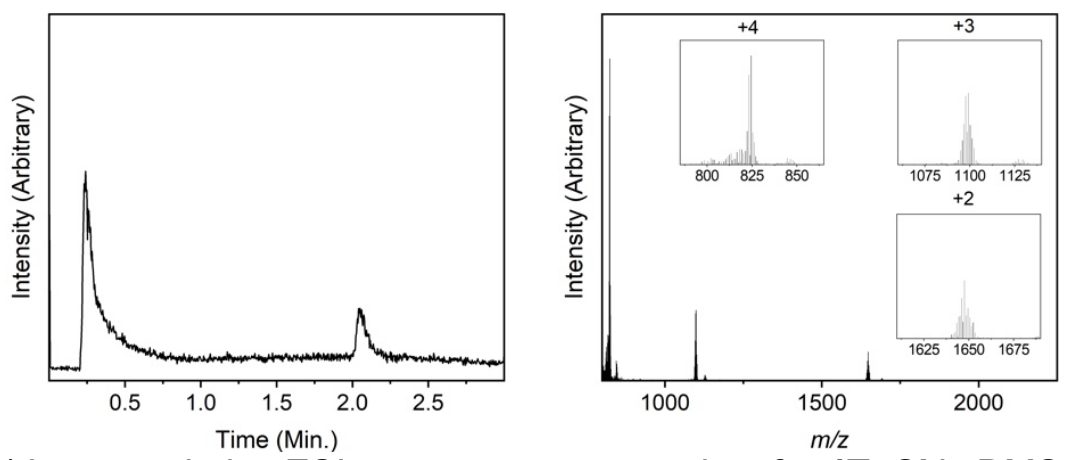

Figure S70. (Left) Low-resolution ESI-mass spectrometry data for 4T_CI in DMSO. The presence of one peak indicates a singular phase, in this case, a tetrahedron. (Right) Low-resolution ESImass spectrum of $4 T_{-} \mathbf{C l}$ in DMSO. The presence of $4+, 3+$, and $2+$ peaks indicates the phase is a tetrahedron. 


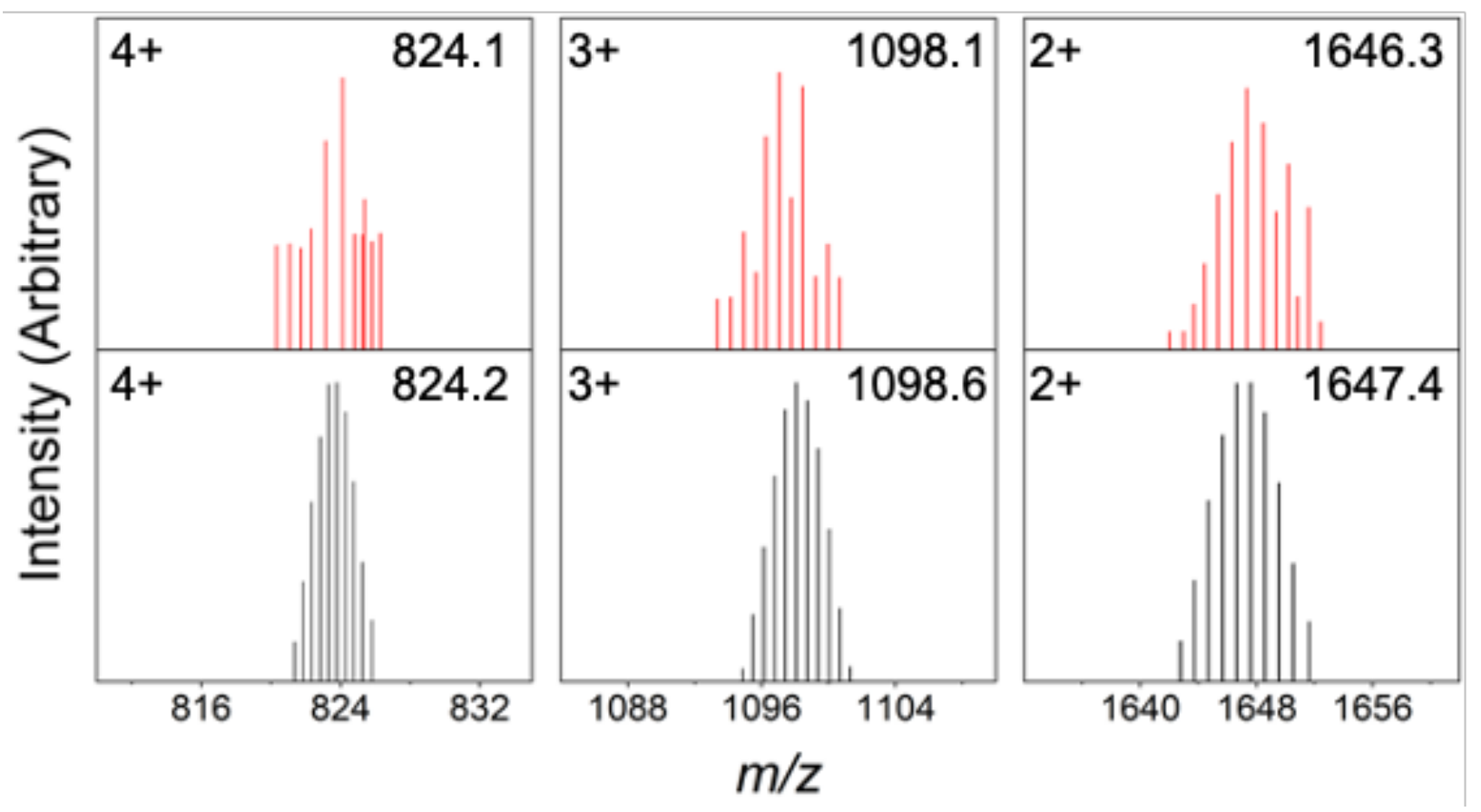

Figure S71 - Simulated (black) vs experimental (red) mass spectrum of 4T_Cl in MeOH.

Species of 4T_Cl present in the mass spectrometry experiments.

4+: $\left[\mathrm{Zr}_{12}\left(\mu_{3}-\mathrm{O}\right)_{4}\left(\mu_{2}-\mathrm{OH}\right)_{12}(\mathrm{Cp})_{12}\left(\mathrm{Me}_{2}-\mathrm{bdc}\right)_{6}\right]^{4+}$

3+: $\left[\mathrm{Zr}_{12}\left(\mu_{3}-\mathrm{O}\right)_{4}\left(\mu_{2}-\mathrm{OH}\right)_{11}\left(\mu_{2}-\mathrm{O}\right)_{1}(\mathrm{Cp})_{12}\left(\mathrm{Me}_{2}-\text { bdc }\right)_{6}\right]^{3+}$

2+: $\left[\mathrm{Zr}_{12}\left(\mu_{3}-\mathrm{O}\right)_{4}\left(\mu_{2}-\mathrm{OH}\right)_{10}\left(\mu_{2}-\mathrm{O}\right)_{2}(\mathrm{Cp})_{12}\left(\mathrm{Me}_{2}-\mathrm{bdc}\right)_{6}\right]^{2+}$ 

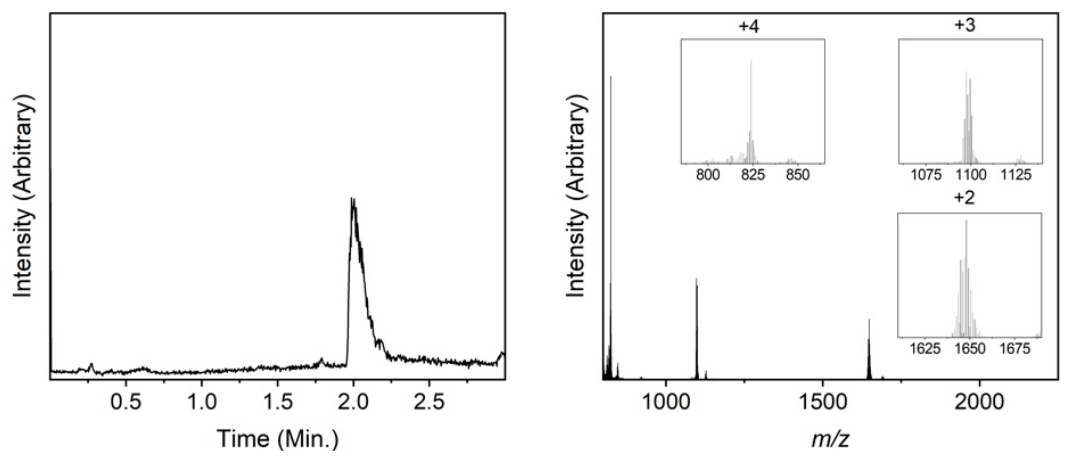

Figure S72. (Left) Low-resolution ESI-mass spectrometry data for 4T_OTf in MeOH. The presence of one peak indicates a singular phase, in this case, a tetrahedron. (Right) Lowresolution ESI-mass spectrum of $4 \mathrm{~T} \_$OTf in $\mathrm{MeOH}$. The presence of a $4+, 3+$, and $2+$ peak indicates the phase is a tetrahedron.
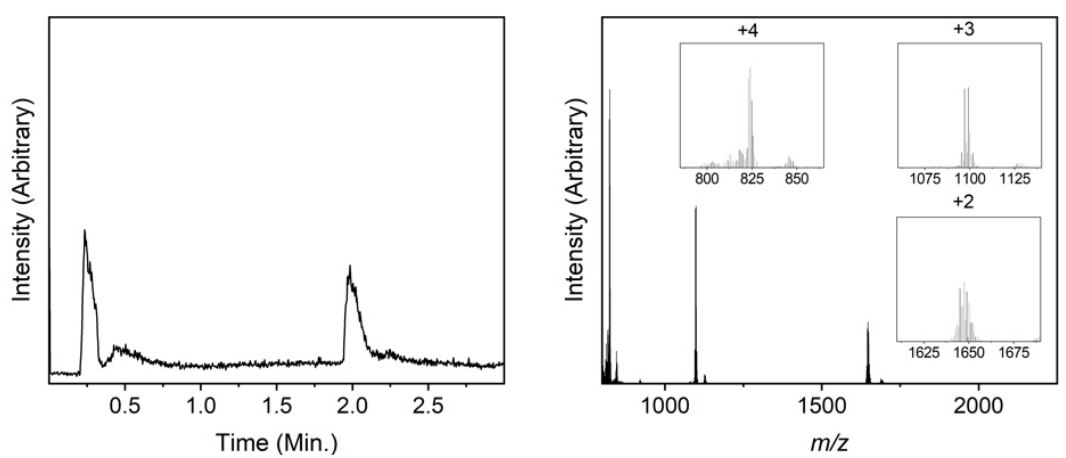

Figure S73. (Left) Low-resolution ESI-mass spectrometry data for 4T_OTf in DMF. The presence of one peak indicates a singular phase, in this case, a tetrahedron. (Right) Low-resolution ESImass spectrum of 4T_OTf in DMF. The presence of a $4+, 3+$, and $2+$ peak indicates the phase is a tetrahedron.
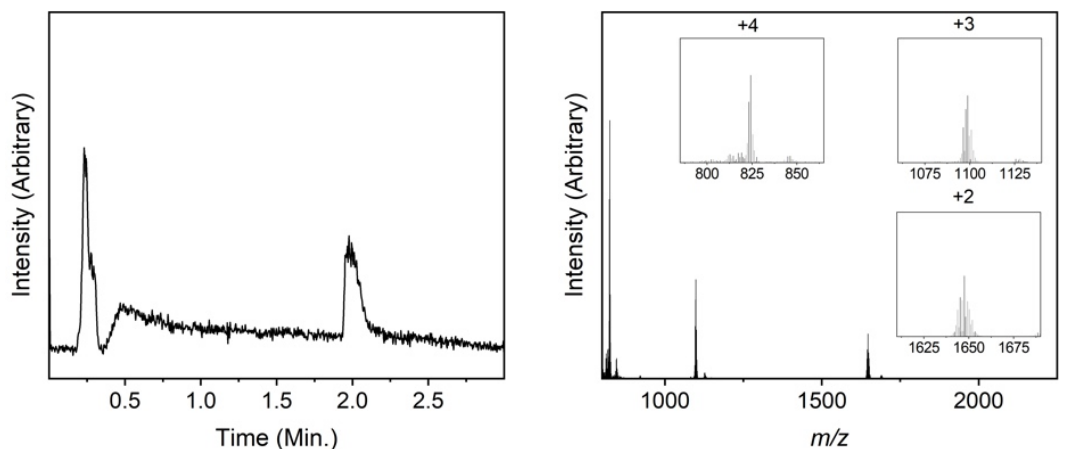

Figure S74. (Left) Low-resolution ESI-mass spectrometry data for 4T_OTf in DMSO. The presence of one peak indicates a singular phase, in this case, a tetrahedron. (Right) Lowresolution ESI-mass spectrum of 4 T_OTf in DMSO. The presence of a $4+, 3+$, and $2+$ peak indicates the phase is a tetrahedron. 


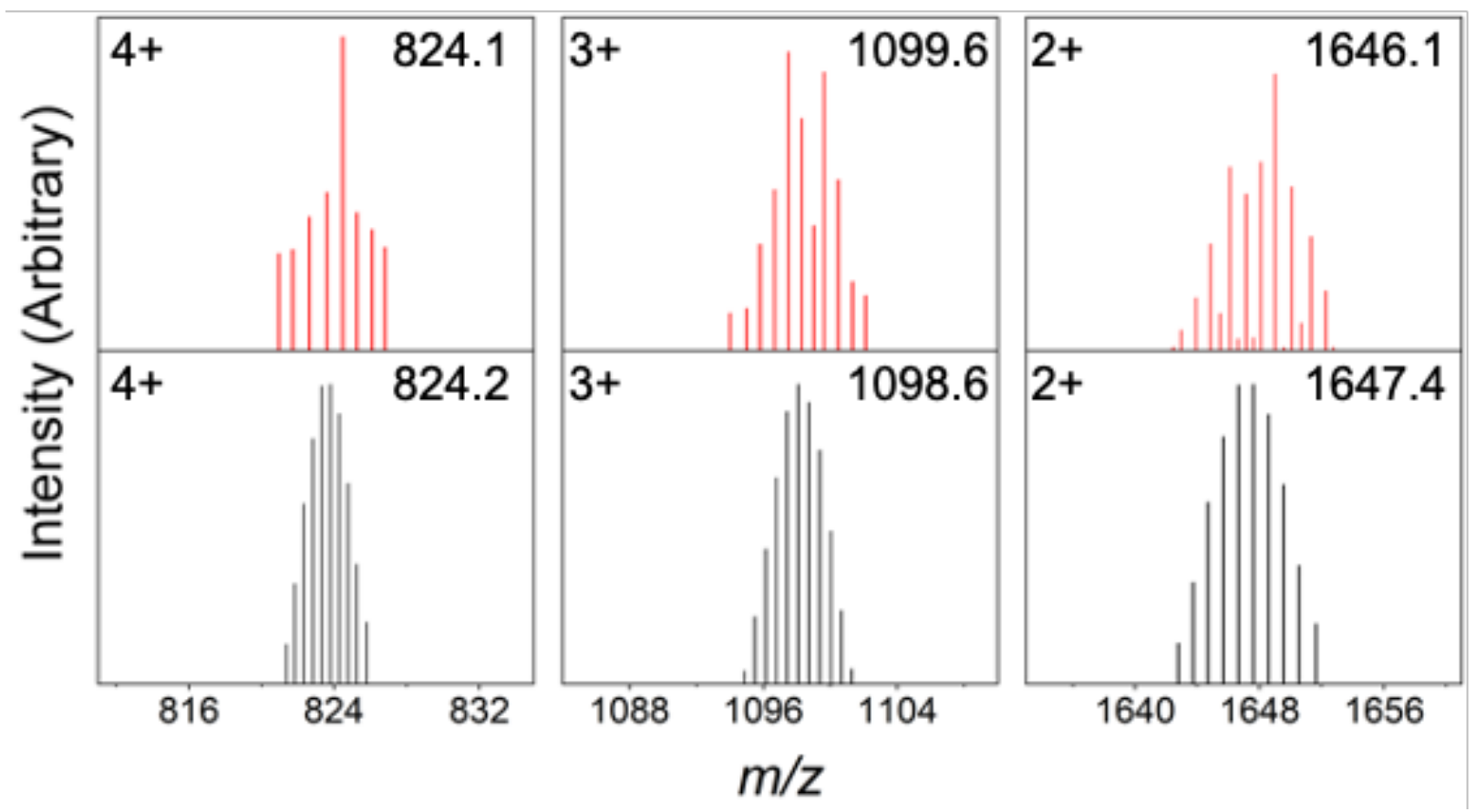

Figure S75 - Simulated (black) vs experimental (red) mass spectrum of 4T_OTf in MeOH.

Species of $\mathbf{4 T}$ _OTf present in the mass spectrometry experiments.

4+: $\left[\mathrm{Zr}_{12}\left(\mu_{3}-\mathrm{O}\right)_{4}\left(\mu_{2}-\mathrm{OH}\right)_{12}(\mathrm{Cp})_{12}\left(\mathrm{Me}_{2}-\mathrm{bdc}\right)_{6}\right]^{4+}$

3+: $\left[\mathrm{Zr}_{12}\left(\mu_{3}-\mathrm{O}\right)_{4}\left(\mu_{2}-\mathrm{OH}\right)_{11}\left(\mu_{2}-\mathrm{O}\right)_{1}(\mathrm{Cp})_{12}\left(\mathrm{Me}_{2}-\mathrm{bdc}\right)_{6}\right]^{3+}$

$2+:\left[\mathrm{Zr}_{12}\left(\mu_{3}-\mathrm{O}\right)_{4}\left(\mu_{2}-\mathrm{OH}\right)_{10}\left(\mu_{2}-\mathrm{O}\right)_{2}(\mathrm{Cp})_{12}\left(\mathrm{Me}_{2}-\mathrm{bdc}\right)_{6}\right]^{2+}$ 

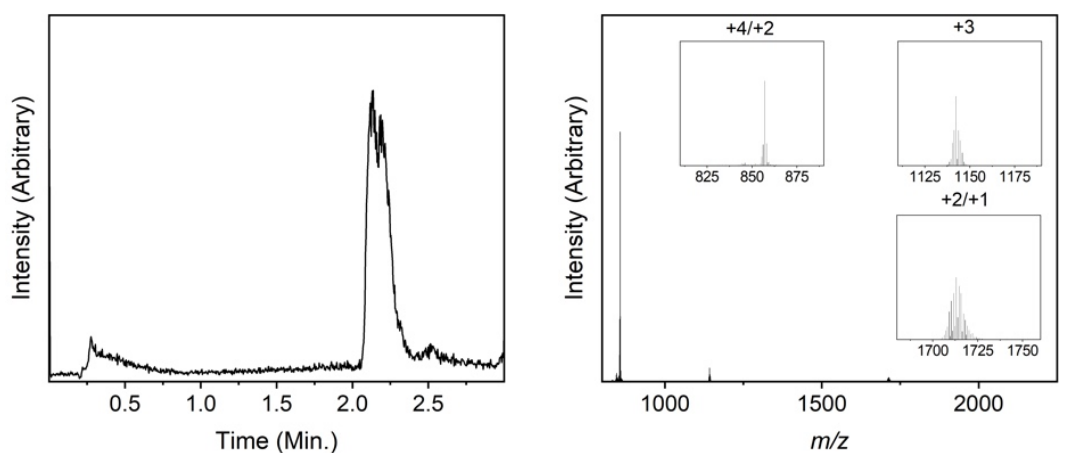

Figure S76. (Left) Low-resolution ESI-mass spectrometry data for 5T/C in $\mathrm{MeOH}$. The presence of two peaks indicates a mixture of the cigar and tetrahedron phases. (Right) Low-resolution ESImass spectrum of $\mathbf{5 T / C}$ in $\mathrm{MeOH}$. The presence of two peaks in the raw data indicates the structure exists as both a tetrahedron and a cigar.
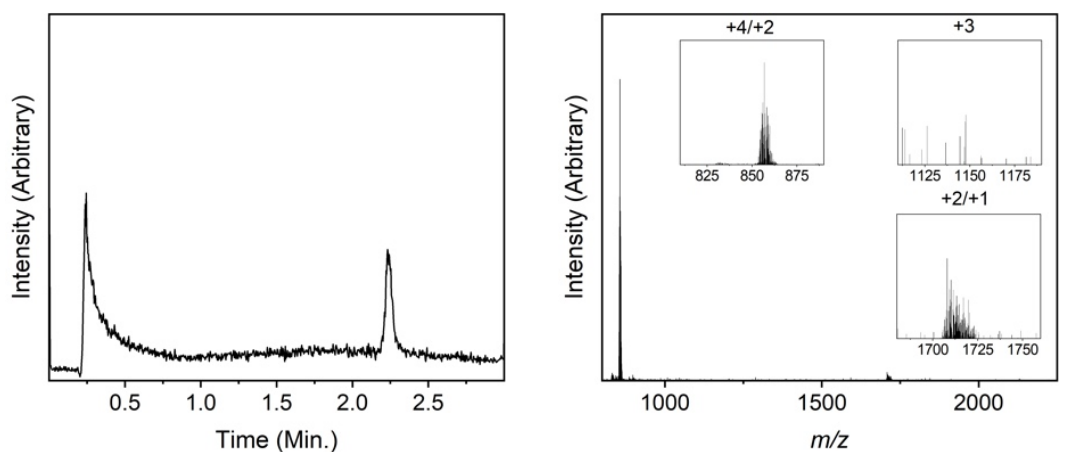

Figure S77. (Left) Low-resolution ESI-mass spectrometry data for 5T/C in DMF. The presence of one peak typically indicates a singular phase, in this case crystallographically both phases have been isolated. (Right) Low-resolution ESI-mass spectrum of 5T/C in DMF. The 4+ and 2+ have the same $\mathrm{m} / \mathrm{z}$ value for the tetrahedron and cigar respectively, $3+$ which is only observed for the tetrahedron, and the 2+ and 1+ peaks also have the same $\mathrm{m} / \mathrm{z}$ value for the tetrahedron and cigar respectively.
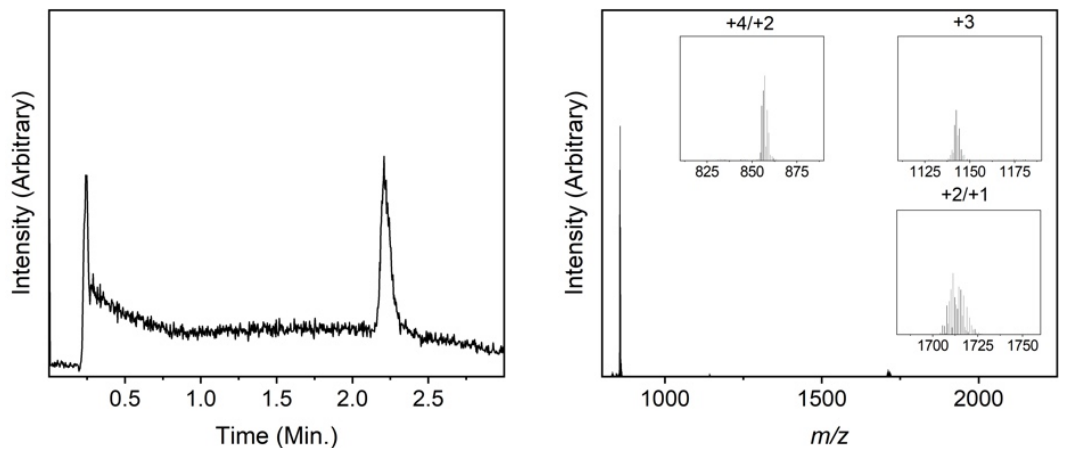

Figure S78. (Left) Low-resolution ESI-mass spectrometry data for 5T/C in DMSO. The presence of one peak typically indicates a singular phase, in this case crystallographically both phases have been isolated. (Right) Low-resolution ESI-mass spectrum of 5T/C in DMSO. The 4+ and 2+ have the same $\mathrm{m} / \mathrm{z}$ value for the tetrahedron and cigar respectively, $3+$ which is only observed for the tetrahedron, and the $2+$ and $1+$ peaks also have the same $\mathrm{m} / \mathrm{z}$ value for the tetrahedron and cigar respectively. 


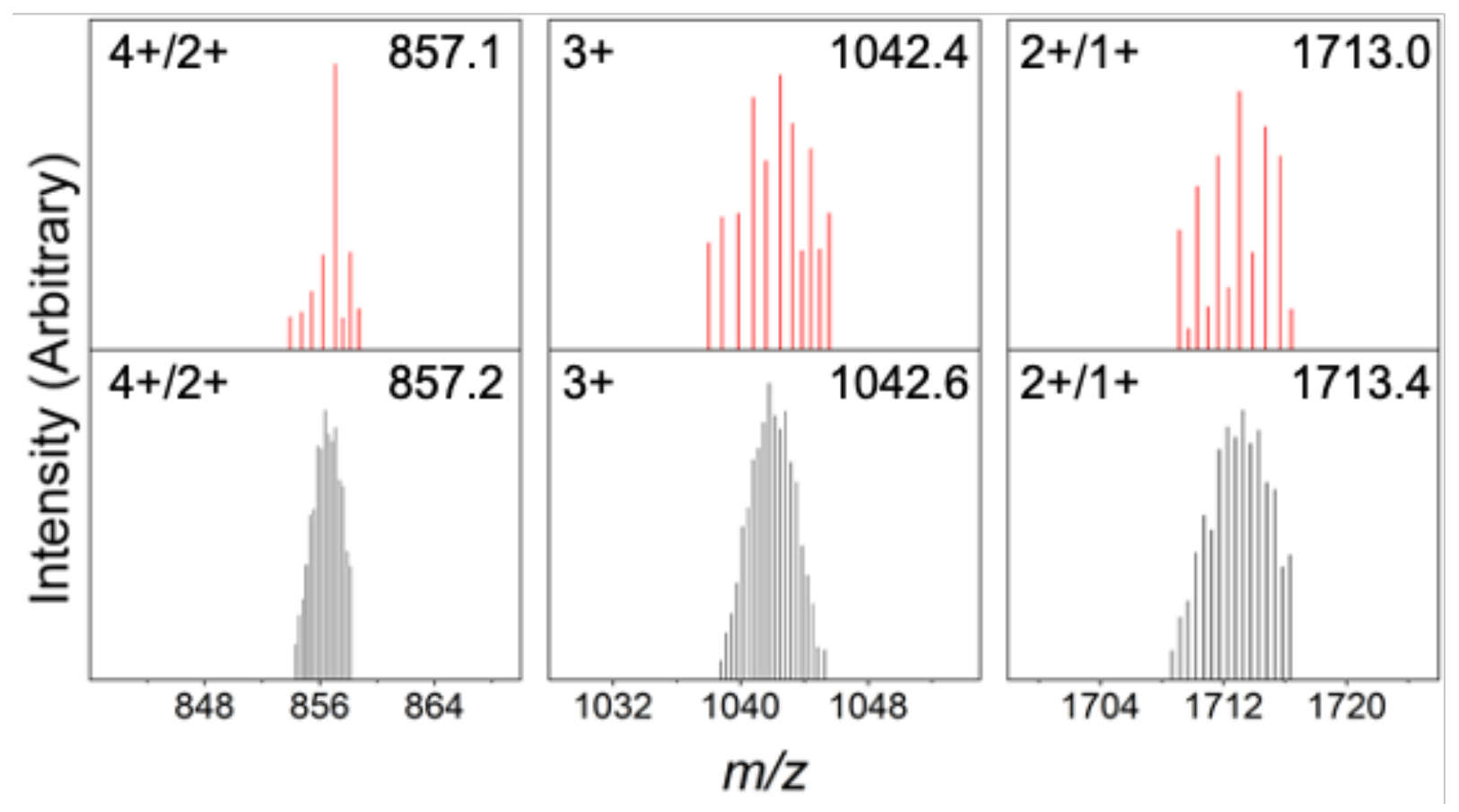

Figure S79 - Simulated (black) vs experimental (red) mass spectrum of 5T/C in MeOH.

Species of 5T/C present in the mass spectrometry experiments.

4+/2+: $\left[\mathrm{Zr}_{12}\left(\mu_{3}-\mathrm{O}\right)_{4}\left(\mu_{2}-\mathrm{OH}\right)_{12}(\mathrm{Cp})_{12}(2,6-\mathrm{ndc})_{6}\right]^{4+} /\left[\mathrm{Zr}_{6}\left(\mu_{3}-\mathrm{O}\right)_{2}\left(\mu_{2}-\mathrm{OH}\right)_{6}(\mathrm{Cp})_{6}(2,6-\mathrm{ndc})_{3}\right]^{2+}$

$$
3+:\left[\mathrm{Zr}_{12}\left(\mu_{3}-\mathrm{O}\right)_{4}\left(\mu_{2}-\mathrm{OH}\right)_{11}\left(\mu_{2}-\mathrm{O}\right)_{1}(\mathrm{Cp})_{12}(2,6-\mathrm{ndc})_{6}\right]^{3+}
$$

2+/1+: $\left[\mathrm{Zr}_{12}\left(\mu_{3}-\mathrm{O}\right)_{4}\left(\mu_{2}-\mathrm{OH}\right)_{10}\left(\mu_{2}-\mathrm{O}\right)_{2}(\mathrm{Cp})_{12}(2,6-\mathrm{ndc})_{6}\right]^{2+} /$

$\left[\mathrm{Zr}_{6}\left(\mu_{3}-\mathrm{O}\right)_{2}\left(\mu_{2}-\mathrm{OH}\right)_{5}\left(\mu_{2}-\mathrm{O}\right)_{1}(\mathrm{Cp})_{6}(2,6-\mathrm{ndc})_{3}\right]^{1+}$ 

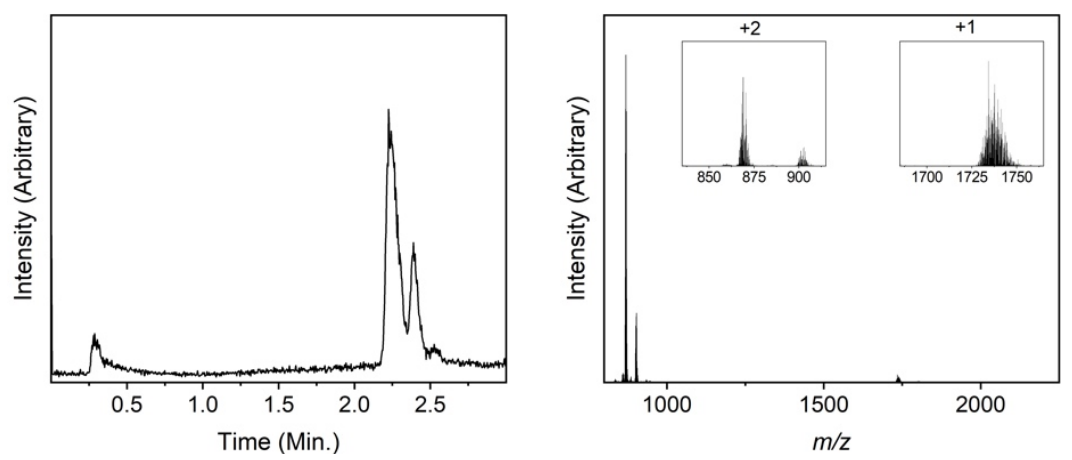

Figure S80. (Left) Low-resolution ESI-mass spectrometry data for $\mathbf{6 C}$ in $\mathrm{MeOH}$. Despite the presence of two peaks there is only a cigar phase. Upon integration of the peak between 2.3 and 2.5 minutes it was clear that the peak was the result of background and thus discarded. (Right) Low-resolution ESI-mass spectrum of $6 \mathrm{C}$ in $\mathrm{MeOH}$. The presence of only a $2+$ and a $1+$ peak indicates the phase is a cigar.
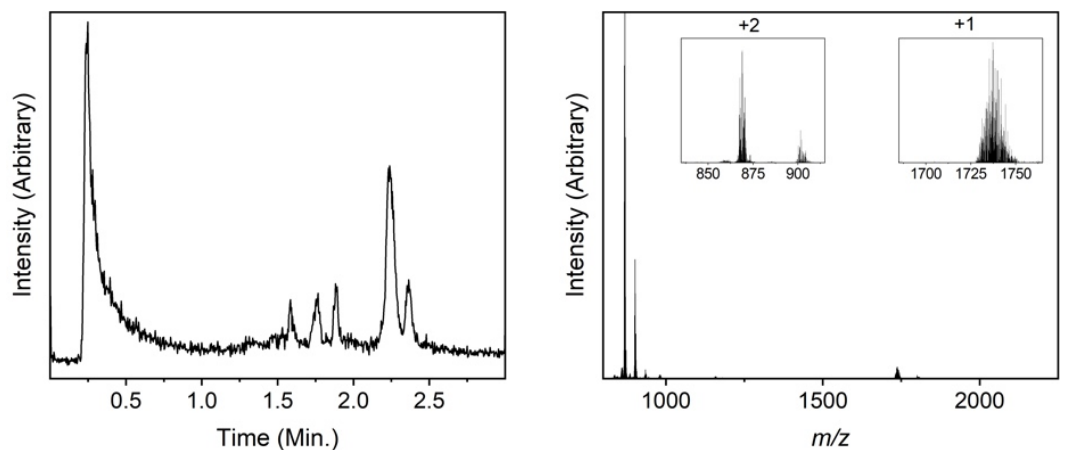

Figure S81. (Left) Low-resolution ESI-mass spectrometry data for 6C in DMA. Upon integration of the peaks between 1.5 and 2.0 minutes, as well as between 2.3 and 2.5 minutes it was clear that the peaks were the result of background and thus discarded. (Right) Low-resolution ESImass spectrum of $6 \mathrm{C}$ in DMA. The presence of only a $2+$ and a 1+ peak indicates the phase is a cigar.
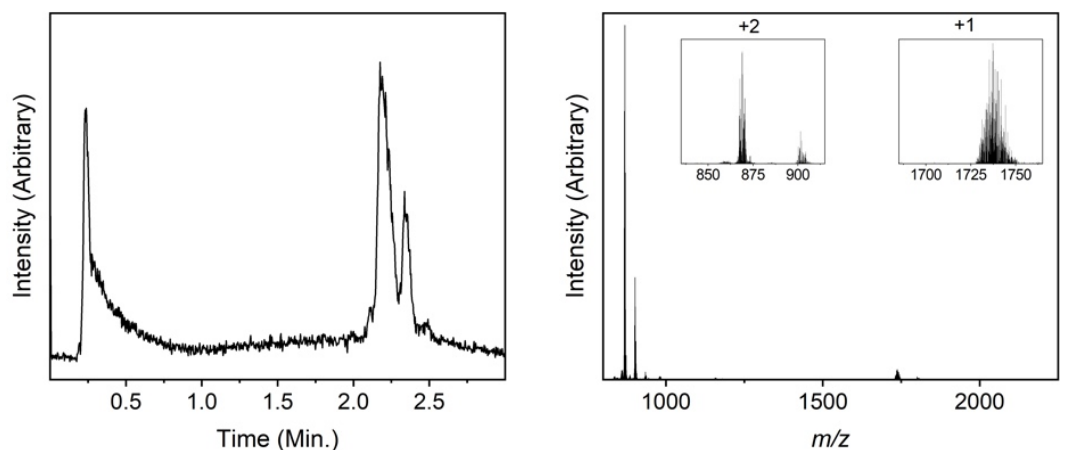

Figure S82. (Left) Low-resolution ESI-mass spectrometry data for 6C in DMSO. Despite the presence of two peaks there is only a cigar phase. Upon integration of the peak between 2.3 and 2.5 minutes it was clear that the peak was the result of background and thus discarded. (Right) Low-resolution ESI-mass spectrum of $6 \mathrm{C}$ in DMSO. The presence of one peak indicates a singular phase, in this case, a cigar. 

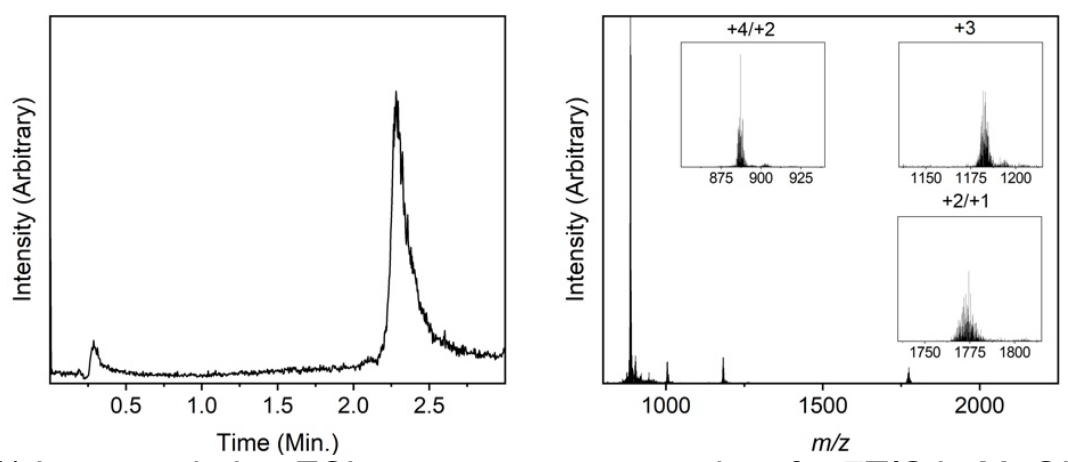

Figure S83. (Left) Low-resolution ESI-mass spectrometry data for 7T/C in $\mathrm{MeOH}$. The presence of two peaks indicates a mixture of the cigar and tetrahedron phases. (Right) Low-resolution ESImass spectrum of $7 \mathrm{~T} / \mathrm{C}$ in $\mathrm{MeOH}$. The presence of two peaks in the raw data indicates the structure exists as both a tetrahedron and a cigar as detailed in figure S56 with the 2T/C. The 4+ and $2+$ have the same $\mathrm{m} / \mathrm{z}$ value for the tetrahedron and cigar respectively, $3+$ which is only observed for the tetrahedron, and the $2+$ and $1+$ peaks also have the same $\mathrm{m} / \mathrm{z}$ value for the tetrahedron and cigar respectively.
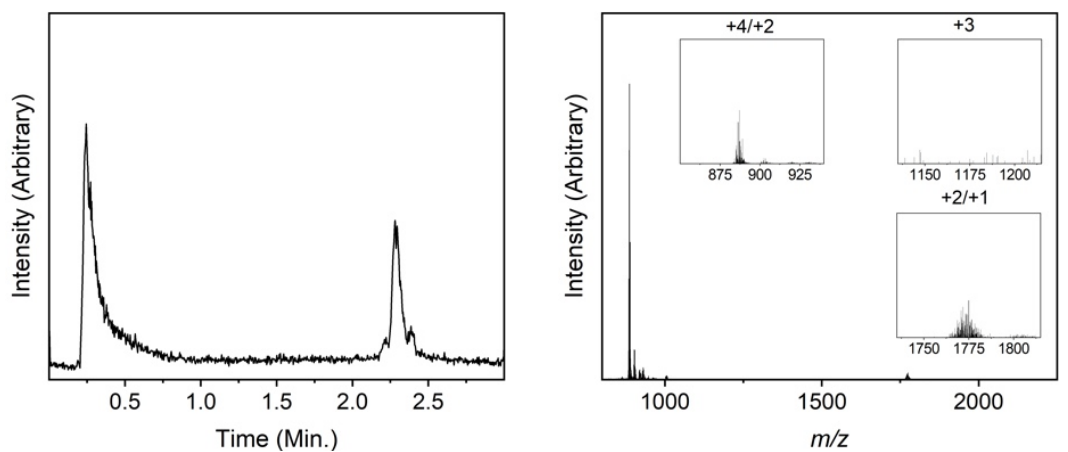

Figure S84. (Left) Low-resolution ESI-mass spectrometry data for 7T/C in DMA. The presence of two peaks indicates a mixture of the cigar and tetrahedron phases. (Right) Low-resolution ESImass spectrum of 7T/C in DMA. The presence of multiple peaks in the raw data indicates the structure exists as both a tetrahedron and a cigar.
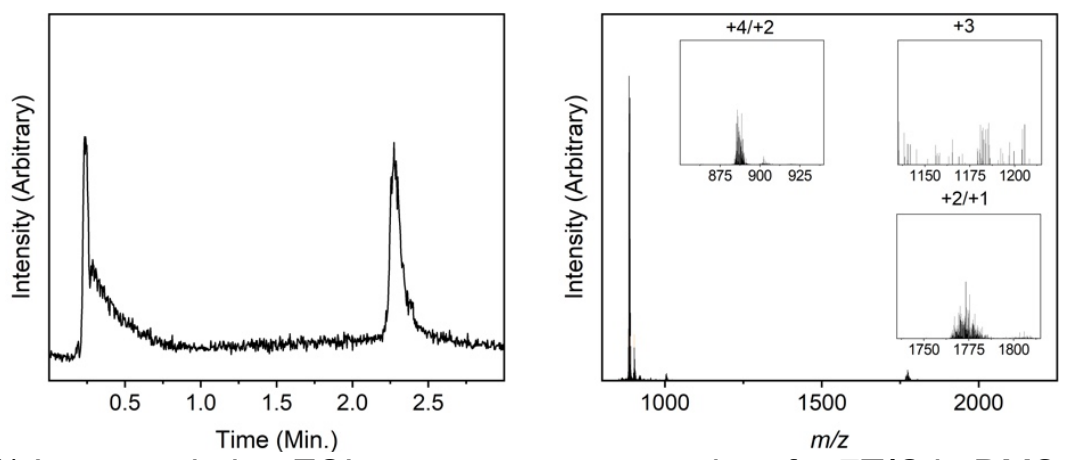

Figure S85. (Left) Low-resolution ESI-mass spectrometry data for 7T/C in DMSO. The presence of two peaks indicates a mixture of the cigar and tetrahedron phases. (Right) Low-resolution ESImass spectrum of 7T/C in DMSO. The presence of two peaks in the raw data indicates the structure exists as both a tetrahedron and a cigar as detailed in figure S56 with the 2T/C. The 4+ and $2+$ have the same $\mathrm{m} / \mathrm{z}$ value for the tetrahedron and cigar respectively, $3+$ which is only observed for the tetrahedron, and the $2+$ and $1+$ peaks also have the same $\mathrm{m} / \mathrm{z}$ value for the tetrahedron and cigar respectively. 

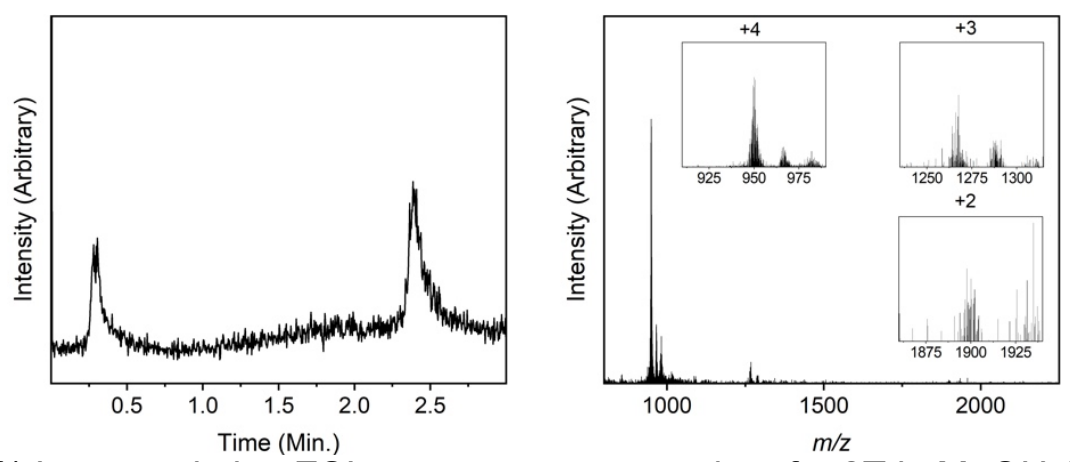

Figure S86. (Left) Low-resolution ESI-mass spectrometry data for 8T in MeOH. The presence of one peak indicates a singular phase, in this case, a tetrahedron. (Right) Low-resolution ESI-mass spectrum of $\mathbf{8 T}$ in $\mathrm{MeOH}$. The presence of a $4+, 3+$, and $2+$ peak indicates the phase is a tetrahedron.
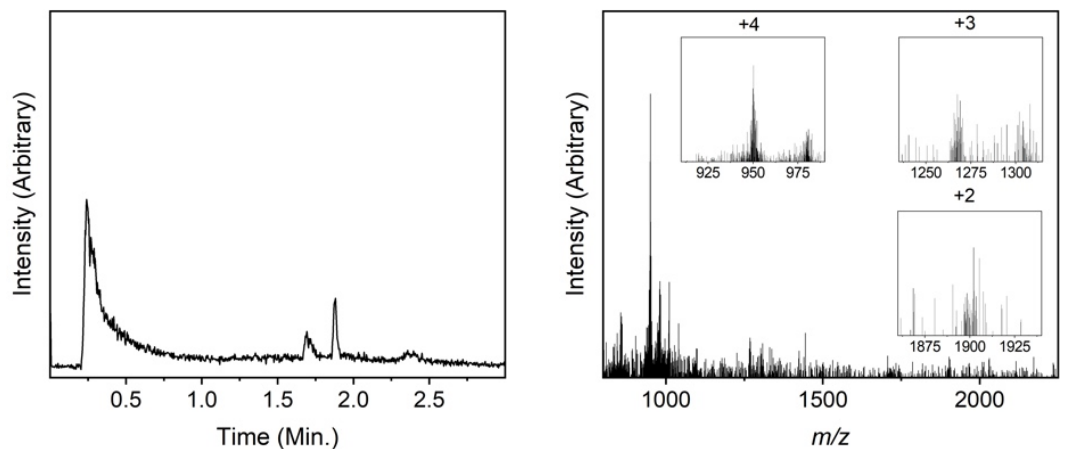

Figure S87. (Left) Low-resolution ESI-mass spectrometry data for 8T in DMA. Despite the presence of two peaks there is only a tetrahedron phase. (Right) Low-resolution ESI-mass spectrum of $\mathbf{8 T}$ in DMA. The presence of a $4+, 3+$, and $2+$ peak indicates the phase is a tetrahedron.
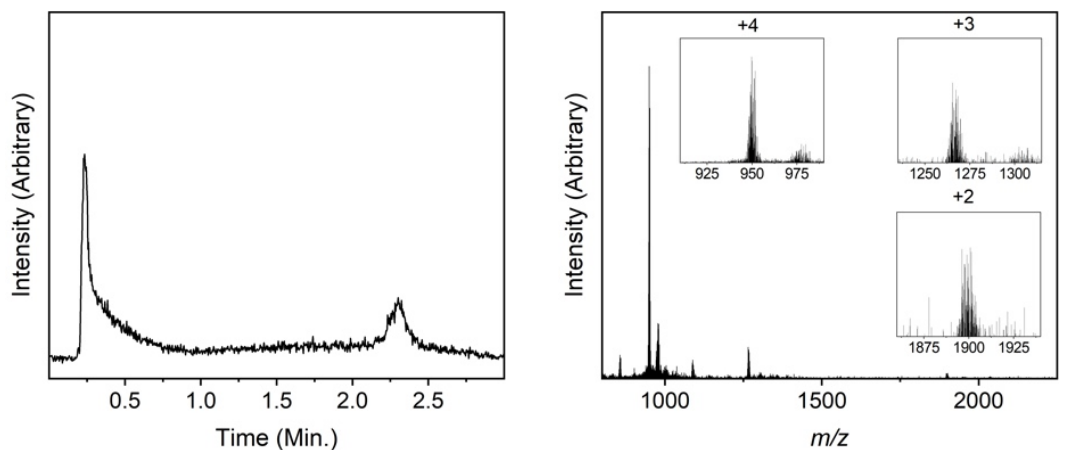

Figure S88. (Left) Low-resolution ESI-mass spectrometry data for 8T in DMSO. The presence of one peak indicates a singular phase, in this case, a tetrahedron. (Right) Low-resolution ESI-mass spectrum of $\mathbf{8 T}$ in DMSO. The presence of a $4+, 3+$, and $2+$ peak indicates the phase is a tetrahedron. 

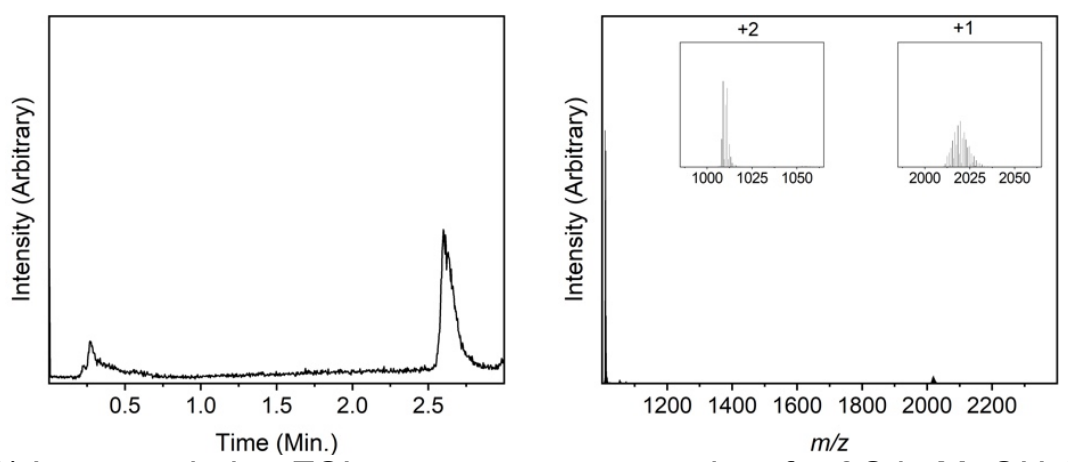

Figure S89. (Left) Low-resolution ESI-mass spectrometry data for 9C in $\mathrm{MeOH}$. The presence of one peak indicates a singular phase, in this case, a cigar. (Right) Low-resolution ESI-mass spectrum of $9 \mathrm{C}$ in $\mathrm{MeOH}$. The presence of only a $2+$ and a $1+$ peak indicates the phase is a cigar.
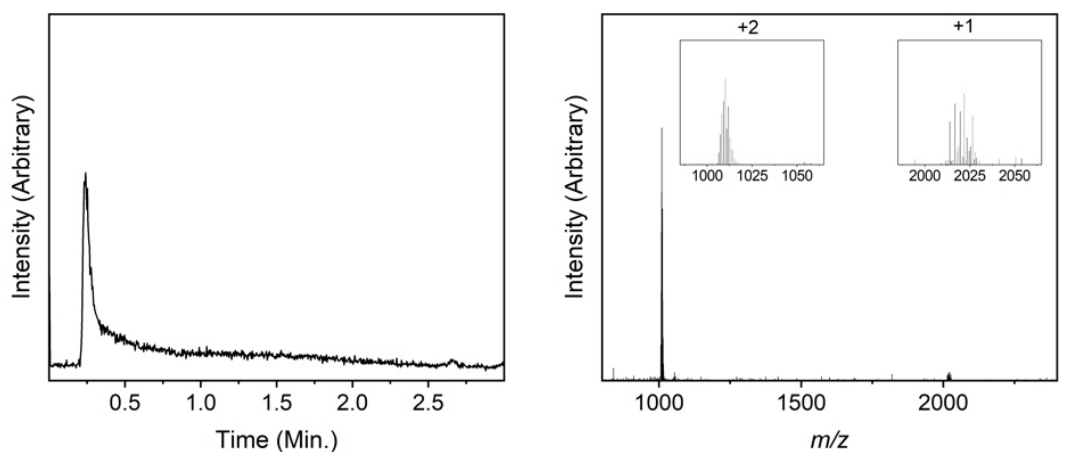

Figure S90. (Left) Low-resolution ESI-mass spectrometry data for 9C in DMF. The presence of one small peak at 2.65 minutes indicates a singular phase, in this case, a cigar. (Right) Lowresolution ESI-mass spectrum of $9 \mathrm{C}$ in DMF. The presence of only a $2+$ and a $1+$ peak indicates the phase is a cigar.
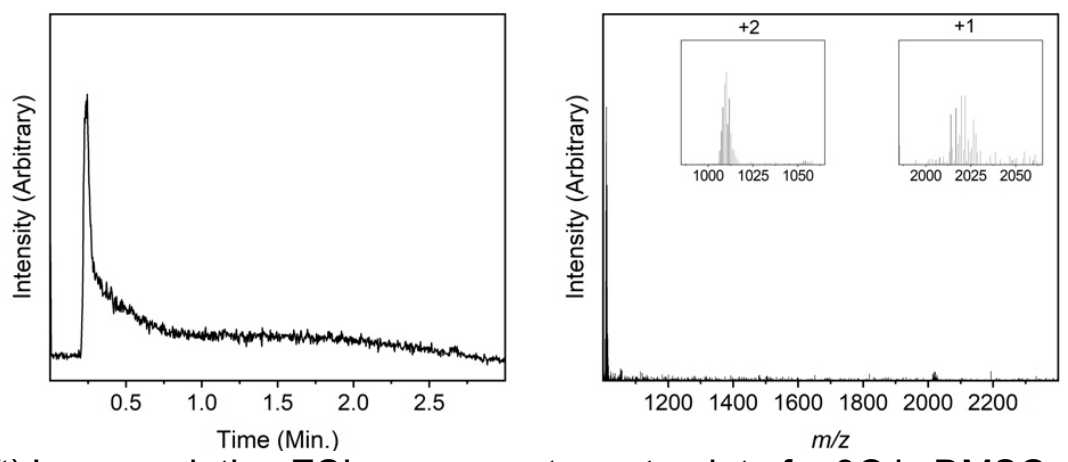

Figure S91. (Left) Low-resolution ESI-mass spectrometry data for 9C in DMSO. The presence of one small peak at 2.65 minutes indicates a singular phase, in this case, a cigar. (Right) Lowresolution ESI-mass spectrum of $9 \mathrm{C}$ in DMSO. The presence of only a $2+$ and a $1+$ peak indicates the phase is a cigar. 


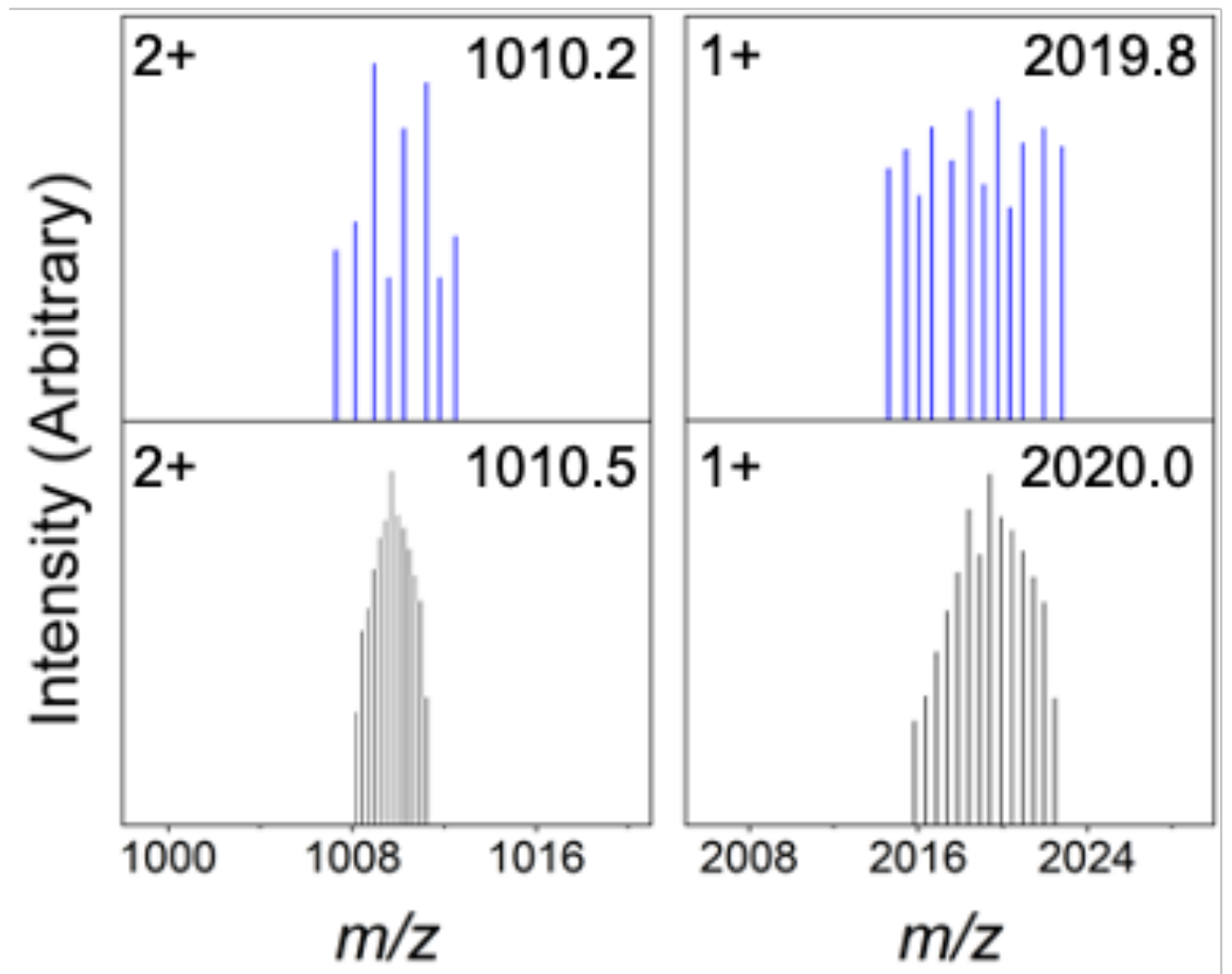

Figure S92 - Simulated (black) vs experimental (blue) mass spectrum of $9 \mathbf{C}$ in $\mathrm{MeOH}$.

Species of $\mathbf{9 C}$ present in the mass spectrometry experiments.

$$
\begin{gathered}
2+:\left[\mathrm{Zr}_{6}\left(\mu_{3}-\mathrm{O}\right)_{2}\left(\mu_{2}-\mathrm{OH}\right)_{6}(\mathrm{Cp})_{6}(\mathrm{tpdc})_{3}\right]^{2+} \\
1+:\left[\mathrm{Zr}_{6}\left(\mu_{3}-\mathrm{O}\right)_{2}\left(\mu_{2}-\mathrm{OH}\right)_{5}\left(\mu_{2}-\mathrm{O}\right)_{1}(\mathrm{Cp})_{6}(\mathrm{tpdc})_{3}\right]^{1+}
\end{gathered}
$$



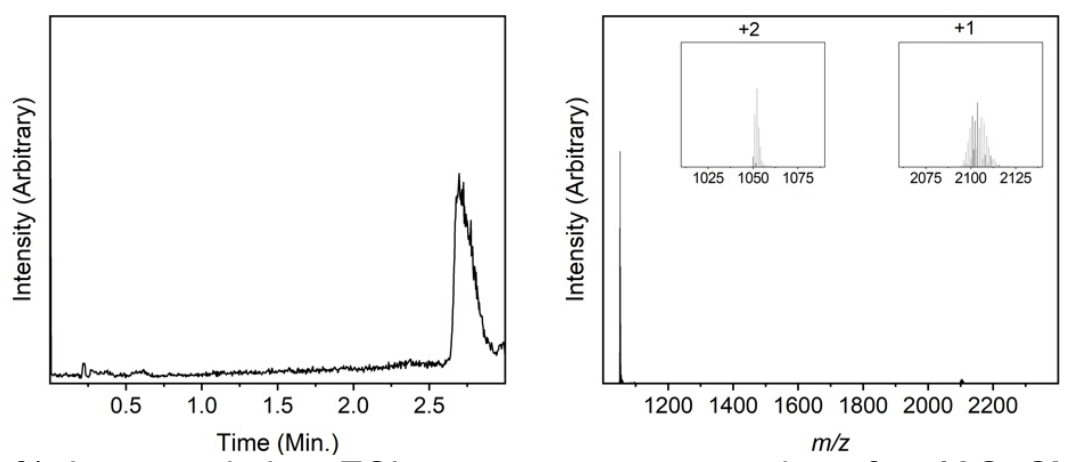

Figure S93. (Left) Low-resolution ESI-mass spectrometry data for $10 \mathrm{C} \_\mathrm{Cl}$ in $\mathrm{MeOH}$. The presence of one peak indicates a singular phase, in this case, a cigar. (Right) Low-resolution ESImass spectrum of ${ }_{10} \mathrm{C} \_\mathrm{Cl}$ in $\mathrm{MeOH}$. The presence of only a 2+ and a 1+ peak indicates the phase is a cigar.
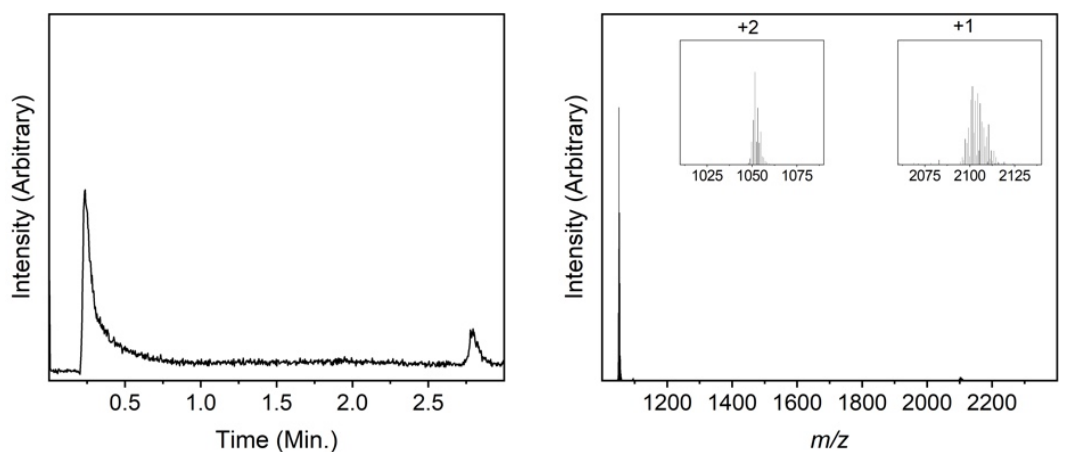

Figure S94. (Left) Low-resolution ESI-mass spectrometry data for $10 \mathrm{C}$ CI in DMF. The presence of one peak indicates a singular phase, in this case, a cigar. (Right) Low-resolution ESI-mass spectrum of 10C_Cl in DMF. The presence of only a 2+ and a 1+ peak indicates the phase is a cigar.
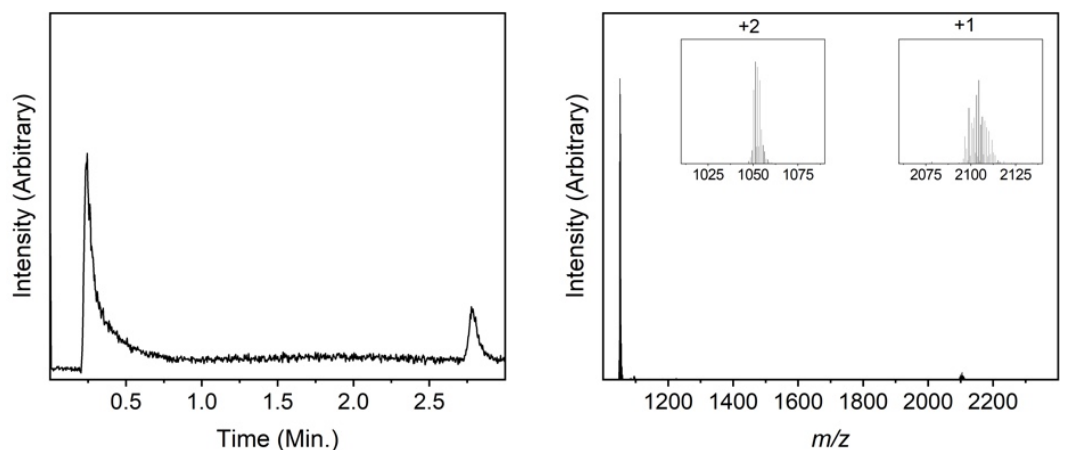

Figure S95. (Left) Low-resolution ESI-mass spectrometry data for $10 \mathrm{C} \_\mathrm{Cl}$ in DMSO. The presence of one peak indicates a singular phase, in this case, a cigar. (Right) Low-resolution ESImass spectrum of $10 \mathrm{C} \_\mathbf{C l}$ in DMSO. The presence of only a 2+ and a 1+ peak indicates the phase is a cigar. 

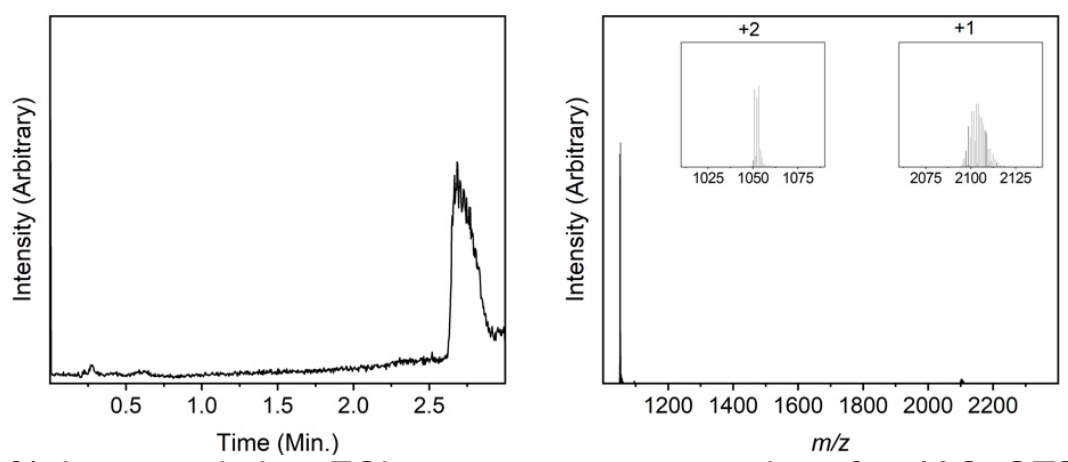

Figure S96. (Left) Low-resolution ESI-mass spectrometry data for 10C_OTf in MeOH. The presence of one peak indicates a singular phase, in this case, a cigar. (Right) Low-resolution ESImass spectrum of 10C_OTf in $\mathrm{MeOH}$. The presence of only a $2+$ and a $1+$ peak indicates the phase is a cigar.
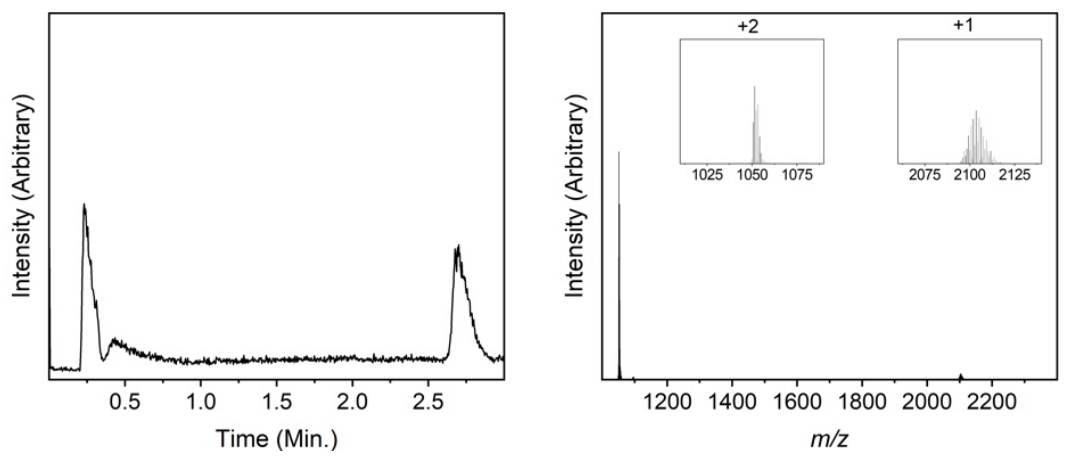

Figure S97. (Left) Low-resolution ESI-mass spectrometry data for 10C_OTf in DMF. The presence of one peak indicates a singular phase, in this case, a cigar. (Right) Low-resolution ESImass spectrum of 10C_OTf in DMF. The presence of only a 2+ and a 1+ peak indicates the phase is a cigar.
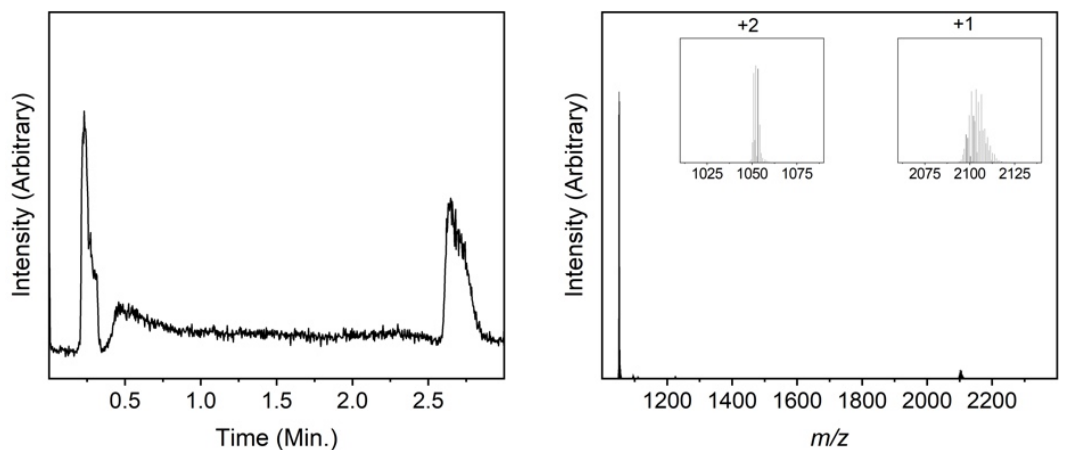

Figure S98. (Left) Low-resolution ESI-mass spectrometry data for 10C_OTf in DMSO. The presence of one peak indicates a singular phase, in this case, a cigar. (Right) Low-resolution ESImass spectrum of 10C_OTf in DMSO. The presence of only a $2+$ and a $1+$ peak indicates the phase is a cigar. 

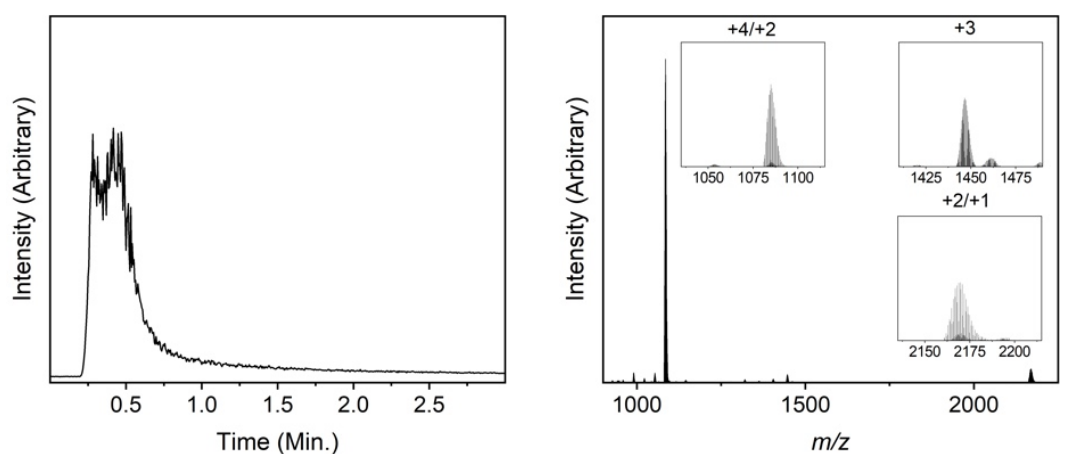

Figure S99. (Left) High-resolution ESI-mass spectrometry data for 11T/C in $\mathrm{MeOH}$. The presence of two peaks at 0.3 and 0.5 minutes indicates a mixture of the cigar and tetrahedron phases. (Right) High-resolution ESI-mass spectrum of 11T/C in $\mathrm{MeOH}$. The presence of two peaks in the raw data indicates the structure exists as both a tetrahedron and a cigar as detailed in figure S56 with the 2 T/C. The $4+$ and $2+$ have the same $\mathrm{m} / \mathrm{z}$ value for the tetrahedron and cigar respectively, $3+$ which is only observed for the tetrahedron, and the $2+$ and $1+$ peaks also have the same $\mathrm{m} / \mathrm{z}$ value for the tetrahedron and cigar respectively.
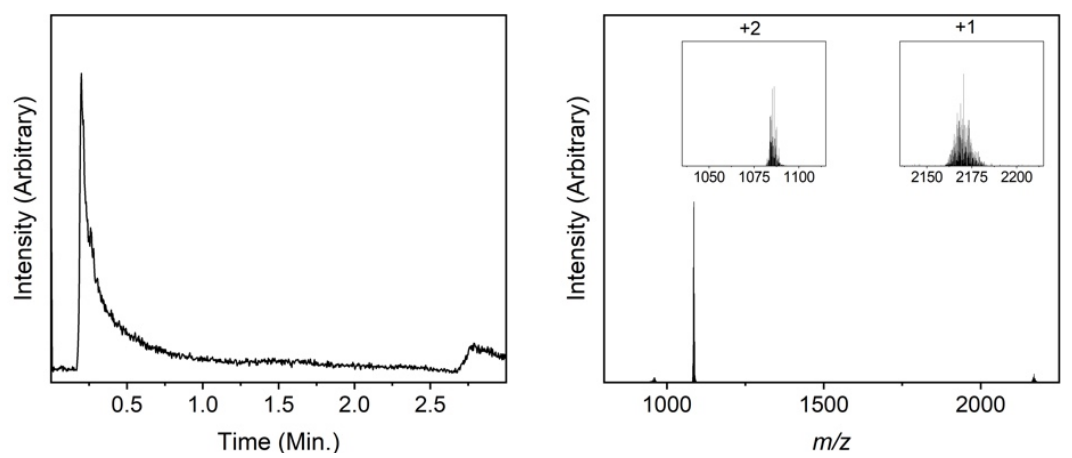

Figure S100. (Left) Low-resolution ESI-mass spectrometry data for 11T/C in DMSO. The presence of one peak indicates a singular phase, in this case, a cigar. (Right) Low-resolution ESImass spectrum of 11T/C in DMSO. The presence of only a 2+ and a 1+ peak indicates the phase is a cigar. 

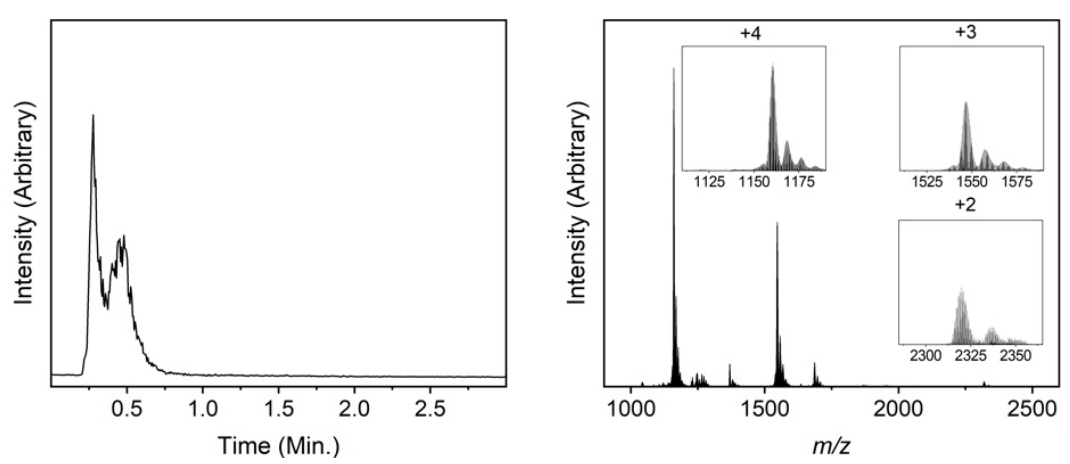

Figure S101. (Left) High-resolution ESI-mass spectrometry data for 12T in $\mathrm{MeOH}$. Despite the presence of two peaks there is only a tetrahedron phase. (Right) High-resolution ESI-mass spectrum of $12 \mathrm{~T}$ in $\mathrm{MeOH}$. The presence of a $4+, 3+$, and $2+$ peak indicates the phase is a tetrahedron.
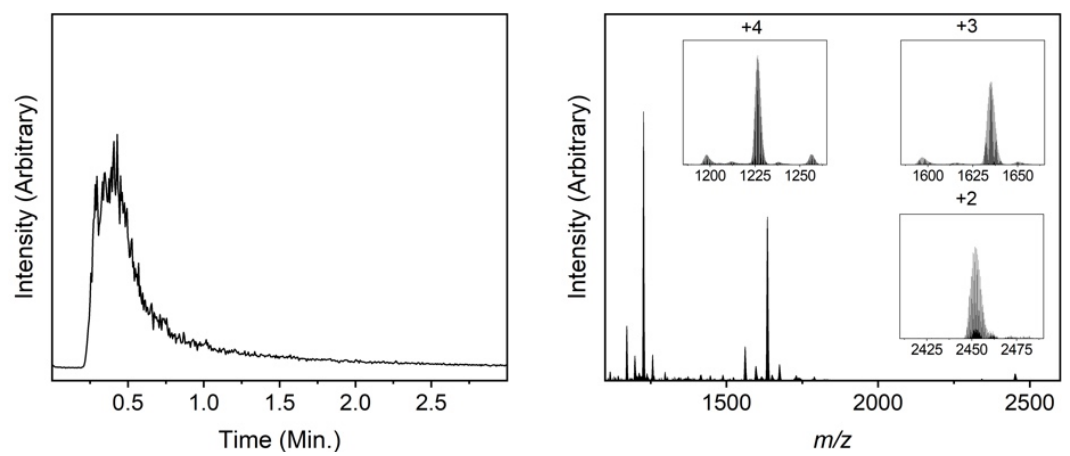

Figure S102. (Left) High-resolution ESI-mass spectrometry data for 13T in $\mathrm{MeOH}$. The presence of one peak at 0.4 minutes indicates a singular phase, in this case, a tetrahedron. (Right) Highresolution ESI-mass spectrum of $13 \mathrm{~T}$ in $\mathrm{MeOH}$. The presence of a $4+, 3+$, and $2+$ peak indicates the phase is a tetrahedron. 


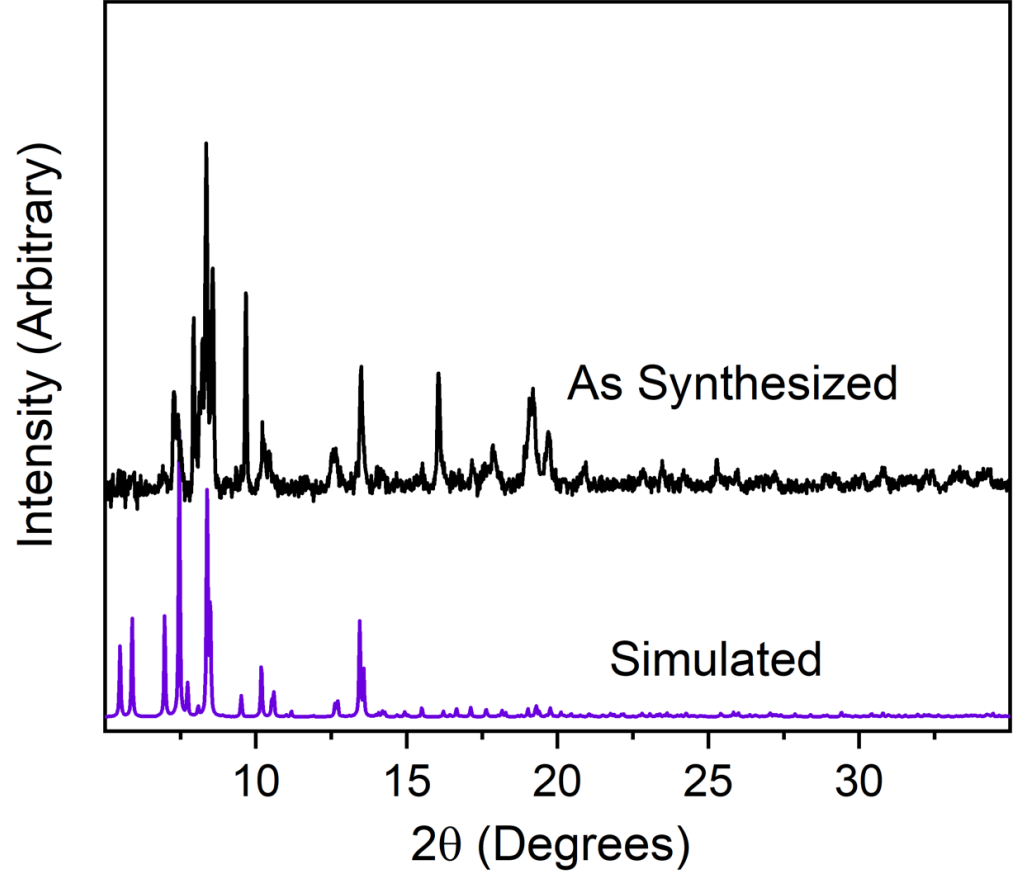

Figure S103. Powder X-Ray diffraction pattern of 1C.

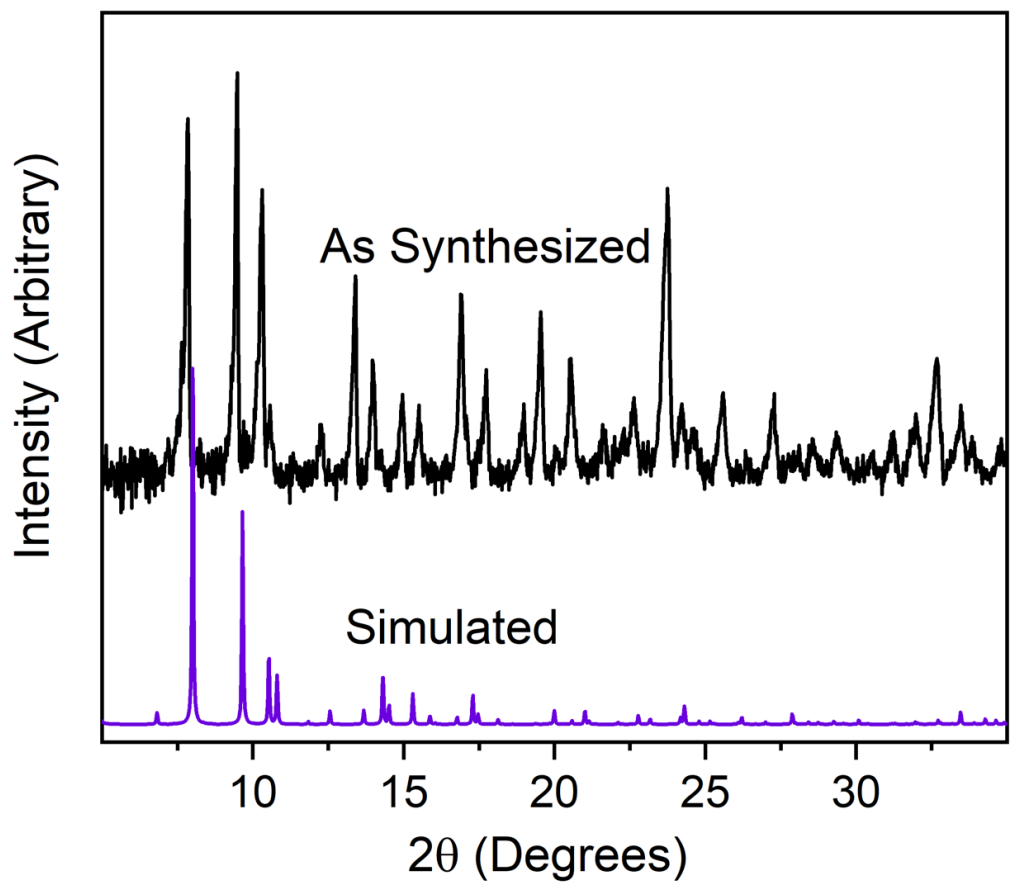

Figure S104. Powder X-Ray diffraction pattern of 4T_Cl. 


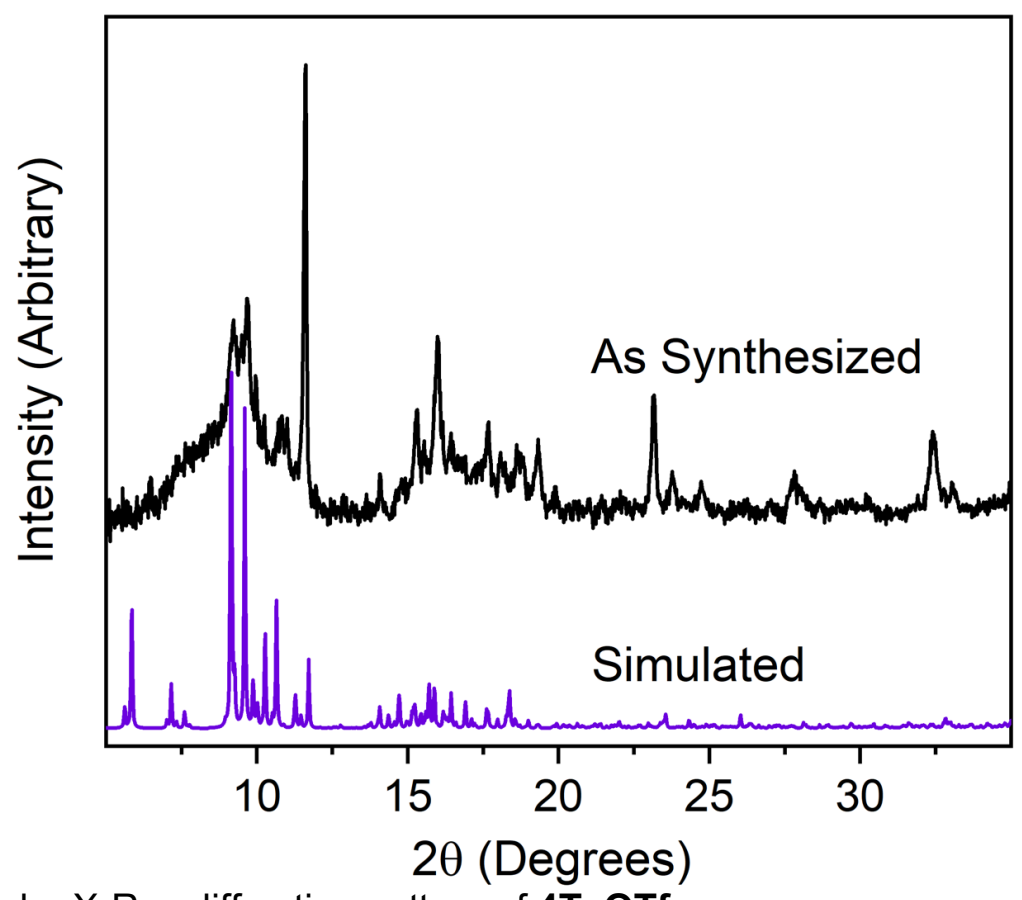

Figure S105. Powder X-Ray diffraction pattern of 4T_OTf.

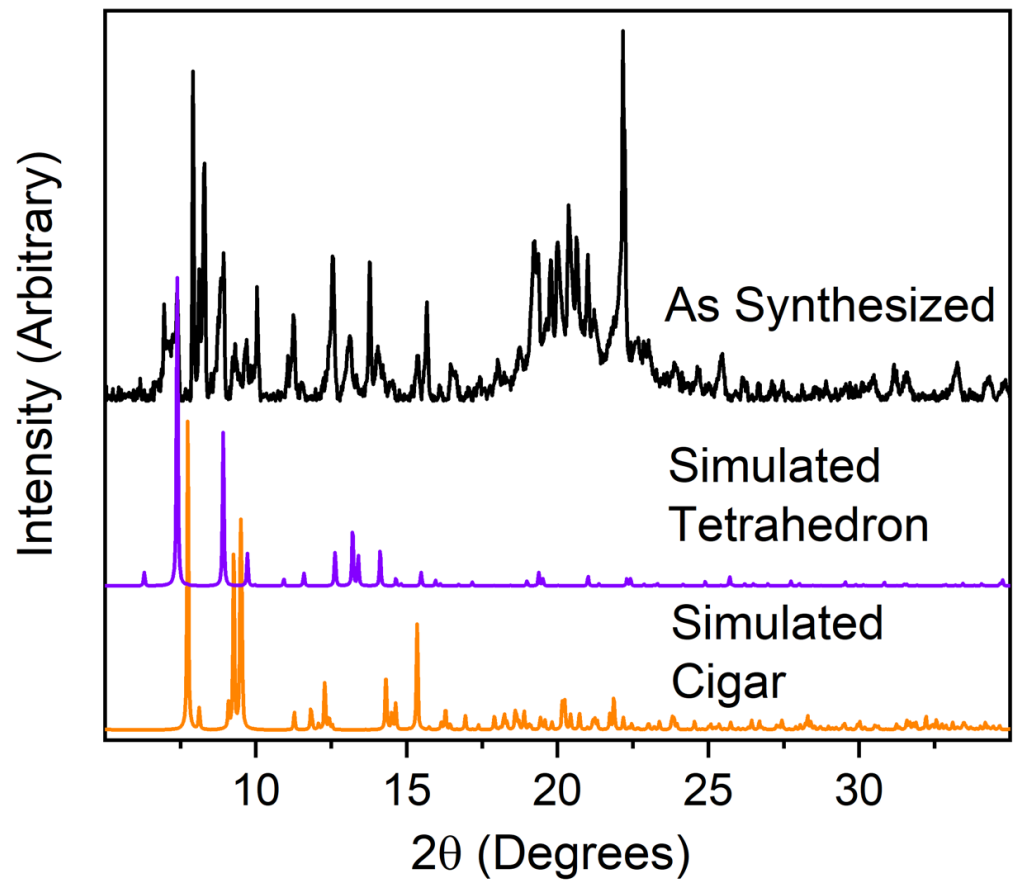

Figure S106. Powder X-Ray diffraction pattern of 5T/C. 


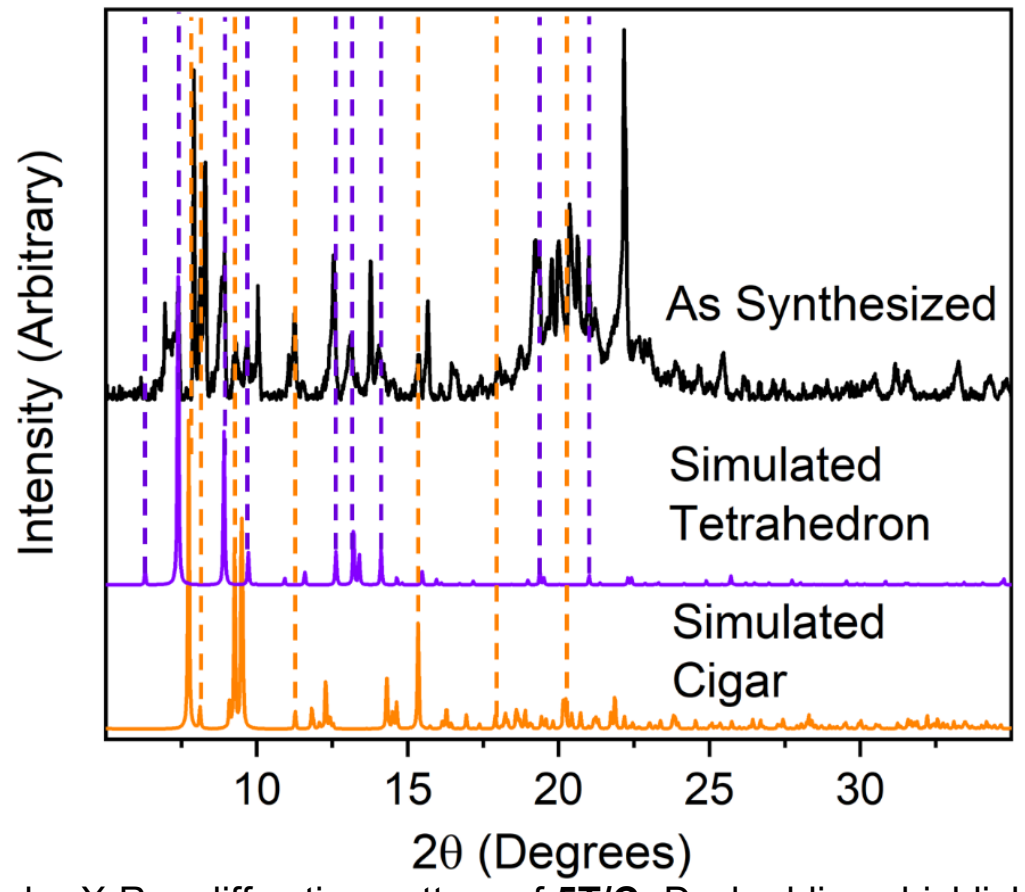

Figure S107. Powder X-Ray diffraction pattern of 5T/C. Dashed lines highlight some matching diffraction peaks from as synthesized crystalline material and simulated PXRD patterns; with as synthesized (black) on top, simulated tetrahedron (purple) in the middle, and the simulated cigar (orange) on bottom.

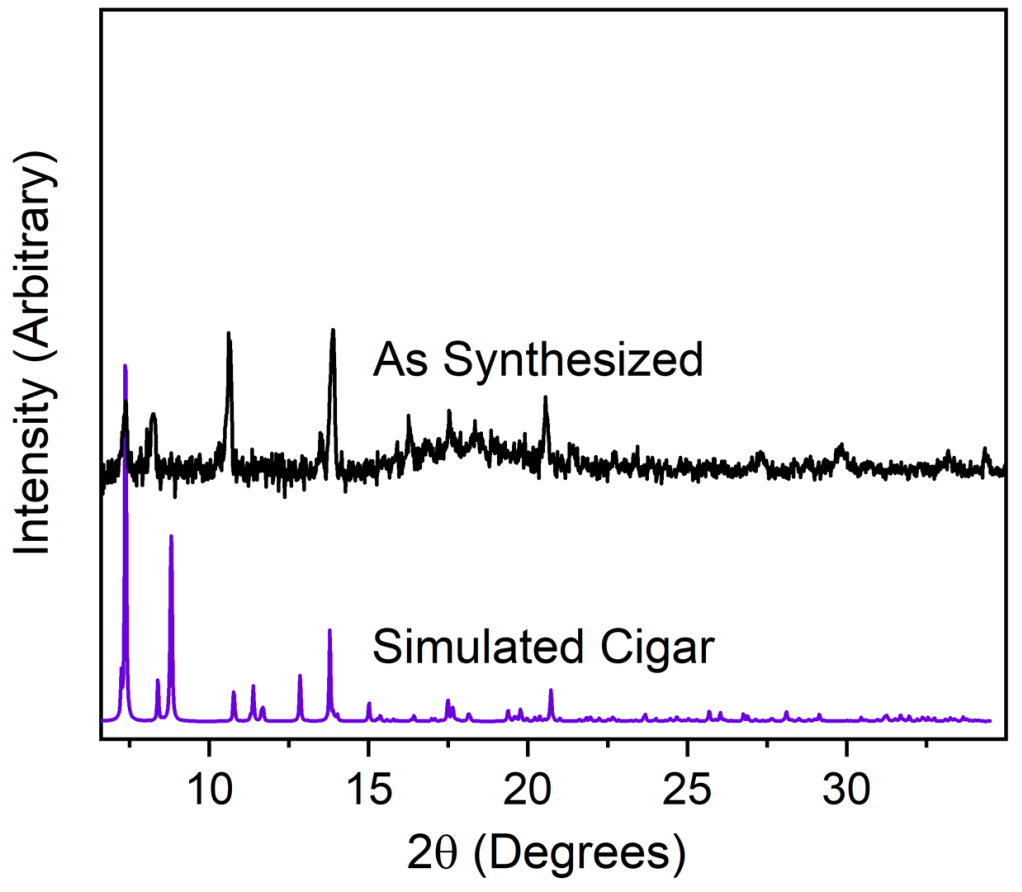

Figure S108. Powder X-Ray diffraction pattern of 6C. 


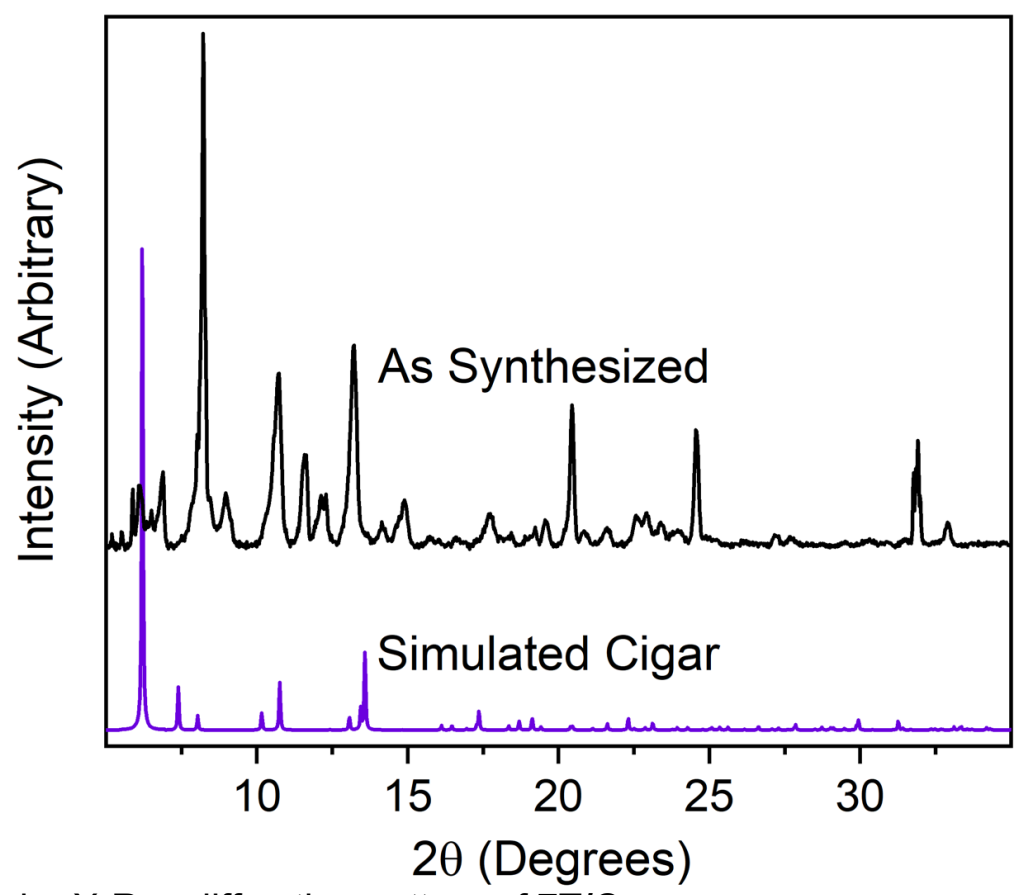

Figure S109. Powder X-Ray diffraction pattern of 7T/C.

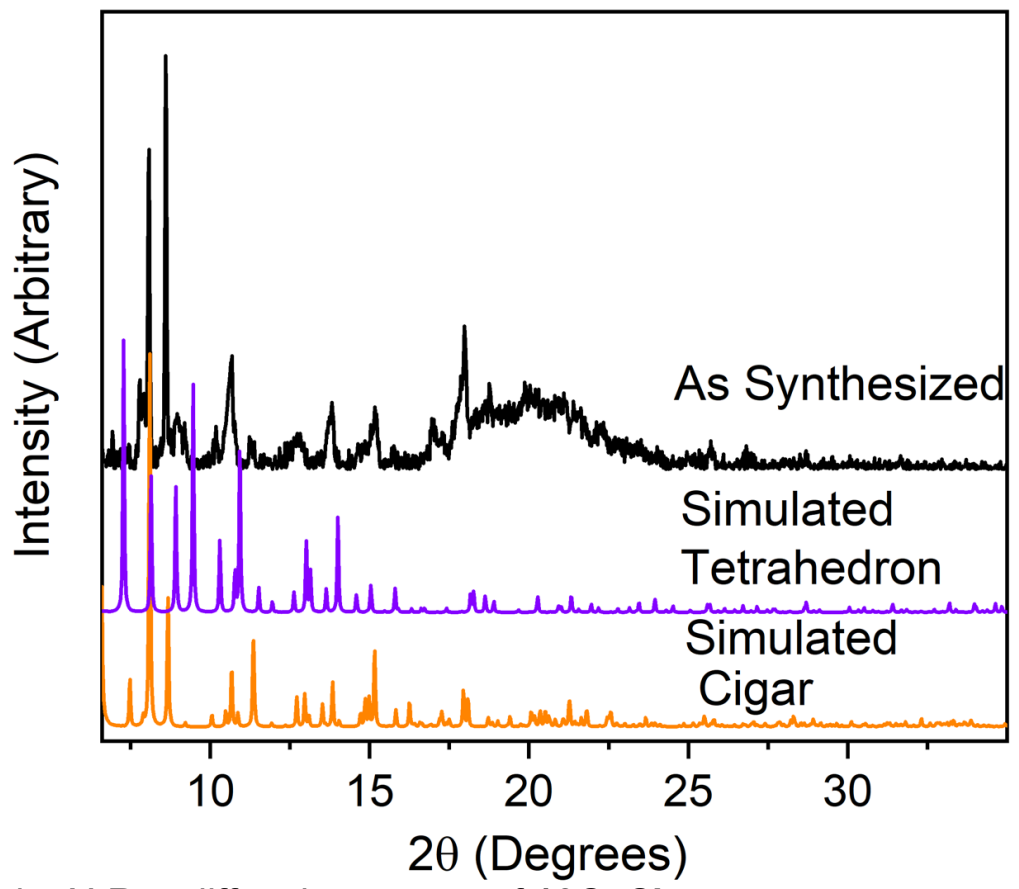

Figure S110. Powder X-Ray diffraction pattern of 10C_Cl. 


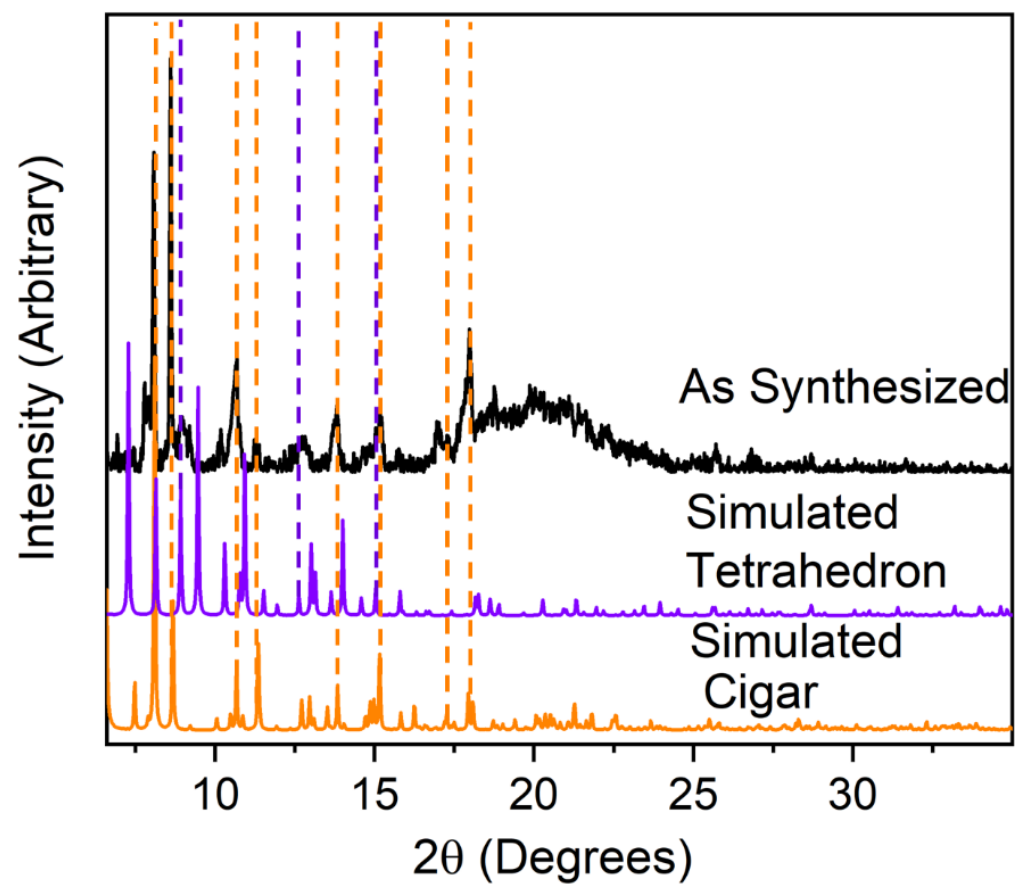

Figure S111. Powder X-Ray diffraction pattern of 10C_Cl. Dashed lines highlight some matching diffraction peaks from as synthesized crystalline material and simulated PXRD patterns; with as synthesized (black) on top, simulated tetrahedron (purple) in the middle, and the simulated cigar (orange) on bottom. 
Thermogravimetric Analysis

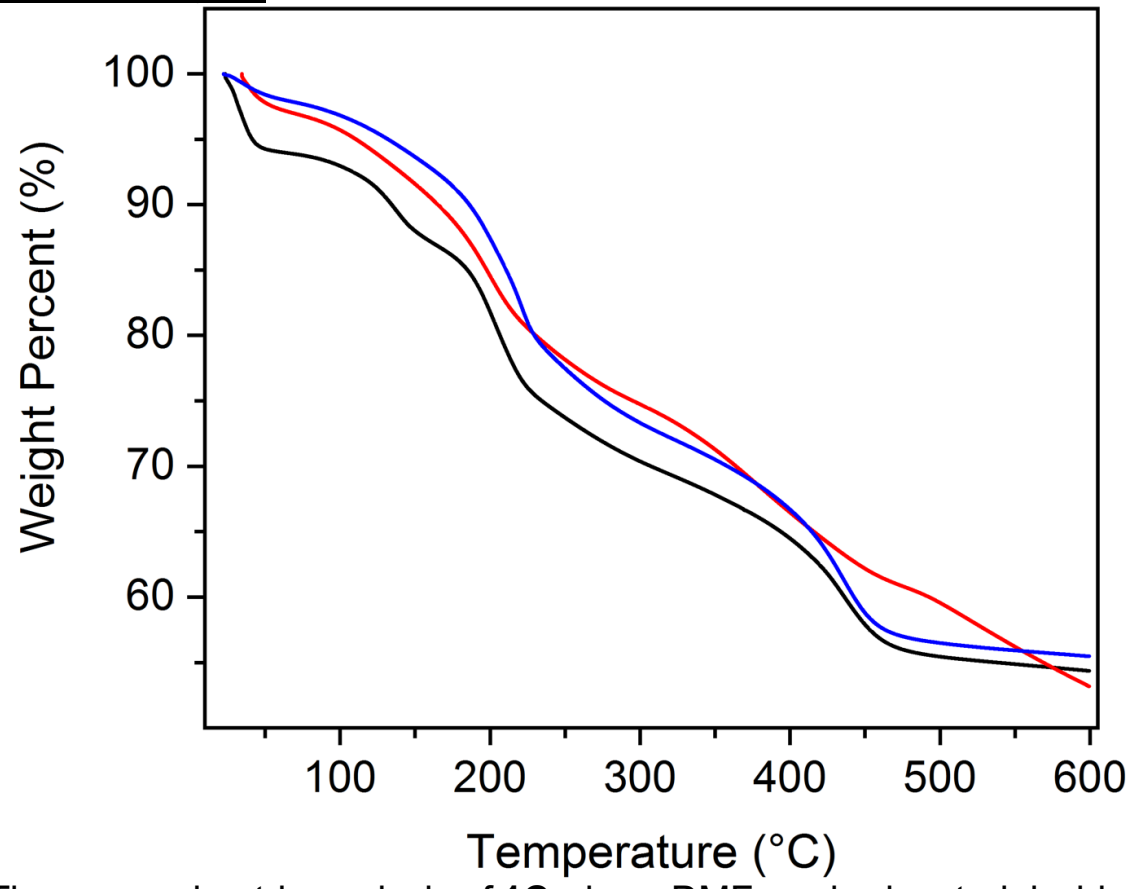

Figure S112. Thermogravimetric analysis of $1 \mathrm{C}$ where DMF washed material, chloroform washed material, and activated material are represented by black, red, and blue, respectively.

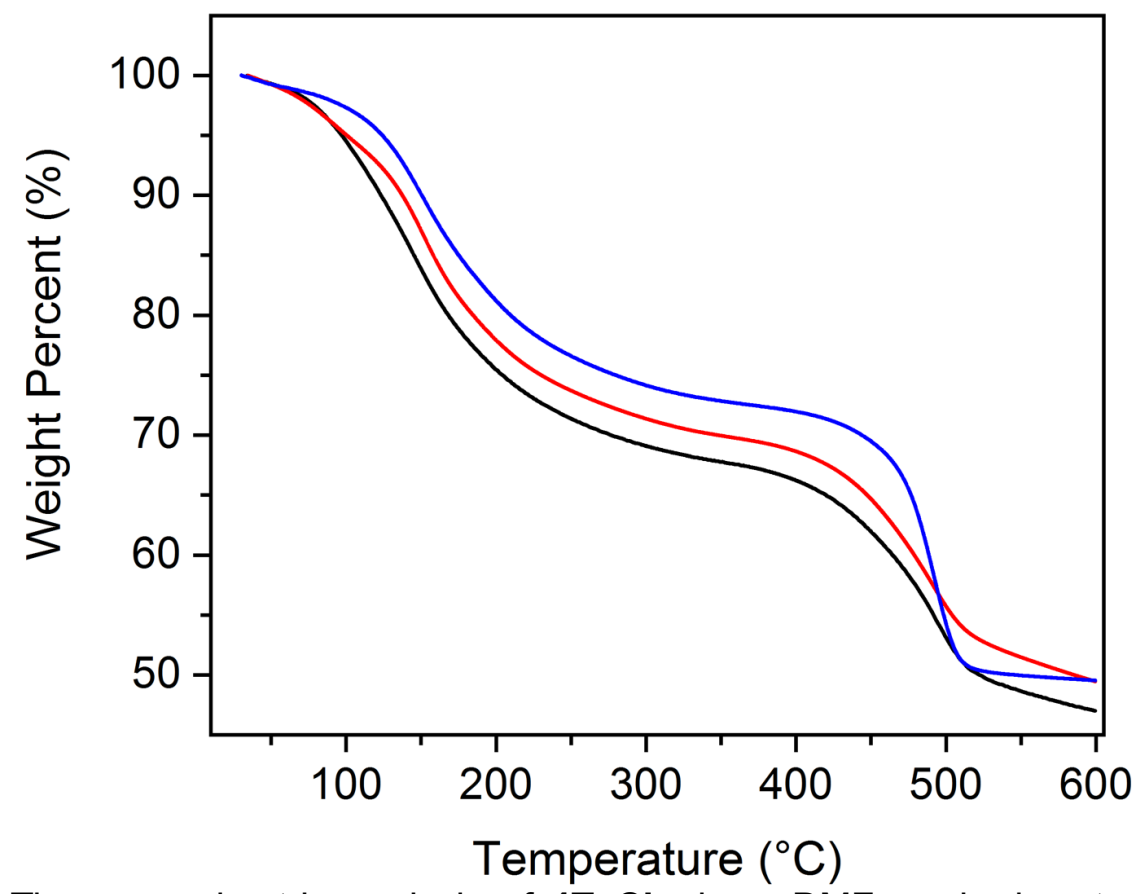

Figure S113. Thermogravimetric analysis of $4 \mathrm{~T}$ _Cl where DMF washed material, chloroform washed material, and activated material are represented by black, red, and blue, respectively. 


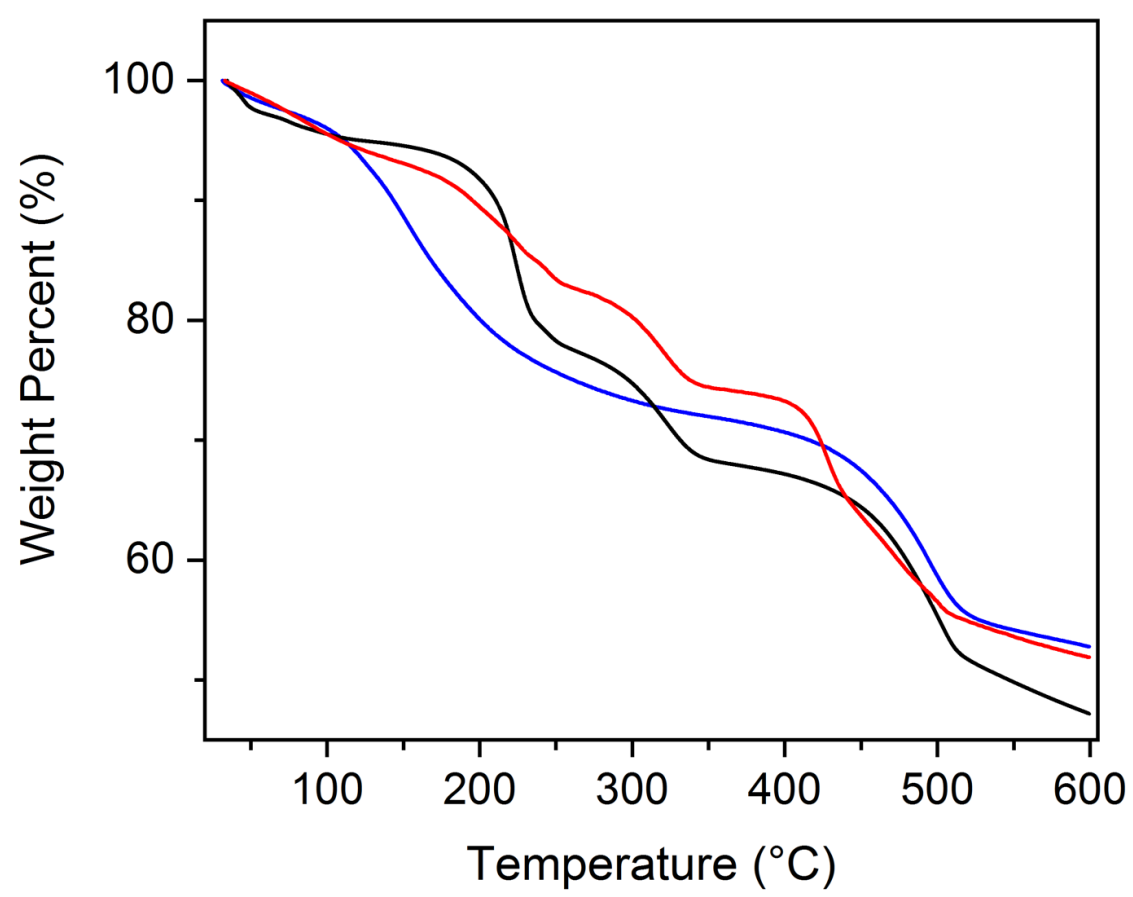

Figure S114. Thermogravimetric analysis of $4 \mathrm{t}$ _OTf where DMF washed material, chloroform washed material, and activated material are represented by black, red, and blue, respectively.

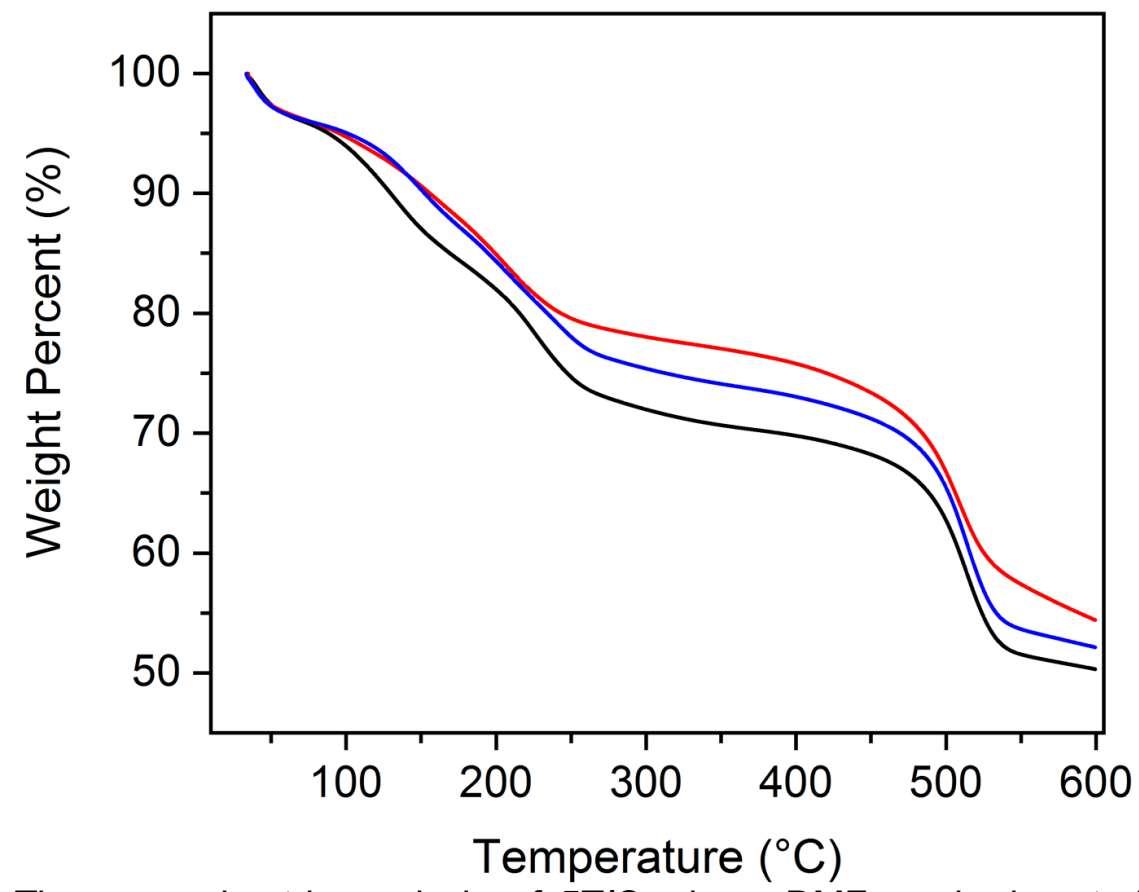

Figure S115. Thermogravimetric analysis of 5T/C where DMF washed material, chloroform washed material, and activated material are represented by black, red, and blue, respectively. 


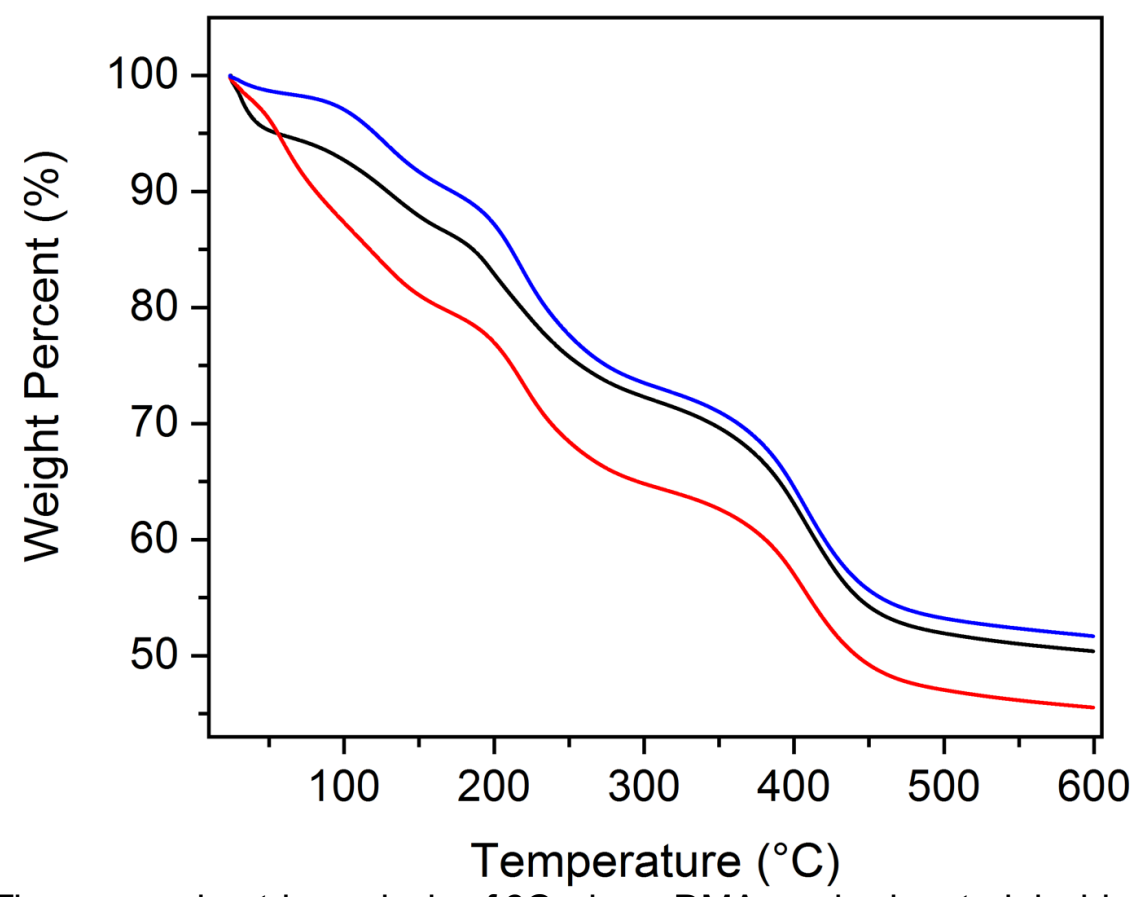

Figure S116. Thermogravimetric analysis of $6 \mathbf{C}$ where DMA washed material, chloroform washed material, and activated material are represented by black, red, and blue, respectively.

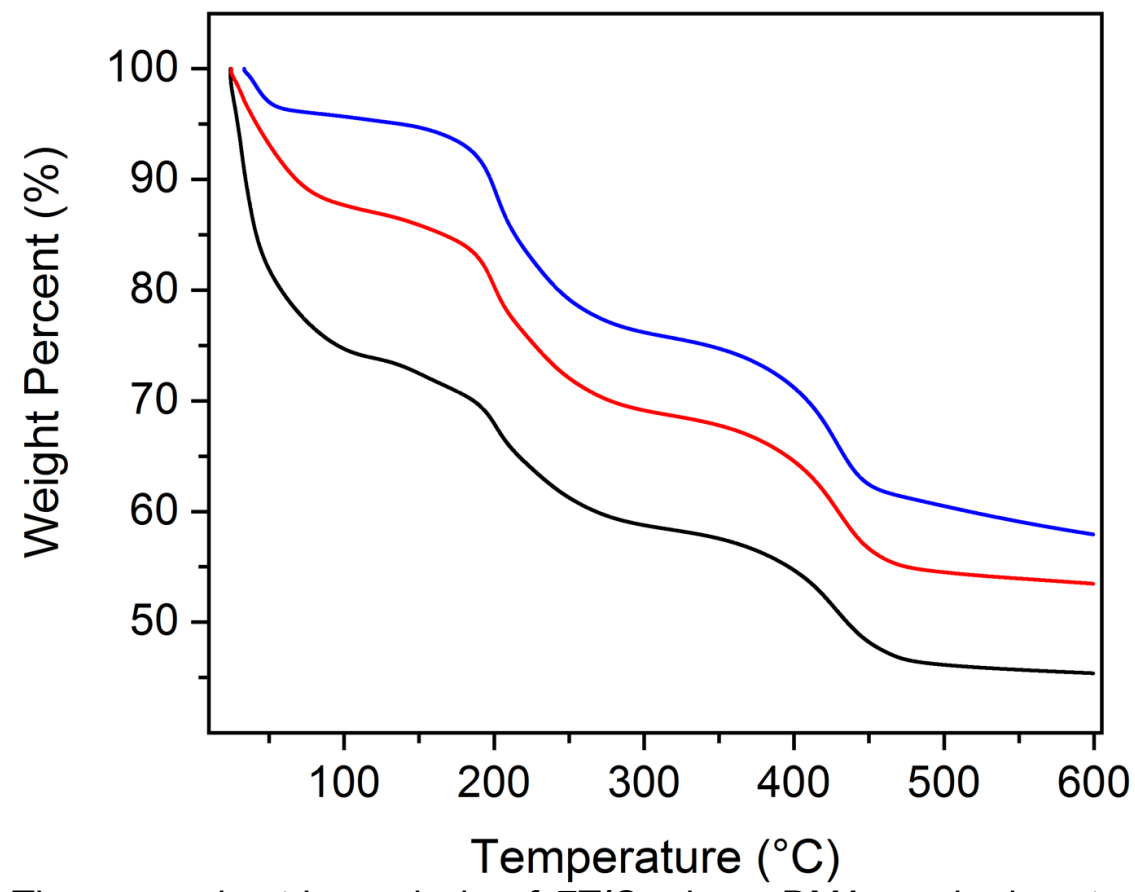

Figure S117. Thermogravimetric analysis of 7T/C where DMA washed material, chloroform washed material, and activated material are represented by black, red, and blue, respectively. 


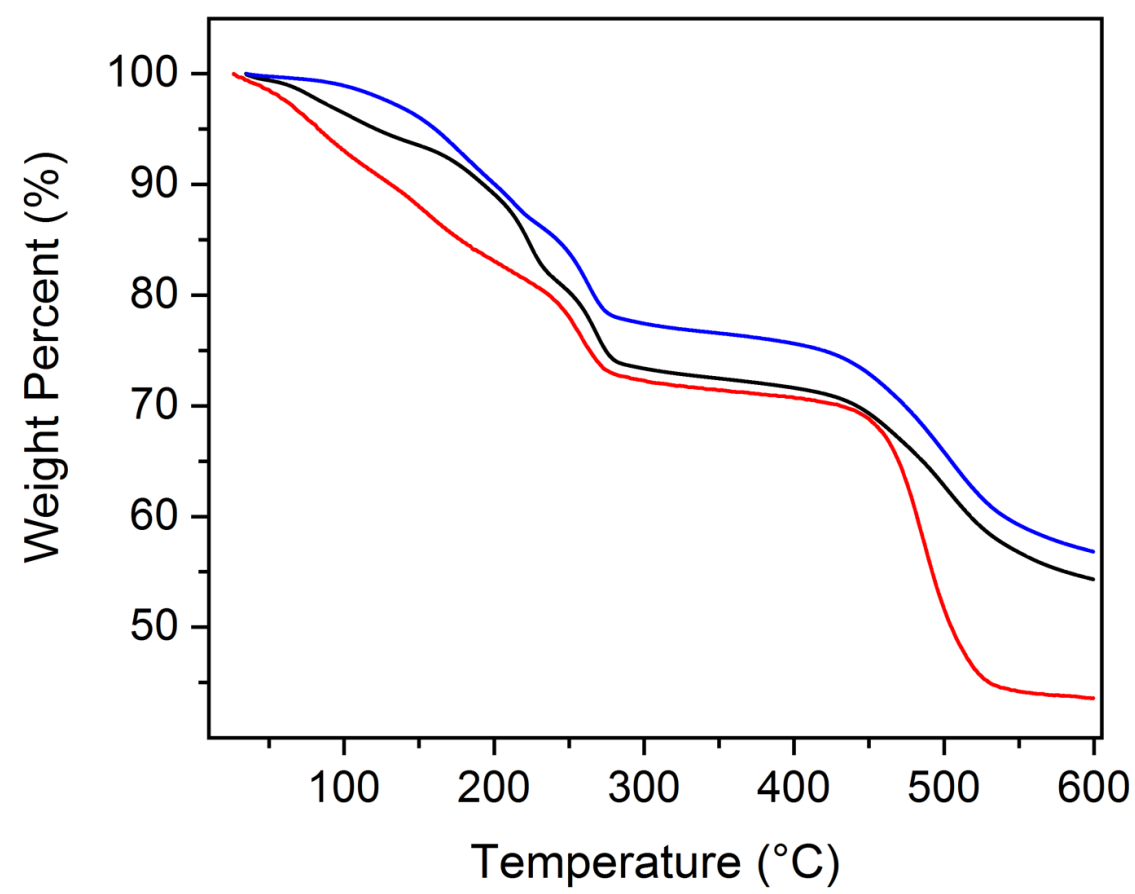

Figure S118. Thermogravimetric analysis of $10 \mathrm{C}$ _Cl where DMF washed material, chloroform washed material, and activated material are represented by black, red, and blue, respectively.

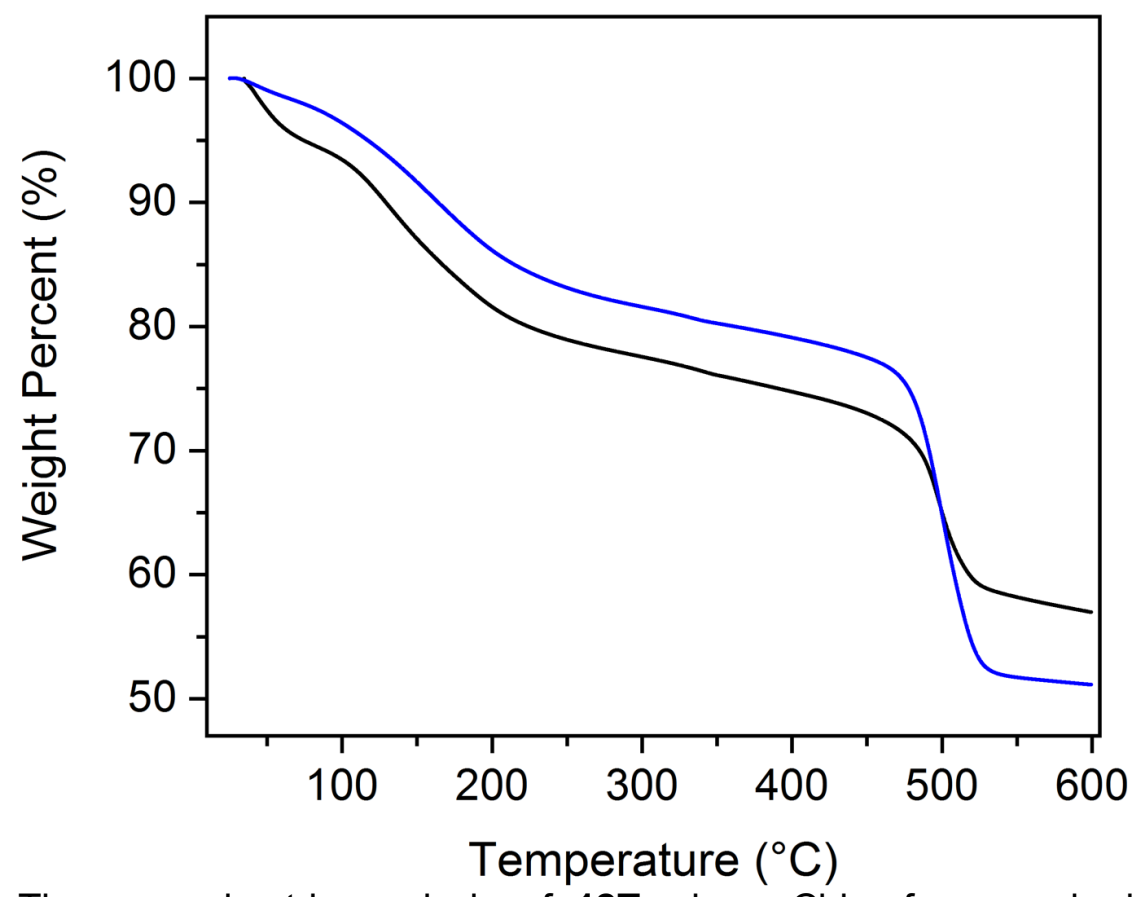

Figure S119. Thermogravimetric analysis of $12 \mathrm{~T}$ where Chloroform washed material and activated material are represented by black and blue, respectively. 


\section{Infrared Analysis}
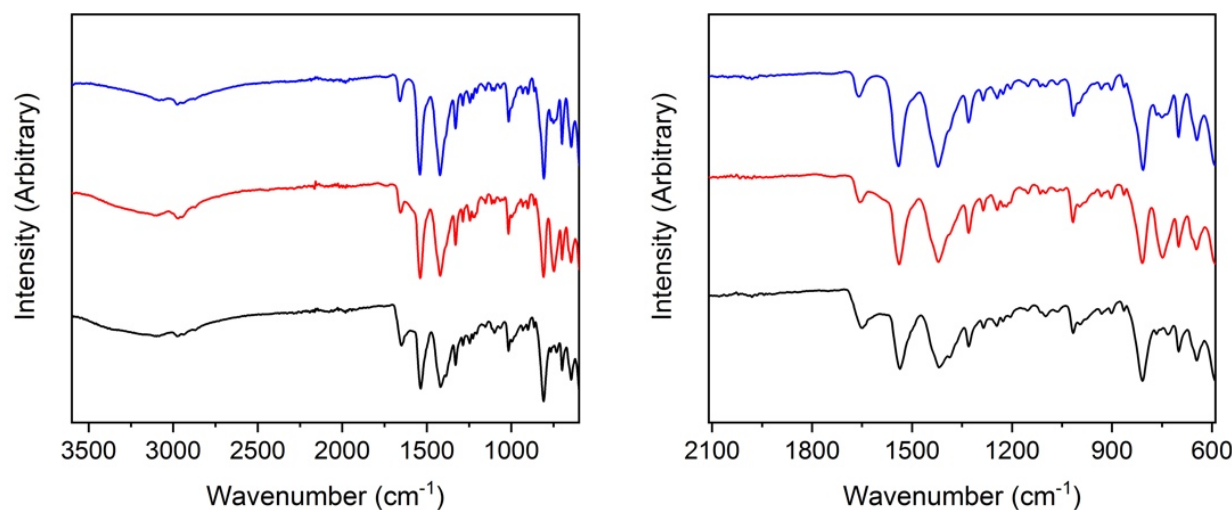

Figure S120. Infrared spectra of 1C where DMF washed material, chloroform washed material, and activated material are represented by black, red, and blue, respectively.
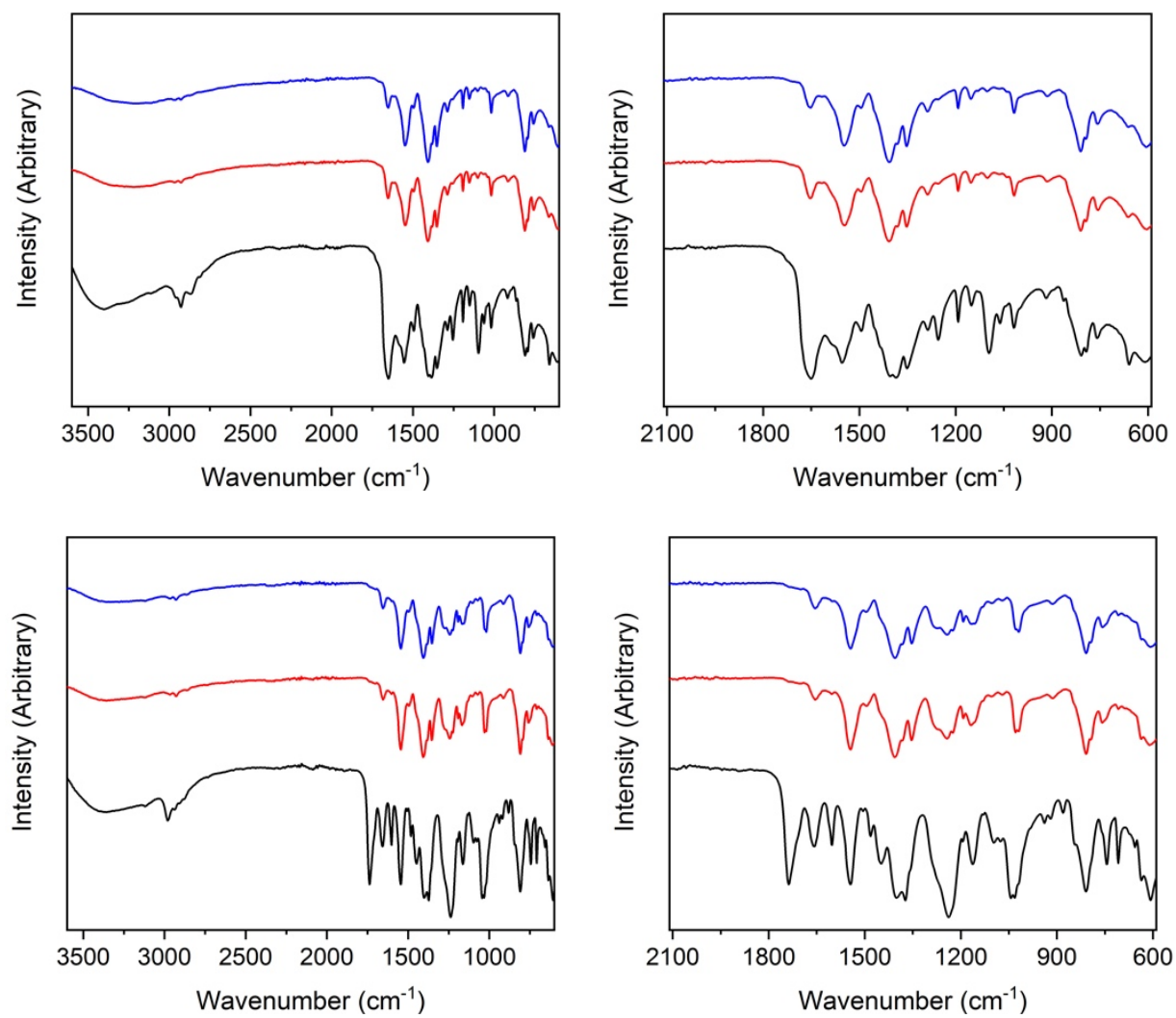

Figure S121. Infrared spectra of 4T_CI (top) and 4T_OTf (bottom) where DMF washed material, chloroform washed material, and activated material are represented by black, red, and blue, respectively. 

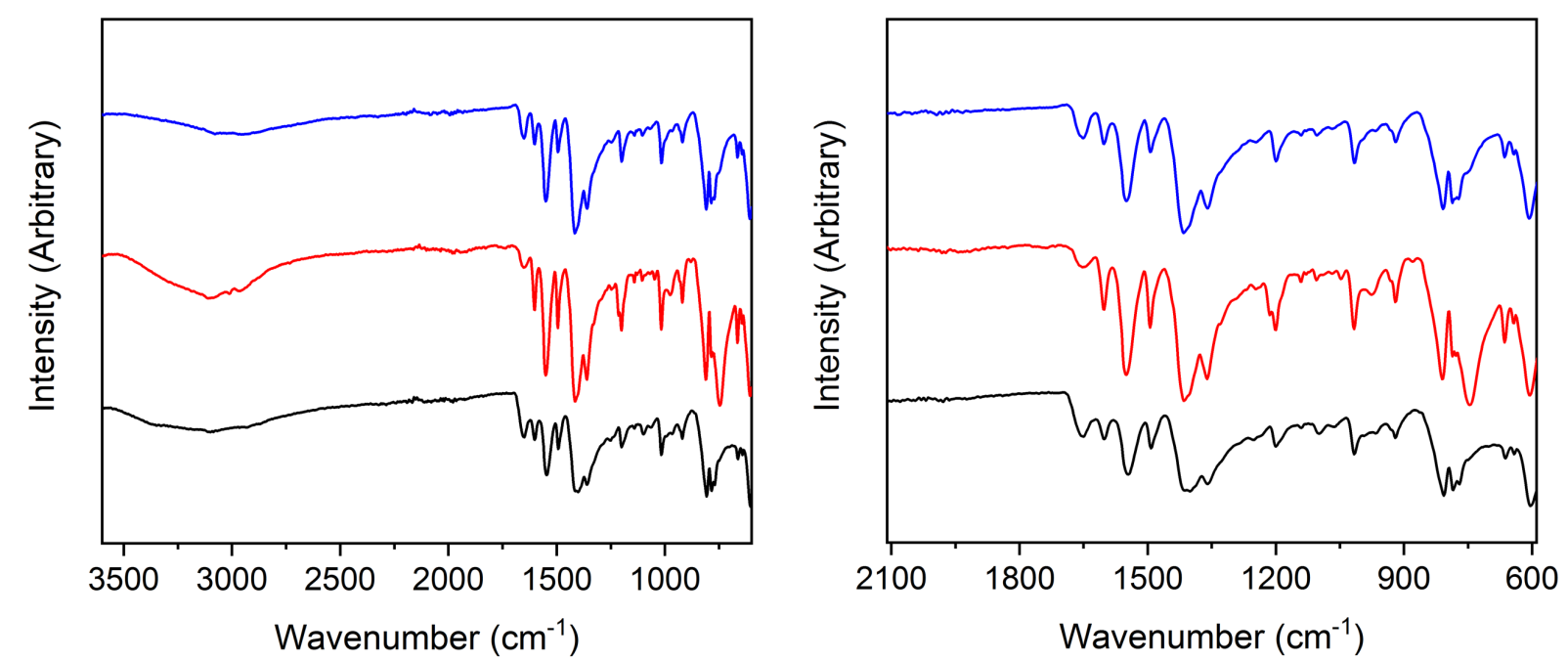

Figure S122. Infrared spectra of 5T/C where DMF washed material, chloroform washed material, and activated material are represented by black, red, and blue, respectively.
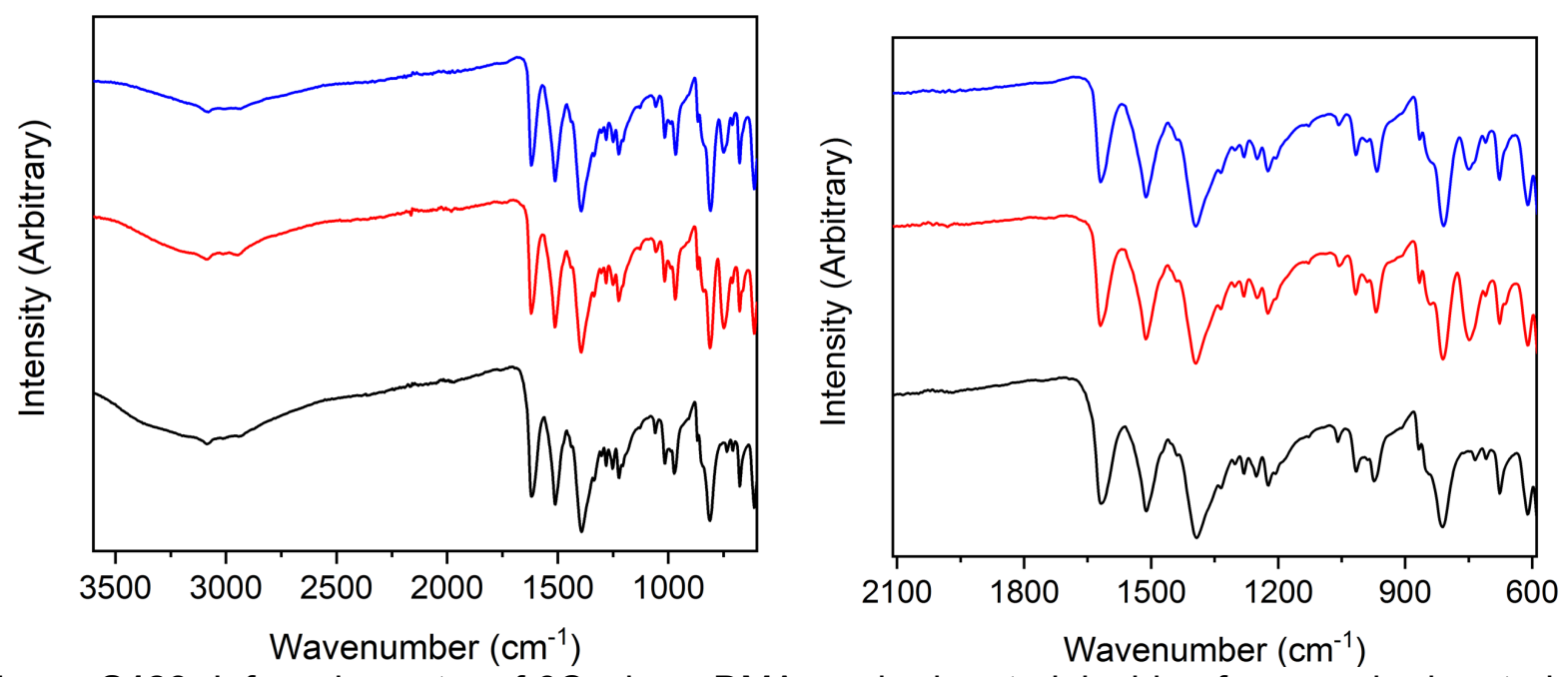

Figure S123. Infrared spectra of 6C where DMA washed material, chloroform washed material, and activated material are represented by black, red, and blue, respectively. 

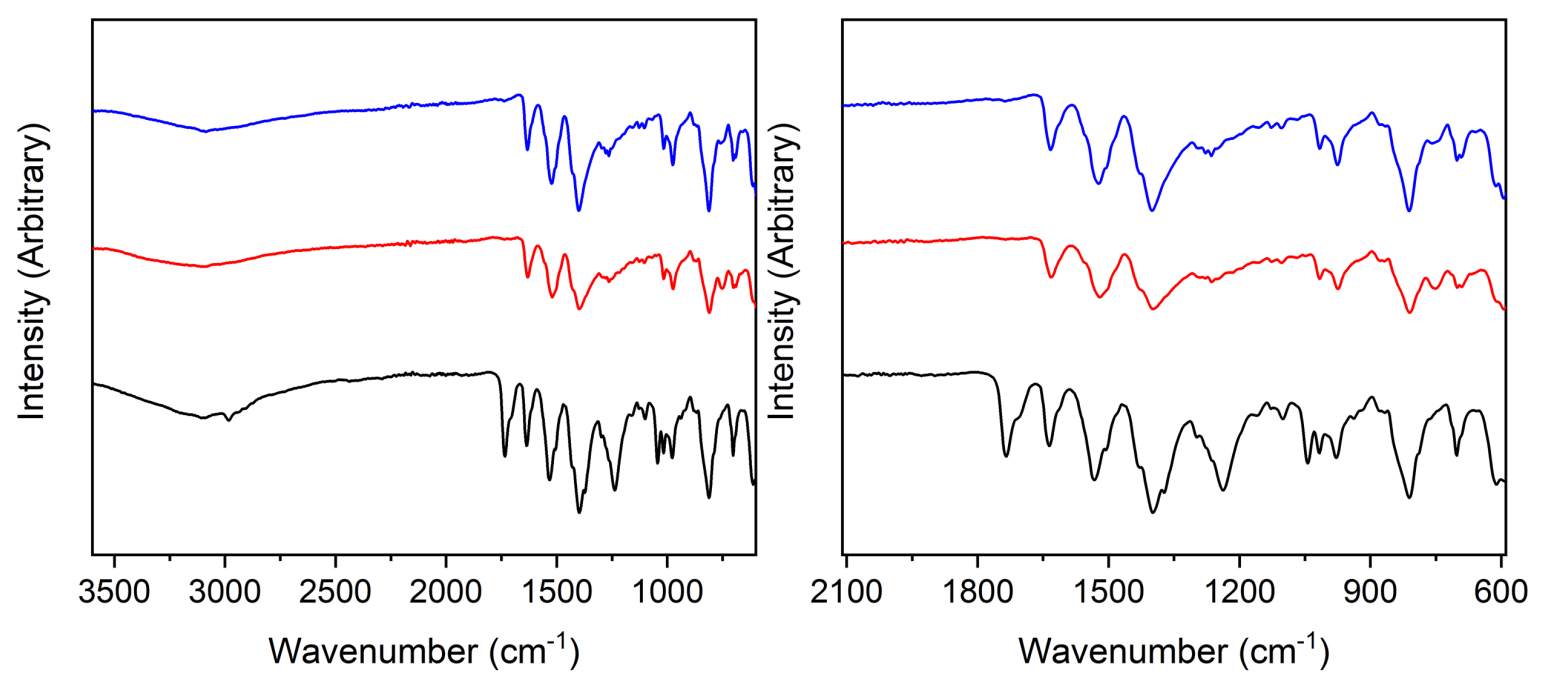

Figure S124. Infrared spectra of 7T/C where DMF washed material, chloroform washed material, and activated material are represented by black, red, and blue, respectively.
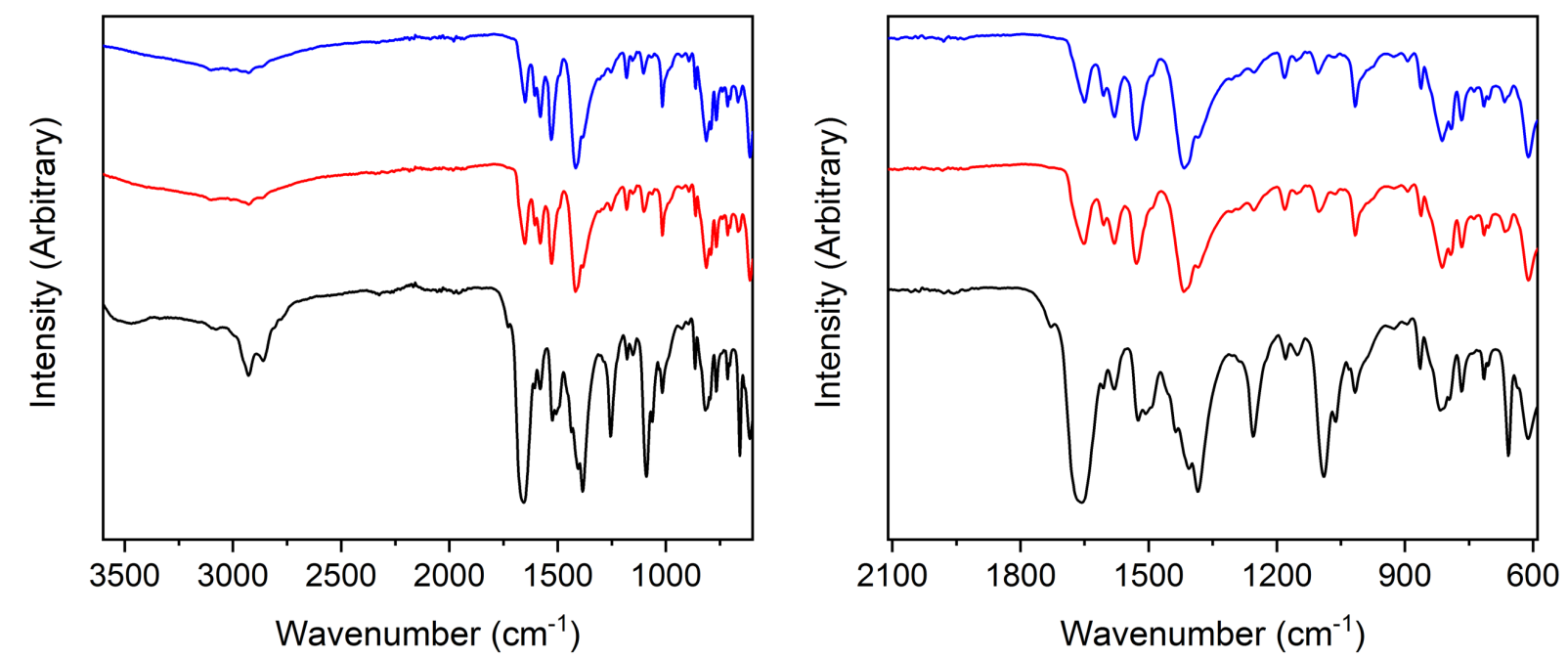

Figure S125. Infrared spectra of $10 \mathrm{C}$ Cl where DMF washed material, chloroform washed material, and activated material are represented by black, red, and blue, respectively. 

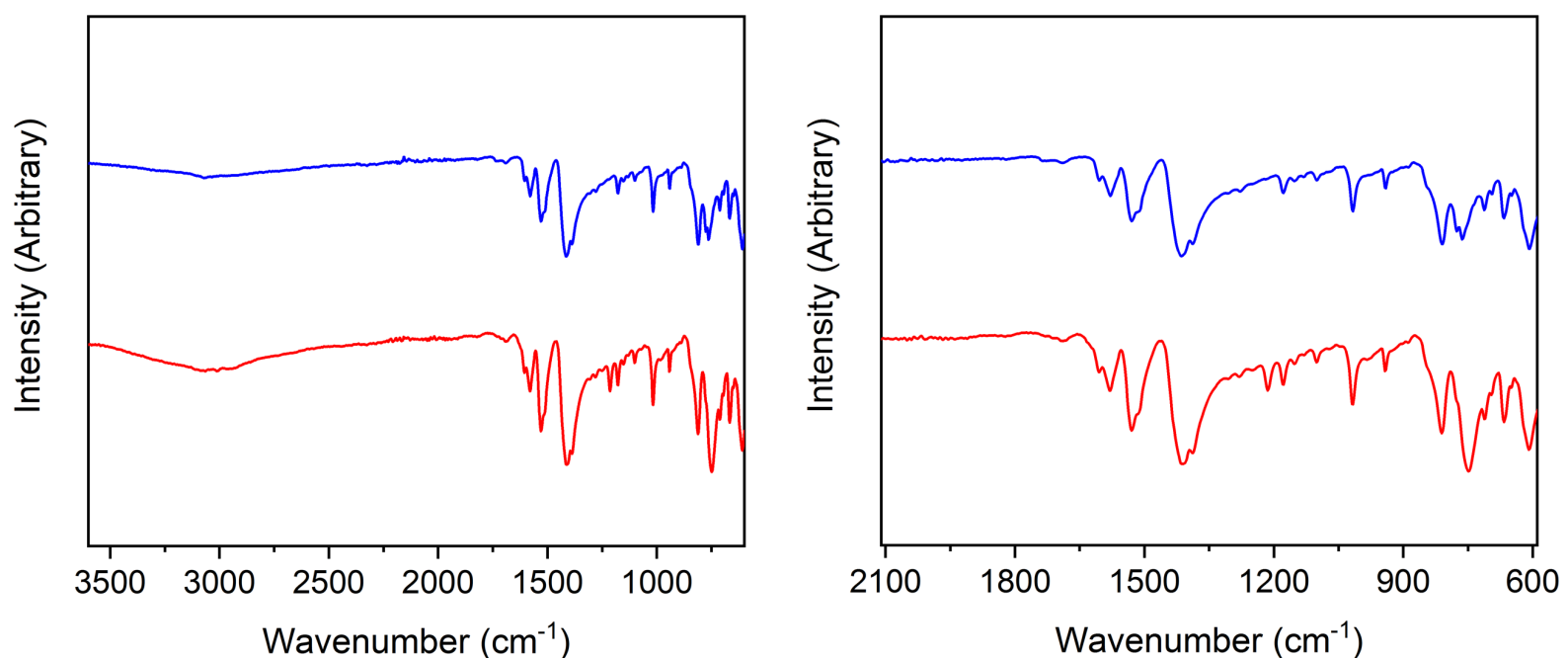

Figure S126. Infrared spectra of $12 \mathrm{~T}$ where chloroform washed material and activated material are represented by red and blue, respectively. 


\section{Gas Adsorption Isotherms}

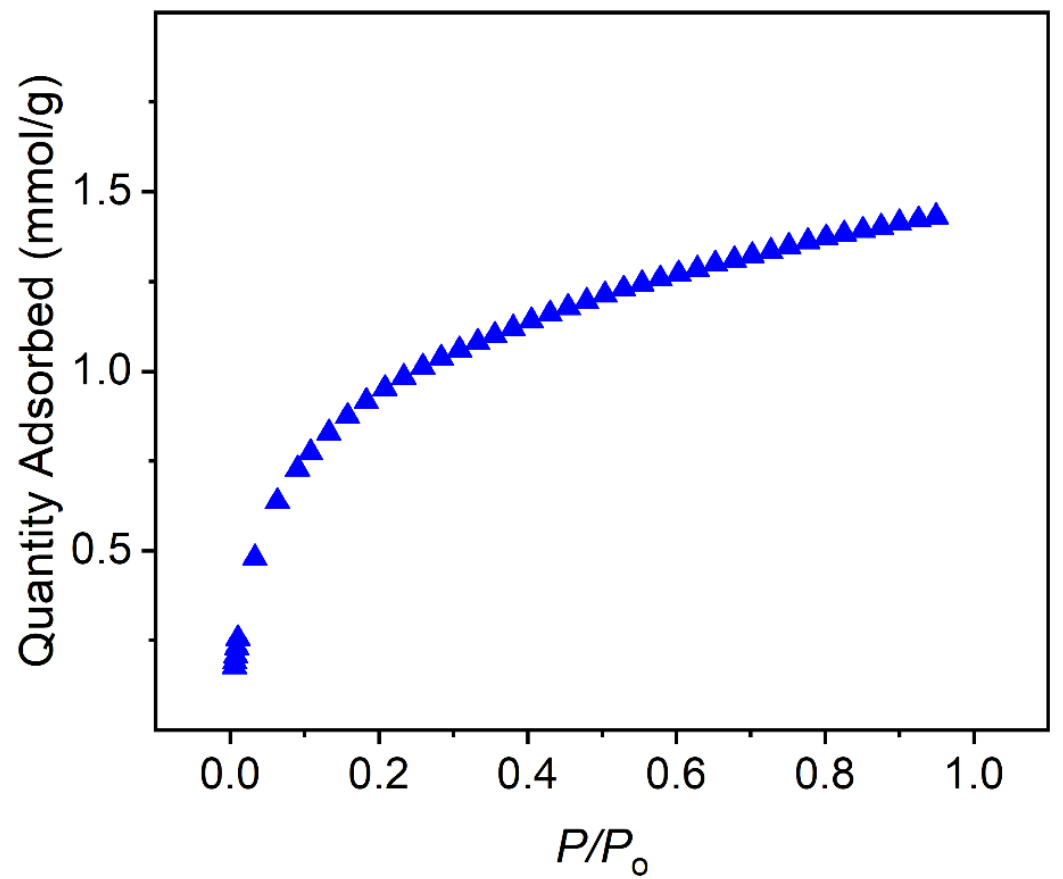

Figure S127. Adsorption of $\mathrm{CO}_{2}$ in $1 \mathrm{C}$ at $195 \mathrm{~K}$.
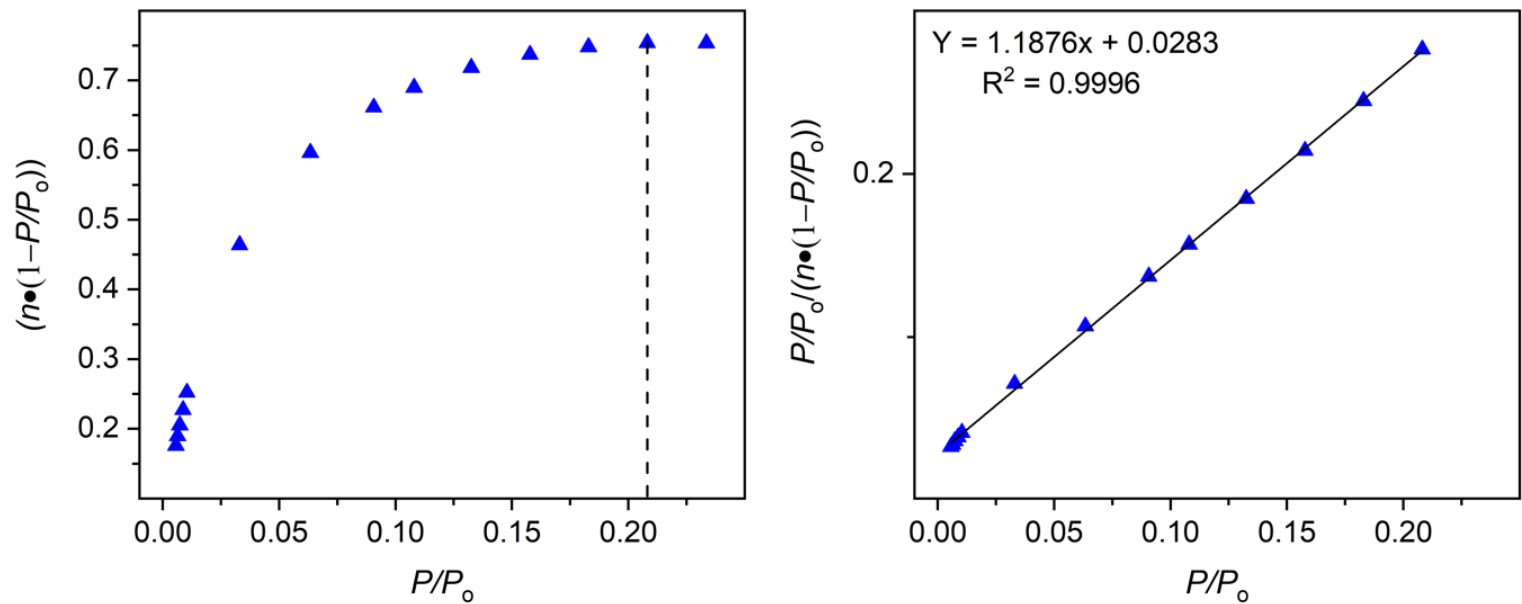

Figure S128. Plot of $n \bullet\left(1-P / P_{\circ}\right)$ vs $P / P_{0}$ to determine the maximum $P / P_{0}$ used in the BET linear fit according to the first BET consistency criterion for the adsorption of $\mathrm{CO}_{2}$ in $1 \mathrm{C}$ at $195 \mathrm{~K}$ and a plot of $\left(P / P_{\mathrm{o}}\right) /\left(n \bullet\left(1-P / P_{\mathrm{o}}\right)\right)$ vs $P / P_{\mathrm{o}}$ to determine the BET surface area from $\mathrm{CO}_{2}$ adsorption at 195 $\mathrm{K}$. The slope of the best fit lit for $P / P_{0}<0.208$ is 1.1876 and the $y$-intercept is 0.0283 , which satisfies the second BET consistency criterion. This results in a surface area of $86.2 \mathrm{~m}^{2} / \mathrm{g}$. 


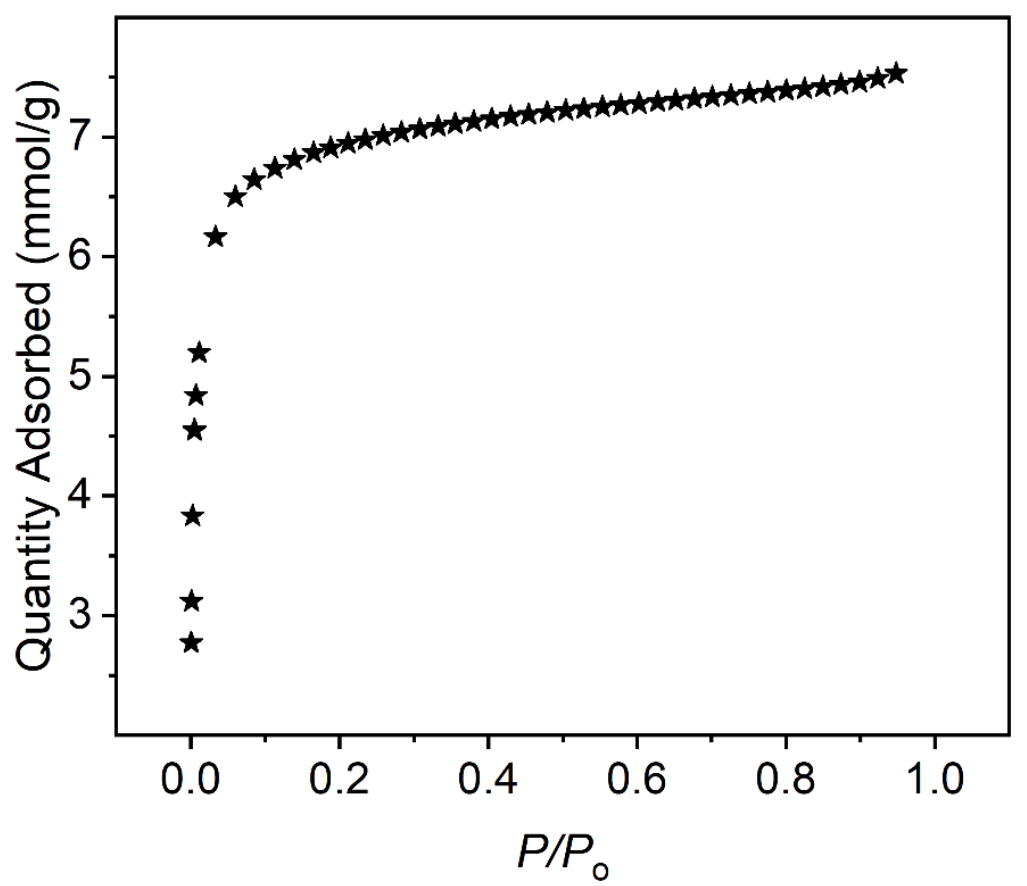

Figure S129. Adsorption of $\mathrm{N}_{2}$ in $4 \mathrm{~T}_{-} \mathrm{Cl}$ at $77 \mathrm{~K}$.
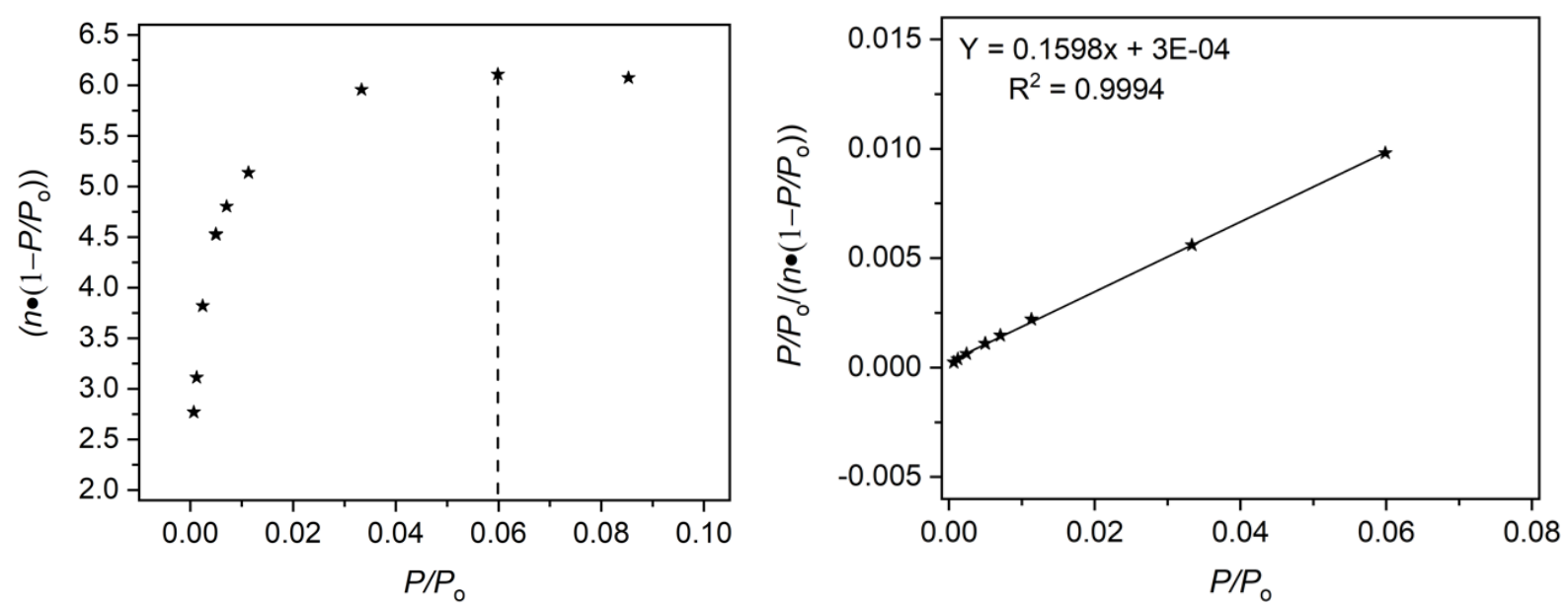

Figure S130. Plot of $n \bullet\left(1-P / P_{\circ}\right)$ vs $P / P_{0}$ to determine the maximum $P / P_{\mathrm{o}}$ used in the BET linear fit according to the first BET consistency criterion for the adsorption of $\mathrm{N}_{2}$ in $4 \mathrm{~T}$ - $\mathrm{Cl}$ at $77 \mathrm{~K}$. Plot of $\left(P / P_{0}\right) /\left(n \bullet\left(1-P / P_{0}\right)\right)$ vs $P / P_{0}$ to determine the BET surface area from $N_{2}$ adsorption at $77 \mathrm{~K}$. The slope of the best fit lit for $P / P_{0}<0.059$ is 0.1598 and the $y$-intercept is 0.0003 , which satisfies the second BET consistency criterion. This results in a surface area of $610.5 \mathrm{~m}^{2} / \mathrm{g}$. 


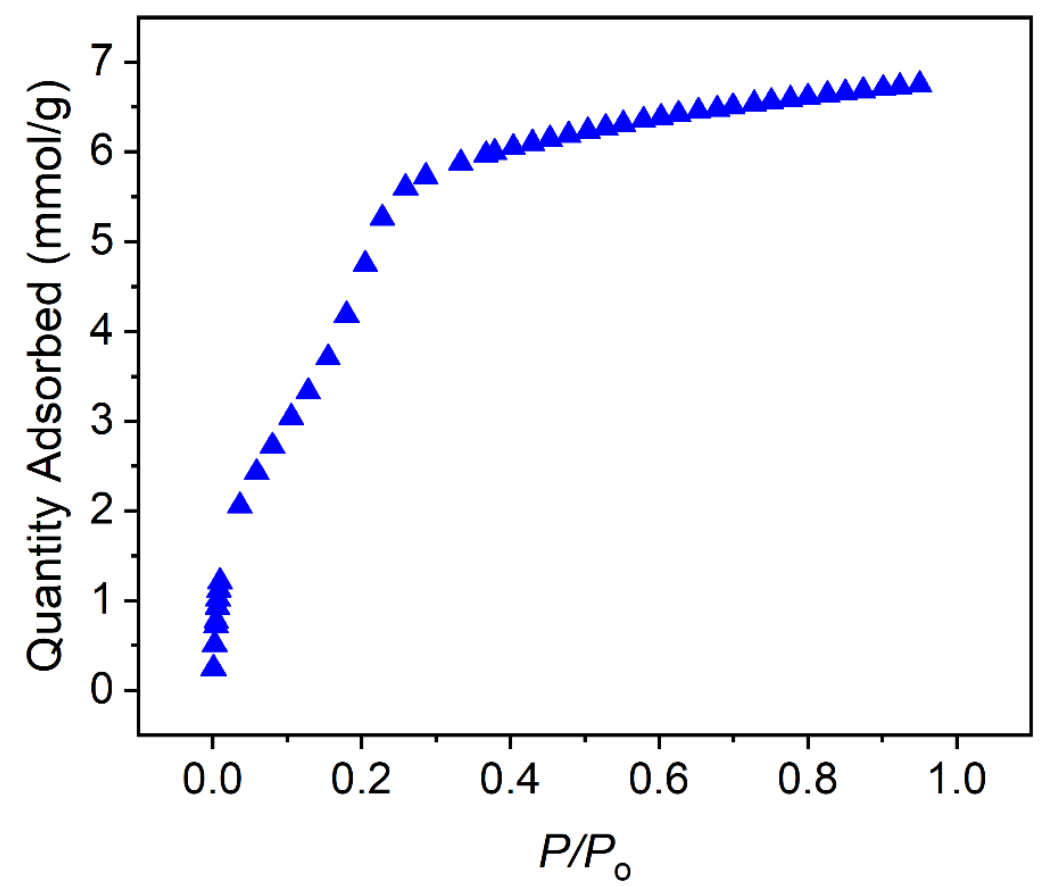

Figure S131. Adsorption of $\mathrm{CO}_{2}$ in 4T_Cl at $195 \mathrm{~K}$.
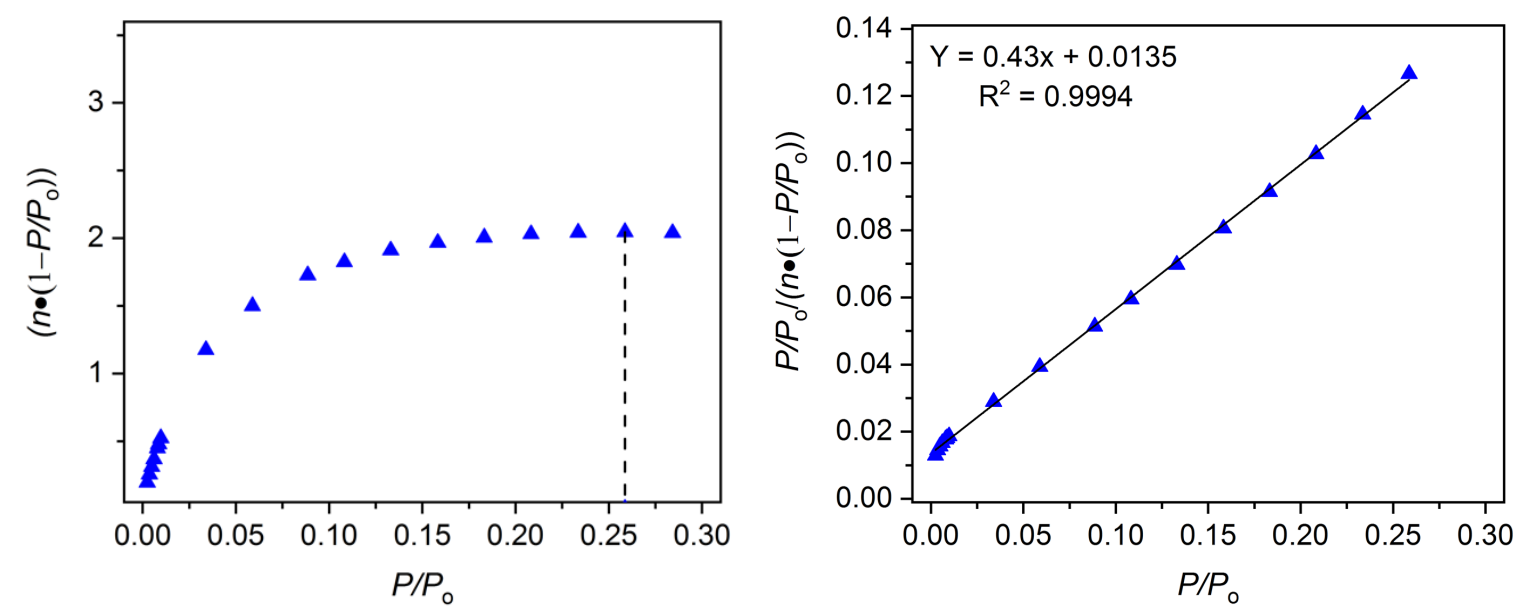

Figure S132. Plot of $n \bullet\left(1-P / P_{0}\right)$ vs $P / P_{0}$ to determine the maximum $P / P_{0}$ used in the BET linear fit according to the first BET consistency criterion for the adsorption of $\mathrm{CO}_{2}$ in $4 \mathrm{~T}$ - $\mathrm{Cl}$ at $195 \mathrm{~K}$. Plot of $\left(P / P_{\mathrm{o}}\right) /\left(n \bullet\left(1-P / P_{\mathrm{o}}\right)\right)$ vs $P / P_{\mathrm{o}}$ to determine the BET surface area from $\mathrm{CO}_{2}$ adsorption at 195 $K$. The slope of the best fit lit for $P / P_{0}<0.258$ is 0.43 and the $y$-intercept is 0.0135 , which satisfies the second BET consistency criterion. This results in a surface area of $238.1 \mathrm{~m}^{2} / \mathrm{g}$. 


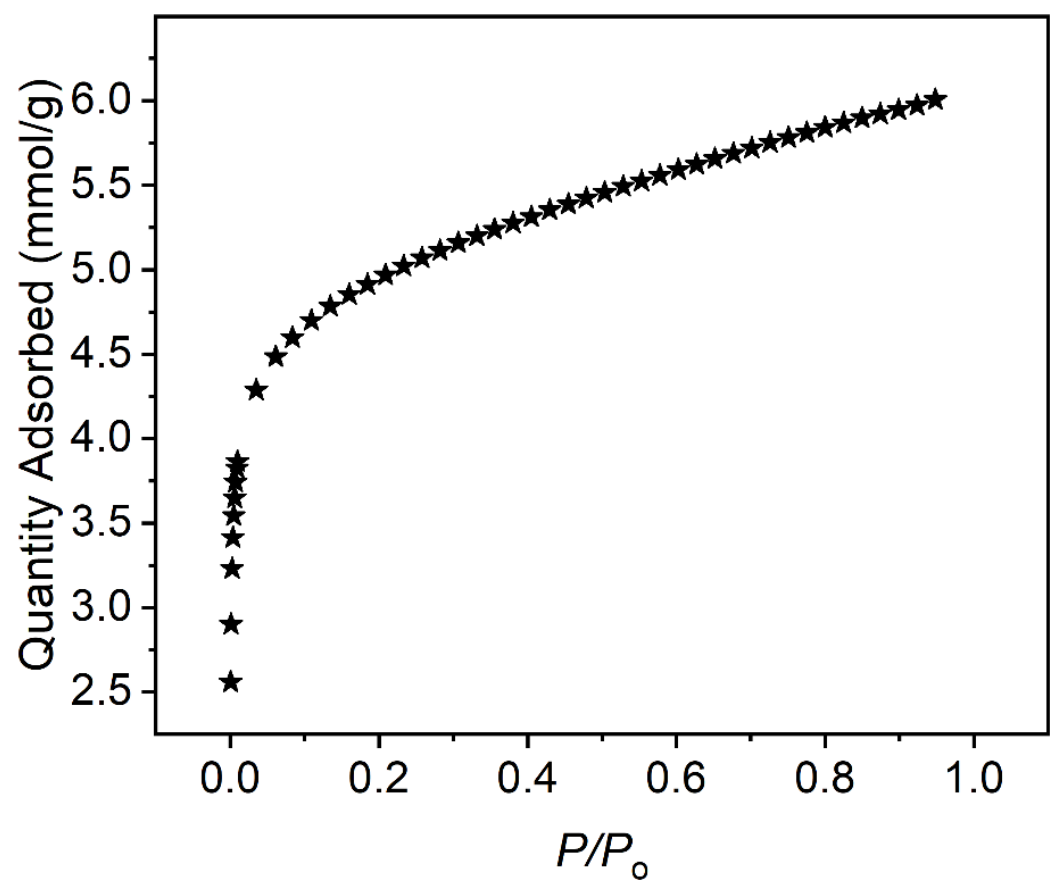

Figure S133. Adsorption of $\mathrm{N}_{2}$ in 4T_OTf at $77 \mathrm{~K}$.
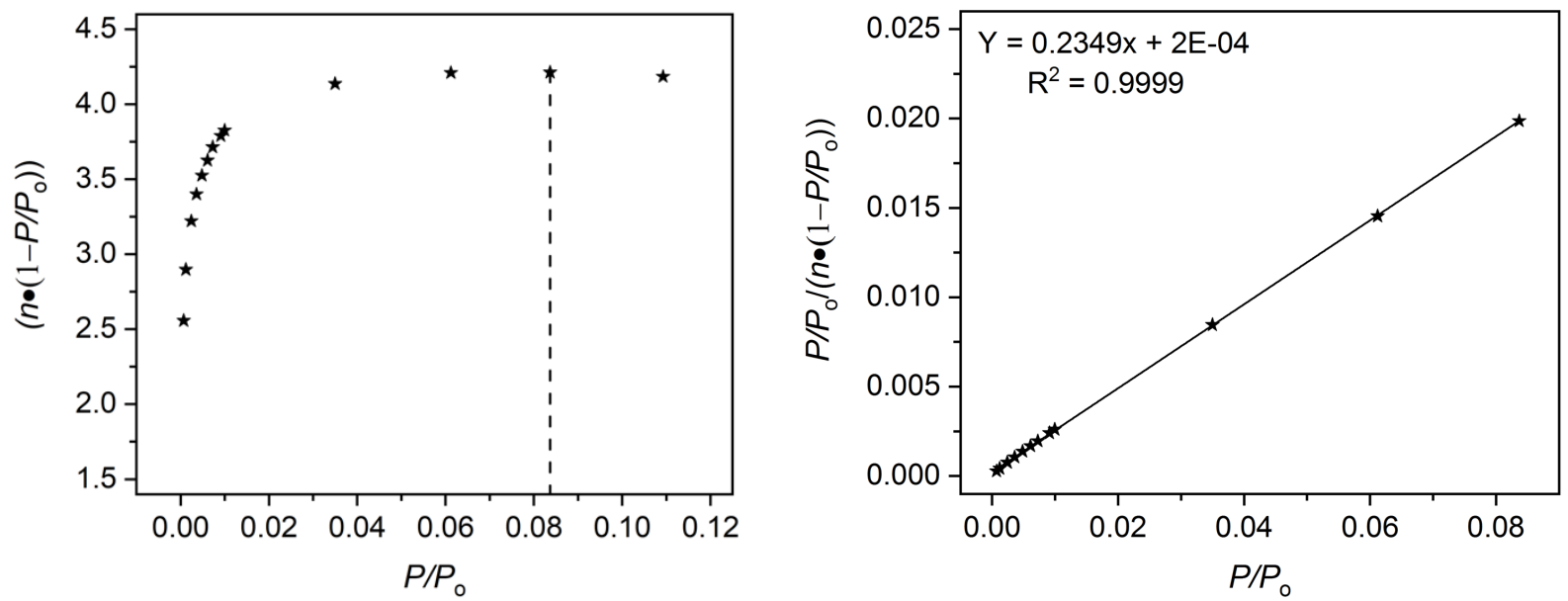

Figure S134. Plot of $n \bullet\left(1-P / P_{\circ}\right)$ vs $P / P_{\circ}$ to determine the maximum $P / P_{\circ}$ used in the $B E T$ linear fit according to the first BET consistency criterion for the adsorption of $\mathrm{N}_{2}$ in $4 \mathrm{~T}$-OTf at $77 \mathrm{~K}$. Plot of $\left(P / P_{0}\right) /\left(n \bullet\left(1-P / P_{0}\right)\right)$ vs $P / P_{0}$ to determine the BET surface area from $N_{2}$ adsorption at $77 \mathrm{~K}$. The slope of the best fit lit for $P / P_{0}<0.084$ is 0.2349 and the $y$-intercept is 0.0002 , which satisfies the second BET consistency criterion. This results in a surface area of $415.5 \mathrm{~m}^{2} / \mathrm{g}$. 


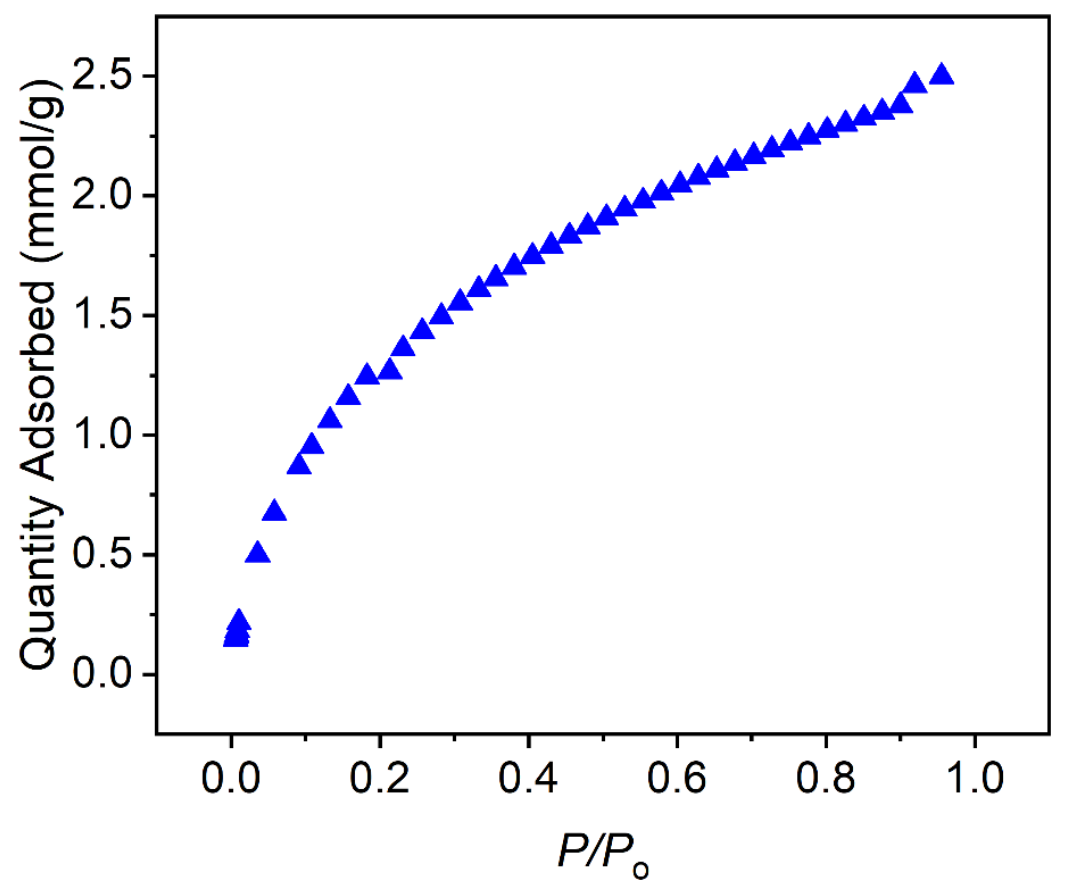

Figure S135. Adsorption of $\mathrm{CO}_{2}$ in 4T_OTf at $195 \mathrm{~K}$.
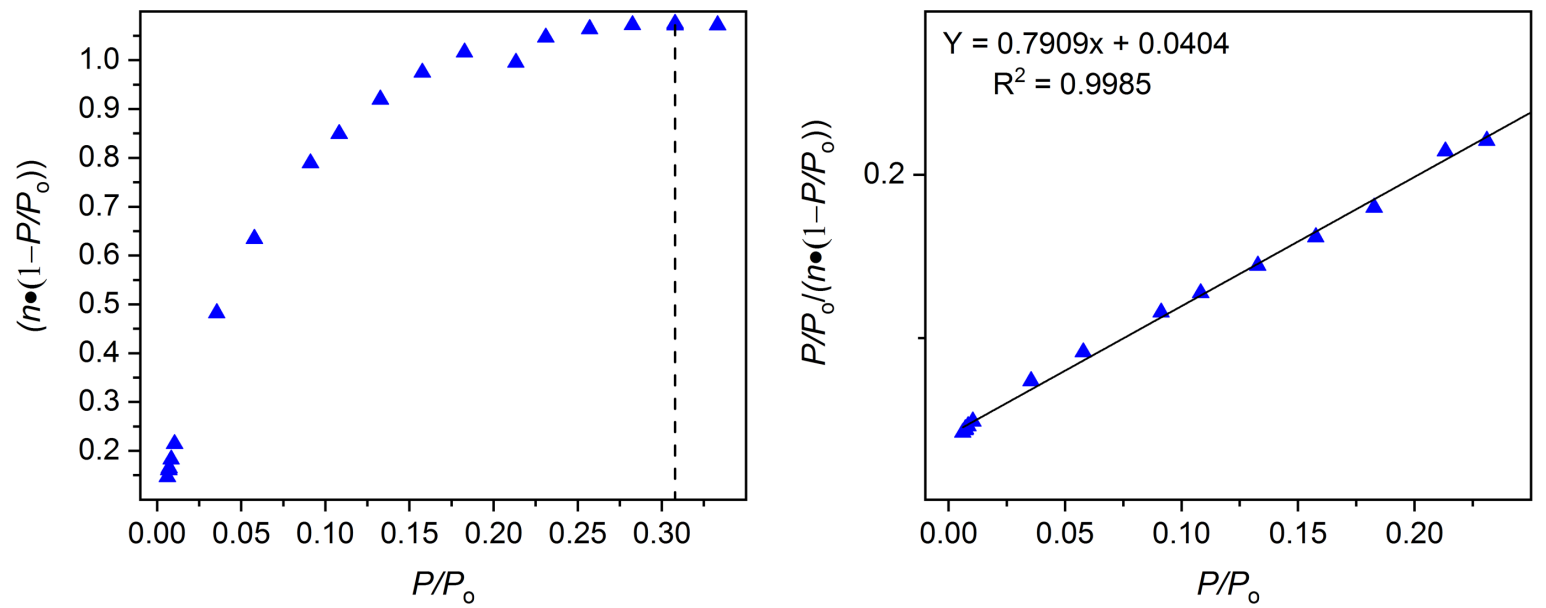

Figure S136. Plot of $n \bullet\left(1-P / P_{0}\right)$ vs $P / P_{0}$ to determine the maximum $P / P_{o}$ used in the BET linear fit according to the first BET consistency criterion for the adsorption of $\mathrm{CO}_{2}$ in 4T_OTf at $195 \mathrm{~K}$. Plot of $\left(P / P_{\mathrm{o}}\right) /\left(n \bullet\left(1-P / P_{\mathrm{o}}\right)\right)$ vs $P / P_{\mathrm{o}}$ to determine the $\mathrm{BET}$ surface area from $\mathrm{CO}_{2}$ adsorption at 195 $\mathrm{K}$. The slope of the best fit lit for $P / P_{0}<0.308$ is 0.7909 and the $y$-intercept is 0.0404 , which satisfies the second BET consistency criterion. This results in a surface area of $129.4 \mathrm{~m}^{2} / \mathrm{g}$. 


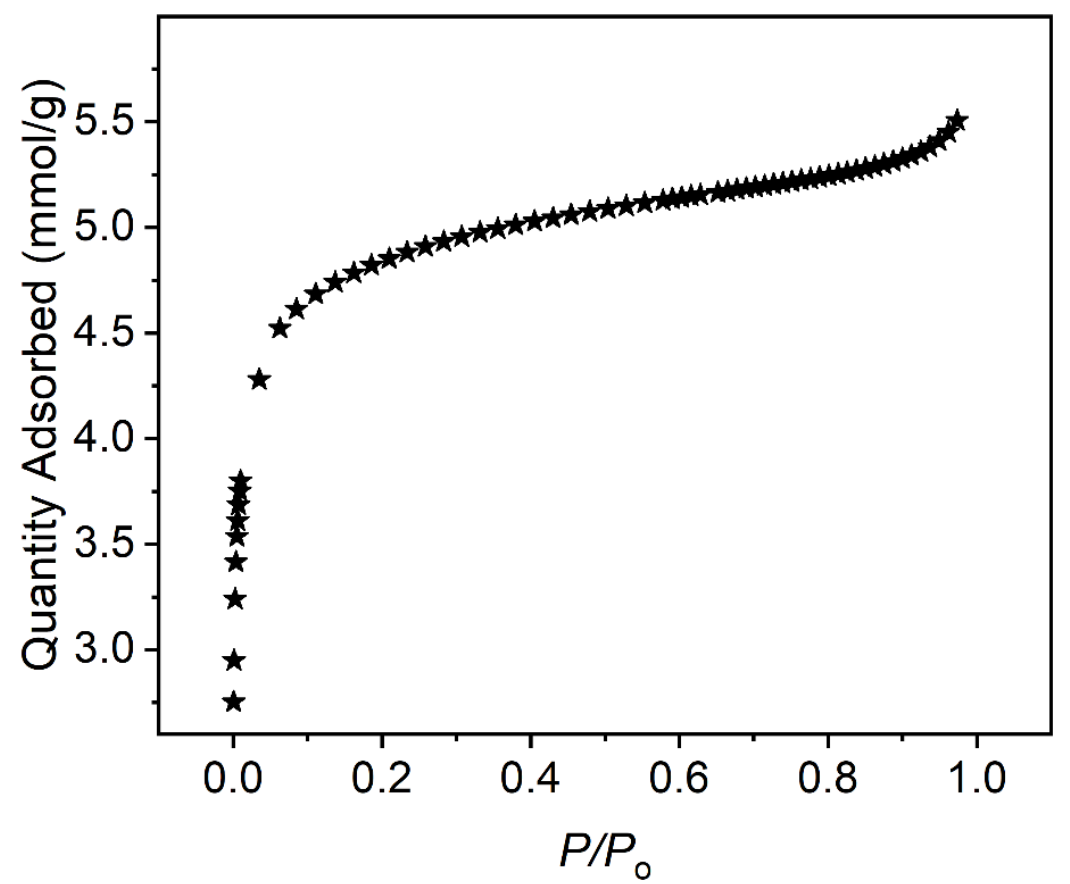

Figure S137. Adsorption of $\mathrm{N}_{2}$ in $5 \mathrm{~T} / \mathrm{C}$ at $77 \mathrm{~K}$.
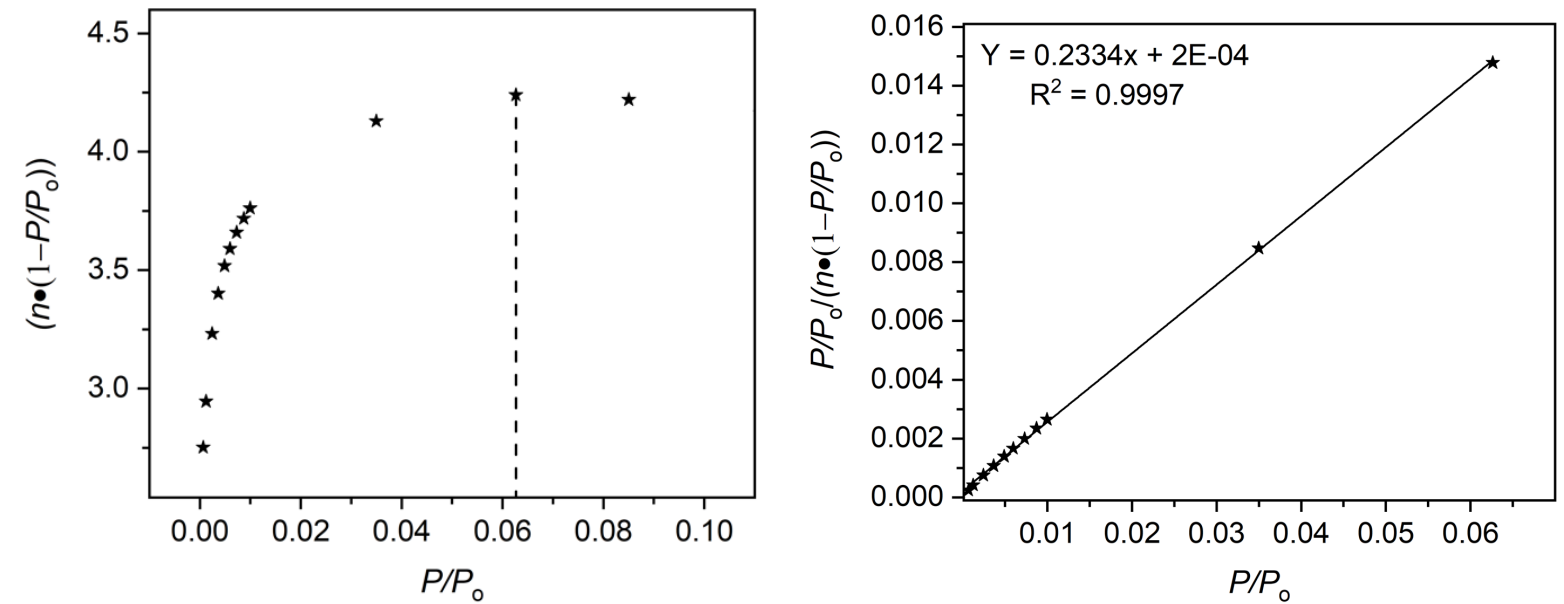

Figure S138. Plot of $n \bullet\left(1-P / P_{0}\right)$ vs $P / P_{0}$ to determine the maximum $P / P_{\mathrm{o}}$ used in the BET linear fit according to the first BET consistency criterion for the adsorption of $\mathrm{N}_{2}$ in $5 \mathrm{~T} / \mathrm{C}$ at $77 \mathrm{~K}$. Plot of $\left(P / P_{0}\right) /\left(n \bullet\left(1-P / P_{0}\right)\right)$ vs $P / P_{0}$ to determine the BET surface area from $N_{2}$ adsorption at $77 \mathrm{~K}$. The slope of the best fit lit for $P / P_{0}<0.063$ is 0.2334 and the $y$-intercept is 0.0002 , which satisfies the second BET consistency criterion. This results in a surface area of $417.9 \mathrm{~m}^{2} / \mathrm{g}$. 


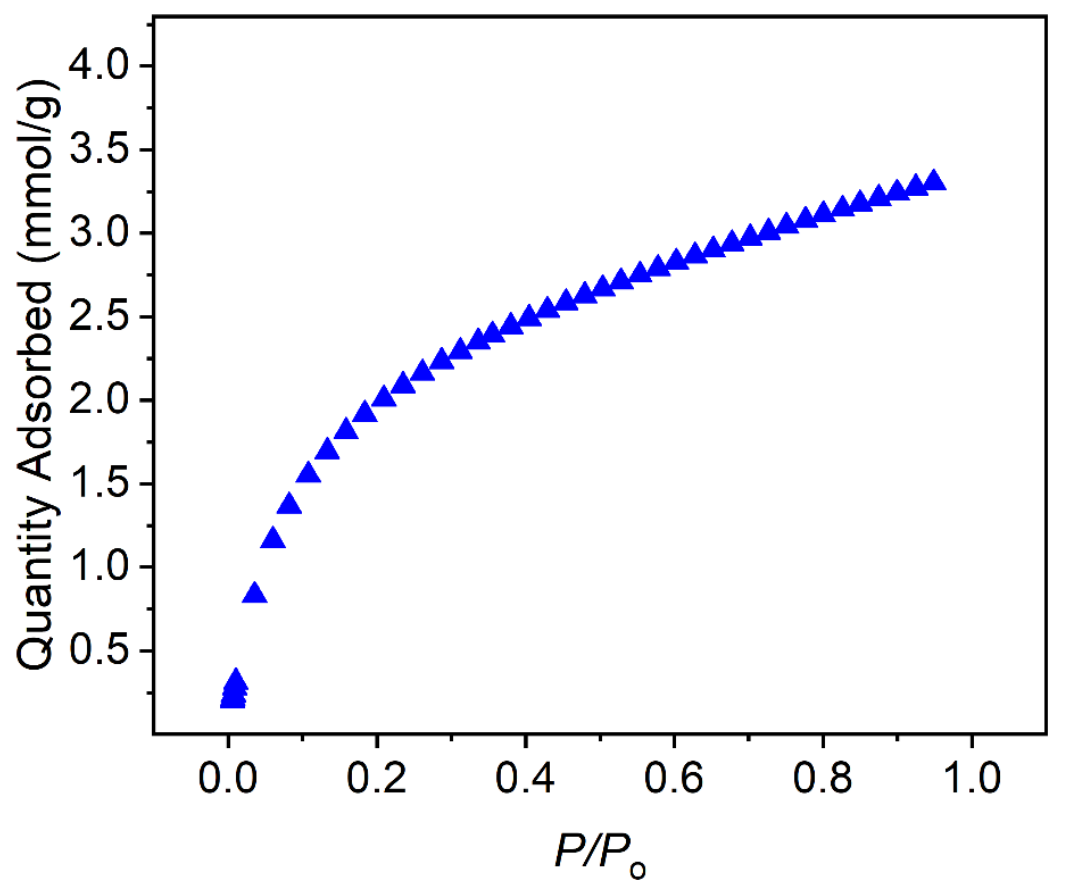

Figure S139. Adsorption of $\mathrm{CO}_{2}$ in $\mathbf{5 T / C}$ at $195 \mathrm{~K}$.
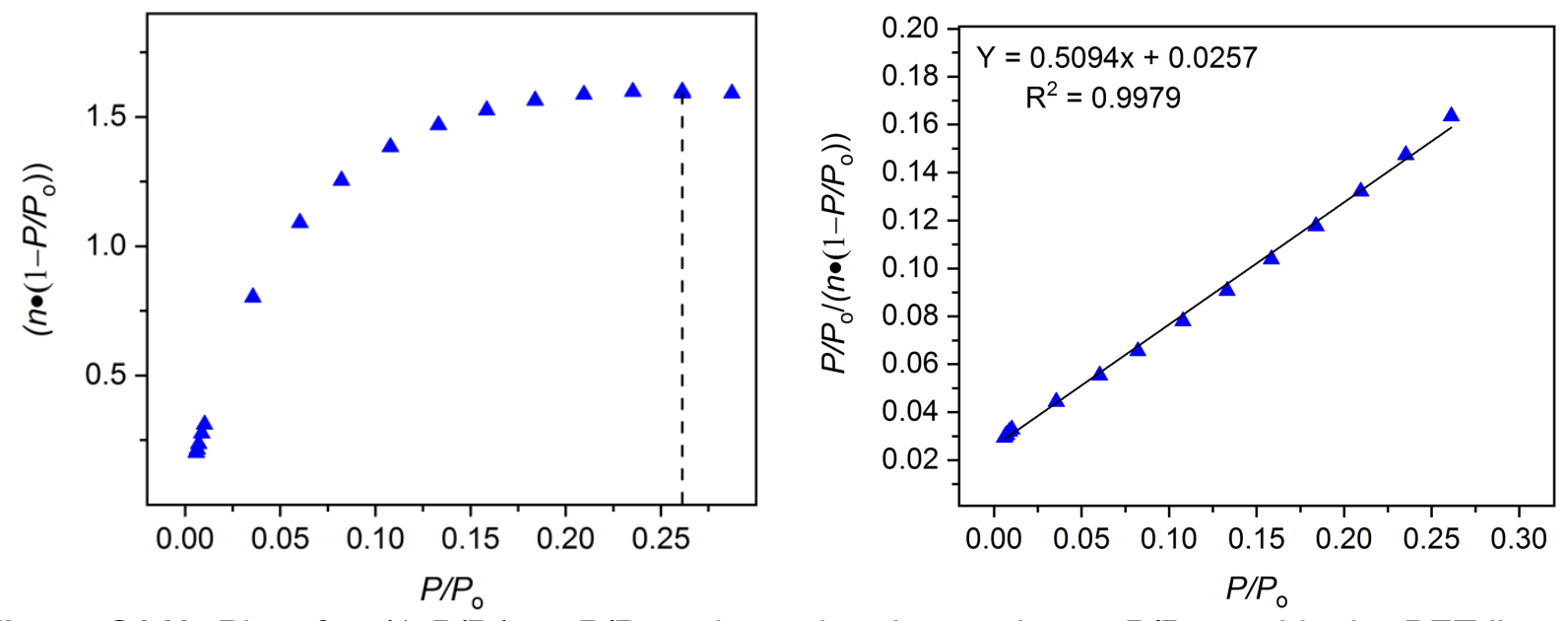

Figure S140. Plot of $n \bullet\left(1-P / P_{0}\right)$ vs $P / P_{0}$ to determine the maximum $P / P_{0}$ used in the BET linear fit according to the first BET consistency criterion for the adsorption of $\mathrm{CO}_{2}$ in $\mathbf{5 T / C}$ at $195 \mathrm{~K}$. Plot of $\left(P / P_{\mathrm{o}}\right) /\left(n \bullet\left(1-P / P_{\mathrm{o}}\right)\right)$ vs $P / P_{\mathrm{o}}$ to determine the BET surface area from $\mathrm{CO}_{2}$ adsorption at $195 \mathrm{~K}$. The slope of the best fit lit for $P / P_{0}<0.261$ is 0.5094 and the $y$-intercept is 0.0257 , which satisfies the second BET consistency criterion. This results in a surface area of $201.0 \mathrm{~m}^{2} / \mathrm{g}$. 


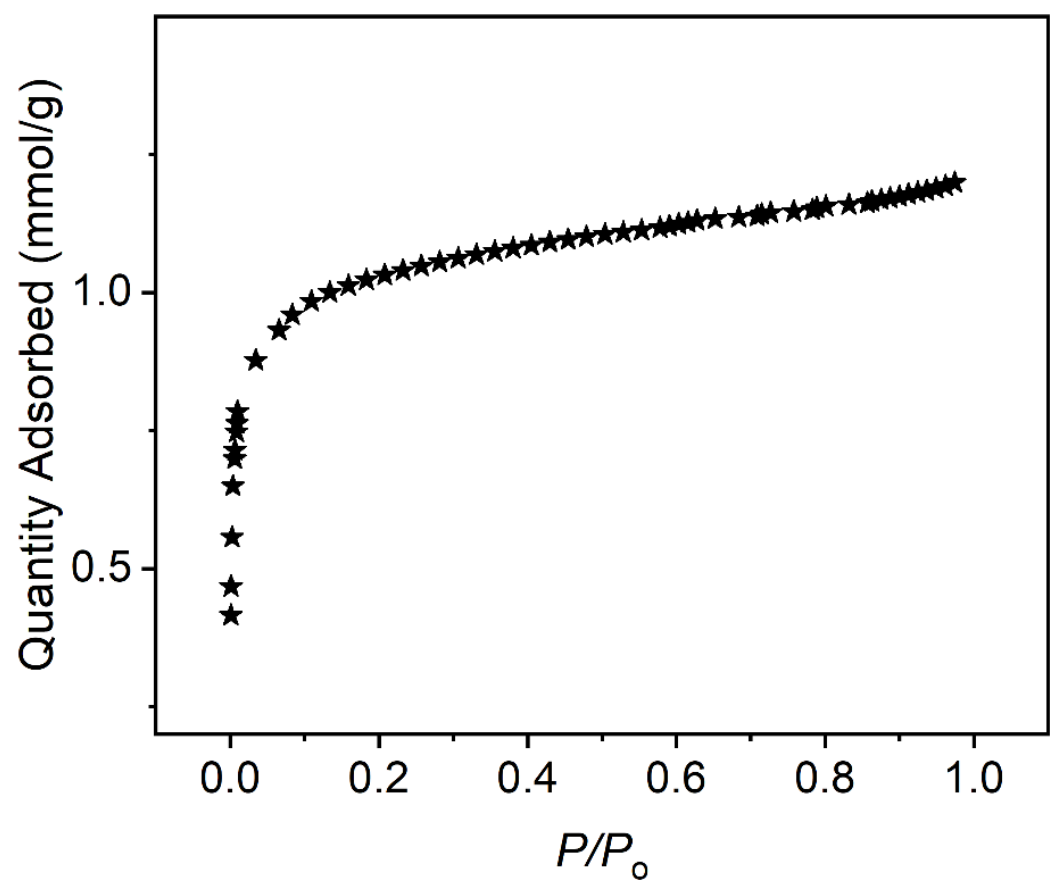

Figure S141. Adsorption of $\mathrm{N}_{2}$ in $6 \mathrm{C}$ at $77 \mathrm{~K}$.
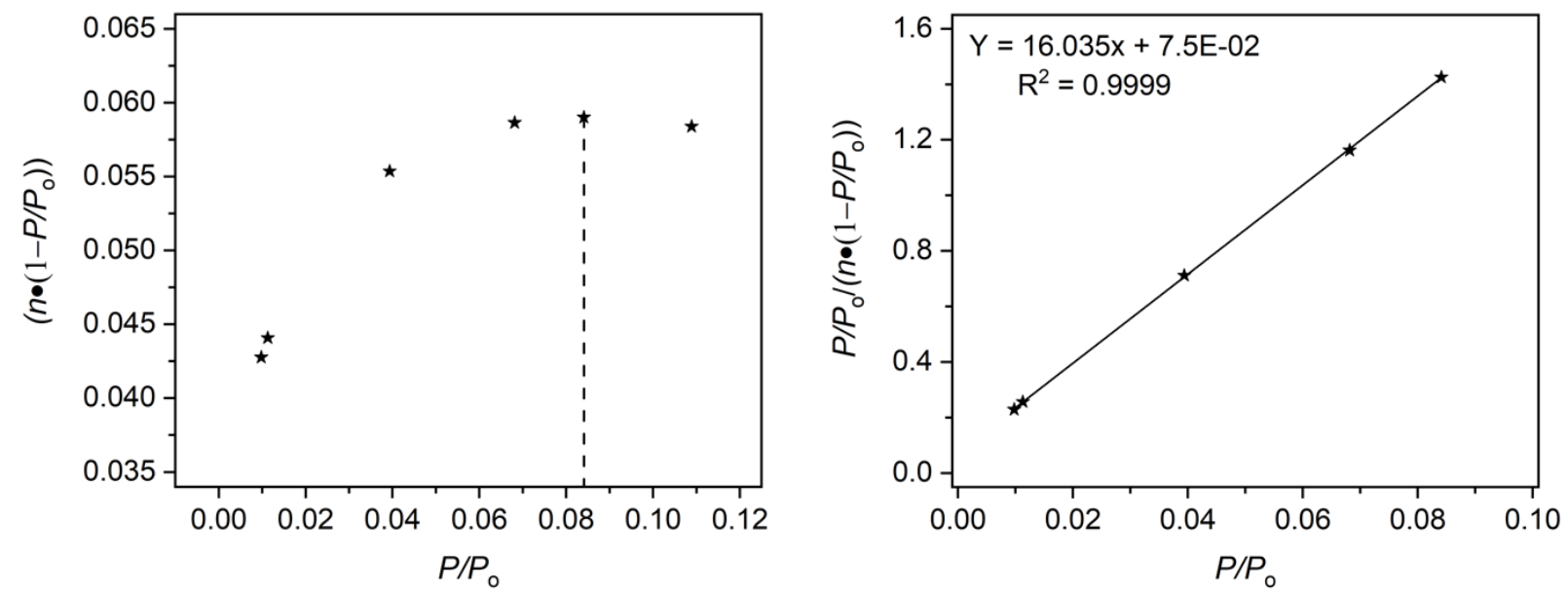

Figure S142. Plot of $n \bullet\left(1-P / P_{0}\right)$ vs $P / P_{o}$ to determine the maximum $P / P_{\mathrm{o}}$ used in the BET linear fit according to the first BET consistency criterion for the adsorption of $\mathrm{N}_{2}$ in $6 \mathrm{C}$ at $77 \mathrm{~K}$. Plot of $\left(P / P_{0}\right) /\left(n \bullet\left(1-P / P_{0}\right)\right)$ vs $P / P_{0}$ to determine the BET surface area from $N_{2}$ adsorption at $77 \mathrm{~K}$. The slope of the best fit lit for $P / P_{0}<0.084$ is 16.035 and the $y$-intercept is 0.075 , which satisfies the second BET consistency criterion. This results in a surface area of $6.1 \mathrm{~m}^{2} / \mathrm{g}$. 


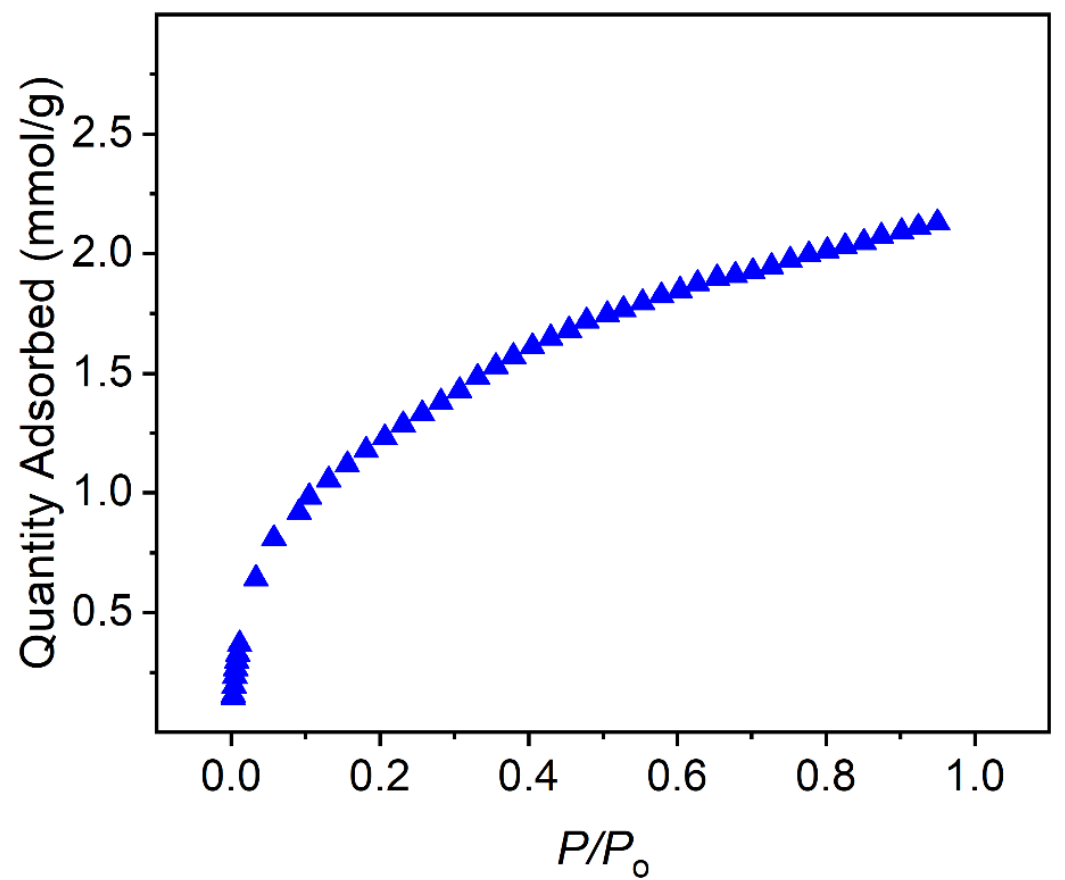

Figure S143. Adsorption of $\mathrm{CO}_{2}$ in $6 \mathrm{C}$ at $195 \mathrm{~K}$.
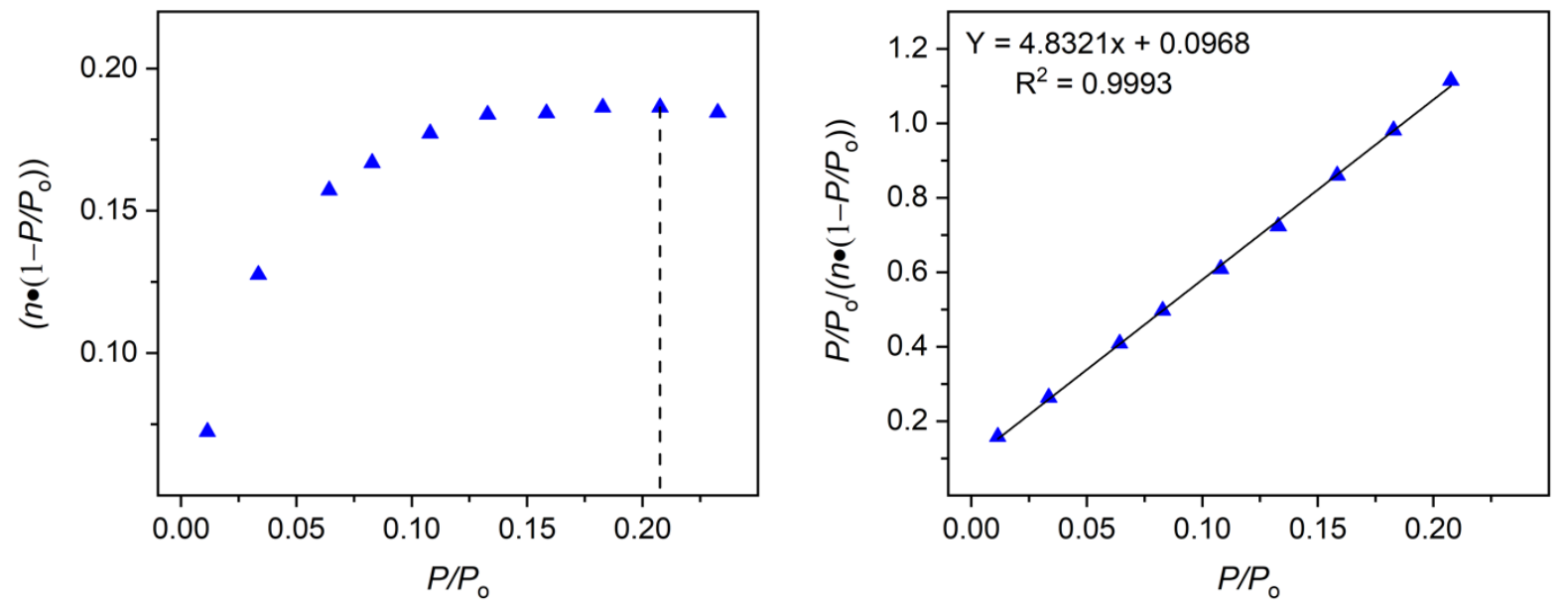

Figure S144. Plot of $n \bullet\left(1-P / P_{0}\right)$ vs $P / P_{0}$ to determine the maximum $P / P_{0}$ used in the BET linear fit according to the first $\mathrm{BET}$ consistency criterion for the adsorption of $\mathrm{CO}_{2}$ in $6 \mathrm{C}$ at $195 \mathrm{~K}$. Plot of $\left(P / P_{0}\right) /\left(n \bullet\left(1-P / P_{0}\right)\right)$ vs $P / P_{0}$ to determine the BET surface area from $\mathrm{CO}_{2}$ adsorption at $195 \mathrm{~K}$. The slope of the best fit lit for $p / p_{o}<0.208$ is 4.8321 and the $y$-intercept is 0.0968 , which satisfies the second BET consistency criterion. This results in a surface area of $21.2 \mathrm{~m}^{2} / \mathrm{g}$. 


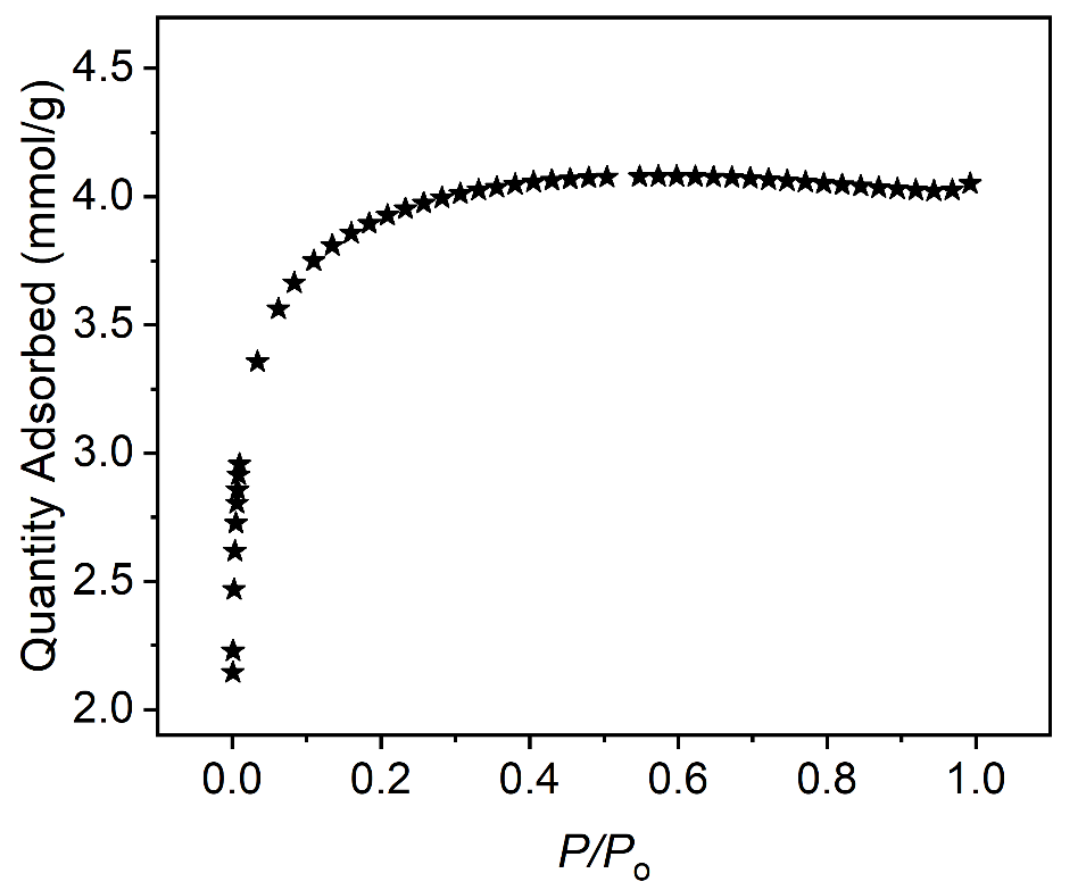

Figure S145. Adsorption of $\mathrm{N}_{2}$ in $7 \mathrm{~T} / \mathrm{C}$ at $77 \mathrm{~K}$.
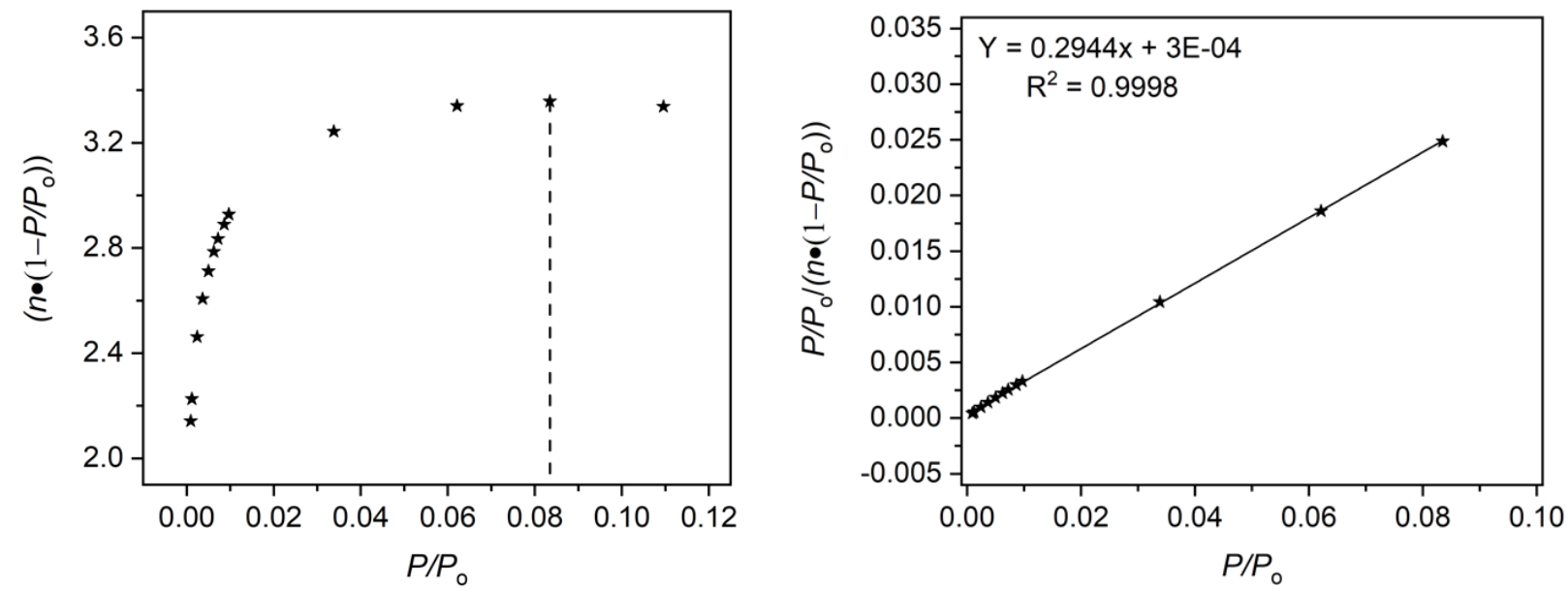

Figure S146. Plot of $n \bullet\left(1-P / P_{\circ}\right)$ vs $P / P_{\circ}$ to determine the maximum $P / P_{\circ}$ used in the $B E T$ linear fit according to the first $\mathrm{BET}$ consistency criterion for the adsorption of $\mathrm{N}_{2}$ in $7 \mathrm{~T} / \mathrm{C}$ at $77 \mathrm{~K}$. Plot of $\left(P / P_{0}\right) /\left(n \bullet\left(1-P / P_{0}\right)\right)$ vs $P / P_{0}$ to determine the BET surface area from $N_{2}$ adsorption at $77 \mathrm{~K}$. The slope of the best fit lit for $P / P_{o}<0.083$ is 0.2944 and the $y$-intercept is 0.0003 , which satisfies the second BET consistency criterion. This results in a surface area of $331.4 \mathrm{~m}^{2} / \mathrm{g}$. 


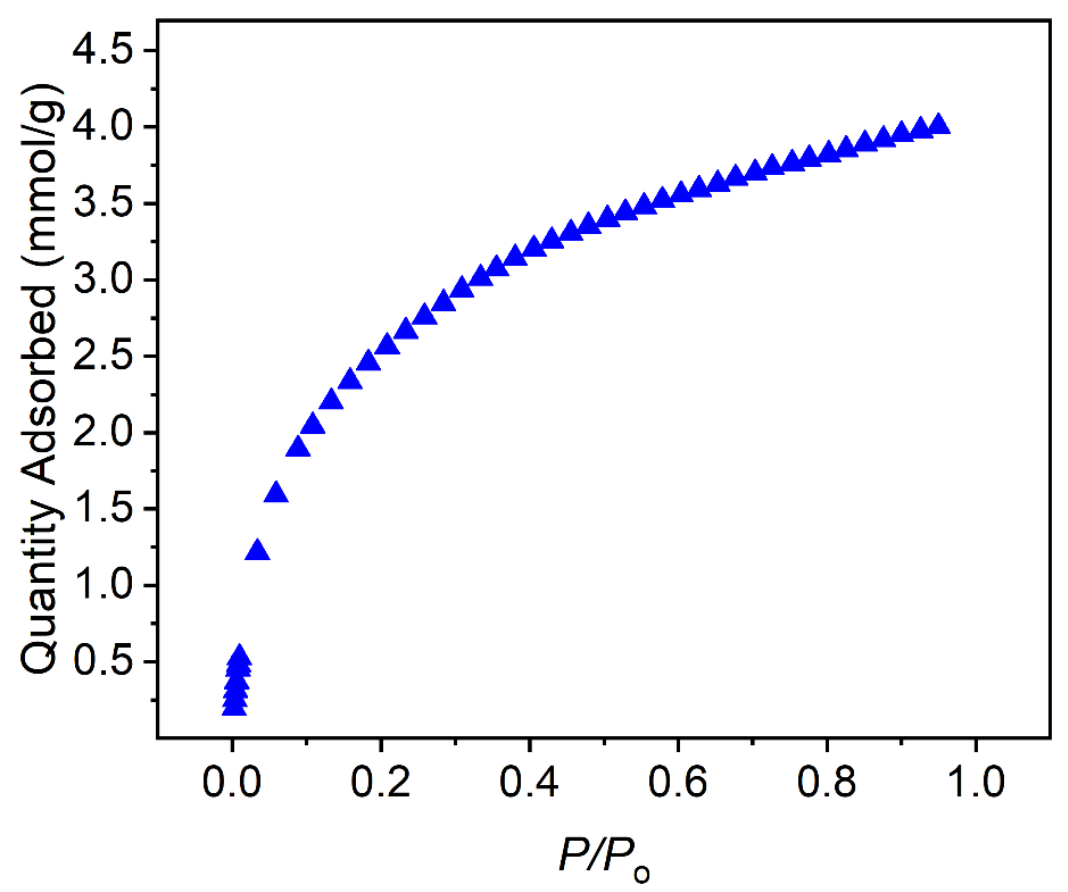

Figure S147. Adsorption of $\mathrm{CO}_{2}$ in $7 \mathrm{~T} / \mathrm{C}$ at $195 \mathrm{~K}$.
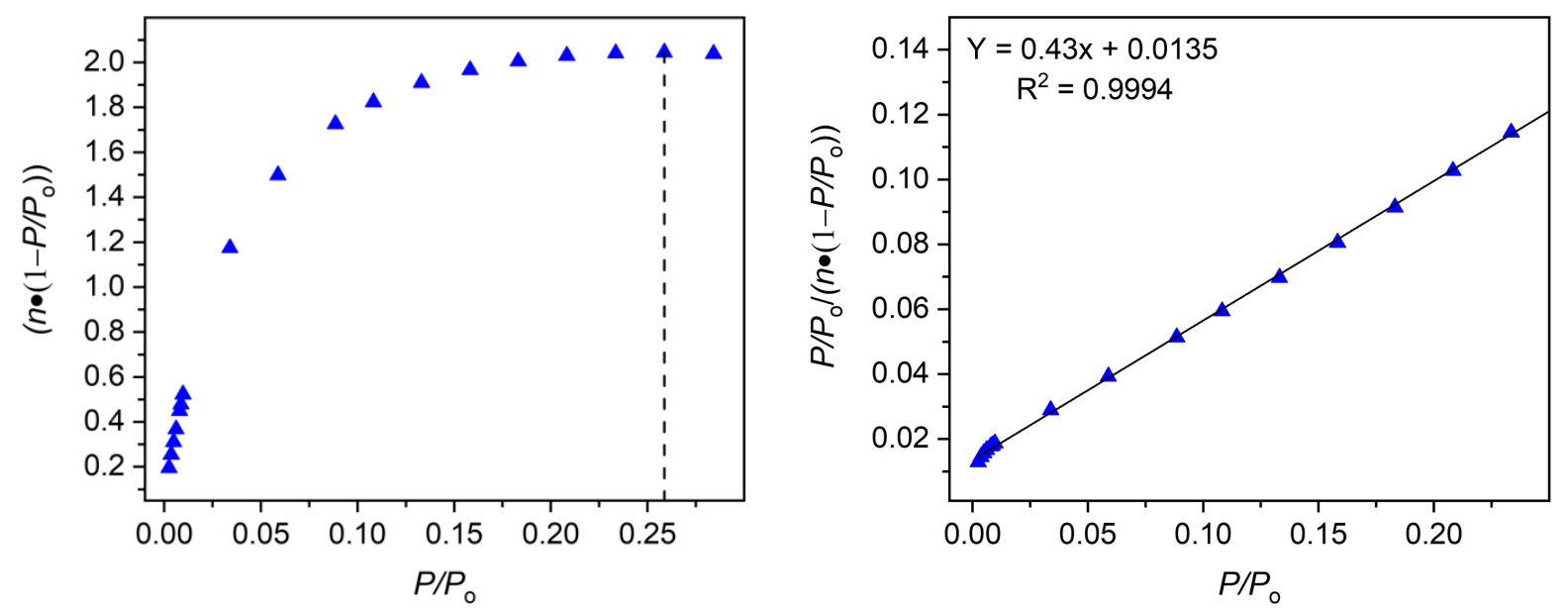

Figure S148. Plot of $n \bullet\left(1-P / P_{0}\right)$ vs $P / P_{0}$ to determine the maximum $P / P_{0}$ used in the BET linear fit according to the first BET consistency criterion for the adsorption of $\mathrm{CO}_{2}$ in $7 \mathrm{~T} / \mathrm{C}$ at $195 \mathrm{~K}$. Plot of $\left(P / P_{\circ}\right) /\left(n \bullet\left(1-P / P_{\circ}\right)\right)$ vs $P / P_{\circ}$ to determine the BET surface area for $\mathrm{CO}_{2}$ adsorption at $195 \mathrm{~K}$ of $7 \mathrm{~T} / \mathrm{C}$. The slope of the best fit lit for $P / P_{0}<0.259$ is 0.43 and the $y$-intercept is 0.0135 , which satisfies the second BET consistency criterion. This results in a surface area of $238.1 \mathrm{~m}^{2} / \mathrm{g}$. 


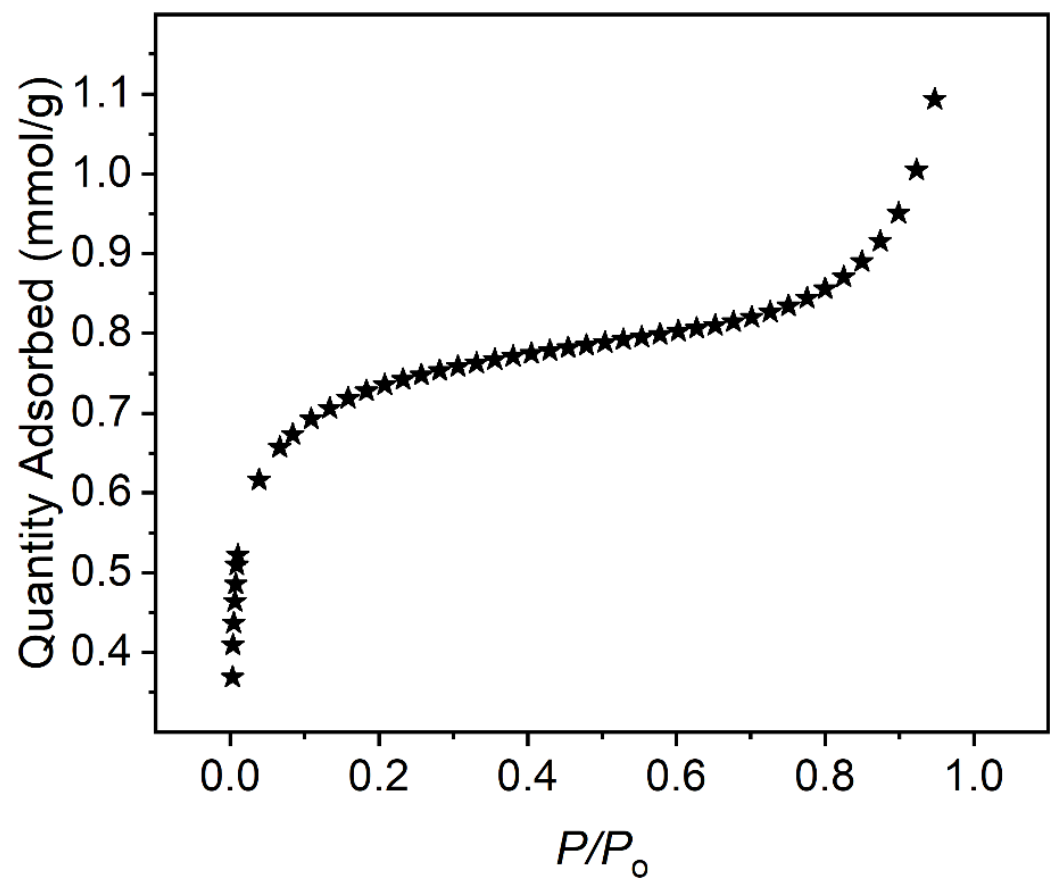

Figure S149. Adsorption of $\mathrm{N}_{2}$ in $10 \mathrm{C} \_\mathrm{Cl}$ at $77 \mathrm{~K}$.
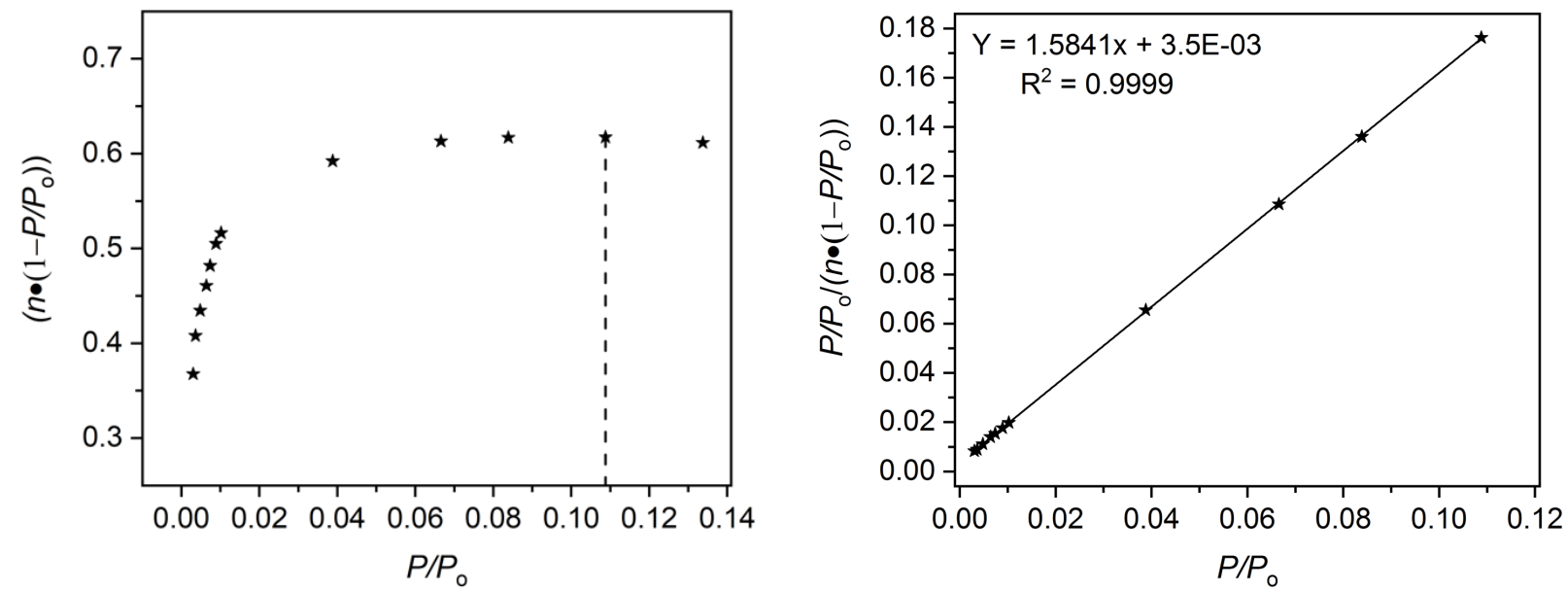

Figure S150. Plot of $n \bullet\left(1-P / P_{\mathrm{o}}\right)$ vs $P / P_{\mathrm{o}}$ to determine the maximum $P / P_{\mathrm{o}}$ used in the $\mathrm{BET}$ linear fit according to the first $\mathrm{BET}$ consistency criterion for the adsorption of $\mathrm{N}_{2}$ in $10 \mathrm{C} \_\mathrm{Cl}$ at $77 \mathrm{~K}$. Plot of $\left(P / P_{0}\right) /\left(n \bullet\left(1-P / P_{0}\right)\right)$ vs $P / P_{0}$ to determine the BET surface area from $N_{2}$ adsorption at $77 \mathrm{~K}$. The slope of the best fit lit for $P / P_{0}<0.109$ is 1.5841 and the $y$-intercept is 0.0035 , which satisfies the second BET consistency criterion. This results in a surface area of $61.6 \mathrm{~m}^{2} / \mathrm{g}$. 


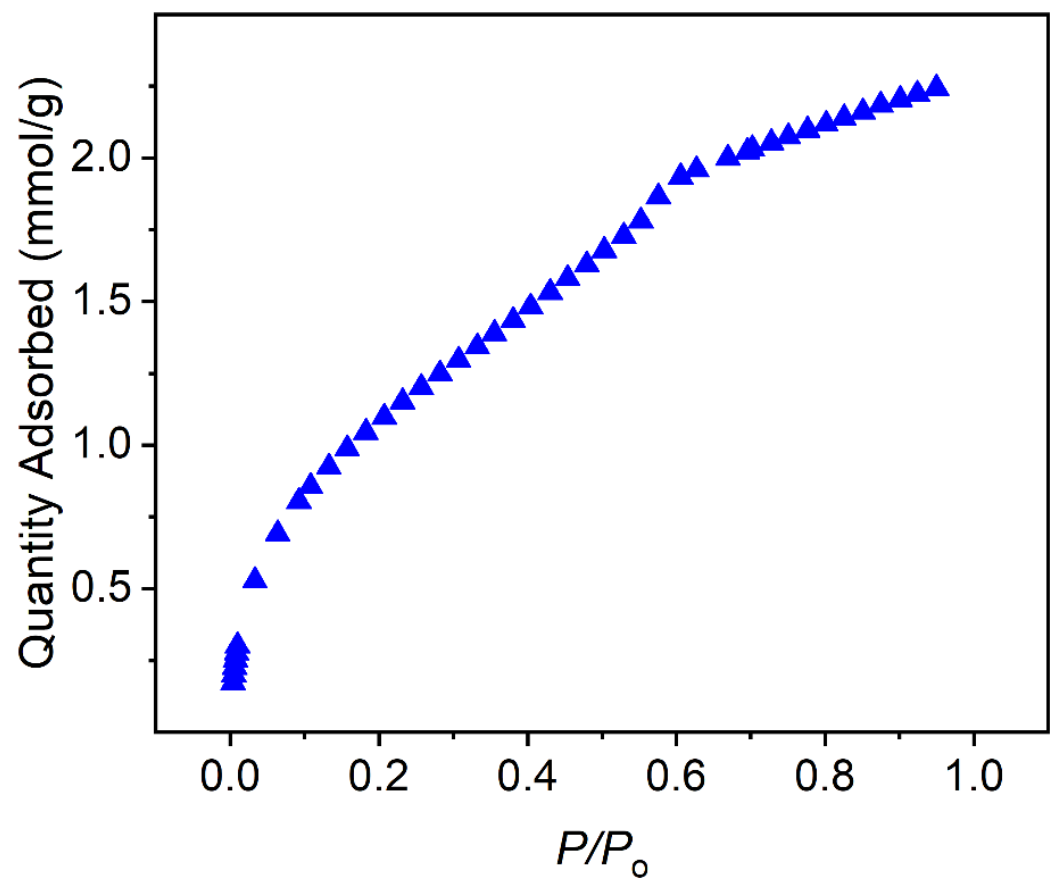

Figure S151. Adsorption of $\mathrm{CO}_{2}$ in $10 \mathrm{C} \_\mathrm{Cl}$ at $195 \mathrm{~K}$.
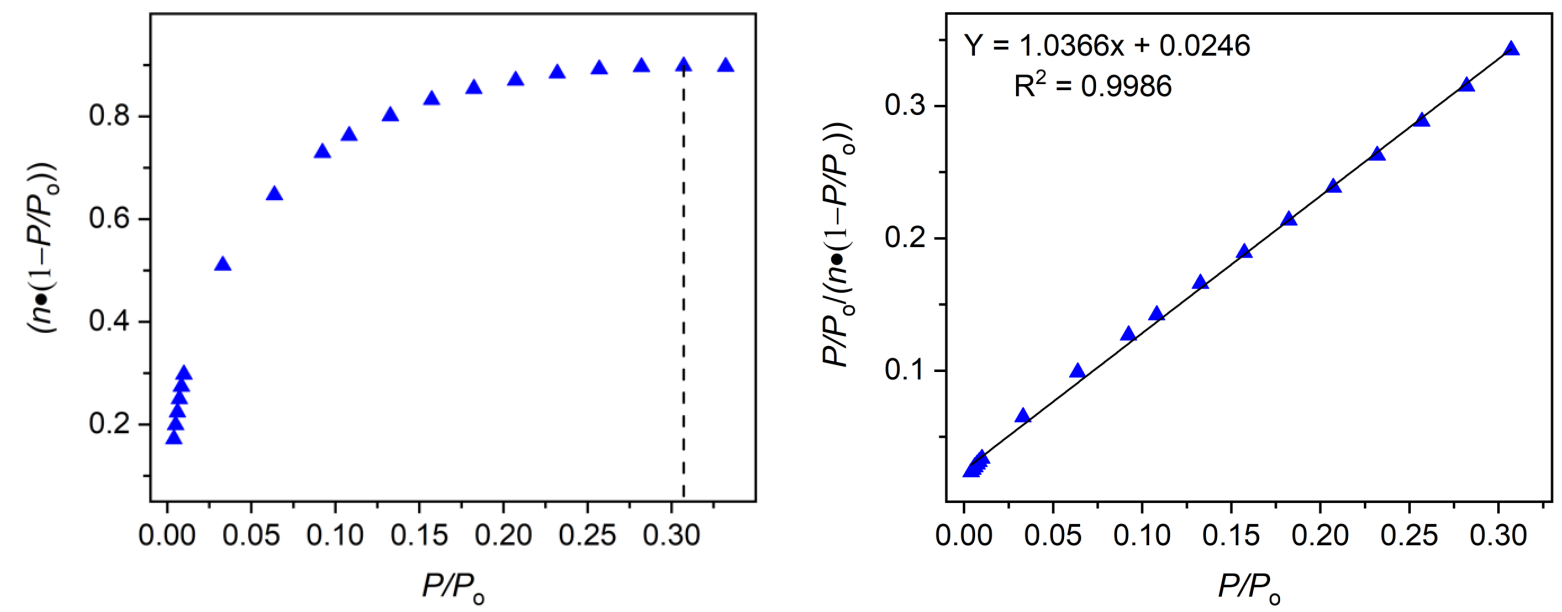

Figure S152. Plot of $n \bullet\left(1-P / P_{o}\right)$ vs $P / P_{o}$ to determine the maximum $p / p_{o}$ used in the BET linear fit according to the first BET consistency criterion for the adsorption of $\mathrm{CO}_{2}$ in $10 \mathrm{C} \_\mathrm{Cl}$ at $195 \mathrm{~K}$. Plot of $\left(P / P_{\mathrm{o}}\right) /\left(n \bullet\left(1-P / P_{\mathrm{o}}\right)\right)$ vs $P / P_{\mathrm{o}}$ to determine the $\mathrm{BET}$ surface area from $\mathrm{CO}_{2}$ adsorption at 195 $\mathrm{K}$. The slope of the best fit lit for $P / P_{0}<0.307$ is 1.0366 and the $y$-intercept is 0.0246 , which satisfies the second BET consistency criterion. This results in a surface area of $98.8 \mathrm{~m}^{2} / \mathrm{g}$. 


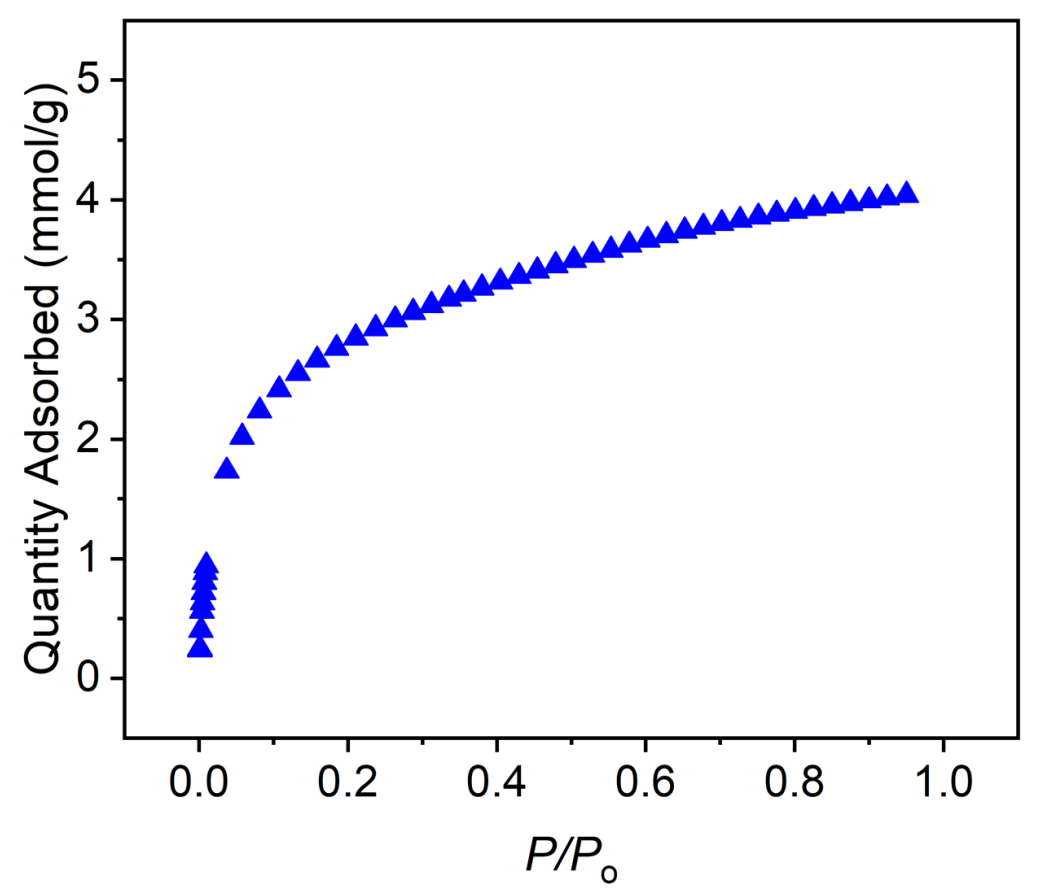

Figure S153. Adsorption of $\mathrm{CO}_{2}$ in $12 \mathrm{~T}$ at $195 \mathrm{~K}$.
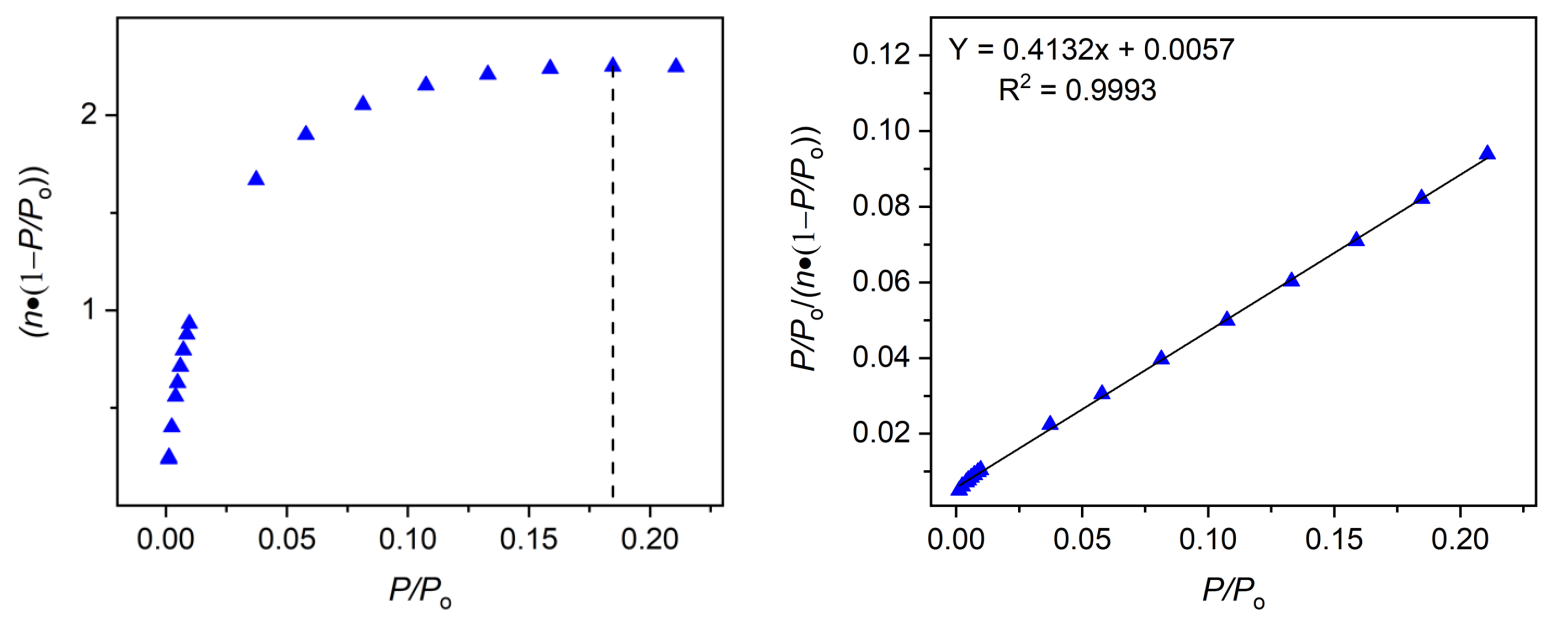

Figure S154. Plot of $n \bullet\left(1-P / P_{0}\right)$ vs $P / P_{0}$ to determine the maximum $P / P_{0}$ used in the BET linear fit according to the first BET consistency criterion for the adsorption of $\mathrm{CO}_{2}$ in $12 \mathrm{~T}$ at $195 \mathrm{~K}$. Plot of $\left(P / P_{\mathrm{o}}\right) /\left(n \bullet\left(1-P / P_{\mathrm{o}}\right)\right)$ vs $P / P_{\mathrm{o}}$ to determine the BET surface area from $\mathrm{CO}_{2}$ adsorption at $195 \mathrm{~K}$. The slope of the best fit lit for $P / P_{0}<0.185$ is 0.4132 and the $y$-intercept is 0.0057 , which satisfies the second BET consistency criterion. This results in a surface area $247.8 \mathrm{~m}^{2} / \mathrm{g}$. 
Table S1 - Nitrogen and $\mathrm{CO}_{2}$ surface areas of select Zirconium Coordination cages.

\begin{tabular}{|c|c|c|c|c|c|}
\hline \# & Material (Phase) & $\begin{array}{c}\mathbf{N}_{\mathbf{2}} \mathbf{B E T} \\
\left(\mathbf{m}^{2} / \mathbf{g}\right)\end{array}$ & $\begin{array}{c}\mathbf{N}_{\mathbf{2}} \text { Langmuir } \\
\left(\mathbf{m}^{2} / \mathbf{g}\right)\end{array}$ & $\begin{array}{c}\mathbf{C O}_{2} \mathbf{~ B E T} \\
\left(\mathbf{m}^{2} / \mathbf{g}\right)\end{array}$ & $\begin{array}{c}\mathbf{C O}_{2} \text { Langmuir } \\
\left(\mathbf{m}^{2} / \mathbf{g}\right)\end{array}$ \\
\hline $\mathbf{1}$ & fum (C) & - & - & 86.8 & 165 \\
\hline $\mathbf{4}$ & $\mathrm{Me}_{2}$-bdc_Cl (T) & 610.5 & 741 & 238.1 & 748 \\
\hline $\mathbf{4}$ & $\mathrm{Me}_{2}$-bdc_OTf (T) & 415.5 & 606 & 129.4 & 331 \\
\hline $\mathbf{5}$ & $2,6-\mathrm{ndc}(\mathrm{T} / \mathrm{C})$ & 417.9 & 525 & 201.0 & 402 \\
\hline $\mathbf{6}$ & $\mathrm{tda}(\mathrm{C})$ & 6.1 & 3 & 21.2 & 23 \\
\hline $\mathbf{7}$ & $\mathrm{F}-\mathrm{pda}(\mathrm{T} / \mathrm{C})$ & 331.4 & 402 & 238.1 & 471 \\
\hline $\mathbf{1 0}$ & $\mathrm{Me}_{2}$-tpdc (T/C) & 61.6 & 84 & 98.8 & 303 \\
\hline $\mathbf{1 2}$ & $9,10-$-aba (T) & - & - & 247.8 & 475 \\
\hline
\end{tabular}




\section{X-Ray Crystallography}

X-ray structural analysis for $\left.\left[\mathrm{Zr}_{6}\left(\mu_{3}-\mathrm{O}\right)_{2}\left(\mu_{2}-\mathrm{OH}\right)_{6}(\mathrm{Cp})_{6} \text { (fum }\right)_{3}\right] \mathrm{Cl}_{2} \quad$ (1C), $\quad\left[\mathrm{Zr}_{6}\left(\mu_{3^{-}} \mathrm{O}\right)_{2}\left(\mu_{2^{-}}\right.\right.$ $\left.\mathrm{OH})_{6}(\mathrm{Cp})_{6}(\mathrm{bdc})_{3}\right](\mathrm{OTf})_{2}$ (2C_OTf), $\left[\mathrm{Zr}_{12}\left(\mu_{3}-\mathrm{O}\right)_{4}\left(\mu_{2}-\mathrm{OH}\right)_{12}(\mathrm{Cp})_{12}(1,4-\mathrm{ndc})_{6}\right] \mathrm{Cl}_{4}$ (3T), $\left[\mathrm{Zr}_{12}\left(\mu_{3}-\mathrm{O}\right)_{4}\left(\mu_{2}-\right.\right.$ $\left.\mathrm{OH})_{12}(\mathrm{Cp})_{12}\left(\mathrm{Me}_{2}-\mathrm{bdc}\right)_{6}\right] \mathrm{Cl}_{4} \quad$ (4T_Cl), $\left[\mathrm{Zr}_{12}\left(\mu_{3}-\mathrm{O}\right)_{4}\left(\mu_{2}-\mathrm{OH}\right)_{12}(\mathrm{Cp})_{12}\left(\mathrm{Me}_{2}-\mathrm{bdc}\right)_{6}\right](\mathrm{OTf})_{4}$ (4T_OTf), $\left[\mathrm{Zr}_{12}\left(\mu_{3}-\mathrm{O}\right)_{4}\left(\mu_{2}-\mathrm{OH}\right)_{12}(\mathrm{Cp})_{12}(2,6-\mathrm{ndc})_{6}\right] \mathrm{Cl}_{4} \quad(\mathbf{5 T}), \quad\left[\mathrm{Zr}_{6}\left(\mu_{3}-\mathrm{O}\right)_{2}\left(\mu_{2}-\mathrm{OH}\right)_{6}(\mathrm{Cp})_{6}(2,6-\mathrm{ndc})_{3}\right] \mathrm{Cl}_{2} \quad$ (5C), $\left[\mathrm{Zr}_{6}\left(\mu_{3}-\mathrm{O}\right)_{2}\left(\mu_{2}-\mathrm{OH}\right)_{6}(\mathrm{Cp})_{6}(\mathrm{tda})_{3}\right] \mathrm{Cl}_{2}(\mathbf{6 C}),\left[\mathrm{Zr}_{6}\left(\mu_{3}-\mathrm{O}\right)_{2}\left(\mu_{2}-\mathrm{OH}\right)_{6}(\mathrm{Cp})_{6}(\mathrm{~F}-\mathrm{pda})_{3}\right] \mathrm{Cl}_{2}$ (7C), $\left[\mathrm{Zr}_{6}\left(\mu_{3}-\mathrm{O}\right)_{2}\left(\mu_{2^{-}}\right.\right.$ $\left.\mathrm{OH})_{6}(\mathrm{Cp})_{6}(\mathrm{tpdc})_{3}\right] \mathrm{Cl}_{2}$ (9C), $\left[\mathrm{Zr}_{12}\left(\mu_{3}-\mathrm{O}\right)_{4}\left(\mu_{2}-\mathrm{OH}\right)_{12}(\mathrm{Cp})_{12}\left(\mathrm{Me}_{2} \text {-tpdc }\right)_{6}\right] \mathrm{Cl}_{4}$ (10T_Cl), $\left[\mathrm{Zr}_{6}\left(\mu_{3}-\mathrm{O}\right)_{2}\left(\mu_{2^{-}}\right.\right.$ $\left.\mathrm{OH})_{6}(\mathrm{Cp})_{6}\left(\mathrm{Me}_{2} \text {-tpdc) }\right)_{3}\right] \mathrm{Cl}_{2}$ (10C_Cl), and $\left[\mathrm{Zr}_{6}\left(\mu_{3}-\mathrm{O}\right)_{2}\left(\mu_{2}-\mathrm{OH}\right)_{6}(\mathrm{Cp})_{6}\left(\mathrm{Me}_{2} \text {-tpdc) }\right)_{3}\right](\mathrm{OTf})_{2}$ (10C_OTf): Crystals were mounted using viscous oil onto a plastic mesh and cooled to the data collection temperature. Data were collected on a Bruker-AXS APEX II DUO CCD diffractometer with Cu-Ka radiation $(\lambda=1.54178 \AA$ ) focused with Goebel mirrors. Unit cell parameters were obtained from 48 data frames, $0.5^{\circ} \omega$, from four different sections of the Ewald sphere. The unit-cell dimensions, equivalent reflections and systematic absences in the diffraction data are consistent with $\mathrm{C} c$ and C2/c for $\left[\mathrm{Zr}_{6}\left(\mu_{3}-\mathrm{O}\right)_{2}\left(\mu_{2}-\mathrm{OH}\right)_{6}(\mathrm{Cp})_{6}(\mathrm{tda})_{3}\right] \mathrm{Cl}_{2}(\mathbf{6 C}),\left[\mathrm{Zr}_{6}\left(\mu_{3}-\mathrm{O}\right)_{2}\left(\mu_{2}-\mathrm{OH}\right)_{6}(\mathrm{Cp})_{6}(2,6-\mathrm{ndc})_{3}\right] \mathrm{Cl}_{2}(\mathbf{5 C})$ and $\left[\mathrm{Zr}_{6}\left(\mu_{3}-\mathrm{O}\right)_{2}\left(\mu_{2}-\mathrm{OH}\right)_{6}(\mathrm{Cp})_{6}\left(\mathrm{Me}_{2} \text {-tpdc }\right)_{3}\right] \mathrm{Cl}_{2} \quad\left(10 \mathrm{C} \_\mathrm{Cl}\right) ;$ uniquely with $P 2_{1} / \mathrm{c}$ for $\left[\mathrm{Zr}_{12}\left(\mu_{3}-\mathrm{O}\right)_{4}\left(\mu_{2^{-}}\right.\right.$ $\left.\mathrm{OH})_{12}(\mathrm{Cp})_{12}\left(\mathrm{Me}_{2}-\mathrm{bdc}\right)_{6}\right](\mathrm{OTf})_{4}$ (4T_OTf), $\left[\mathrm{Zr}_{6}\left(\mu_{3}-\mathrm{O}\right)_{2}\left(\mu_{2}-\mathrm{OH}\right)_{6}(\mathrm{Cp})_{6}\left(\mathrm{Me}_{2} \text {-tpdc }\right)_{3}\right](\mathrm{OTf})_{2}$ (10C_OTf) and $\left[\mathrm{Zr}_{6}\left(\mu_{3}-\mathrm{O}\right)_{2}\left(\mu_{2}-\mathrm{OH}\right)_{6}(\mathrm{Cp})_{6}(\mathrm{fum})_{3}\right] \mathrm{Cl}_{2}(1 \mathrm{C})$; uniquely with $\mathrm{P} 2_{1} / n$ with $14 \mathrm{~mm}, I-42 \mathrm{~m}, I-4 \mathrm{~m} 2$ and $14 / \mathrm{mmm}$ for $\left[\mathrm{Zr}_{12}\left(\mu_{3}-\mathrm{O}\right)_{4}\left(\mu_{2}-\mathrm{OH}\right)_{12}(\mathrm{Cp})_{12}(2,6-\mathrm{ndc})_{6}\right] \mathrm{Cl}_{4}(5 \mathrm{~T})$; with $14 \mathrm{~cm}, 1-4 \mathrm{c} 2$ and $14 / \mathrm{mcm}$ for $\left[\mathrm{Zr}_{12}\left(\mu_{3}-\mathrm{O}\right)_{4}\left(\mu_{2}-\mathrm{OH}\right)_{12}(\mathrm{Cp})_{12}(1,4-\mathrm{ndc})_{6}\right] \mathrm{Cl}_{4}$ (3T); with $\mathrm{P} 6_{3} m c, P-62 c$ and $\mathrm{P}_{3} / m m c$ for $\left[\mathrm{Zr}_{6}\left(\mu_{3}-\mathrm{O}\right)_{2}\left(\mu_{2^{-}}\right.\right.$ $\left.\mathrm{OH})_{6}(\mathrm{Cp})_{6}(\mathrm{~F}-\mathrm{pda})_{3}\right] \mathrm{Cl}_{2} \quad(\mathbf{7 C})$; and with $\mathrm{F} 432, \quad \mathrm{~F}-43 m$ and $\mathrm{Fm}-3 \mathrm{~m}$ for $\left[\mathrm{Zr}_{12}\left(\mu_{3}-\mathrm{O}\right)_{4}\left(\mu_{2^{-}}\right.\right.$ $\left.\mathrm{OH})_{12}(\mathrm{Cp})_{12}\left(\mathrm{Me}_{2}-\mathrm{bdc}\right)_{6}\right] \mathrm{Cl}_{4}\left(\mathbf{4 T} \_\mathrm{CI}\right)$ and $\left[\mathrm{Zr}_{12}\left(\mu_{3}-\mathrm{O}\right)_{4}\left(\mu_{2}-\mathrm{OH}\right)_{12}(\mathrm{Cp})_{12}\left(\mathrm{Me}_{2}-\mathrm{tpdc}\right)_{6}\right] \mathrm{Cl}_{4}$ (10T_Cl). No symmetry higher than triclinic was observed for $\left[\mathrm{Zr}_{6}\left(\mu_{3}-\mathrm{O}\right)_{2}\left(\mu_{2}-\mathrm{OH}\right)_{6}(\mathrm{Cp})_{6}(\mathrm{bdc})_{3}\right](\mathrm{OTf})_{2}$ (2C_OTf). Refinement in the centrosymmetric space group options yielded chemically reasonable and computationally stable results of refinement except in $\left[\mathrm{Zr}_{6}\left(\mu_{3}-\mathrm{O}\right)_{2}\left(\mu_{2}-\mathrm{OH}\right)_{6}(\mathrm{Cp})_{6}(\mathrm{~F}-\mathrm{pda})_{3}\right] \mathrm{Cl}_{2}(\mathbf{7 C})$ where only $P-62 c$ yielded reasonable results. The data were treated with multi-scan absorption corrections. ${ }^{6}$ Structures were solved using intrinsic phasing methods ${ }^{7}$ and refined with full-matrix, least-squares procedures on $F^{2} .8$

The compound molecule is located at a four-fold rotoinversion axis, three-fold rotation axis and a mirror plane for $\left[\mathrm{Zr}_{12}\left(\mu_{3}-\mathrm{O}\right)_{4}\left(\mu_{2}-\mathrm{OH}\right)_{12}(\mathrm{Cp})_{12}\left(\mathrm{Me}_{2}-\mathrm{bdc}\right)_{6}\right] \mathrm{Cl}_{4}$ (4T_Cl) and $\left[\mathrm{Zr}_{12}\left(\mu_{3}-\mathrm{O}\right)_{4}\left(\mu_{2^{-}}\right.\right.$ $\left.\mathrm{OH})_{12}(\mathrm{Cp})_{12}\left(\mathrm{Me}_{2} \text {-tpdc }\right)_{6}\right] \mathrm{Cl}_{4}$ (10T_Cl); at a four-fold rotoinversion axis, two-fold rotation axis and a mirror plane for $\left[\mathrm{Zr}_{12}\left(\mu_{3}-\mathrm{O}\right)_{4}\left(\mu_{2}-\mathrm{OH}\right)_{12}(\mathrm{Cp})_{12}(2,6-\mathrm{ndc})_{6}\right] \mathrm{Cl}_{4}(5 \mathrm{~T})$; at a mirror plane in $\left[\mathrm{Zr}_{12}\left(\mu_{3}-\mathrm{O}\right)_{4}\left(\mu_{2^{-}}\right.\right.$ $\left.\mathrm{OH})_{12}(\mathrm{Cp})_{12}(1,4-\mathrm{ndc})_{6}\right] \mathrm{Cl}_{4}(\mathbf{3 T})$; at a two-fold axis in $\left[\mathrm{Zr}_{6}\left(\mu_{3}-\mathrm{O}\right)_{2}\left(\mu_{2}-\mathrm{OH}\right)_{6}(\mathrm{Cp})_{6}(\mathrm{tda})_{3}\right] \mathrm{Cl}_{2}(\mathbf{6 C})$, $\left[\mathrm{Zr}_{6}\left(\mu_{3}-\mathrm{O}\right)_{2}\left(\mu_{2}-\mathrm{OH}\right)_{6}(\mathrm{Cp})_{6}(2,6-\mathrm{ndc})_{3}\right] \mathrm{Cl}_{2} \quad$ (5C) and $\left[\mathrm{Zr}_{6}\left(\mu_{3}-\mathrm{O}\right)_{2}\left(\mu_{2}-\mathrm{OH}\right)_{6}(\mathrm{Cp})_{6}\left(\mathrm{Me}_{2}-\mathrm{tpdc}\right)_{3}\right] \mathrm{Cl}_{2}$ (10C_Cl); and at a three-fold and two-fold axes in $\left[\mathrm{Zr}_{6}\left(\mu_{3}-\mathrm{O}\right)_{2}\left(\mu_{2}-\mathrm{OH}\right)_{6}(\mathrm{Cp})_{6}(\mathrm{~F}-\mathrm{pda})_{3}\right] \mathrm{Cl}_{2}(7 \mathrm{C})$.

The disordered cell contents of highly porous metal-organic polyhedra (MOP) complexes result in diffraction data that are limited in coverage and resolution. As a result, it is common to have multiple restraints and constraints, incompletely identified moieties, and high residuals in reported structural models. ${ }^{9}$ Thus the structure which has not been treated with Squeeze ${ }^{10}$, $\left[\mathrm{Zr}_{6}\left(\mu_{3}-\mathrm{O}\right)_{2}\left(\mu_{2}-\mathrm{OH}\right)_{6}(\mathrm{Cp})_{6}(2,6-\mathrm{ndc})_{3}\right] \mathrm{Cl}_{2} \quad$ (5C) (vide supra et infra), display multiple solvent molecules with varying degrees of disorder. Presumably disordered solvent molecules and nonlocatable parts of moieties were treated as diffused contributions using Squeeze. ${ }^{10}$ As a result, the formulas reported herein reflect only the atoms that were discretely modeled.

In order to refine site occupancies of disordered groups, chemically equivalent atoms in modelled disordered contributions were constrained with equal atomic displacement parameters: $57 / 43$ (DMF) in $\left[\mathrm{Zr}_{6}\left(\mu_{3}-\mathrm{O}\right)_{2}\left(\mu_{2}-\mathrm{OH}\right)_{6}(\mathrm{Cp})_{6}(\mathrm{tpdc})_{3}\right] \mathrm{Cl}_{2}(9 \mathrm{C}) ; 62 / 38,55 / 45,53 / 47$ and 54/46 (four chloride anion positions) in $\left[\mathrm{Zr}_{12}\left(\mu_{3}-\mathrm{O}\right)_{4}\left(\mu_{2}-\mathrm{OH}\right)_{12}(\mathrm{Cp})_{12}(1,4-\mathrm{ndc})_{6}\right] \mathrm{Cl}_{4}$ (3T) with a disordered napthyl moiety set to $50 / 50 ; 51 / 49$ (p-dimethylphenyl moiety) in $\left[\mathrm{Zr}_{6}\left(\mu_{3}-\mathrm{O}\right)_{2}\left(\mu_{2}-\mathrm{OH}\right)_{6}(\mathrm{Cp})_{6}\left(\mathrm{Me}_{2^{-}}\right.\right.$ tpdc) $)_{3} \mathrm{Cl}_{2}$ (10C_Cl); and 57/43 and 52/48 (two $p$-dimethylphenyl moieties) in $\left[\mathrm{Zr}_{12}\left(\mu_{3}-\mathrm{O}\right)_{4}\left(\mu_{2}-\right.\right.$ $\left.\mathrm{OH})_{12}(\mathrm{Cp})_{12}\left(\mathrm{Me}_{2}-\mathrm{bdc}\right)_{6}\right] \mathrm{Cl}_{4}$ (4T_Cl).

Various geometrical constraints and restraints were applied, based on chemical knowledge, where required to compensate for the imprecision of the structures resulting from low resolution 
data to obtain converged results of refinement. Three-dimensional rigid bond restraints on anisotropic displacement parameters were applied. Non-hydrogen atoms were refined with anisotropic displacement parameters. All hydrogen atoms were treated as idealized contributions with geometrically calculated positions and with $U_{\text {iso }}$ equal to $1.2 U_{\text {eq }}\left(1.5 U_{\text {eq }}\right.$ for methyl) of the attached atom. Atomic scattering factors are contained in the SHELXTL program library. ${ }^{8}$ The structures have been deposited at the Cambridge Structural Database under the following CCDC deposition numbers: 1955203-1955220 and 1955417. 


\section{checkCIF/PLATON report}

Structure factors have been supplied for datablock(s) eric309_sq

THIS REPORT IS FOR GUIDANCE ONLY. IF USED AS PART OF A REVIEW PROCEDURE FOR PUBLICATION, IT SHOULD NOT REPLACE THE EXPERTISE OF AN EXPERIENCED CRYSTALLOGRAPHIC REFEREE.

No syntax errors found. CIF dictionary Interpreting this report

\section{Datablock: 1C}

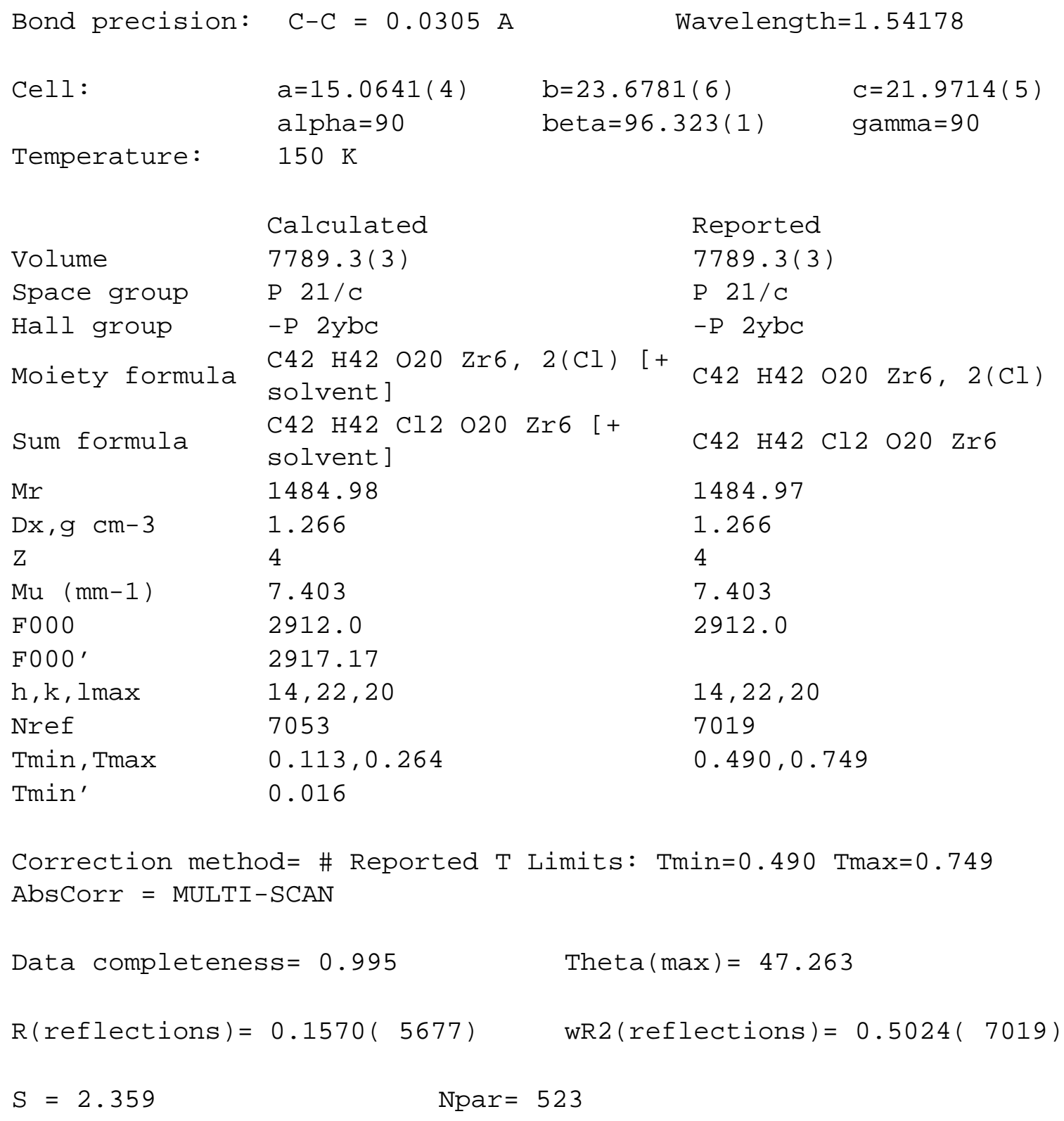




\section{checkCIF/PLATON report}

Structure factors have been supplied for datablock(s) eric190_sq

THIS REPORT IS FOR GUIDANCE ONLY. IF USED AS PART OF A REVIEW PROCEDURE FOR PUBLICATION, IT SHOULD NOT REPLACE THE EXPERTISE OF AN EXPERIENCED CRYSTALLOGRAPHIC REFEREE.

No syntax errors found. CIF dictionary Interpreting this report

\section{Datablock: 2C OTf}

\begin{tabular}{|c|c|c|}
\hline Bond precision: & \multicolumn{2}{|r|}{ Wavelength $=1.54178$} \\
\hline Cell: & $\begin{array}{l}a=12.8761(4) \\
a l p h a=102.277(2)\end{array}$ & $\begin{array}{ll}\mathrm{b}=16.5123(5) & \mathrm{c}=18.5370(6) \\
\text { bet } \mathrm{a}=104.442(2) & \text { gamma=97.331(2) }\end{array}$ \\
\hline \multirow[t]{2}{*}{ Temperature: } & $200 \mathrm{~K}$ & \\
\hline & Calculated & Reported \\
\hline Volume & $3660.8(2)$ & $3660.8(2)$ \\
\hline Space group & $P-1$ & $\mathrm{P}-1$ \\
\hline Hall group & $-\mathrm{P} 1$ & $\begin{array}{ll}-\mathrm{P} & 1\end{array}$ \\
\hline Moiety formula & $\begin{array}{lll}\mathrm{C} 54 & \mathrm{H} 48 \text { O } 20 \text { Zr6, } \\
\mathrm{S}), & \mathrm{CH} 4 \mathrm{O}[+ \text { sol }\end{array}$ & 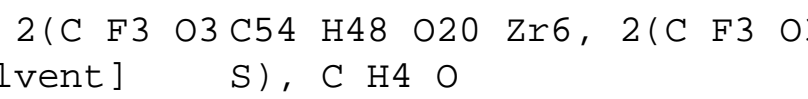 \\
\hline Sum formula & $\begin{array}{l}\text { C57 H52 F6 O27 S2 } \\
\text { solvent] }\end{array}$ & C57 H52 F6 O27 S2 Zr6 \\
\hline $\mathrm{Mr}$ & 1894.43 & 1894.42 \\
\hline $\mathrm{Dx}, \mathrm{gcm}-3$ & 1.719 & 1.719 \\
\hline Z & 2 & 2 \\
\hline $\mathrm{Mu} \quad(\mathrm{mm}-1)$ & 8.091 & 8.091 \\
\hline F000 & 1872.0 & 1872.0 \\
\hline F000' & 1876.46 & \\
\hline $\mathrm{h}, \mathrm{k}, \mathrm{lmax}$ & $12,16,18$ & $12,16,18$ \\
\hline Nref & 7702 & 7545 \\
\hline $\operatorname{Tmin}, \operatorname{Tmax}$ & $0.399,0.503$ & $0.475,0.750$ \\
\hline Tmin' & 0.164 & \\
\hline \multicolumn{3}{|c|}{$\begin{array}{l}\text { Correction method= \# Reported T Limits: Tmin=0.475 Tmax=0.750 } \\
\text { AbsCorr = MULTI-SCAN }\end{array}$} \\
\hline \multicolumn{2}{|c|}{ Data completeness $=0.980$} & Theta $(\max )=50.566$ \\
\hline \multicolumn{2}{|c|}{$R($ reflections $)=0.0584(5854)$} & wR2 (reflections) $=0.1627(7545)$ \\
\hline$=1.102$ & Npar $=\varepsilon$ & 887 \\
\hline
\end{tabular}




\section{checkCIF/PLATON report}

Structure factors have been supplied for datablock(s) eric311_sq

THIS REPORT IS FOR GUIDANCE ONLY. IF USED AS PART OF A REVIEW PROCEDURE FOR PUBLICATION, IT SHOULD NOT REPLACE THE EXPERTISE OF AN EXPERIENCED CRYSTALLOGRAPHIC REFEREE.

No syntax errors found. CIF dictionary Interpreting this report

\section{Datablock: 3T}

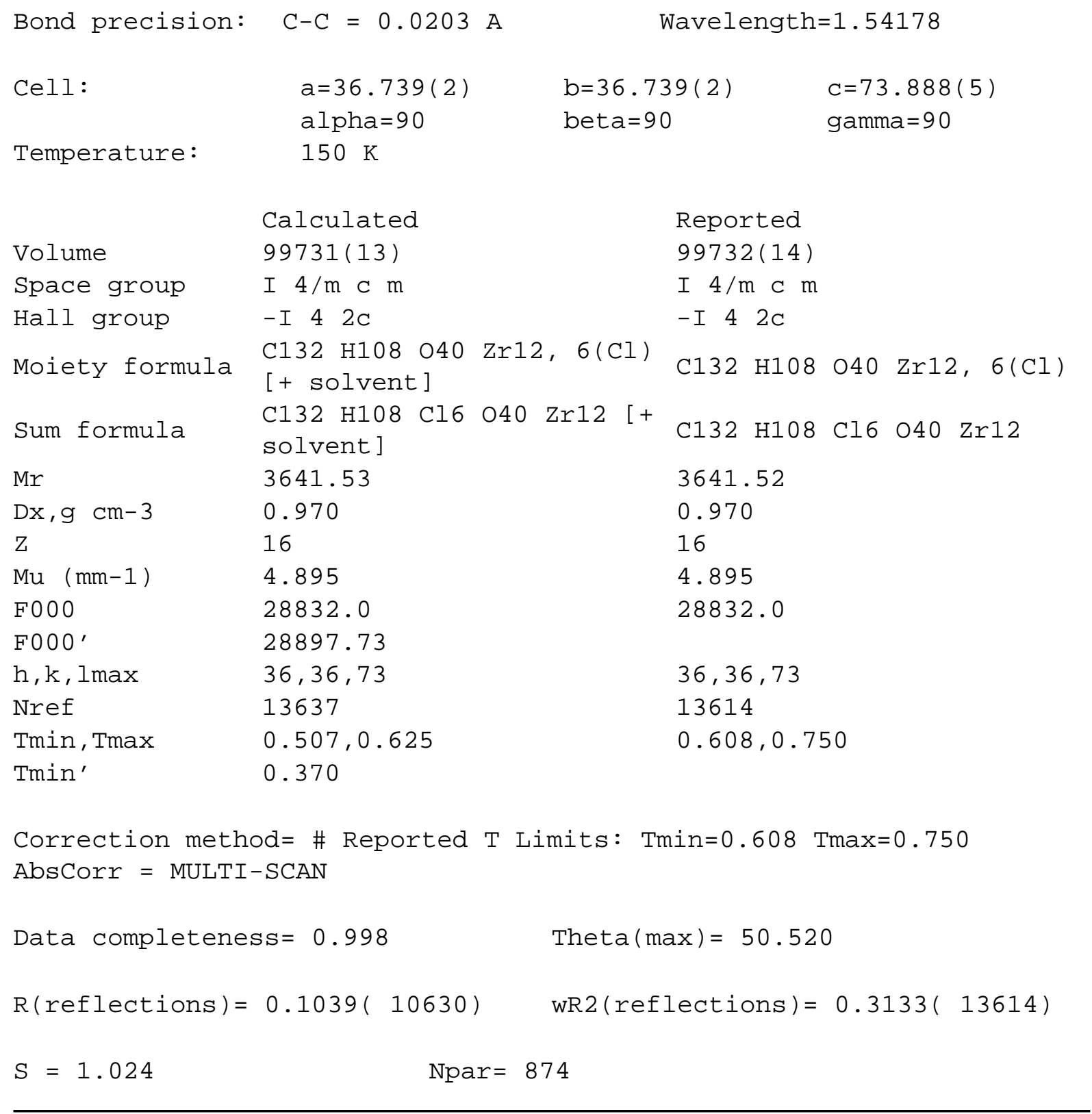




\section{checkCIF/PLATON report}

Structure factors have been supplied for datablock(s) eric214_sq

THIS REPORT IS FOR GUIDANCE ONLY. IF USED AS PART OF A REVIEW PROCEDURE FOR PUBLICATION, IT SHOULD NOT REPLACE THE EXPERTISE OF AN EXPERIENCED CRYSTALLOGRAPHIC REFEREE.

No syntax errors found. CIF dictionary Interpreting this report

\section{Datablock: 4T OTf}

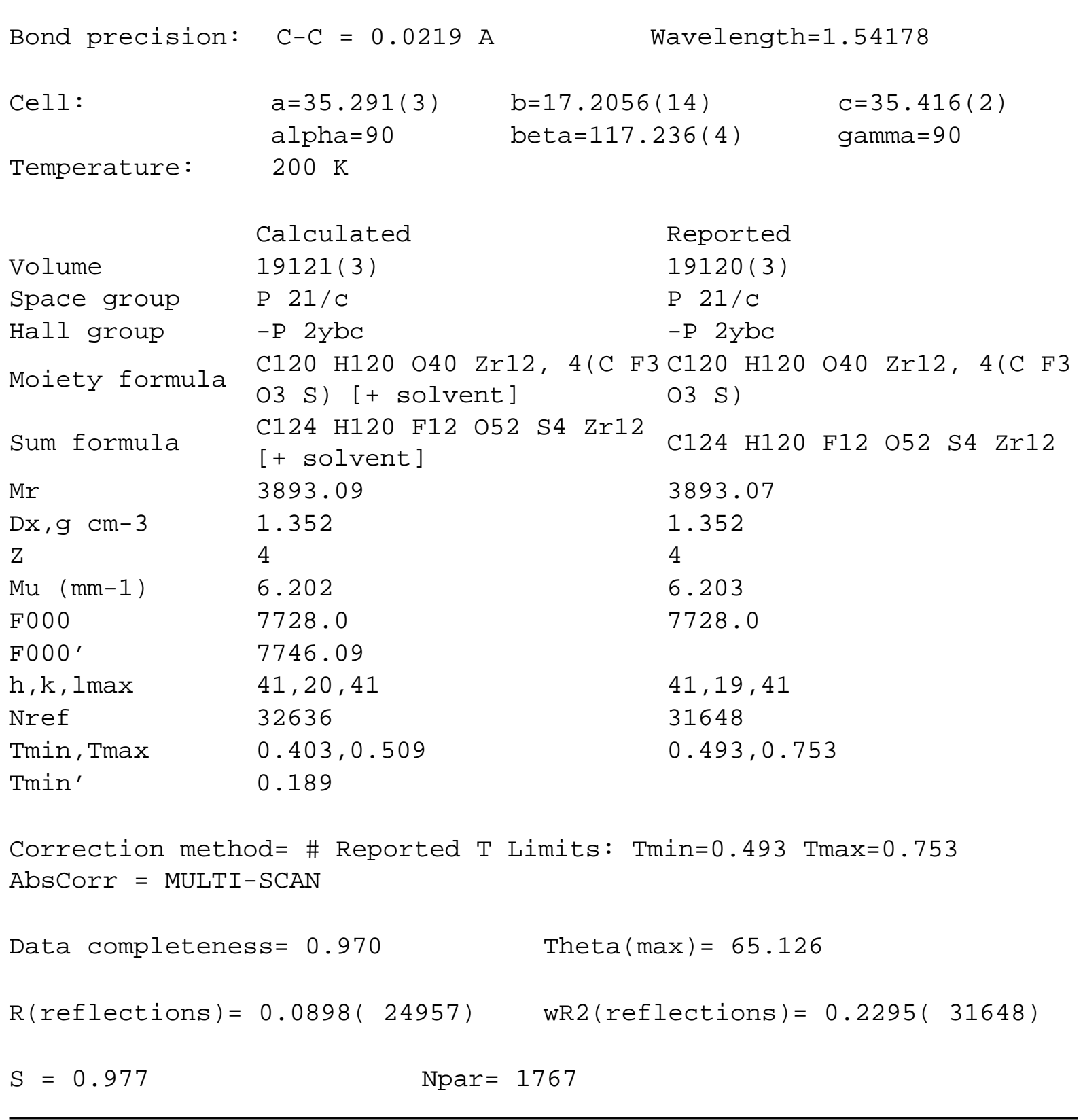




\section{checkCIF/PLATON report}

Structure factors have been supplied for datablock(s) eric171_sq

THIS REPORT IS FOR GUIDANCE ONLY. IF USED AS PART OF A REVIEW PROCEDURE FOR PUBLICATION, IT SHOULD NOT REPLACE THE EXPERTISE OF AN EXPERIENCED CRYSTALLOGRAPHIC REFEREE.

No syntax errors found. CIF dictionary Interpreting this report

\section{Datablock: 4T}

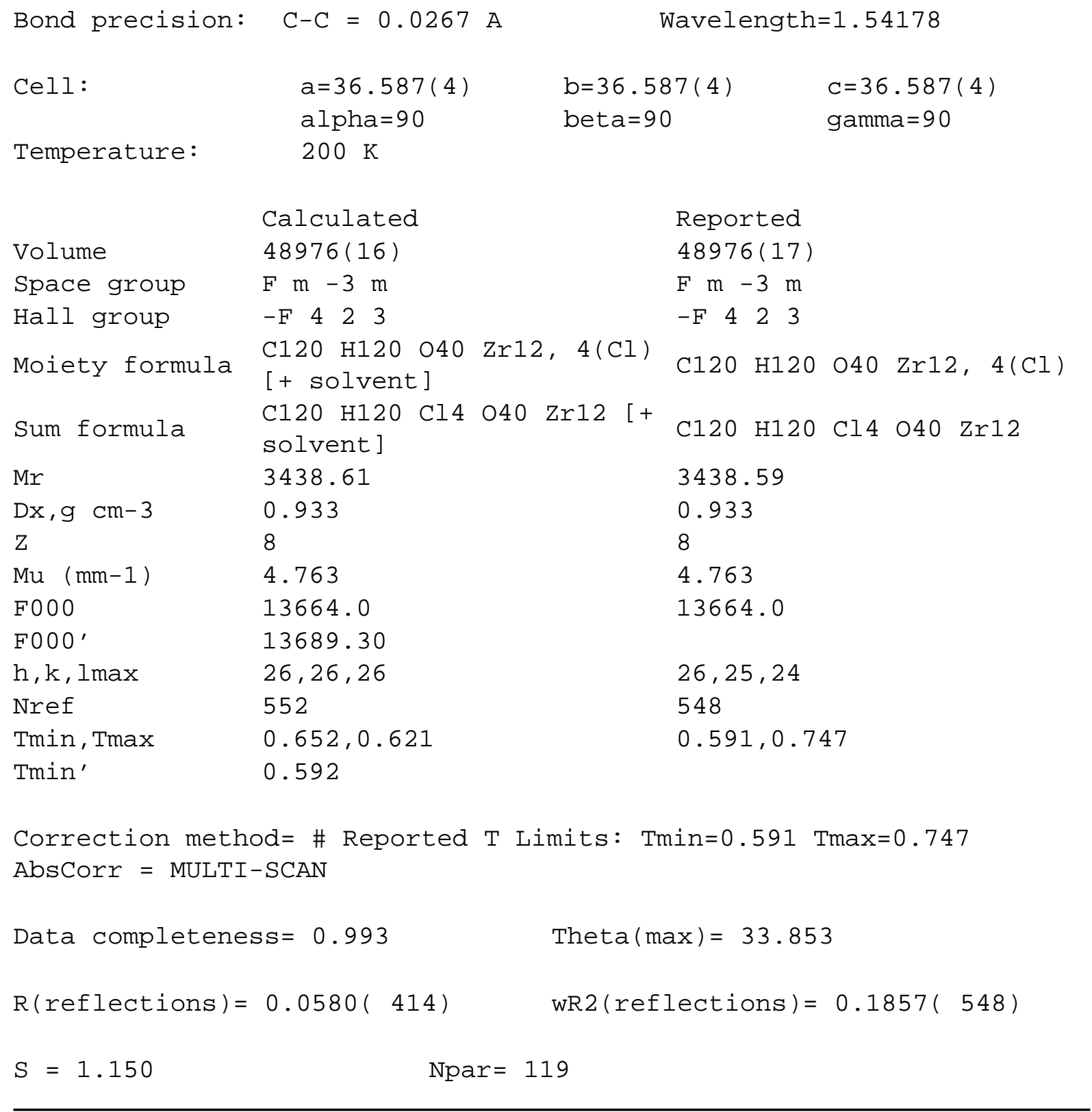




\section{checkCIF/PLATON report}

Structure factors have been supplied for datablock(s) eric328

THIS REPORT IS FOR GUIDANCE ONLY. IF USED AS PART OF A REVIEW PROCEDURE FOR PUBLICATION, IT SHOULD NOT REPLACE THE EXPERTISE OF AN EXPERIENCED CRYSTALLOGRAPHIC REFEREE.

No syntax errors found. CIF dictionary Interpreting this report

\section{Datablock: 5C}

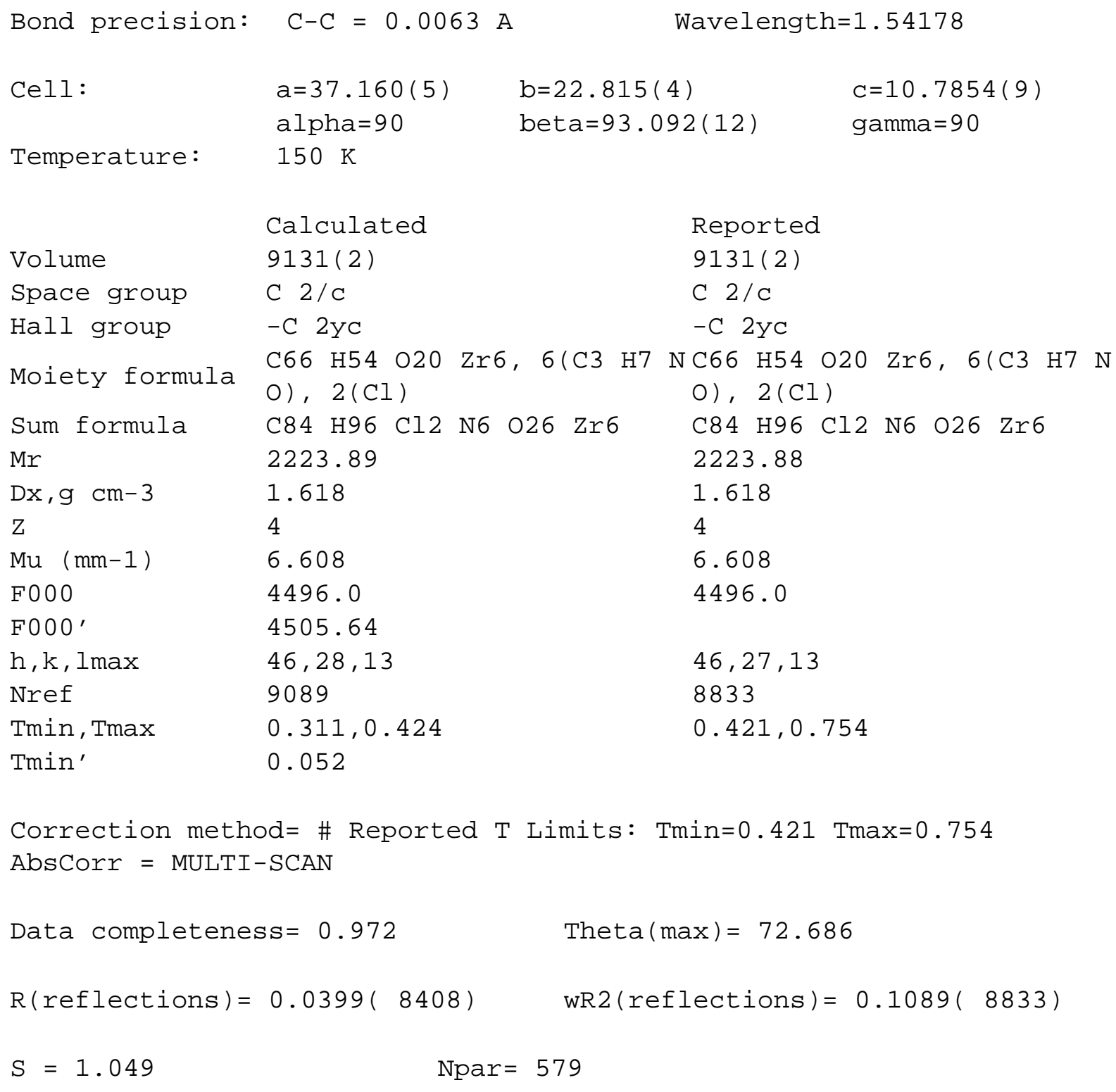




\section{checkCIF/PLATON report}

Structure factors have been supplied for datablock(s) eric310_sq

THIS REPORT IS FOR GUIDANCE ONLY. IF USED AS PART OF A REVIEW PROCEDURE FOR PUBLICATION, IT SHOULD NOT REPLACE THE EXPERTISE OF AN EXPERIENCED CRYSTALLOGRAPHIC REFEREE.

No syntax errors found. CIF dictionary Interpreting this report

\section{Datablock: 5 T}

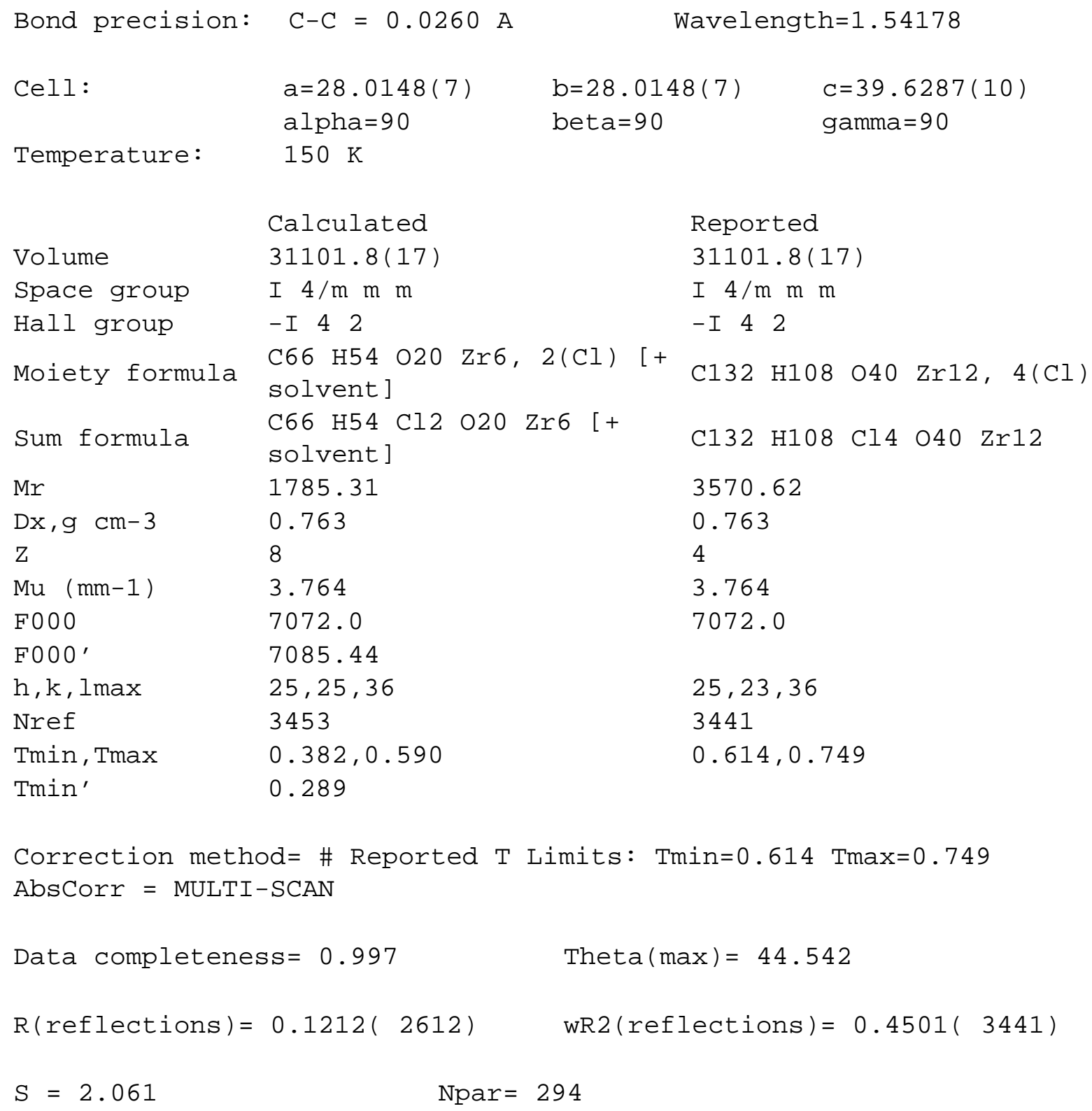




\section{checkCIF/PLATON report}

Structure factors have been supplied for datablock(s) eric312_sq

THIS REPORT IS FOR GUIDANCE ONLY. IF USED AS PART OF A REVIEW PROCEDURE FOR PUBLICATION, IT SHOULD NOT REPLACE THE EXPERTISE OF AN EXPERIENCED CRYSTALLOGRAPHIC REFEREE.

No syntax errors found. CIF dictionary Interpreting this report

\section{Datablock: 6C}

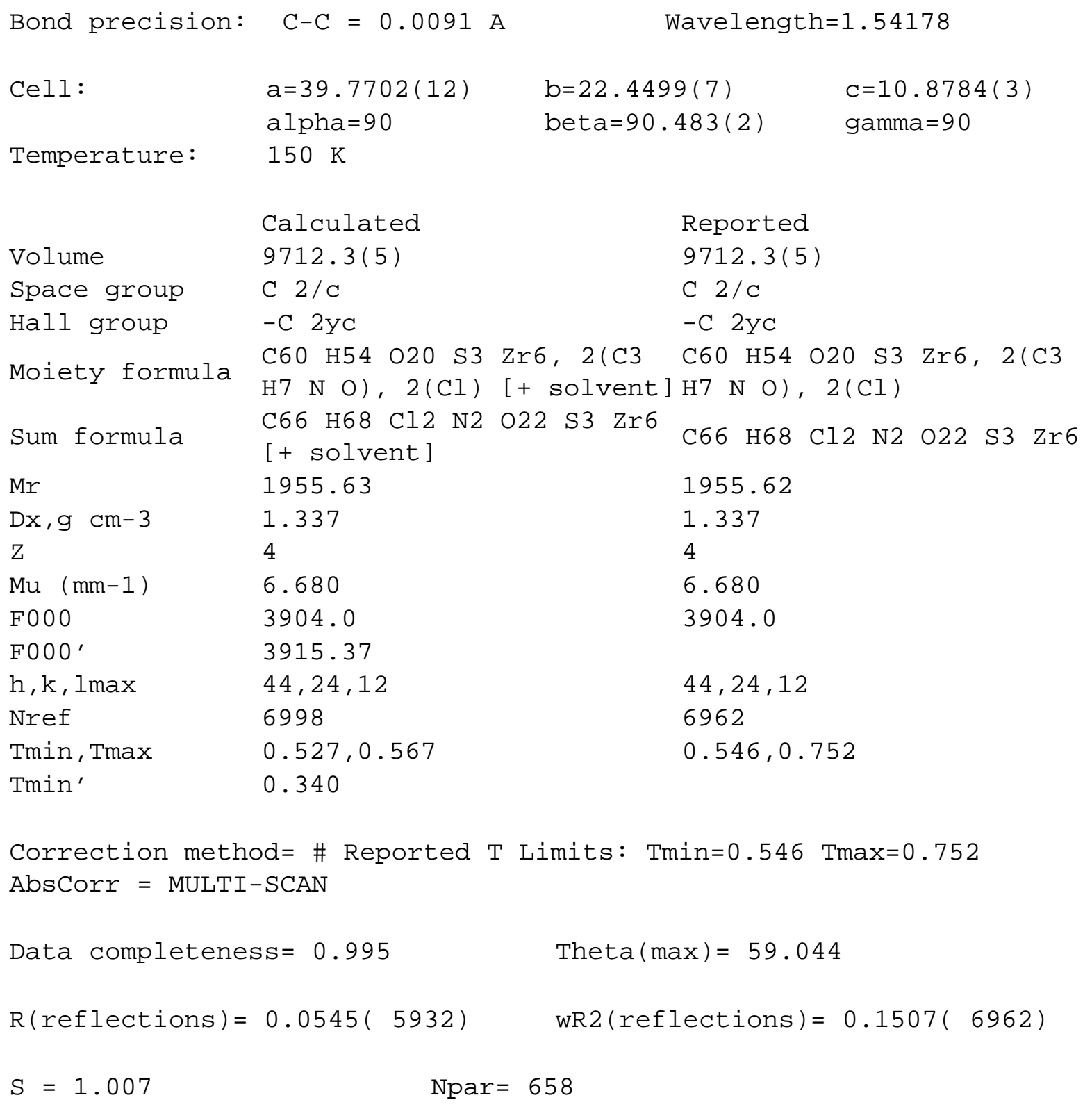




\section{checkCIF/PLATON report}

Structure factors have been supplied for datablock(s) eric316a_sq

THIS REPORT IS FOR GUIDANCE ONLY. IF USED AS PART OF A REVIEW PROCEDURE FOR PUBLICATION, IT SHOULD NOT REPLACE THE EXPERTISE OF AN EXPERIENCED CRYSTALLOGRAPHIC REFEREE.

No syntax errors found. CIF dictionary Interpreting this report

\section{Datablock: 7C}

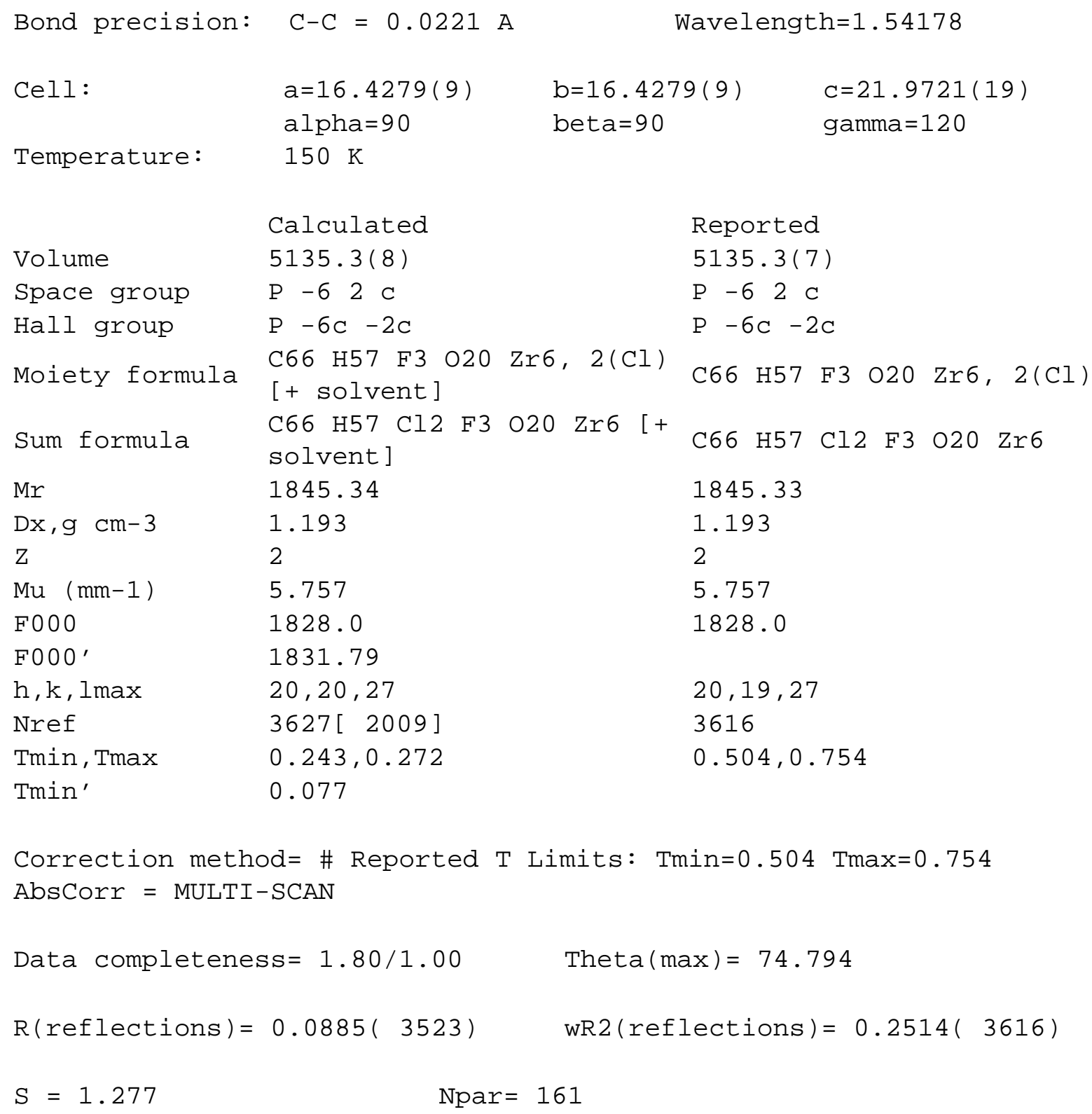




\section{checkCIF/PLATON report}

Structure factors have been supplied for datablock(s) eric303_sq

THIS REPORT IS FOR GUIDANCE ONLY. IF USED AS PART OF A REVIEW PROCEDURE FOR PUBLICATION, IT SHOULD NOT REPLACE THE EXPERTISE OF AN EXPERIENCED CRYSTALLOGRAPHIC REFEREE.

No syntax errors found. CIF dictionary Interpreting this report

\section{Datablock: 9C}

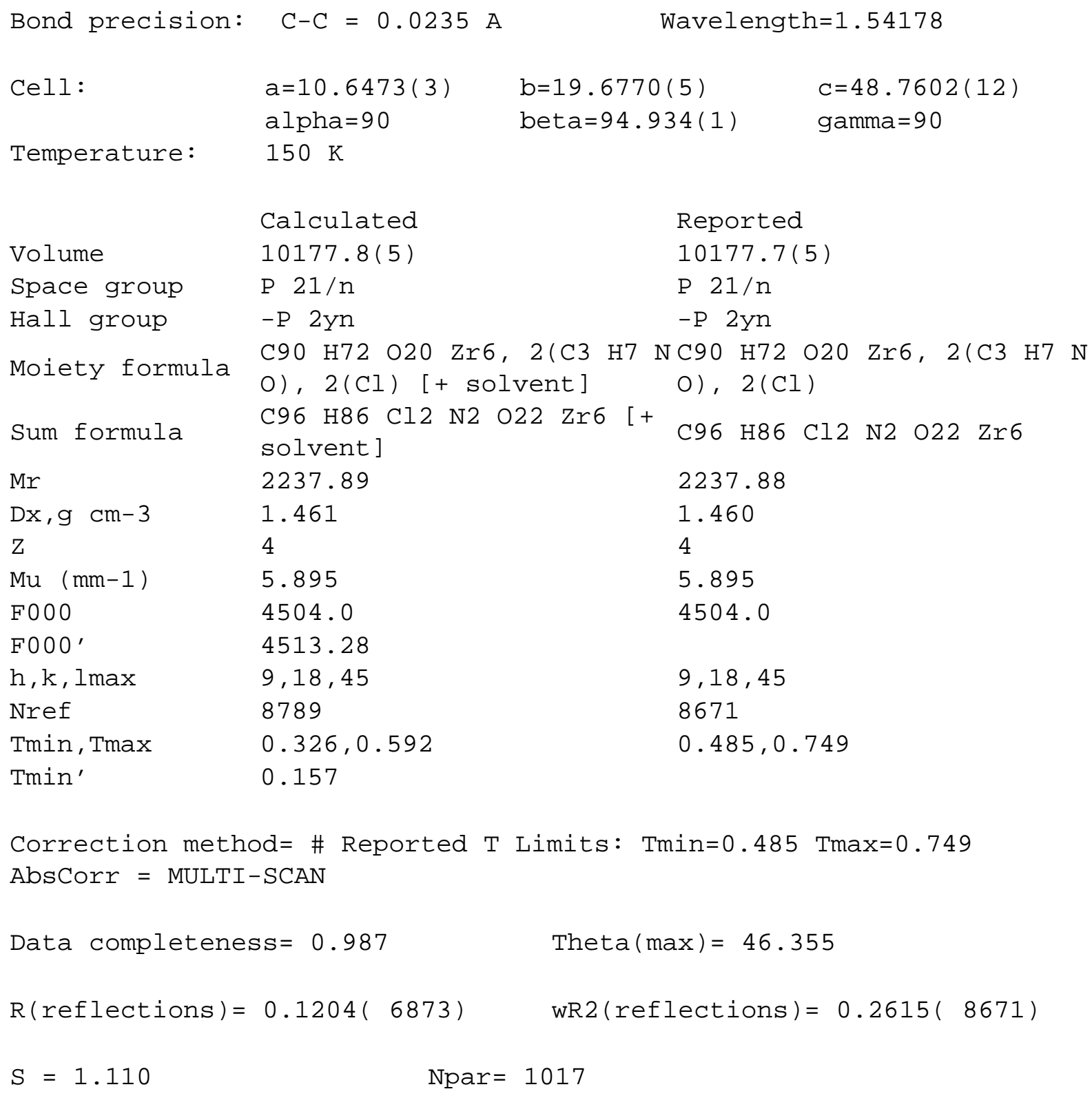




\section{checkCIF/PLATON report}

Structure factors have been supplied for datablock(s) eric300_sq

THIS REPORT IS FOR GUIDANCE ONLY. IF USED AS PART OF A REVIEW PROCEDURE FOR PUBLICATION, IT SHOULD NOT REPLACE THE EXPERTISE OF AN EXPERIENCED CRYSTALLOGRAPHIC REFEREE.

No syntax errors found. CIF dictionary Interpreting this report

\section{Datablock: 10C OTf}

\begin{tabular}{|c|c|c|}
\hline Bond precision: & $C-C=0.0116 \mathrm{~A}$ & Wavelength $=1.54178$ \\
\hline Cell: & $\begin{array}{l}a=18.8649(6) \\
a l p h a=90\end{array}$ & $\begin{array}{l}\mathrm{b}=28.8850(8) \\
\mathrm{bet} \mathrm{a}=105.667(2)\end{array}$ \\
\hline \multirow[t]{2}{*}{ Temperature: } & $150 \mathrm{~K}$ & \\
\hline & Calculated & Reported \\
\hline Volume & $12562.7(7)$ & $12562.6(7)$ \\
\hline Space group & P 21/C & P $21 / C$ \\
\hline Hall group & $-\mathrm{P} 2 \mathrm{ybc}$ & $-\mathrm{P} 2 \mathrm{ybc}$ \\
\hline Moiety formula & $\begin{array}{l}\text { C96 H84 O20 Zr6, } \\
\text { S), } 2(\text { ( } \mathrm{H} 4 \text { O) }\end{array}$ & 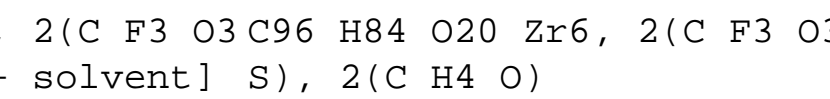 \\
\hline Sum formula & $\begin{array}{l}\text { C100 H92 F6 O28 } \\
\text { solvent] }\end{array}$ & S2 Zr6 ${ }^{+}$C100 H92 F6 O28 S2 Zr6 \\
\hline $\mathrm{Mr}$ & 2467.18 & 2467.17 \\
\hline $\mathrm{Dx}, \mathrm{gcm}-3$ & 1.304 & 1.304 \\
\hline Z & 4 & 4 \\
\hline $\mathrm{Mu} \quad(\mathrm{mm}-1)$ & 4.849 & 4.849 \\
\hline F000 & 4968.0 & 4968.0 \\
\hline F000' & 4979.96 & \\
\hline $\mathrm{h}, \mathrm{k}, \mathrm{lmax}$ & $21,32,26$ & $20,32,26$ \\
\hline Nref & 18164 & 17736 \\
\hline $\operatorname{Tmin}, \operatorname{Tmax}$ & $0.444,0.562$ & $0.551,0.752$ \\
\hline Tmin' & 0.325 & \\
\hline \multicolumn{3}{|c|}{$\begin{array}{l}\text { Correction method= \# } \\
\text { AbsCorr = MULTI-SCAN }\end{array}$} \\
\hline \multicolumn{2}{|c|}{ Data completeness $=0.976$} & Theta $(\max )=59.160$ \\
\hline$R($ reflections $)=$ & $0.0577(13986)$ & $\mathrm{wR} 2($ reflections $)=0.1768(17736)$ \\
\hline$S=1.052$ & Npar $=$ & 1285 \\
\hline
\end{tabular}




\section{checkCIF/PLATON report}

Structure factors have been supplied for datablock(s) eric338_sq

THIS REPORT IS FOR GUIDANCE ONLY. IF USED AS PART OF A REVIEW PROCEDURE FOR PUBLICATION, IT SHOULD NOT REPLACE THE EXPERTISE OF AN EXPERIENCED CRYSTALLOGRAPHIC REFEREE.

No syntax errors found. CIF dictionary Interpreting this report

\section{Datablock: 10C}

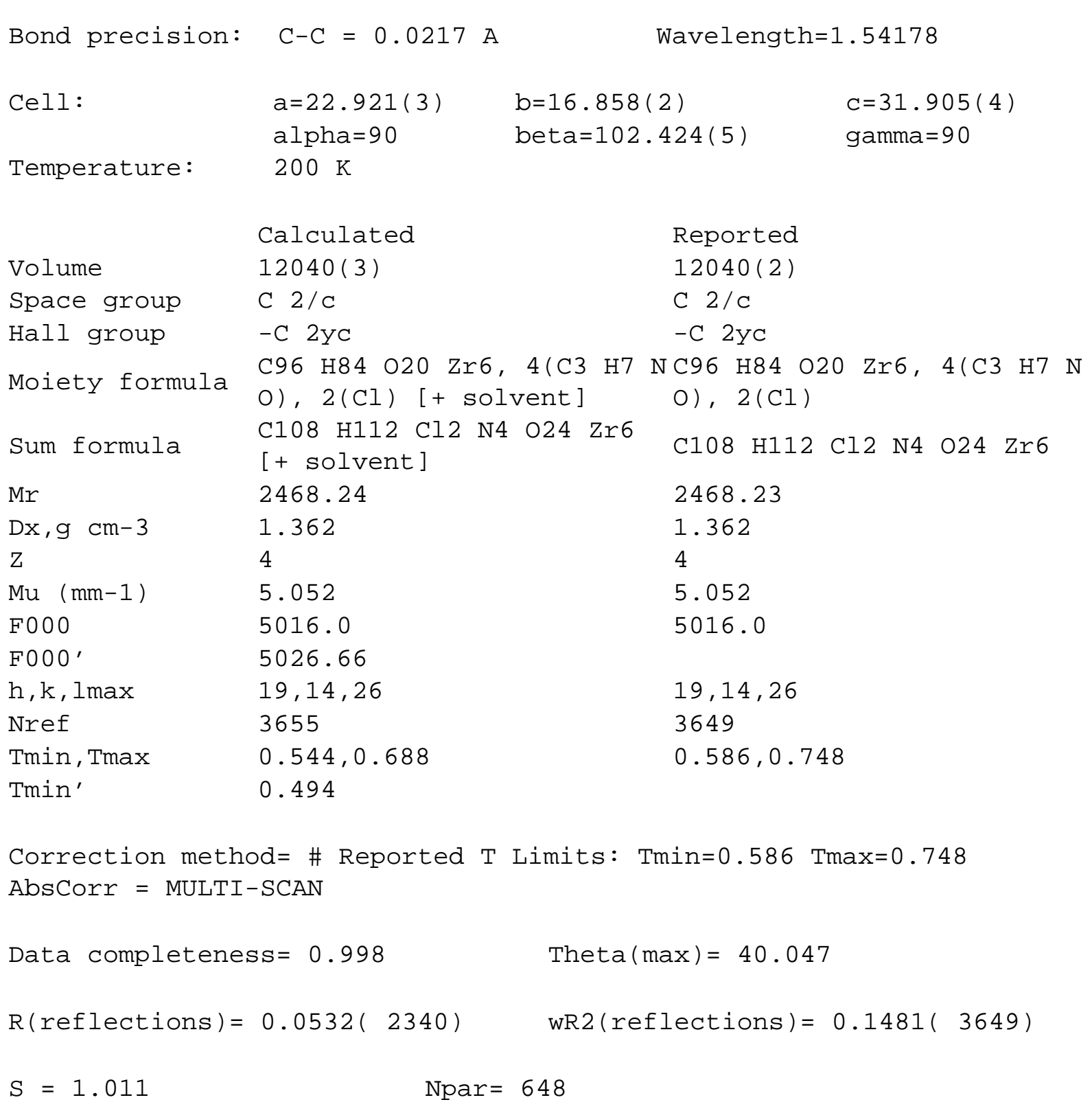




\section{checkCIF/PLATON report}

Structure factors have been supplied for datablock(s) eric285_sq

THIS REPORT IS FOR GUIDANCE ONLY. IF USED AS PART OF A REVIEW PROCEDURE FOR PUBLICATION, IT SHOULD NOT REPLACE THE EXPERTISE OF AN EXPERIENCED CRYSTALLOGRAPHIC REFEREE.

No syntax errors found. CIF dictionary Interpreting this report

\section{Datablock: 10T}

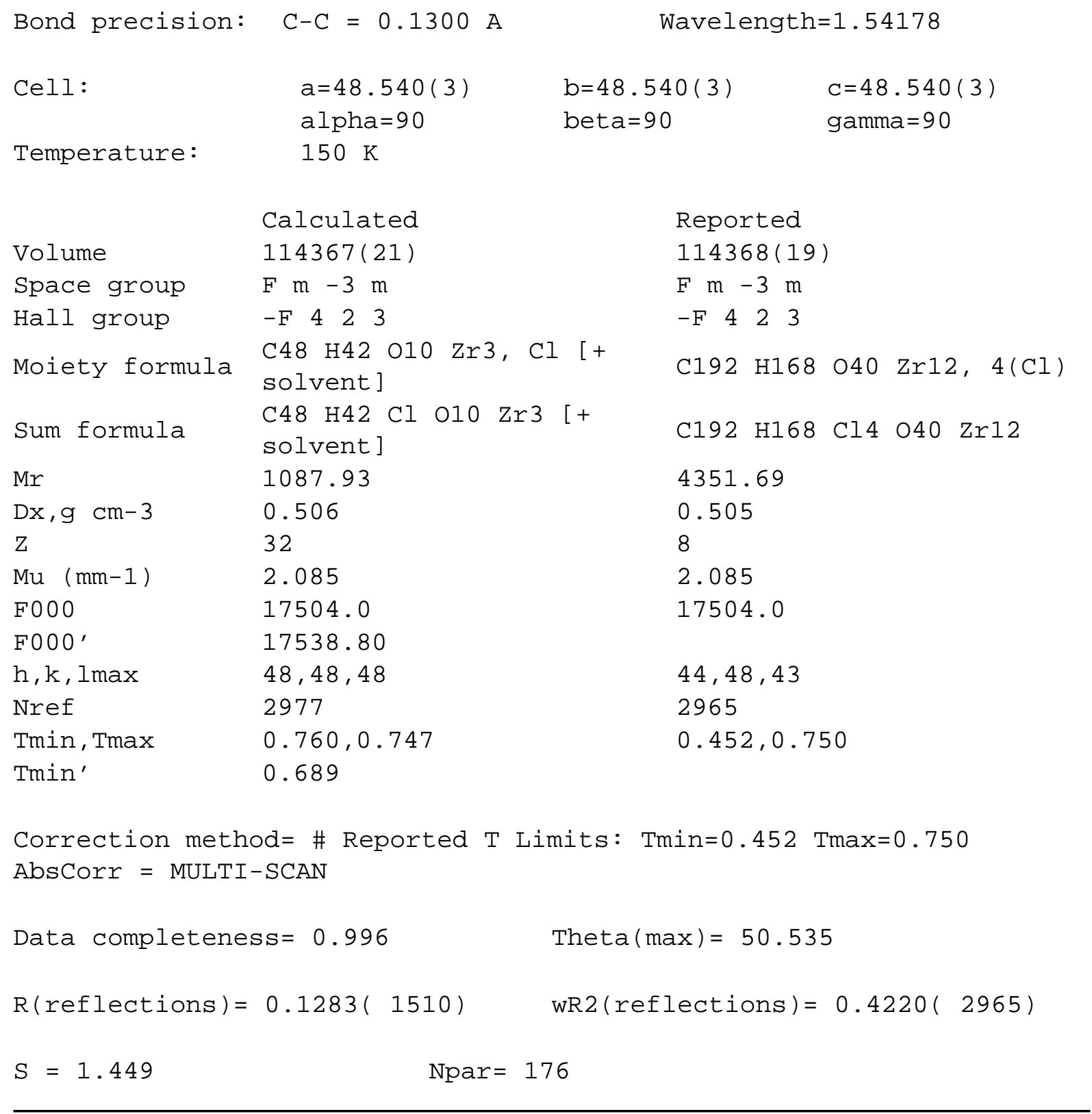




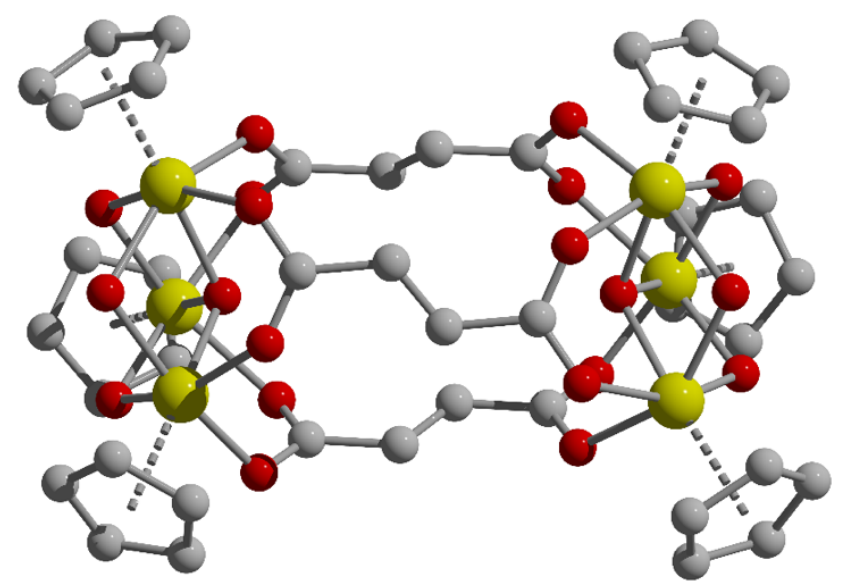

Figure S155. Crystal structure of $\left[\mathrm{Zr}_{6}\left(\mu_{3}-\mathrm{O}\right)_{2}\left(\mu_{2}-\mathrm{OH}\right)_{6}(\mathrm{Cp})_{6}(\mathrm{fum})_{3}\right] \mathrm{Cl}_{2}(1 \mathrm{C})$. Yellow, gray, and red spheres represent zirconium, carbon, and oxygen, respectively. Anions and hydrogen atoms have been omitted for clarity.

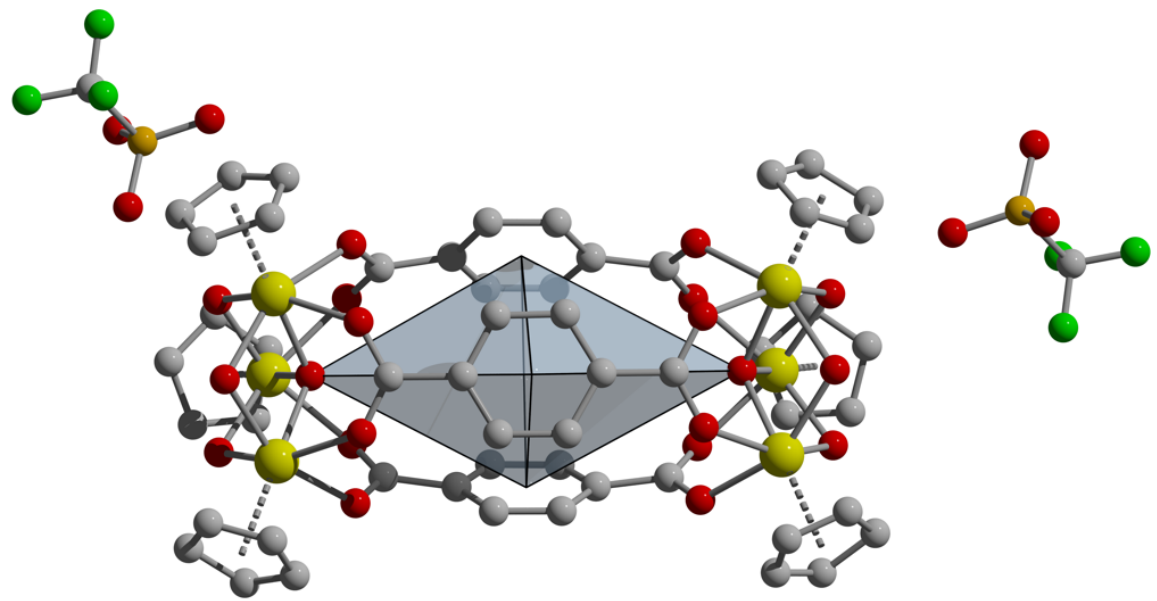

Figure S156. Crystal structure of $\left[\mathrm{Zr}_{6}\left(\mu_{3}-\mathrm{O}\right)_{2}\left(\mu_{2}-\mathrm{OH}\right)_{6}(\mathrm{Cp})_{6}(\mathrm{bdc})_{3}\right] \mathrm{OTf}_{2}$ (2C_OTf). Yellow, gray, green, orange, and red spheres represent zirconium, carbon, fluorine, sulfur, and oxygen, respectively. Hydrogen atoms have been omitted for clarity. 


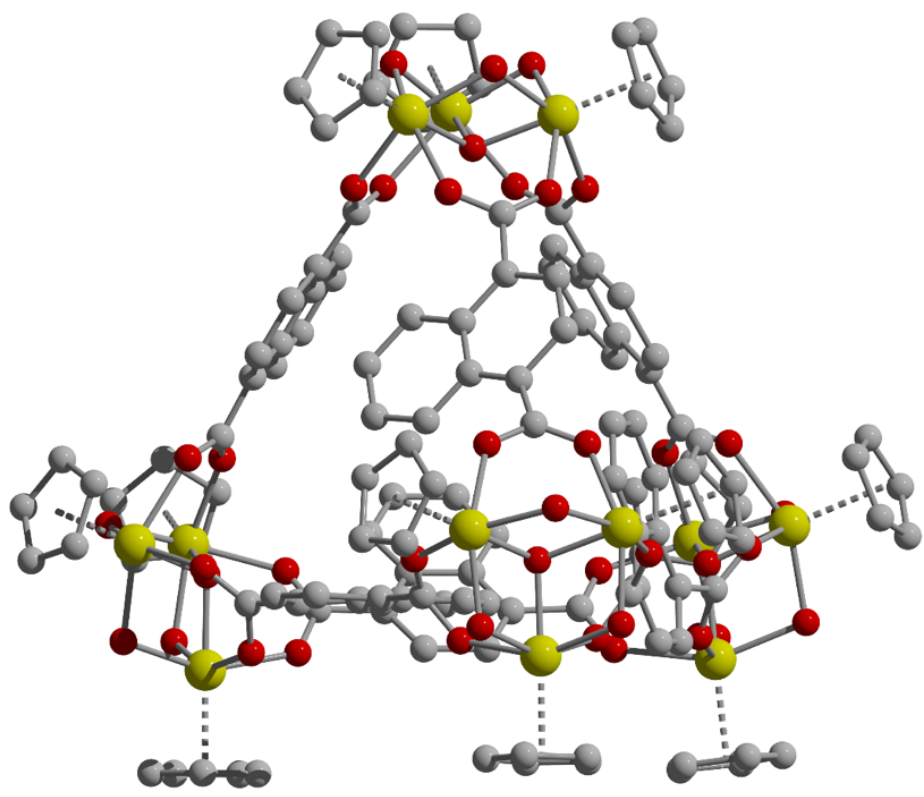

Figure S157. Crystal structure of $\left[\mathrm{Zr}_{12}\left(\mu_{3}-\mathrm{O}\right)_{4}\left(\mu_{2}-\mathrm{OH}\right)_{12}(\mathrm{Cp})_{12}(1,4-\mathrm{ndc})_{6}\right] \mathrm{Cl}_{4}(3 \mathrm{~T})$. Yellow, gray, and red spheres represent zirconium, carbon, and oxygen, respectively. Anions and hydrogen atoms have been omitted for clarity.

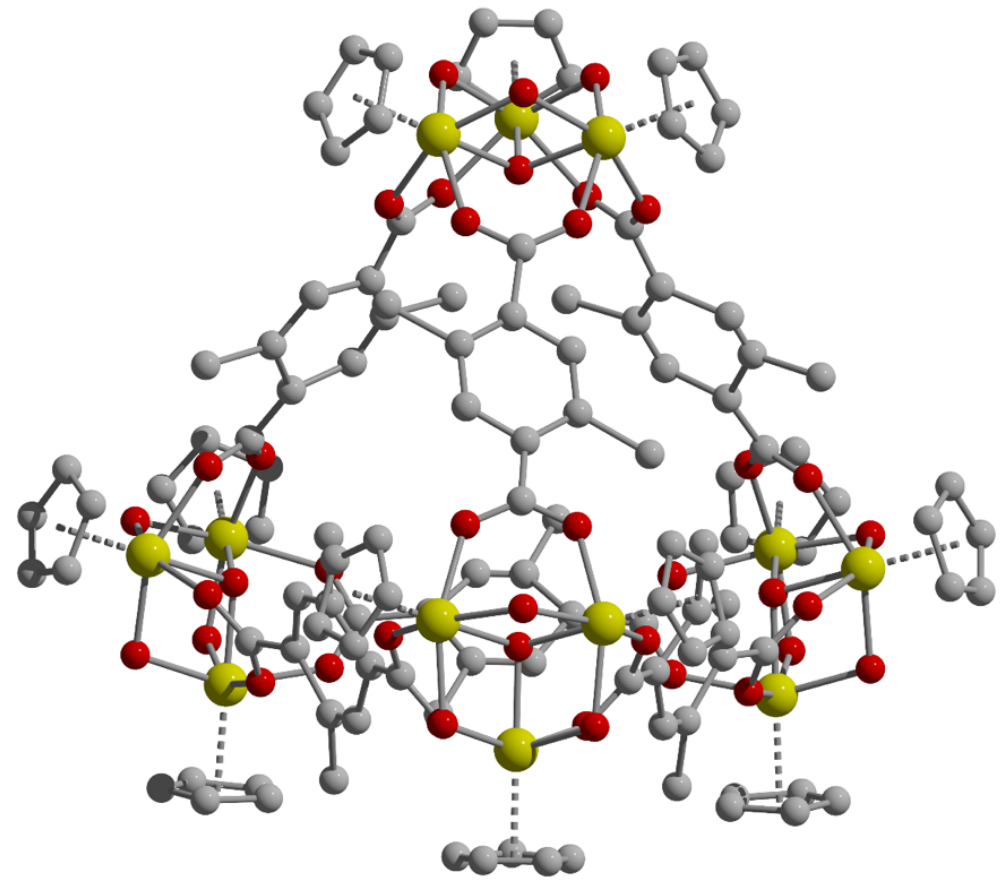

Figure S158. Crystal structure of $\left[\mathrm{Zr}_{12}\left(\mu_{3}-\mathrm{O}\right)_{4}\left(\mu_{2}-\mathrm{OH}\right)_{12}(\mathrm{Cp})_{12}\left(\mathrm{Me}_{2}-\mathrm{bdc}\right)_{6}\right] \mathrm{Cl}_{4}(\mathbf{4 T}$ _Cl). Yellow, gray, and red spheres represent zirconium, carbon, and oxygen, respectively. Anions and hydrogen atoms have been omitted for clarity. 


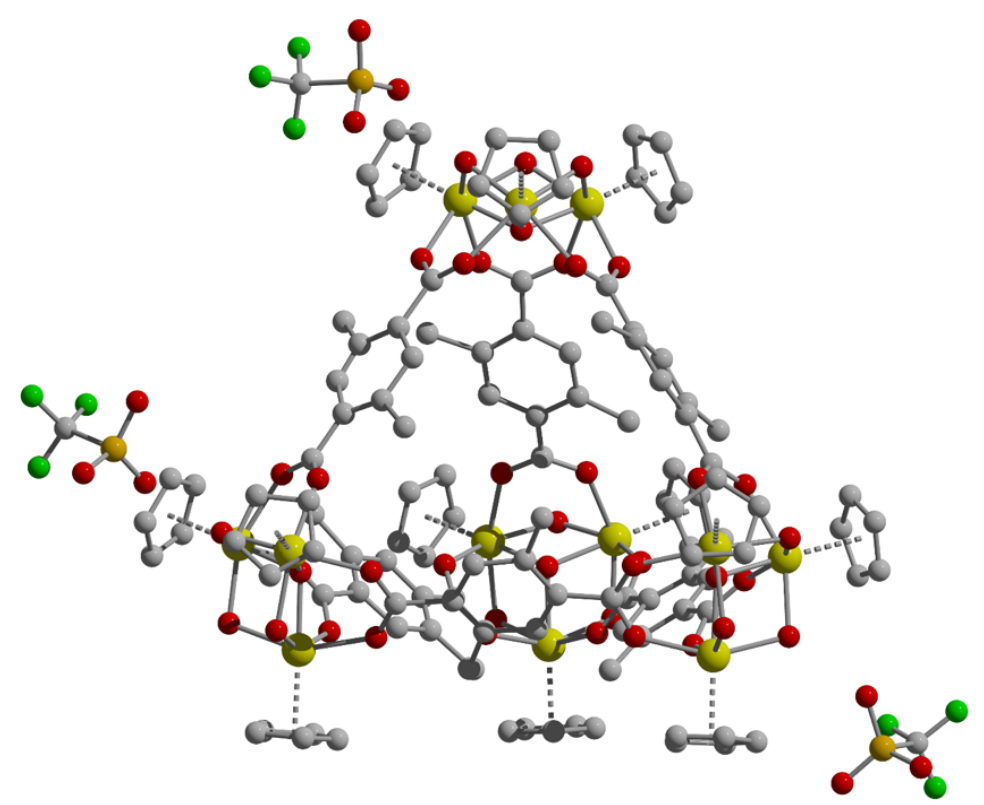

Figure S159. Crystal structure of $\left[\mathrm{Zr}_{12}\left(\mu_{3}-\mathrm{O}\right)_{4}\left(\mu_{2}-\mathrm{OH}\right)_{12}(\mathrm{Cp})_{12}\left(\mathrm{Me}_{2} \text {-bdc }\right)_{6}\right] \mathrm{OTf} f_{4}$ (4T_OTf). Yellow, gray, green, orange, and red spheres represent zirconium, carbon, fluorine, sulfur, and oxygen, respectively. Hydrogen atoms have been omitted for clarity.

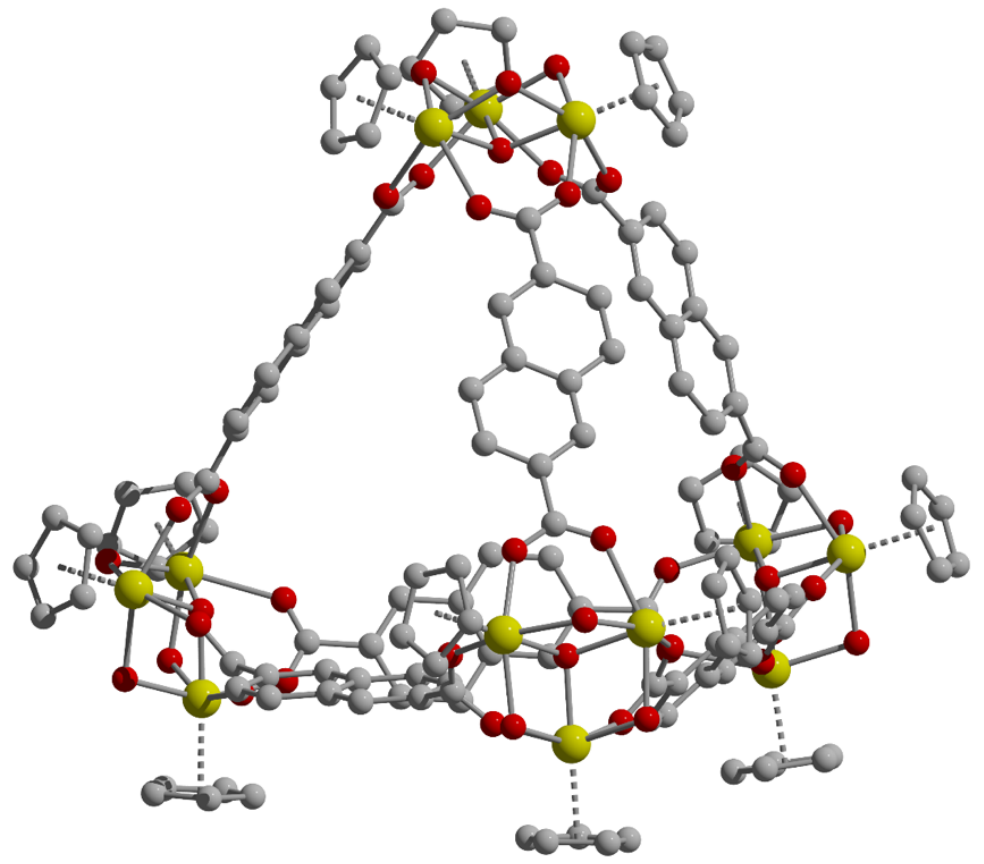

Figure S160. Crystal structure of $\left[\mathrm{Zr}_{12}\left(\mu_{3}-\mathrm{O}\right)_{4}\left(\mu_{2}-\mathrm{OH}\right)_{12}(\mathrm{Cp})_{12}(2,6-n d c)_{6}\right] \mathrm{Cl}_{4}(\mathbf{5 T})$. Yellow, gray, and red spheres represent zirconium, carbon, and oxygen, respectively. Anions and hydrogen atoms have been omitted for clarity. 


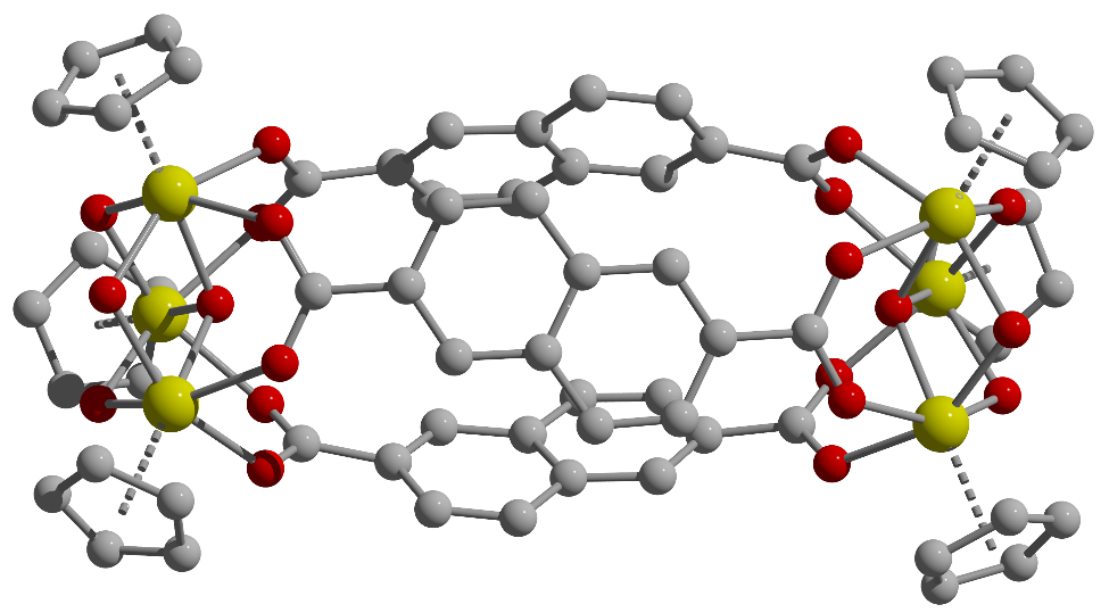

Figure S161. Crystal structure of $\left[\mathrm{Zr}_{6}\left(\mu_{3}-\mathrm{O}\right)_{2}\left(\mu_{2}-\mathrm{OH}\right)_{6}(\mathrm{Cp})_{6}(2,6-\mathrm{ndc})_{3}\right] \mathrm{Cl}_{2}(\mathbf{5 C})$. Yellow, gray, and red spheres represent zirconium, carbon, and oxygen, respectively. Anions and hydrogen atoms have been omitted for clarity.

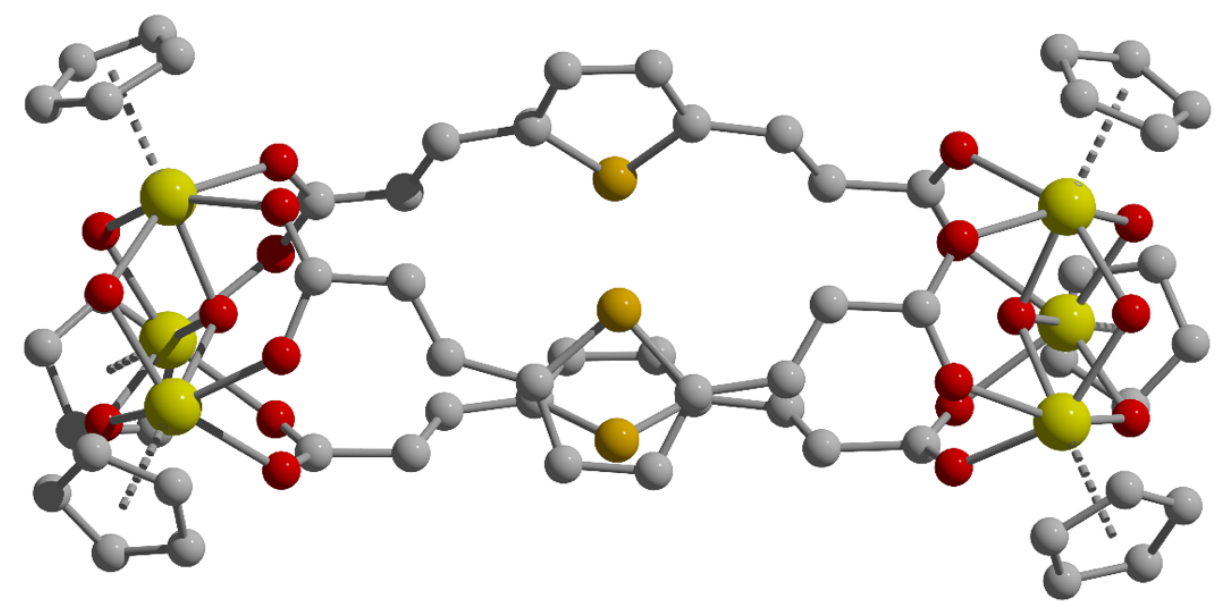

Figure S162. Crystal structure of $\left[\mathrm{Zr}_{6}\left(\mu_{3}-\mathrm{O}\right)_{2}\left(\mu_{2}-\mathrm{OH}\right)_{6}(\mathrm{Cp})_{6}(\mathrm{tda})_{3}\right] \mathrm{Cl}_{2}(\mathbf{6 C})$. Yellow, gray, orange, and red spheres represent zirconium, carbon, sulfur, and oxygen, respectively. Anions and hydrogen atoms have been omitted for clarity. 


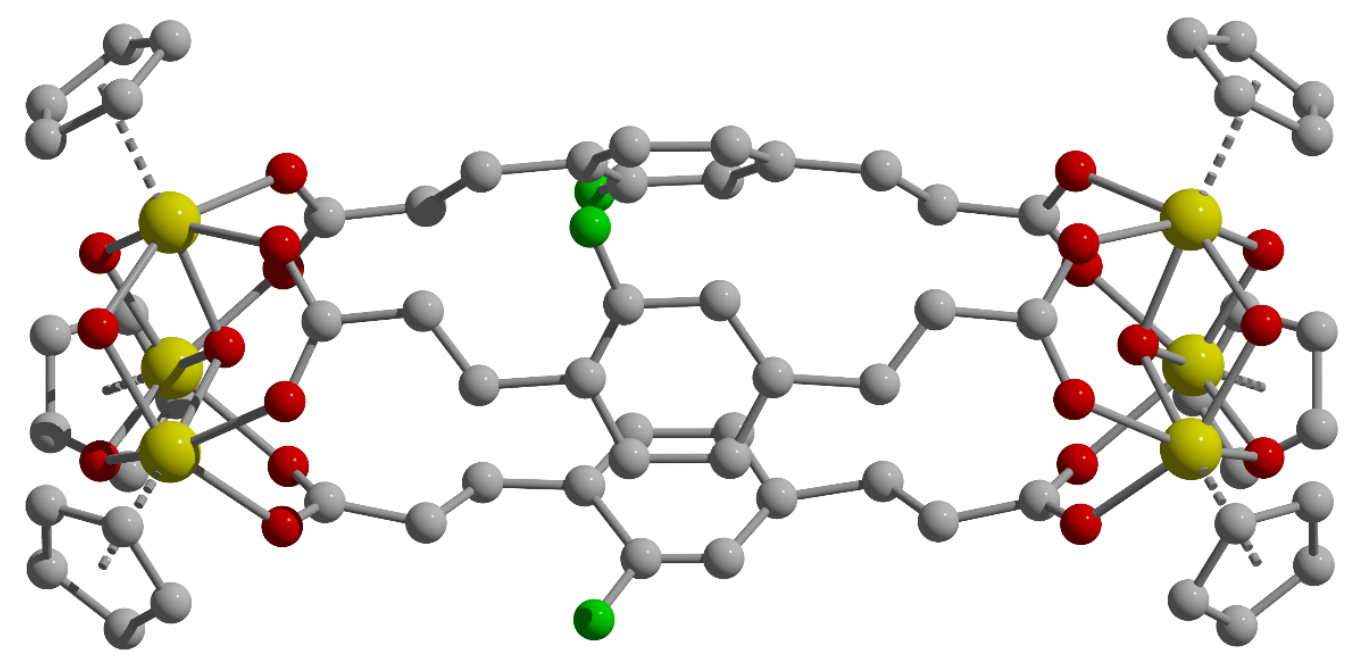

Figure S163. Crystal structure of $\left[\mathrm{Zr}_{6}\left(\mu_{3}-\mathrm{O}\right)_{2}\left(\mu_{2}-\mathrm{OH}\right)_{6}(\mathrm{Cp})_{6}(\mathrm{~F}-\mathrm{pda})_{3}\right] \mathrm{Cl}_{2}(7 \mathrm{C})$. Yellow, gray, green, and red spheres represent zirconium, carbon, fluorine, and oxygen, respectively. Anions and hydrogen atoms have been omitted for clarity.

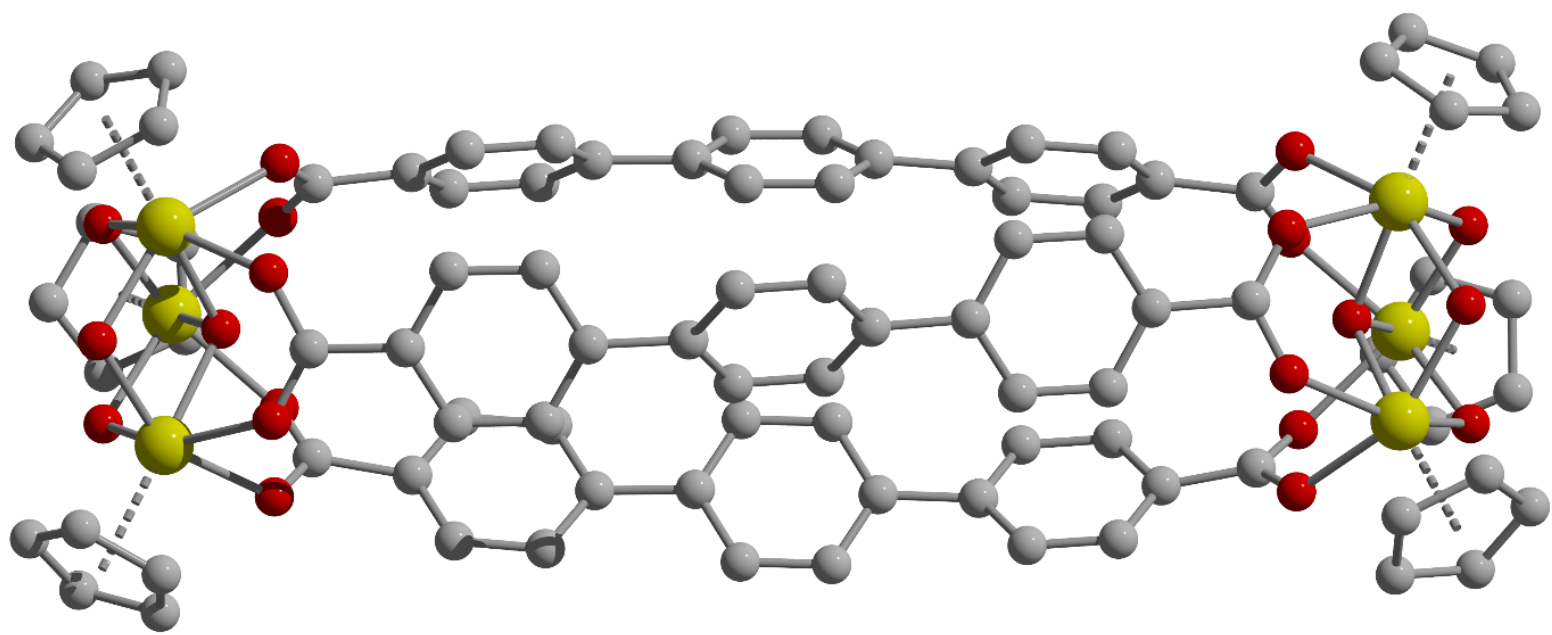

Figure S164. Crystal structure of $\left[\mathrm{Zr}_{6}\left(\mu_{3}-\mathrm{O}\right)_{2}\left(\mu_{2}-\mathrm{OH}\right)_{6}(\mathrm{Cp})_{6}(\mathrm{tpdc})_{3}\right] \mathrm{Cl}_{2}(9 \mathrm{C})$. Yellow, gray, and red spheres represent zirconium, carbon, and oxygen, respectively. Anions and hydrogen atoms have been omitted for clarity. 


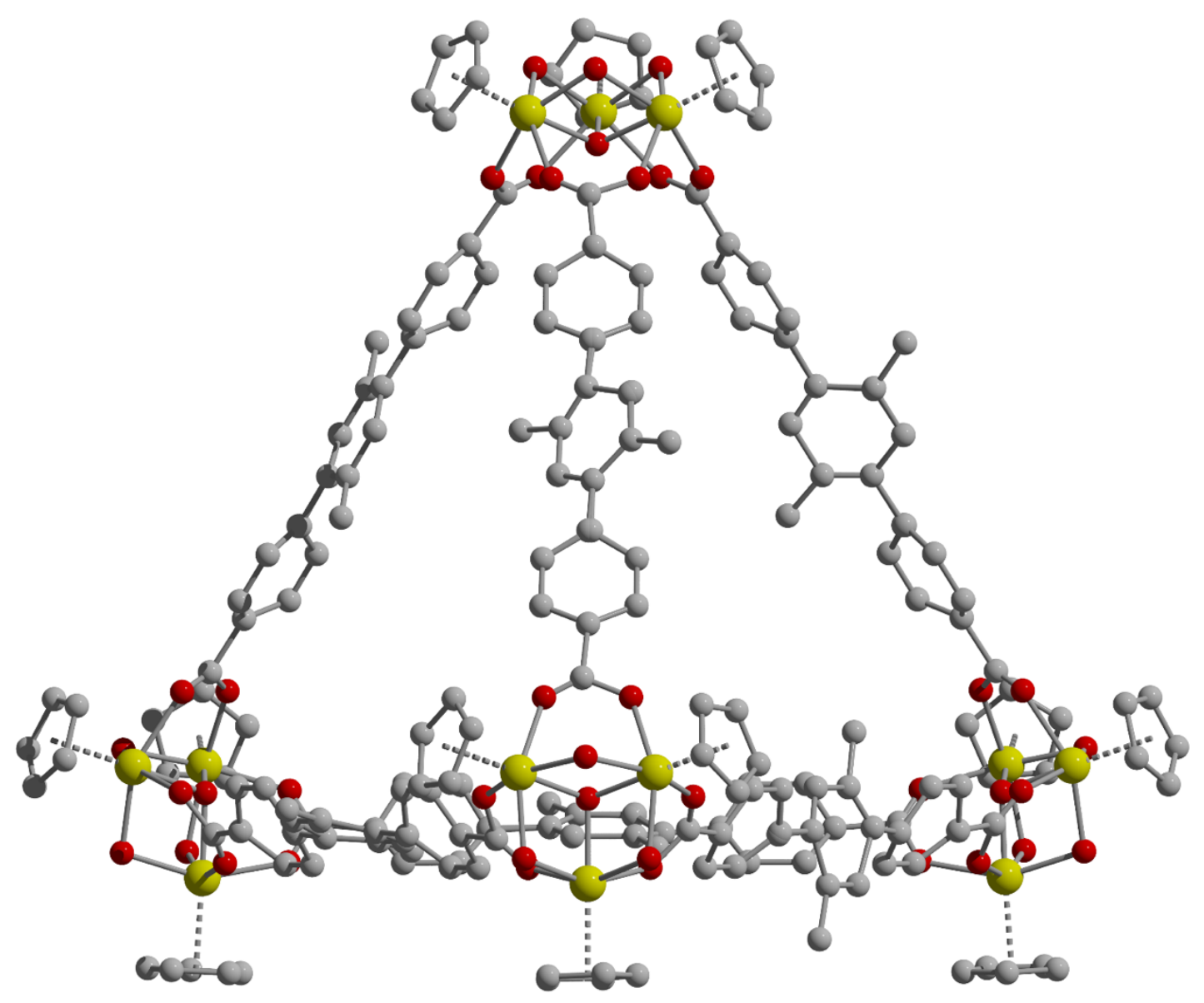

Figure S165. Crystal structure of $\left[\mathrm{Zr}_{12}\left(\mu_{3}-\mathrm{O}\right)_{4}\left(\mu_{2}-\mathrm{OH}\right)_{12}(\mathrm{Cp})_{12}\left(\mathrm{Me}_{2}-\mathrm{tpdc}\right)_{6}\right] \mathrm{Cl}_{4}$ (10T_Cl). Yellow, gray, and red spheres represent zirconium, carbon, and oxygen, respectively. Anions and hydrogen atoms have been omitted for clarity.

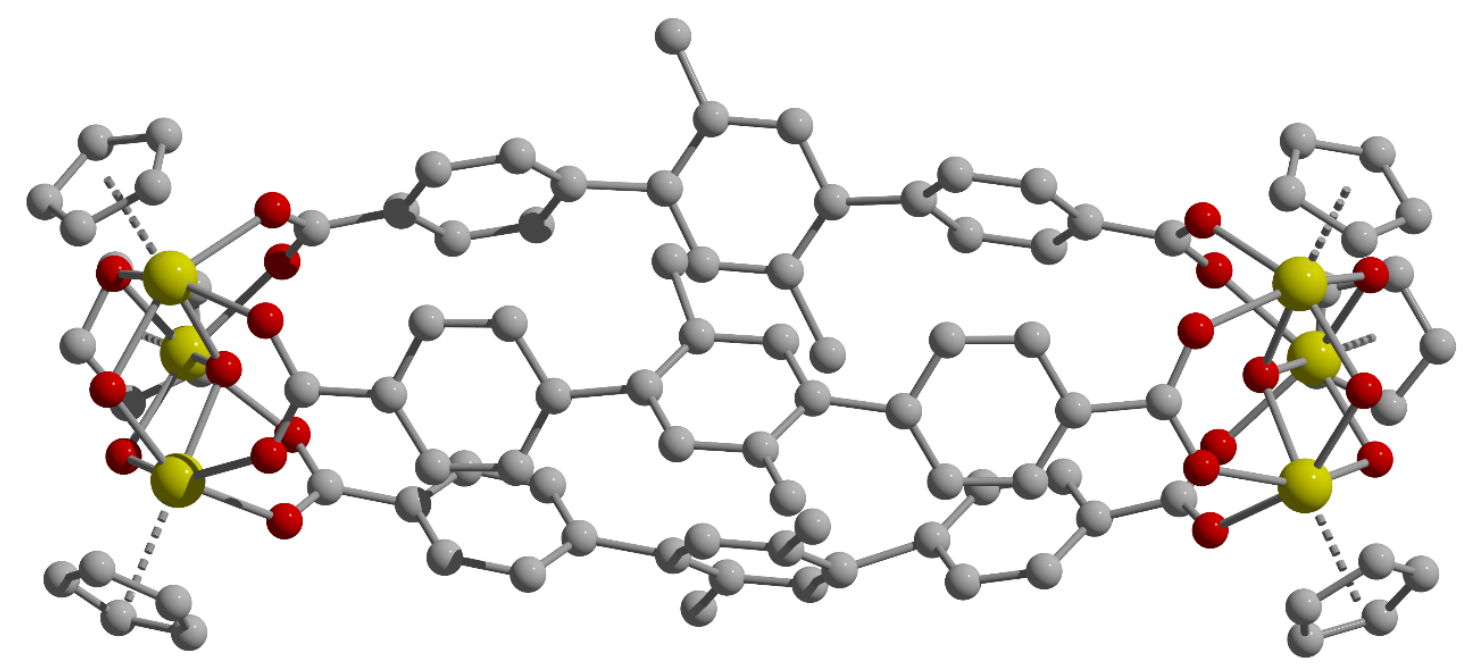

Figure S166. Crystal structure of $\left[\mathrm{Zr}_{6}\left(\mu_{3}-\mathrm{O}\right)_{2}\left(\mu_{2}-\mathrm{OH}\right)_{6}(\mathrm{Cp})_{6}\left(\mathrm{Me}_{2}-\mathrm{tpdc}\right)_{3}\right] \mathrm{Cl}_{2}\left(1_{0} \mathrm{C} \_\mathrm{Cl}\right)$. Yellow, gray, and red spheres represent zirconium, carbon, and oxygen, respectively. Anions and hydrogen atoms have been omitted for clarity. 


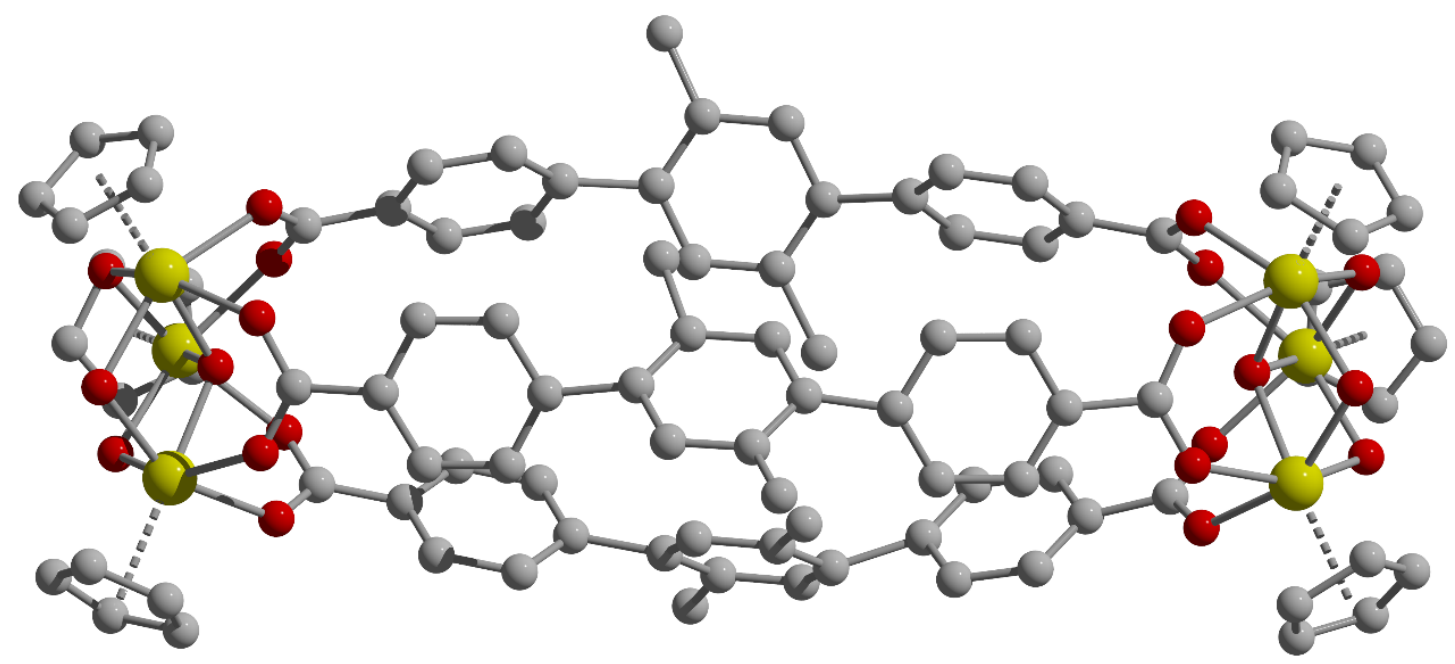

Figure S167. Crystal structure of $\left[\mathrm{Zr}_{6}\left(\mu_{3}-\mathrm{O}\right)_{2}\left(\mu_{2}-\mathrm{OH}\right)_{6}(\mathrm{Cp})_{6}\left(\mathrm{Me}_{2}-\mathrm{tpdc}\right)_{3}\right] \mathrm{OTf}_{2}$ (10C_OTf). Yellow, gray, and red spheres represent zirconium, carbon, and oxygen, respectively. Anions and hydrogen atoms have been omitted for clarity.

\section{References}

1) Loos, M.; Gerber, C.; Corona, F.; Hollender, J.; Singer, H. Accelerated Isotope Fine Structure Calculation Using Pruned Transition Trees. Anal. Chem. 2015, 87, 5738-5744.

2) Huang, X.; Yang, L.; Bergquist, J.; Strømme, M.; Gogoll, A.; Sjödin, M. Synthesis and Redox Properties of Thiophene Terephthalate Building Blocks for Low-Potential Conducting Redox Polymers. J. Phys. Chem. C. 2015, 119, 27247-27254.

3) Liu, J.; Lukose, B.; Shekhah, O.; Arslan, H. K.; Weidler, P.; Gliemann, H.; Bräse, S.; Grosjean, S.; Godt, A.; Feng, X.; Müllen, K.; Magdau, I.-B.; Heine, T.; Wöll, C. A Novel Series of Isoreticular Metal Organic Frameworks: Realizing Metastable Structures by Liquid Phase Epitaxy. Sci. Rep. 2012, 2, 921-926

4) Deng, H.; Grunder, S.; Cordova, K. E.; Valente, C.; Furukawa, H.; Hmadeh, M.; Gándara, F.; Whalley, A. C.; Liu, Z.; Asahina, S.; Kazumori, H.; O’Keeffe, M.; Terasaki, O.; Stoddart, J. F.; Yaghi, O. M. LargePore Apertures in a Series of Metal-Organic Frameworks. Science 2012, 336, 1018-1023.

5) Liu, S.; Jin, Z.; Teo, Y. C.; Xia, Y. Efficient Synthesis of Rigid Ladder Polymers via Palladium Catalyzed Annulation. J. Am. Chem. Soc. 2014, 136, 17434.

6) Apex3; Bruker AXS Inc.: Madison, WI, 2015.

7) Sheldrick, G. M. SHELXT - Integrated Space-Group and Crystal-Structure Determination. Acta. Cryst. 2015, A71, 3-8.

8) Sheldrick, G. M. Crystal Structure Refinement with SHELXL. Acta. Cryst. 2015, C71, 3-8.

9) Park, J.; Perry, Z.; Chen, Y.-P.; Bae, J.; Zhou, H.-C. Chromium(II) Metal-Organic Polyhedra as Highly Porous Materials. ACS Appl. Mater. Interfaces, 2017, 9, 28064-28068.

10) Spek, A. L. PLATON SQUEEZE: A Tool for the Calculation of the Disordered Solvent Contribution to the Calculated Structure Factors. Acta. Cryst. 2015, C71, 9-18. 